NISTIR 6659

\title{
Thermodynamic, Transport, and Chemical Properties of "Reference" JP-8
}

Thomas J. Bruno

Marcia Huber

Arno Laesecke

Eric Lemmon

Mark McLinden

Stephanie L. Outcalt

Richard Perkins

Beverly L. Smith

Jason A. Widegren

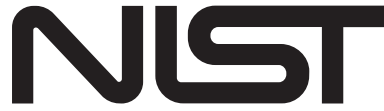

National Institute of Standards and Technology United States Department of Commerce 

NISTIR 6659

\title{
Thermodynamic, Transport, and Chemical Properties of "Reference" JP-8
}

\author{
Thomas J. Bruno \\ Marcia Huber \\ Arno Laesecke \\ Eric Lemmon \\ Mark McLinden \\ Stephanie L. Outcalt \\ Richard Perkins \\ Beverly L. Smith \\ Jason A. Widegren
}

Physical and Chemical Properties Division National Institute of Standards and Technology

325 Broadway

Boulder, CO 80305-3337

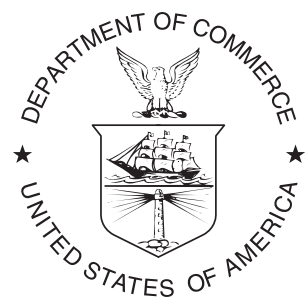

U.S. DEPARTMENT OF COMMERCE Gary Locke, Secretary 



\section{Table of Contents}

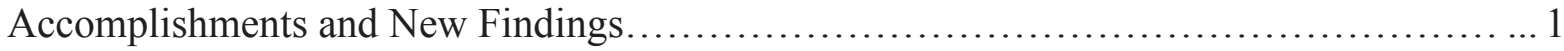

Chemical Analyses of JP-8 and Jet-A samples ................................... 1

Thermal Decomposition........................................................ 6

Thermal Decomposition of Jet-A-4658............................................. 6

Thermal Decomposition of Propylcyclohexane .......................................... 13

Thermophysical Property Measurements on Methylcyclohexane ........................................

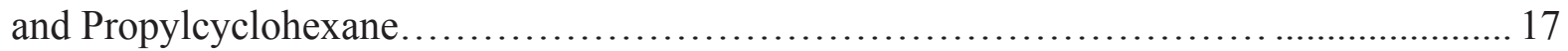

Compressed Liquid Density Measurements for Methyl-

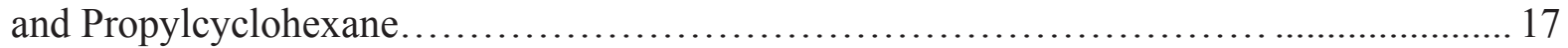

Viscosity Measurements of Methyl- and Propylcyclohexane................................ 24

Sound Speed Measurements of Methyl- and Propylcyclohexane............................ 28

Thermal Conductivity of Methyl- and Propylcyclohexane ............................. 31

Thermophysical Property Measurements on Jet-A, JP-8 and S-8 ....................... 34

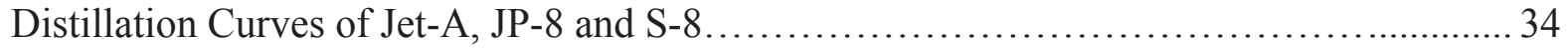

Density Measurements of Compressed Liquid Jet-A, JP-8 and S-8 .....................59

Viscosity Measurements of Jet-A Fuels at Ambient Pressure................................. 71

Thermal Conductivity Measurements of the Compressed

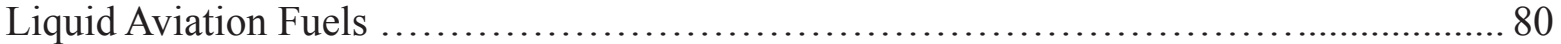

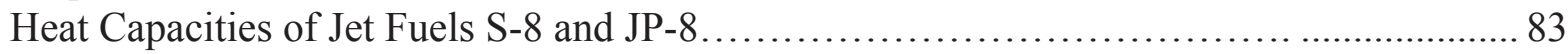

Development of the Thermodynamic and Transport Model............................... 86

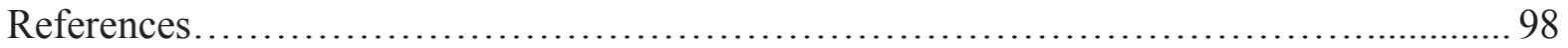

Appendix 1: Thermal Conductivity Measurements for Aviation Fuels ...................... 102 



\section{Accomplishments and New Findings:}

This report will not necessarily be presented in the order in which work was performed, but rather we will progress from the general topics to the more specific topics. Thus, the chemical analysis and the thermal decomposition measurements that were made, which necessarily affect all conclusions that can be drawn from all subsequent measurements, will be presented first. Then, we will present the property measurement work on the pure fluids that were needed to support model development. Subsequent to this section, we present the measurements on the actual aviation fuels, and then finally the thermodynamic and transport modeling results.

\section{Chemical Analyses of JP-8 and Jet-A samples:}

A total of five individual samples of representative aviation fuels (one JP-8, three Jet-A, one Fischer Tropsch synthetic fuel, S-8) were obtained from the Air Force Research Laboratory for this work. The sample of JP-8 was POSF-3773, directly from the Wright Patterson Air Force Base flight line. The three samples of Jet-A were POSF -3602, -3638 and -4658 , the latter being a composite mixture prepared by AFRL. The synthetic Fischer Tropsch fuel was POSF-4734.

A chemical analysis was done on each of the fluid samples by gas chromatography mass spectrometry $(30 \mathrm{~m}$ capillary column of $5 \%$ phenyl polydimethyl siloxane having a thickness of $1 \mu \mathrm{m}$, temperature program from 90 to $250{ }^{\circ} \mathrm{C}, 10^{\circ} \mathrm{C}$ per minute). Mass spectra were collected for each peak from 15 to 550 RMM (relative molecular mass) units $^{1,2}$. Chromatographic peaks made up of individual mass spectra were examined for peak purity, then the mass spectra were used for qualitative identification. Components in excess of 0.5 mole percent were selected for identification and tabulated for each fluid. In addition to this detailed analysis, the hydrocarbon type classification based on ASTM D-2789 was performed. These results figure in the overall mixture characterization, and are also used for comparisons with the chemical analyses of individual distillate fractions (discussed in the section on distillation curves). In addition, this approach to characterizing the mixtures allows the development of fluid mixture files for equation of state development, which will be described later.

The chemical analysis typically allows the identification of between 40 and 60 percent (by mass) of the fluid components. There are usually numerous minor components that cannot be identified because of their low concentrations, and other cases in which chromatographic peak overlap prevents reliable identification of even the more abundant components. An example of the summary of a chemical analysis for Jet-A (the results for Jet-A-4658) is provided in Table 1. Since this fluid represents a composite of samples of Jet-A, additional information is provided for this fluid. In this table, peaks are labeled by numbers or letters. Lettered peaks are relatively minor but are included for a specific reason, such as to provide a budget for the highly volatile components. The peak profile describes how the peak was handled for mass spectral determination. This is typically a single (S) point, an average (A) or both. The correlation coefficient is a numerical figure of merit describing the match of the analyte peak with a library entry. It is important to 
understand that this number is not necessarily the best measure of the "goodness of fit". The confidence indicator, ranging from high $(\mathrm{H})$, moderate $(\mathrm{M})$ to uncertain $(\mathrm{U})$ is a more reliable indicator, since it is based on more factors, including chromatographic behavior. The area percentages provided are uncalibrated, raw area counts on the total ion chromatogram.

For comparison, the summary analyses for S-8-4734 is provided in Table 2, and for JP-83773 is provided in Table 3. For these fluids we provide a synopsis only, without the chromatographic details. We note that occasionally, it is not possible to determine the isomerization of a branched hydrocarbon on the basis of the mass spectrum of the chromatographic peak. In these cases, we have used the variable " $x$ " to note the uncertainty. For example, x-methyl dodecane simply indicates uncertainty in the position of the methyl group on the hydrocarbon backbone.

Table 1: A chemical analysis for Jet-A-4658 performed with gas chromatography - mass spectrometry, used for fuel characterization, and for the development of mixture equations of state.

\begin{tabular}{|c|c|c|c|c|c|c|c|}
\hline $\begin{array}{l}\text { Peak } \\
\text { No. }\end{array}$ & $\begin{array}{c}\text { Retention } \\
\text { Time, } \\
\text { min }\end{array}$ & $\begin{array}{c}\text { Peak } \\
\text { Profile }\end{array}$ & $\begin{array}{l}\text { Correlation } \\
\text { Coefficient }\end{array}$ & Confidence & Name & CAS No. & $\begin{array}{c}\text { Area } \\
\text { Percentage }\end{array}$ \\
\hline $\mathrm{a}$ & 1.726 & $\mathrm{~S}$ & 72.9 & $\mathrm{H}$ & n-heptane & $142-82-5$ & 0.125 \\
\hline $\mathrm{b}$ & 1.878 & $\mathrm{~S}$ & 76.9 & $\mathrm{H}$ & methyl cyclohexane & $108-87-2$ & 0.198 \\
\hline $\mathrm{c}$ & 2.084 & $\mathrm{~S}$ & 71.6 & $\mathrm{H}$ & 2-methyl heptane & $592-27-8$ & 0.202 \\
\hline 1 & 2.144 & $\mathrm{~S}$ & 29.2 & $\mathrm{H}$ & Toluene & $108-88-3$ & 0.320 \\
\hline $\mathrm{d}$ & 2.223 & $\mathrm{~S}$ & 41.9 & $\mathrm{H}$ & $\begin{array}{l}\text { cis-1,3-dimethyl } \\
\text { cyclohexane }\end{array}$ & $638-04-0$ & 0.161 \\
\hline 2 & 2.351 & $\mathrm{~S}$ & 44.0 & $\mathrm{H}$ & n-octane & $111-65-9$ & 0.386 \\
\hline $\mathrm{e}$ & 2.945 & $\mathrm{~S}$ & 31.1 & $\mathrm{H}$ & $\begin{array}{c}\text { 1,2,4-trimethyl } \\
\text { cyclohexane }\end{array}$ & $2234-75-5$ & 0.189 \\
\hline 3 & 3.036 & $\mathrm{~S}$ & 12.4 & $\mathrm{H}$ & 4-methyl octane & $2216-34-4$ & 0.318 \\
\hline 4 & 3.169 & $\mathrm{~S}$ & 37.6 & $\mathrm{H}$ & 1,2-dimethyl benzene & $95-47-6$ & 0.575 \\
\hline 5 & 3.527 & $\mathrm{~S}$ & 33.9 & $\mathrm{H}$ & n-nonane & $111-84-2$ & 1.030 \\
\hline 6 & 3.921 & $\mathrm{~S}$ & NA & $\mathrm{U}$ & $?$ & & 0.321 \\
\hline 7 & 4.066 & $\mathrm{~S} \& \mathrm{~A}$ & NA & $\mathrm{H}$ & $\mathrm{x}$-methyl nonane & NA & 0.597 \\
\hline 8 & 4.576 & S \& A & 7.97 & $M^{1}$ & 4-methyl nonane & $17301-94-9$ & 0.754 \\
\hline 9 & 4.655 & $\mathrm{~S}$ & 35.8 & $\mathrm{H}$ & $\begin{array}{l}\text { 1-ethyl-3-methyl } \\
\text { benzene }\end{array}$ & $620-14-4$ & 1.296 \\
\hline 10 & 4.764 & $\mathrm{~S}$ & 10.7 & $\mathrm{H}$ & 2,6-dimethyl octane & $2051-30-1$ & 0.749 \\
\hline 11 & 4.836 & A & 5.27 & $\mathrm{U}^{2}$ & $\begin{array}{l}\text { 1-methyl-3-(2- } \\
\text { methylpropyl) } \\
\text { cyclopentane }\end{array}$ & 29053-04-1 & 0.285 \\
\hline 12 & 5.012 & $\mathrm{~S}$ & 27.8 & $\mathrm{M}^{2}$ & $\begin{array}{l}\text { 1-ethyl-4-methyl } \\
\text { benzene }\end{array}$ & $622-96-8$ & 0.359 \\
\hline 13 & 5.049 & A & 13.7 & $\mathrm{M}^{2}$ & $\begin{array}{l}\text { 1-methyl-2-propyl } \\
\text { cyclohexane }\end{array}$ & $4291-79-6$ & 0.370 \\
\hline
\end{tabular}




\begin{tabular}{|c|c|c|c|c|c|c|c|}
\hline 14 & 5.291 & $\mathrm{~S}$ & 26.3 & $\mathrm{H}$ & 1,2,4-trimethyl benzene & $95-63-6$ & 1.115 \\
\hline 15 & 5.325 & $\mathrm{~S}$ & 37.7 & $\mathrm{H}$ & n-decane & $124-18-5$ & 1.67 \\
\hline 16 & 5.637 & $\mathrm{~S}$ & 36 & $\mathrm{H}$ & $\begin{array}{l}\text { 1-methyl-2-propyl } \\
\text { benzene }\end{array}$ & $1074-17-5$ & 0.367 \\
\hline 17 & 5.825 & $\mathrm{~S}$ & 36 & $\mathrm{H}$ & 4-methyl decane & $2847-72-5$ & 0.657 \\
\hline 18 & 5.910 & $\mathrm{~S}$ & 26.9 & $\mathrm{H}$ & 1,3,5-trimethyl benzene & $108-67-8$ & 0.949 \\
\hline 19 & 6.073 & S \& A & NA & $\mathrm{M}$ & $\mathrm{x}$-methyl decane & NA & 0.613 \\
\hline 20 & 6.176 & $\mathrm{~S}$ & 5.01 & $\mathrm{M}^{2}$ & 2,3-dimethyl decane & $17312-44-6$ & 0.681 \\
\hline 21 & 6.364 & $S \& A$ & 25.7 & $\mathrm{M}^{2}$ & $\begin{array}{c}\text { 1-ethyl-2,2,6-trimethyl } \\
\text { cyclohexane }\end{array}$ & $71186-27-1$ & 0.364 \\
\hline 22 & 6.516 & $\mathrm{~S} \& \mathrm{~A}$ & 35.6 & $\mathrm{H}$ & $\begin{array}{l}\text { 1-methyl-3-propyl } \\
\text { benzene }\end{array}$ & $1074-43-7$ & 0.569 \\
\hline $\mathrm{f}$ & 6.662 & S \& A & NA & $\mathrm{U}^{2}$ & aromatic & NA & 0.625 \\
\hline 23 & 6.589 & $\mathrm{~S}$ & 20.4 & $\mathrm{M}^{3}$ & 5-methyl decane & $13151-35-4$ & 0.795 \\
\hline 24 & 6.728 & $\mathrm{~S}$ & 22.9 & $\mathrm{H}$ & 2-methyl decane & $6975-98-0$ & 0.686 \\
\hline 25 & 6.862 & A & 23.2 & $\mathrm{H}$ & 3-methyl decane & $13151-34-3$ & 0.969 \\
\hline 26 & 7.110 & $\mathrm{~S}$ & NA & $\mathrm{U}$ & Aromatic & NA & 0.540 \\
\hline 27 & 7.159 & $\mathrm{~S}$ & NA & $\mathrm{U}$ & Aromatic & NA & 0.599 \\
\hline 28 & 7.310 & $\mathrm{~S}$ & 17.9 & M & $\begin{array}{c}\text { 1-methyl-(4- } \\
\text { methylethyl) benzene }\end{array}$ & $99-87-6$ & 0.650 \\
\hline 29 & 7.626 & A & 22.0 & $\mathrm{H}$ & n-undecane & $1120-21-4$ & 2.560 \\
\hline 29 & 7.971 & A & NA & M & $\mathrm{x}$-methyl undecane & NA & 1.086 \\
\hline 30 & 8.875 & A & 22.3 & $\mathrm{M}$ & $\begin{array}{l}\text { 1-ethyl-2,3-dimethyl } \\
\text { benzene }\end{array}$ & $933-98-2$ & 1.694 \\
\hline 31 & 9.948 & A & 19.6 & $\mathrm{H}$ & n-dodecane & $112-40-3$ & 3.336 \\
\hline 32 & 10.324 & $\mathrm{~S}$ & 19.0 & $\mathrm{H}$ & 2,6-dimethyl undecane & $17301-23-4$ & 1.257 \\
\hline 33 & 12.377 & S \& A & 10.8 & $\mathrm{H}$ & n-tridecane & $629-50-5$ & 3.998 \\
\hline $33 a$ & 12.901 & $\mathrm{~S}$ & $24.1^{\circ}$ & $\bar{M}$ & $\begin{array}{l}\text { 1,2,3,4-tetrahydro-2,7- } \\
\text { dimethyl naphthalene }\end{array}$ & $13065-07-1$ & 0.850 \\
\hline $33 b$ & 13.707 & $\mathrm{~S}$ & 3.5 & $\mathrm{M}$ & 2,3-dimethyl dodecane & $6117-98-2$ & 0.657 \\
\hline $33 \mathrm{c}$ & 14.138 & $S$ & 14.5 & $\mathrm{M}$ & $\begin{array}{l}\text { 2,6,10-trimethyl } \\
\text { dodecane }\end{array}$ & $3891-98-3$ & 0.821 \\
\hline $33 \mathrm{~d}$ & 13.834 & $\mathrm{~S}$ & NA & M & $\mathrm{x}$-methyl tridecane & NA & 0.919 \\
\hline $33 \mathrm{e}$ & 13.998 & $\mathrm{~S}$ & NA & $\mathrm{M}$ & $\mathrm{x}$-methyl tridecane & NA & 0.756 \\
\hline 34 & 14.663 & $\mathrm{~S}$ & 29.8 & $\mathrm{H}$ & n-tetradecane & $629-59-4$ & 1.905 \\
\hline 35 & 16.86 & $\mathrm{~S}$ & 24.7 & $\mathrm{H}$ & n-pentadecane & $629-62-9$ & 1.345 \\
\hline
\end{tabular}

1 trailing impurity

2 highly impure composite peak

3 there is evidence of an aromatic impurity in this peak

The meaning of the confidence and profile indicators $(\mathrm{H}, \mathrm{M}, \mathrm{U}, \mathrm{S}, \mathrm{A})$ are discussed in the text. 
Table 2: A listing of the major components found in the sample of S-8-4734. The area percentages provided are from raw uncorrected areas resulting from the integration of the GC-MS total ion chromatogram. When ambiguity exists regarding isomerization, the substituent position is indicated as a general variable, $\mathrm{x}$.

\begin{tabular}{|c|c|c|c|c|c|}
\hline Name & CAS No. & $\begin{array}{c}\text { Area } \\
\text { Percentage }\end{array}$ & Name & CAS No. & $\begin{array}{c}\text { Area } \\
\text { Percentage }\end{array}$ \\
\hline $\begin{array}{l}\text { 2-methyl } \\
\text { heptane }\end{array}$ & $592-27-8$ & 0.323 & n-undecane & $1120-21-4$ & 2.420 \\
\hline $\begin{array}{l}\text { 3-methyl } \\
\text { heptane }\end{array}$ & $589-81-1$ & 0.437 & $\begin{array}{l}\mathrm{x} \text {-methyl } \\
\text { undecane }\end{array}$ & NA & 1.590 \\
\hline $\begin{array}{c}1,2,3- \\
\text { trimethyl } \\
\text { cyclopentane }\end{array}$ & $15890-40-1$ & 0.965 & $\begin{array}{l}\text { 3-methyl } \\
\text { undecane }\end{array}$ & $1002-43-3$ & 1.15 \\
\hline $\begin{array}{c}\text { 2,5-dimethyl } \\
\text { heptane }\end{array}$ & $2216-30-0$ & 1.131 & $\begin{array}{l}\text { 5-methyl } \\
\text { undecane }\end{array}$ & $1632-70-8$ & 1.696 \\
\hline $\begin{array}{c}\text { 4-methyl } \\
\text { octane }\end{array}$ & $2216-34-4$ & 2.506 & $\begin{array}{l}\text { 4-methyl } \\
\text { undecane }\end{array}$ & 2980-69-0 & 1.045 \\
\hline $\begin{array}{l}\text { 3-methyl } \\
\text { octane }\end{array}$ & $2216-33-3$ & 1.323 & $\begin{array}{l}\text { 2-methyl } \\
\text { undecane }\end{array}$ & $7045-71-8$ & 1.072 \\
\hline n-nonane & $111-84-2$ & 1.623 & $\begin{array}{l}\text { 2,3-dimethyl } \\
\text { undecane }\end{array}$ & $17312-77-5$ & 1.213 \\
\hline $\begin{array}{l}\text { 3,5-dimethyl } \\
\text { octane }\end{array}$ & $15869-96-9$ & 1.035 & n-dodecane & $112-40-3$ & 2.595 \\
\hline $\begin{array}{l}\text { 2,6-dimethyl } \\
\text { octane }\end{array}$ & 2051-30-1 & 0.756 & $\begin{array}{l}\text { 4-methyl } \\
\text { dodecane }\end{array}$ & $6117-97-1$ & 0.929 \\
\hline $\begin{array}{l}\text { 4-ethyl } \\
\text { octane }\end{array}$ & $15869-86-0$ & 1.032 & $\begin{array}{l}\mathrm{x} \text {-methyl } \\
\text { dodecane }\end{array}$ & NA & 0.744 \\
\hline $\begin{array}{l}\text { 4-methyl } \\
\text { nonane }\end{array}$ & $17301-94-9$ & 1.904 & $\begin{array}{l}\text { 2-methyl } \\
\text { dodecane }\end{array}$ & $1560-97-0$ & 1.293 \\
\hline $\begin{array}{c}\text { 2-methyl } \\
\text { nonane }\end{array}$ & $871-83-0$ & 1.019 & $\begin{array}{l}\mathrm{x} \text {-methyl } \\
\text { dodecane }\end{array}$ & NA & 1.281 \\
\hline $\begin{array}{c}\text { 3-methyl } \\
\text { nonane }\end{array}$ & 5911-04-6 & 1.385 & n-tridecane & $629-50-5$ & 1.739 \\
\hline n-decane & $124-18-5$ & 2.050 & $\begin{array}{l}\text { 4-methyl } \\
\text { tridecane }\end{array}$ & $26730-12-1$ & 0.836 \\
\hline $\begin{array}{l}\text { 2-5-dimethyl } \\
\text { nonane }\end{array}$ & $17302-27-1$ & 1.175 & $\begin{array}{l}\text { 6-propyl } \\
\text { tridecane }\end{array}$ & $55045-10-8$ & 1.052 \\
\hline $\begin{array}{c}\text { 5-ethyl-2- } \\
\text { methyl } \\
\text { octane }\end{array}$ & $62016-18-6$ & 1.015 & $\begin{array}{l}\mathrm{x} \text {-methyl } \\
\text { tridecane }\end{array}$ & NA & 1.066 \\
\hline $\begin{array}{c}\text { 5-methyl } \\
\text { decane }\end{array}$ & $13151-35-4$ & 1.315 & $\begin{array}{c}\mathrm{n}- \\
\text { tetradecane }\end{array}$ & $629-59-4$ & 1.562 \\
\hline $\begin{array}{l}\text { 4-methyl } \\
\text { decane }\end{array}$ & $2847-72-5$ & 1.134 & $\begin{array}{c}\mathrm{x} \text {-methyl } \\
\text { tetradecane }\end{array}$ & NA & 1.198 \\
\hline 2-methyl & $6975-98-0$ & 1.529 & 5-methyl & $25117-32-2$ & 0.720 \\
\hline
\end{tabular}




\begin{tabular}{|c|c|c|c|c|c|}
\hline decane & & & tetradecane & & 1.032 \\
\hline $\begin{array}{c}\text { 3-methyl } \\
\text { decane }\end{array}$ & $13151-34-3$ & 1.583 & $\begin{array}{c}\mathrm{n}- \\
\text { pentadecane }\end{array}$ & $629-62-9$ & NA \\
\hline & & & $\begin{array}{c}\text { X-methyl } \\
\text { tetradecane }\end{array}$ & 0.727 \\
\hline
\end{tabular}

Table 3: A listing of the major components found in the sample of JP-8-3773. The area percentages provided are from raw uncorrected areas resulting from the integration of the GC-MS total ion chromatogram. When ambiguity exists regarding isomerization, the substituent position is indicated as a general variable, $\mathrm{x}$.

\begin{tabular}{|c|c|c|c|c|c|}
\hline Compound & CAS No. & Area $\%$ & Compound & CAS No. & Area $\%$ \\
\hline n-heptane & $142-82-5$ & 0.125 & $\begin{array}{l}\text { 2,3-dimethyl } \\
\text { decane }\end{array}$ & $17312-44-6$ & 0.681 \\
\hline $\begin{array}{c}\text { methyl } \\
\text { cyclohexane }\end{array}$ & $108-87-2$ & 0.198 & $\begin{array}{c}\text { 1-ethyl-2,2,6- } \\
\text { trimethyl } \\
\text { cyclohexane }\end{array}$ & $71186-27-1$ & 0.364 \\
\hline $\begin{array}{c}\text { 2- } \\
\text { methylheptane }\end{array}$ & $592-27-8$ & 0.202 & $\begin{array}{c}\text { 1-methyl-3- } \\
\text { propyl } \\
\text { benzene }\end{array}$ & $1074-43-7$ & 0.569 \\
\hline toluene & $108-88-3$ & 0.320 & $\begin{array}{l}\text { aromatic } \\
\text { unknown }\end{array}$ & NA & 0.625 \\
\hline $\begin{array}{c}\text { cis-1,3- } \\
\text { dimethyl } \\
\text { cyclohexane }\end{array}$ & $638-04-0$ & 0.161 & $\begin{array}{c}5- \\
\text { methyldecane }\end{array}$ & $13151-35-4$ & 0.795 \\
\hline n-octane & $111-65-9$ & 0.386 & $\begin{array}{c}2- \\
\text { methyldecane }\end{array}$ & $6975-98-0$ & 0.686 \\
\hline $\begin{array}{c}1,2,4- \\
\text { trimethyl } \\
\text { cyclohexane }\end{array}$ & $2234-75-5$ & 0.189 & $\begin{array}{c}3- \\
\text { methyldecane }\end{array}$ & $13151-34-3$ & 0.969 \\
\hline $\begin{array}{c}\text { 4-methyl } \\
\text { octane }\end{array}$ & $2216-34-4$ & 0.318 & $\begin{array}{l}\text { aromatic } \\
\text { unknown }\end{array}$ & NA & 0.540 \\
\hline $\begin{array}{c}\text { 1,2-dimethyl } \\
\text { benzene }\end{array}$ & $95-47-6$ & 0.575 & $\begin{array}{l}\text { aromatic } \\
\text { unknown }\end{array}$ & NA & 0.599 \\
\hline n-nonane & $111-84-2$ & 1.030 & $\begin{array}{c}\text { 1-methyl-(4- } \\
\text { methylethyl) } \\
\text { benzene }\end{array}$ & $99-87-6$ & 0.650 \\
\hline $\begin{array}{c}\mathrm{x}- \\
\text { methylnonane }\end{array}$ & NA & 0.597 & n-undecane & $1120-21-4$ & 2.560 \\
\hline $\begin{array}{c}4- \\
\text { methylnonane }\end{array}$ & $17301-94-9$ & 0.754 & $\begin{array}{l}\mathrm{x} \text {-methyl } \\
\text { undecane }\end{array}$ & NA & 1.086 \\
\hline $\begin{array}{c}\text { 1-ethyl-3- } \\
\text { methyl } \\
\text { benzene }\end{array}$ & $620-14-4$ & 1.296 & $\begin{array}{c}\text { 1-ethyl-2,3- } \\
\text { dimethyl } \\
\text { benzene }\end{array}$ & $933-98-2$ & 1.694 \\
\hline
\end{tabular}




\begin{tabular}{|c|c|c|c|c|c|}
\hline $\begin{array}{c}2,6-\text {-dimethyl } \\
\text { octane }\end{array}$ & $2051-30-1$ & 0.749 & n-dodecane & $112-40-3$ & 3.336 \\
\hline $\begin{array}{c}\text { 1-methyl-3- } \\
(2- \\
\text { methylpropyl) } \\
\text { cyclopentane }\end{array}$ & $29053-04-1$ & 0.285 & $\begin{array}{c}2,6 \text {-dimethyl } \\
\text { undecane }\end{array}$ & $17301-23-4$ & 1.257 \\
\hline $\begin{array}{c}1-\text {-ethyl-4- } \\
\text { methyl } \\
\text { benzene }\end{array}$ & $622-96-8$ & 0.359 & n-tridecane & $629-50-5$ & 3.998 \\
\hline $\begin{array}{c}\text { 1-methyl-2- } \\
\text { propyl } \\
\text { cyclohexane }\end{array}$ & $4291-79-6$ & 0.370 & $\begin{array}{c}1,2,3,4- \\
\text { tetrahydro- } \\
\text { 2,7-dimethyl } \\
\text { naphthalene }\end{array}$ & $13065-07-1$ & 0.850 \\
\hline $\begin{array}{c}1,2,4- \\
\text { trimethyl } \\
\text { benzene }\end{array}$ & $95-63-6$ & 1.115 & $\begin{array}{c}2,3 \text {-dimethyl } \\
\text { dodecane }\end{array}$ & $6117-98-2$ & 0.657 \\
\hline $\begin{array}{c}\text { n-decane } \\
\text { 1-methyl-2- } \\
\text { propyl } \\
\text { benzene }\end{array}$ & $124-18-5$ & 1.67 & $\begin{array}{c}2,6,10- \\
\text { trimethyl } \\
\text { dodecane }\end{array}$ & $3891-98-3$ & 0.821 \\
\hline $\begin{array}{c}4-m e t h y l \\
\text { decane }\end{array}$ & $2847-72-5$ & 0.657 & $\begin{array}{c}\text { x-methyl } \\
\text { tridecane } \\
\text { tridecane }\end{array}$ & NA & 0.756 \\
\hline $\begin{array}{c}1,3,5- \\
\text { trimethyl } \\
\text { benzene }\end{array}$ & $108-67-8$ & 0.949 & n-tetradecane & $629-59-4$ & 1.905 \\
\hline $\begin{array}{c}\text { x-methyl } \\
\text { decane }\end{array}$ & $\mathrm{NA}$ & 0.613 & $\begin{array}{c}\text { n- } \\
\text { pentadecane }\end{array}$ & $629-62-9$ & 1.345 \\
\hline
\end{tabular}

\section{Thermal Decomposition:}

\section{Thermal Decomposition of Jet-A-4658:}

The thermal decomposition of the aviation fuels has been assessed with an ampoule testing instrument and approach that has been developed at $\mathrm{NIST}^{3,4}$. We note that this work is meant strictly to support the physical property measurement work, and not to delineate reaction mechanisms. The instrument, shown schematically in Figure 1, consists of a 304L stainless steel thermal block that is heated to the desired experimental temperature (here, between 250 and $450{ }^{\circ} \mathrm{C}$, although our rate constants were measured between 375 and $450{ }^{\circ} \mathrm{C}$ ). The block is supported in an insulated box with carbon rods; the temperature is maintained and controlled (by a PID controller) to within $0.1{ }^{\circ} \mathrm{C}$ in response to a platinum resistance sensor embedded in the thermal block. The ampoule cells consist of $6.4 \mathrm{~cm}$ lengths of ultrahigh pressure $316 \mathrm{~L}$ stainless steel tubing $(0.64 \mathrm{~cm}$ 
external diameter, $0.18 \mathrm{~cm}$ internal diameter) that are sealed on one end with a TIG welded stainless steel plug. Each cell is connected to a high-pressure high-temperature

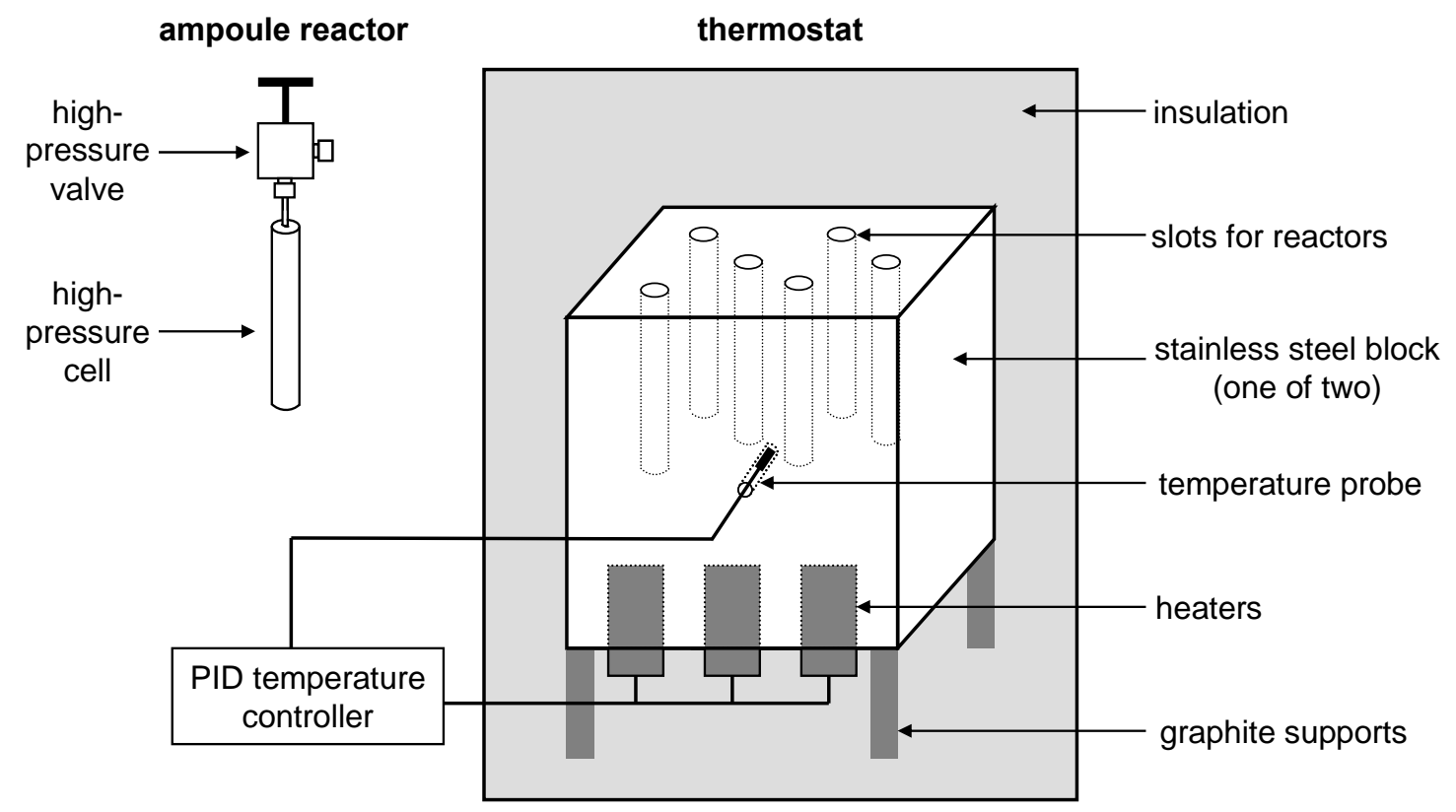

Figure 1: A schematic diagram showing the ampoule thermal decomposition apparatus that was developed at NIST to assess the thermal stability of the aviation fuels studied in this work.

valve at the other end with a short length of $0.16 \mathrm{~cm}$ diameter 316 stainless steel tubing with an internal diameter of $0.02 \mathrm{~cm}$, also TIG welded to the cell. Each cell and valve is capable of withstanding a pressure in excess of $105 \mathrm{MPa}$ at the desired temperature. The internal volume of each cell is known and remains constant at a given temperature. Fluid is added to the individual cell by mass (as determined by an approximate equation of state calculation) to give a total pressure of $34 \mathrm{MPa}$ at the final fluid temperature. Measurements are done by measuring the integrated area of an emergent chromatographic peak suite that results from the decomposition. This is illustrated in Figure 2, in which a representative chromatogram of Jet-A is shown along with magnified insets of the emergent peak zone. In the "as received" sample, there are no peaks in the emergent zone, while after thermal stress, the suite develops and is seen to grow into the chromatogram as a function of increasing exposure time and temperature.

During the course of this work, we performed kinetic studies on two samples that are relevant to the development of the surrogate model for JP-8. First, we measured Jet-A4658, which is the composite Jet-A sample ${ }^{5}$. Next, in order to facilitate the modeling process, we found it necessary to measure propylcyclohexane ${ }^{6}$. This became important because of the need to represent this class of cycloalkane. Before doing any property measurements, we needed to assess the thermal stability. 


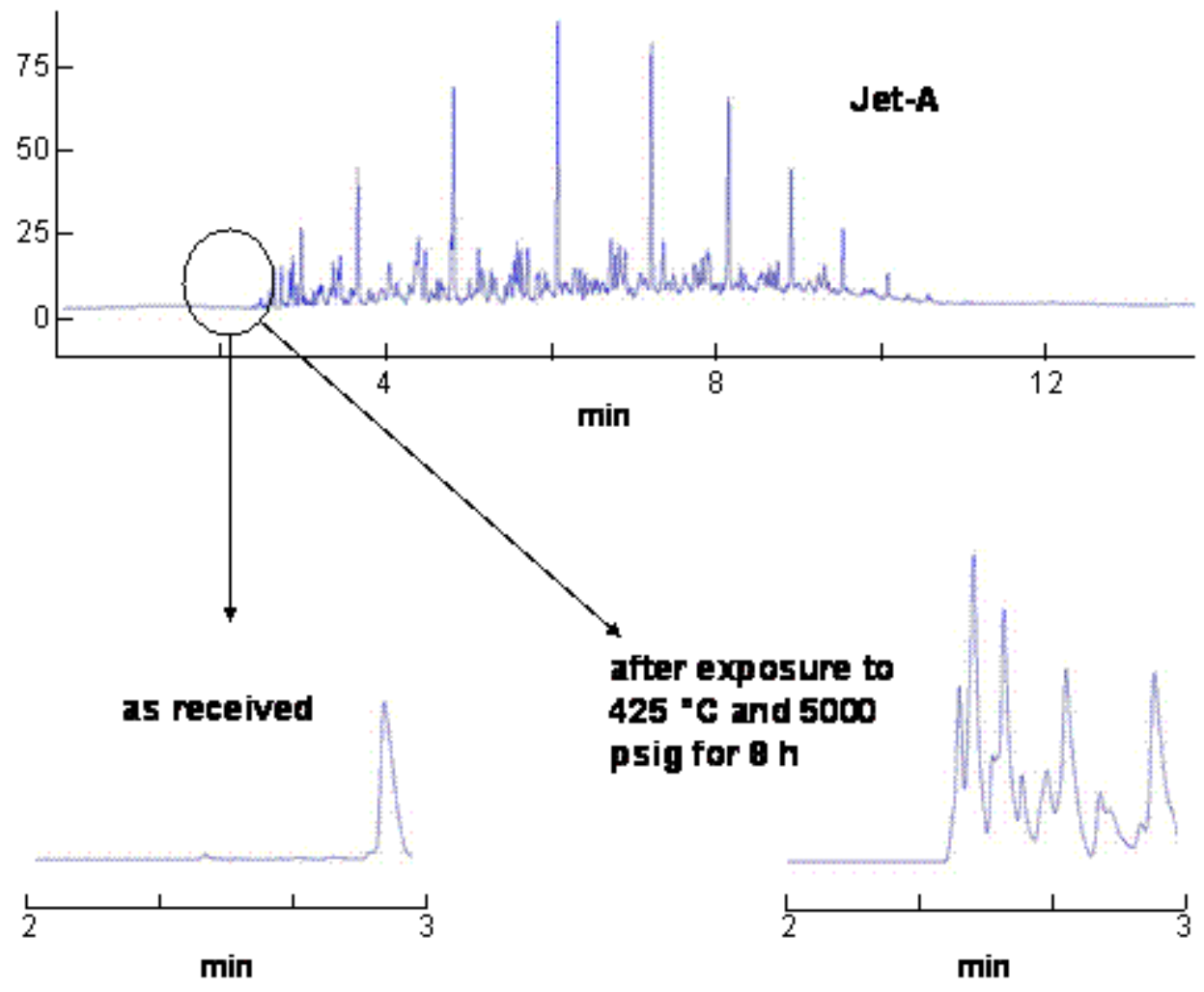

Figure 2: Representative chromatograms showing the usual kerosene component distribution, with the insets showing the very early eluting region. Upon thermal stress, one notes the development of emergent decomposition peaks.

The simplest type of decomposition is a first-order reaction in which a reactant (A) thermally decomposes into a product (B), equation 1 . The rate law for such a reaction can be written in terms of the reactant or the product, equation 2 , where $[\mathrm{A}]$ is the concentration of $\mathrm{A},[\mathrm{B}]$ is the concentration of $\mathrm{B}, k$ is the reaction rate constant, and $t$ is the time. Equation 3 shows the integrated expression in terms of the reactant, where $[\mathrm{A}]_{t}$ is the concentration of reactant at time $t$ and $[\mathrm{A}]_{0}$ is the initial reactant concentration:

$$
\begin{gathered}
\mathrm{A} \rightarrow \mathrm{B}, \\
-\mathrm{d}[\mathrm{A}] / \mathrm{d} t=\mathrm{d}[\mathrm{B}] / \mathrm{d} t=k t, \\
\ln [\mathrm{A}]_{t}=\ln [\mathrm{A}]_{0}-k t .
\end{gathered}
$$

Specifically, for a first-order reaction, a plot of $\ln [\mathrm{A}]$ as a function of $t$ should result in a straight line. Additionally, an Arrhenius plot should also yield a straight line. 
The half-life, $t_{0.5}$, of a decomposition reaction is the time required for half of the reactants to become products. For a first-order reaction such as the one shown in equation 1, the half-life can be calculated directly from the rate constant, equation 4 . A related quantity is the time it takes for $1 \%$ of the reactants to become products, $t_{0.01}$. For first-order reactions, $t_{0.01}$ also can be calculated directly from the rate constant, equation 5 . The $t_{0.5}$ and $t_{0.01}$ of thermal decomposition are useful because they give a direct measure of the time period over which the concentration of thermal decomposition products will reach an unacceptable level. Hence, they are useful when deciding what conditions and protocols are to be used for property measurements. These quantities are given by:

$$
\begin{gathered}
t_{0.5}=0.6931 / k, \\
t_{0.01}=0.01005 / k .
\end{gathered}
$$

In addition to calculating values for $t_{0.5}$ and $t_{0.01}$, rate constants determined over a temperature range can be used to evaluate the parameters of the Arrhenius equation, equation 6 , where $A$ is the pre-exponential factor, $E_{\mathrm{a}}$ is the activation energy, $R$ is the gas constant, and $T$ is the temperature. The Arrhenius parameters can then be used to predict rate constants at temperatures other than those examined experimentally:

$$
k=A \exp \left(-E_{\mathrm{a}} / R T\right) .
$$

Samples of Jet-A-4658 were decomposed in the stainless steel ampoule reactors at 375 , 400,425 and $450{ }^{\circ} \mathrm{C}$. This temperature range was chosen because it allowed for reaction times of a convenient length. At $375^{\circ} \mathrm{C}$ the reaction is relatively slow, so reaction times ranged from 4 to $24 \mathrm{~h}$. At $450{ }^{\circ} \mathrm{C}$ the reaction is much faster, so reaction times ranged from 10 to $120 \mathrm{~min}$. The unreacted Jet A was clear and nearly colorless. Mild thermal stress (i.e., the shortest reaction times at the lower temperatures) caused the liquid to become pale yellow. Severe thermal stress (i.e., the longest reaction times at the higher temperatures) caused the liquid to become very dark brown, opaque, and viscous. A small amount of dark particulate was regularly seen in the more thermally stressed samples. Additionally, low-molecular-weight decomposition products caused a pressurized vapor phase to develop inside the reactors. For the more severely stressed samples, it was common for the entire liquid sample to be expelled under pressure when the reactor valve was opened.

A separate analysis of this vapor phase was desired, and to accomplish this a gas-liquid separator designed at NIST for such work was employed ${ }^{7}$. This device is shown in Figure 3. The gas phase was then analyzed using a gas chromatograph with MS detection. Over 30 compounds were identified in the gas phase, with light alkanes being the most abundant. Table 4 shows the 10 most abundant compounds, based on total ion current in the MS detector. Note that the MS method employed precludes observation of methane. The apparent lack of alkene decomposition products is somewhat surprising, although it is known that high pressures and long reaction times decrease the yield of alkenes from the decomposition of alkanes. The rate of decomposition from alkanes 


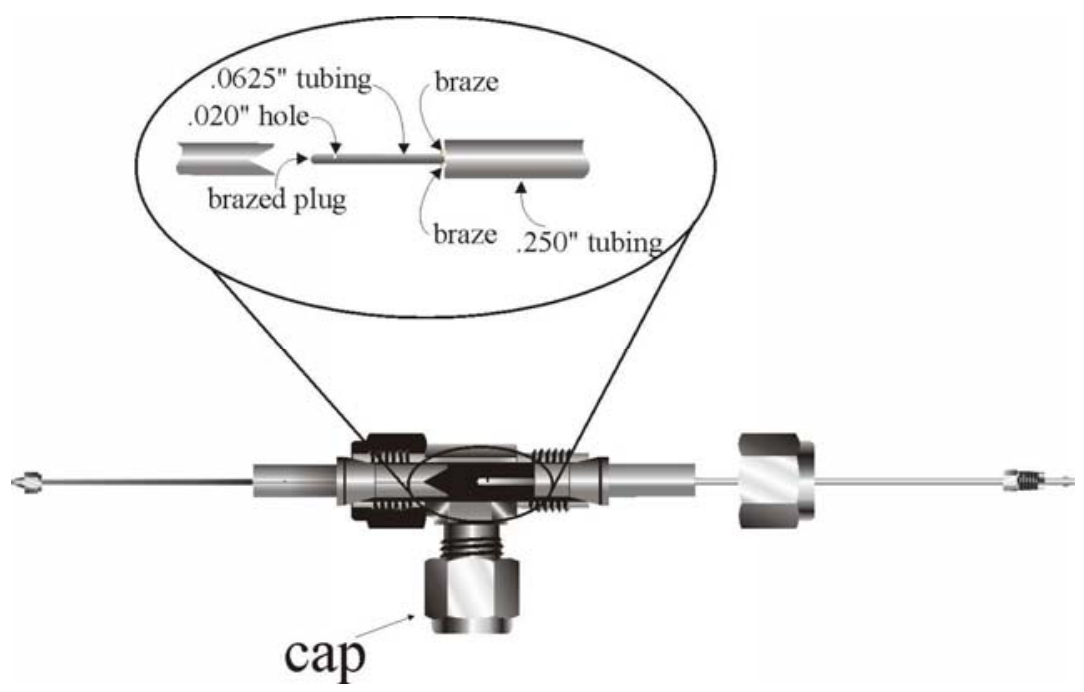

Figure 3: A schematic diagram of the gas-liquid separator that was used to examine the vapor phase of the thermally stressed Jet-A-4658. More details regarding this device can be found in ref 5 .

Table 4: A listing of the most abundant compounds found in the vapor phase of thermally stressed Jet-A-4658, maintained for $2 \mathrm{hrs}$. at $450{ }^{\circ} \mathrm{C}$.

\section{Compound}

butane

pentane

propane

2-methylpropane

2-methylbutane

ethane

hexane

2-methylpentane

methylcyclopentane

3-methylpentane

\section{\% of Total Ion Current}

13.0

10.6

10.4

8.6

8.1

6.6

6.4

5.9

3.3

3.2

are also known to depend on the material used to construct the reactor. 
The thermally stressed liquid phase of each sample was analyzed by a gas chromatograph equipped with a flame ionization detector. An easily identifiable suite of decomposition products had retention times between 2.3 and 2.8 min, Figure 4 . The kinetic analysis was done based on this suite of peaks. We did not identify all of the individual compounds responsible for these peaks, but it is worth noting that pentane and hexane had retention times of $2.4 \mathrm{~min}$ and $2.5 \mathrm{~min}$ under these conditions, which suggests that most of these decomposition products had 5-7 carbon atoms. The observed product suite was essentially the same at all temperatures, with retention times that were constant to within $0.01 \mathrm{~min}$. Undoubtedly, there were peaks for decomposition products in the broad kerosene "hump" that began around 2.9 min, but use of them for the kinetic analysis was impractical because of peak overlap and the lack of baseline resolution. Additionally, we did not routinely monitor compounds that were not retained in the liquid phase, including vapor-phase products and potential coke deposits.

As mentioned above, the kinetic analysis was done using the emergent suite of decomposition products in the liquid phase with retention times between 2.3 and $2.8 \mathrm{~min}$. The rate constant, $\mathrm{k}$, at each temperature was determined from data collected at four different reaction times, with 3 to 6 replicate decomposition reactions run at each reaction time. The value of $\mathrm{k}$ was obtained from a nonlinear least-squares fit of these data to equation 3. For example, Figure 4 is a plot of the data and curve-fit for $425^{\circ} \mathrm{C}$. Note that data were collected at seven time points, but only the first four data points in Figure 4 were used to determine $\mathrm{k}$. The reason for excluding the later time points was to limit the influence of any secondary decomposition reactions on the kinetics. Even though it is unlikely that measurements would intentionally be carried out with instrumental residence times in excess of the first four time points, this area of the plot is still useful in that it represents the chemical decomposition regime that is possible if an instrument or engine enters an upset condition resulting in long residence times. Values for $\mathrm{t}_{0.5}$ and $\mathrm{t}_{0.01}$ are calculated from $\mathrm{k}$ by use of equations 4 and 5 . The decomposition rate constants at all four temperatures, along with values of $t_{0.5}$ and $t_{0.01}$, are presented in Table 5. The standard uncertainties given were calculated from the standard deviation of replicate measurements and from the standard error in the nonlinear fit. The values of $t_{0.01}$ show that physical property measurements at $\geq 400{ }^{\circ} \mathrm{C}$ would require apparatus residence times on the order of $5 \mathrm{~min}$ or less. On the other hand, at $375{ }^{\circ} \mathrm{C}$ a residence time of about half an hour may be acceptable. First order rate constants reported for the decomposition of $\mathrm{n}$ tetradecane are $\mathrm{k}=1.78 \times 10^{-5} \mathrm{~s}^{-1}$ at $400{ }^{\circ} \mathrm{C}, \mathrm{k}=1.01 \times 10^{-4} \mathrm{~s}^{-1}$ at $425^{\circ} \mathrm{C}$, and $\mathrm{k}=4.64 \times$ $10^{-4} \mathrm{~s}^{-1}$ at $450^{\circ} \mathrm{C}$. Within our experimental uncertainty, these are the same as the values in Table 5 for Jet A.

An Arrhenius plot of the rate constants is shown in Figure 5. The Arrhenius parameters determined from a linear regression of the data are $A=4.1 \times 10^{12} \mathrm{~s}^{-1}$ and $E_{\mathrm{a}}=220$ $\mathrm{kJ} \cdot \mathrm{mol}^{-1}$. The standard uncertainty in Ea, calculated from the standard error in the slope of the regression, is $10 \mathrm{~kJ} \cdot \mathrm{mol}-1$. The linearity of the Arrhenius plot $\left(\mathrm{r}^{2}>0.9978\right)$ over the $75{ }^{\circ} \mathrm{C}$ temperature range is an important validation that the assumption of first-order kinetics is reasonable. Note that the activation energy for the decomposition of Jet A is slightly lower than the values reported for pure $\mathrm{C} 10-\mathrm{C} 14$ n-alkanes; for example, for $\mathrm{n}$ dodecane Ea is $260 \mathrm{~kJ} \cdot \mathrm{mol}^{-1}$ (with a reported uncertainty of $8 \mathrm{~kJ} \cdot \mathrm{mol}^{-1}$ ). 


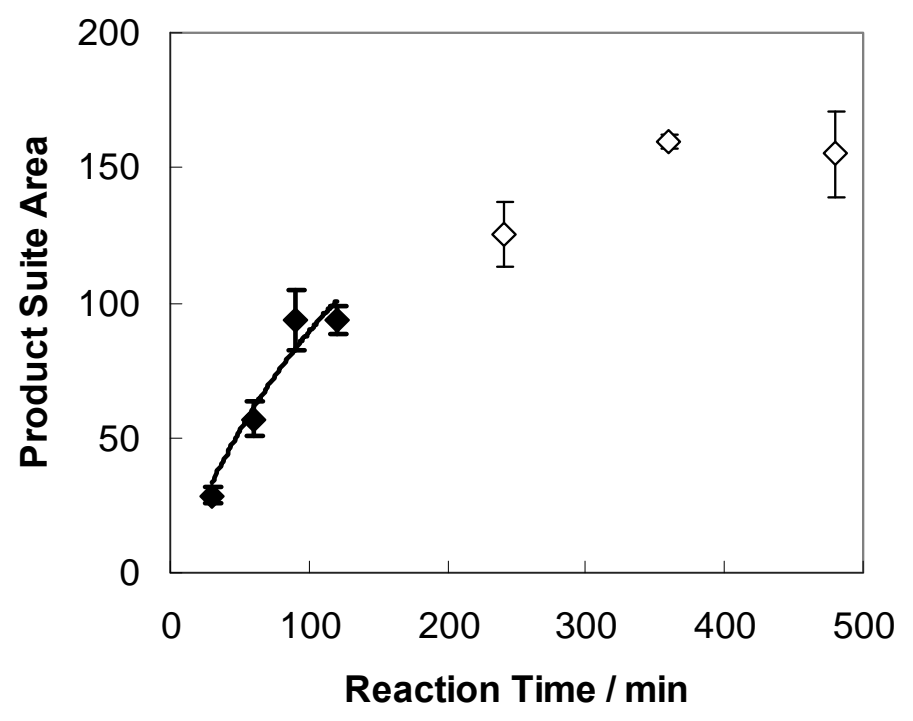

Figure 4: Plot of the corrected area counts of the decomposition product suite as a function of time at $425{ }^{\circ} \mathrm{C}$. Only the data at short reaction times (solid symbols) were used to determine the rate constant. The error bars represent the standard deviation for replicate decomposition reactions at each time point.

Table 5: Kinetic data for the thermal decomposition of Jet-A-4658.

\begin{tabular}{|c|c|c|c|c|}
\hline$\underline{T} /{ }^{\circ} \mathrm{C}$ & $\underline{k} / \mathbf{s}^{-1}$ & Uncertainty in $k / s^{-1}$ & $\underline{t_{0.5}} \underline{/ h}$ & $\underline{t_{0.01}} / \mathrm{min}$ \\
\hline 375 & $5.9 \times 10^{-6}$ & $3.9 \times 10^{-6}$ & 33 & 28 \\
\hline 400 & $3.3 \times 10^{-5}$ & $1.8 \times 10^{-5}$ & 5.8 & 5.0 \\
\hline 425 & $1.2 \times 10^{-4}$ & $0.6 \times 10^{-4}$ & 1.7 & 1.4 \\
\hline 450 & $4.4 \times 10^{-4}$ & $2.3 \times 10^{-4}$ & 0.44 & 0.38 \\
\hline
\end{tabular}




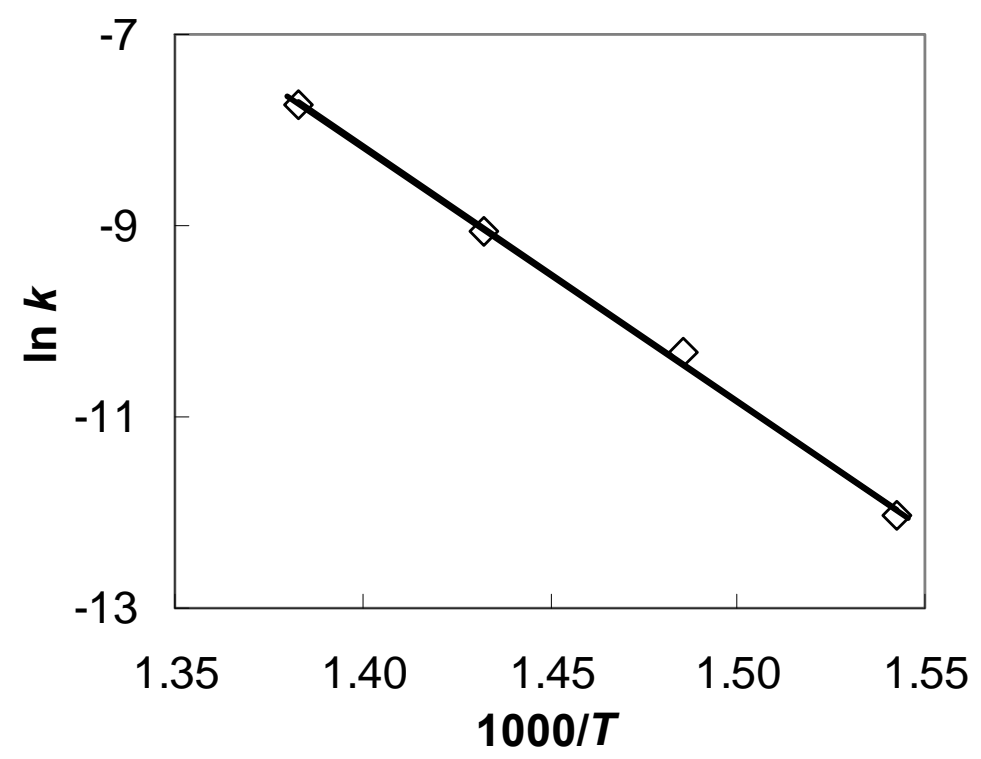

Figure 5: Arrhenius plot for the decomposition of Jet-A-4658. The Arrhenius parameters determined from the fit to the data are $A=4.1 \times 10^{12} \mathrm{~s}^{-1}$ and $E_{\mathrm{a}}=220 \mathrm{~kJ} \cdot \mathrm{mol}^{-1}$.

\section{Thermal Decomposition of Propylcyclohexane:}

As mentioned above, we also found it necessary to incorporate some pure component property measurements into the model development. Two fluids were chosen to represent cyclic branched alkanes: methylcyclohexane and propylcyclohexane. Because adequate thermal stability data could be found for methyl cyclohexane, no additional measurements were done on this fluid. Propylcyclohexane required measurements, however, since no thermal decomposition data could be found.

The ampoule reactors were filled with propylcyclohexane by use of a procedure designed to achieve an initial pressure of $34.5 \mathrm{MPa}$ (5000 psi) for all of the decomposition reactions. This is important because it mimics the high-pressure conditions during some physical property measurements, and it helps ensure that differences in observed decomposition rates are not due to differences in pressure. It also allows comparability with the jet-A-4658 measurements described above. After filling, air in the void space of the reactor was removed by one freeze-pump-thaw cycle. The loaded reactors were then inserted into the thermostatted stainless steel block and maintained at the reaction temperature for a period of time ranging from $10 \mathrm{~min}$ to $32 \mathrm{~h}$. After decomposition, the reactors were removed from the thermostatted block and immediately cooled in roomtemperature water. The thermally stressed propylcyclohexane was recovered and analyzed as described below. After each run, the cells and valves were carefully cleaned and dried. Blank experiments, in which the cell was loaded as described above but not heated, confirmed the effectiveness of the cleaning protocol. 
The products of a 40 min decomposition reaction at $450{ }^{\circ} \mathrm{C}$ were identified by GC-MS. To accomplish this, a short length of glass capillary tubing was connected to the outlet on the reactor valve. The valve on the reactor was opened just enough to allow the pressurized mixture of gas and liquid in the reactor to escape slowly. Then the end of the capillary was briefly pushed through the inlet septum of the split/splitless injection port of the GC-MS, directly introducing the decomposed sample by flowing capillary injection. The components of the sample were then separated on a $30 \mathrm{~m}$ capillary column coated with a $0.25 \mu \mathrm{m}$ film of ( $5 \%$-phenyl)-methylpolysiloxane. The temperature program for the separation started with an initial isothermal separation at $35^{\circ} \mathrm{C}$ for $6 \mathrm{~min}$, followed by a $20^{\circ} \mathrm{C} / \mathrm{min}$ ramp to $175^{\circ} \mathrm{C}$. The most abundant decomposition products identified in this manner are listed in Table 6.

Table 6. Summary of the most abundant decomposition products after 40 min at $450{ }^{\circ} \mathrm{C}$.

\section{Compound}

$$
\text { ethane }+ \text { propane (not resolved) }
$$$$
\text { pentane }
$$

methylcyclopentane

cyclohexane

cyclohexene

methylcyclohexane

methylenecyclohexane

1-methylcyclohexene

ethylcyclohexane

1-methyl-2-propylcyclopentane

propylcyclohexene (all isomers)

butylcyclohexane

1,3-diisopropylcyclohexane

\begin{tabular}{c} 
\% of Total Ion \\
\hline Abundance \\
\hline 2.3 \\
0.7 \\
1.1 \\
5.5 \\
3.8 \\
2.1 \\
3.4 \\
4.7 \\
0.7 \\
6.9 \\
2.1 \\
1.1 \\
2.8
\end{tabular}

In order to determine the kinetics of decomposition, the thermally stressed liquid phase of every decomposition reaction was analyzed by a gas chromatograph equipped with a flame ionization detector (GC-FID). Evaporative losses were minimized by transferring the liquid phase into a chilled $\left(7^{\circ} \mathrm{C}\right)$ glass vial and immediately diluting it with a known amount of n-dodecane. The resulting $n$-dodecane solution was typically $5 \%$ reacted propylcyclohexane (mass/mass). The sample was then analyzed by GC-FID using a $30 \mathrm{~m}$ capillary column coated with a $0.1 \mu \mathrm{m}$ film of ( $5 \%$-phenyl)-methylpolysiloxane. The temperature program for the chromatographic separation consisted of an initial isothermal separation at $80^{\circ} \mathrm{C}$ for $4 \mathrm{~min}$, followed by a $30^{\circ} \mathrm{C} / \mathrm{min}$ gradient to $250{ }^{\circ} \mathrm{C}$, with an additional minute at the final temperature. Figure 6 shows the suite of decomposition products that was seen in the chromatograms. The decomposition products were essentially the same at all temperatures, with retention times that were constant to within 
$0.01 \mathrm{~min}$. Although we did not attempt to identify the individual peaks, the product suite observed by GC-FID is consistent with the product suite identified by GC-MS. These routine GC-FID analyses allowed us to track the extent of decomposition for each reaction. For example, about $20 \%$ of the propylcyclohexane had decomposed after 40 min at $450{ }^{\circ} \mathrm{C}$, but only about $4 \%$ of the propylcyclohexane had decomposed after $32 \mathrm{~h}$ at $375^{\circ} \mathrm{C}$.

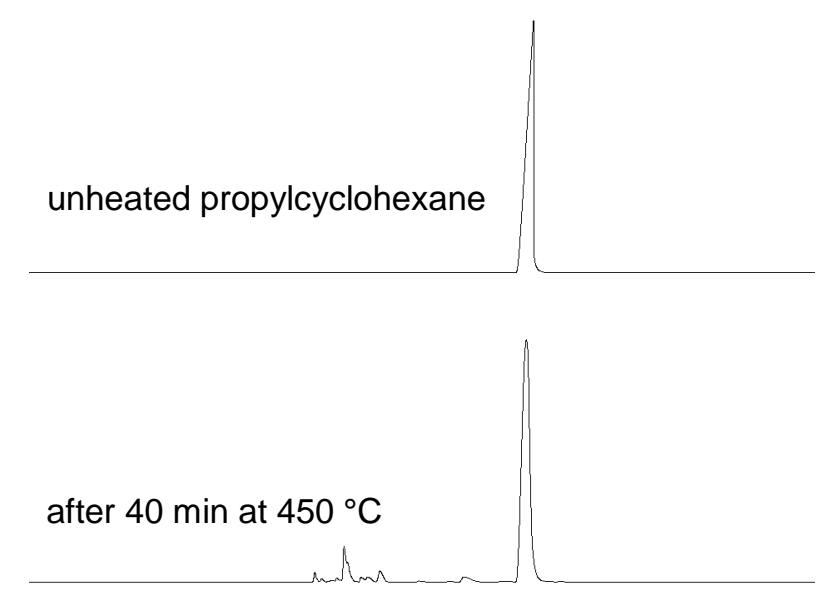

Figure 6: Chromatograms obtained by gas chromatography for unheated propylcyclohexane and for decomposed propylcyclohexane. The decomposed sample had been maintained at $450{ }^{\circ} \mathrm{C}$ for $40 \mathrm{~min}$, which caused about $20 \%$ of the propylcyclohexane to decompose.

The kinetic analysis was done by monitoring the relative decrease in the chromatographic signal of propylcyclohexane compared to the chromatographic signals for decomposition products. At each temperature data were collected at four or five different reaction times, with 3 to 5 replicate decomposition reactions at each reaction time. Following equation 3 , the value of $k$ at each temperature was obtained from the slope of a linear fit of $\ln$ (propylcyclohexane peak area \%) as a function of $t$. Figure 7 shows such a plot obtained from the data at $450{ }^{\circ} \mathrm{C}$. The linearity of the data justifies the assumption of first-order kinetics. The first-order rate constant obtained from the plot is $8.63 \times 10^{-5} \mathrm{~s}^{-1}$, with a standard uncertainty of $0.18 \times 10^{-5} \mathrm{~s}^{-1}$. The rate constants measured for all temperatures are provided in Table 7. An Arrhenius plot of the rate constants is shown in Figure 8. The Arrhenius parameters determined from a linear regression of the data are A $=2.56 \times 10^{16} \mathrm{~s}^{-1}$ and $E_{\mathrm{a}}=283 \mathrm{~kJ} \cdot \mathrm{mol}^{-1}$. The standard uncertainty in $E_{\mathrm{a}}$, calculated from the standard error in the slope of the regression, is $6 \mathrm{~kJ} \cdot \mathrm{mol}^{-1}$. The linearity of the Arrhenius plot $\left(\mathrm{r}^{2}=0.9999\right)$ over the $75^{\circ} \mathrm{C}$ temperature range is an important validation that the assumption of first-order kinetics is reasonable. Note that the activation energy for the decomposition of propylcyclohexane is slightly higher than the values reported for $\mathrm{C}_{10}-\mathrm{C}_{14} n$-alkanes; for example, for n-dodecane $E_{\mathrm{a}}$ is $260 \mathrm{~kJ} \cdot \mathrm{mol}^{-1}$ (with a reported uncertainty of $\left.8 \mathrm{~kJ} \cdot \mathrm{mol}^{-1}\right)^{6}$. 


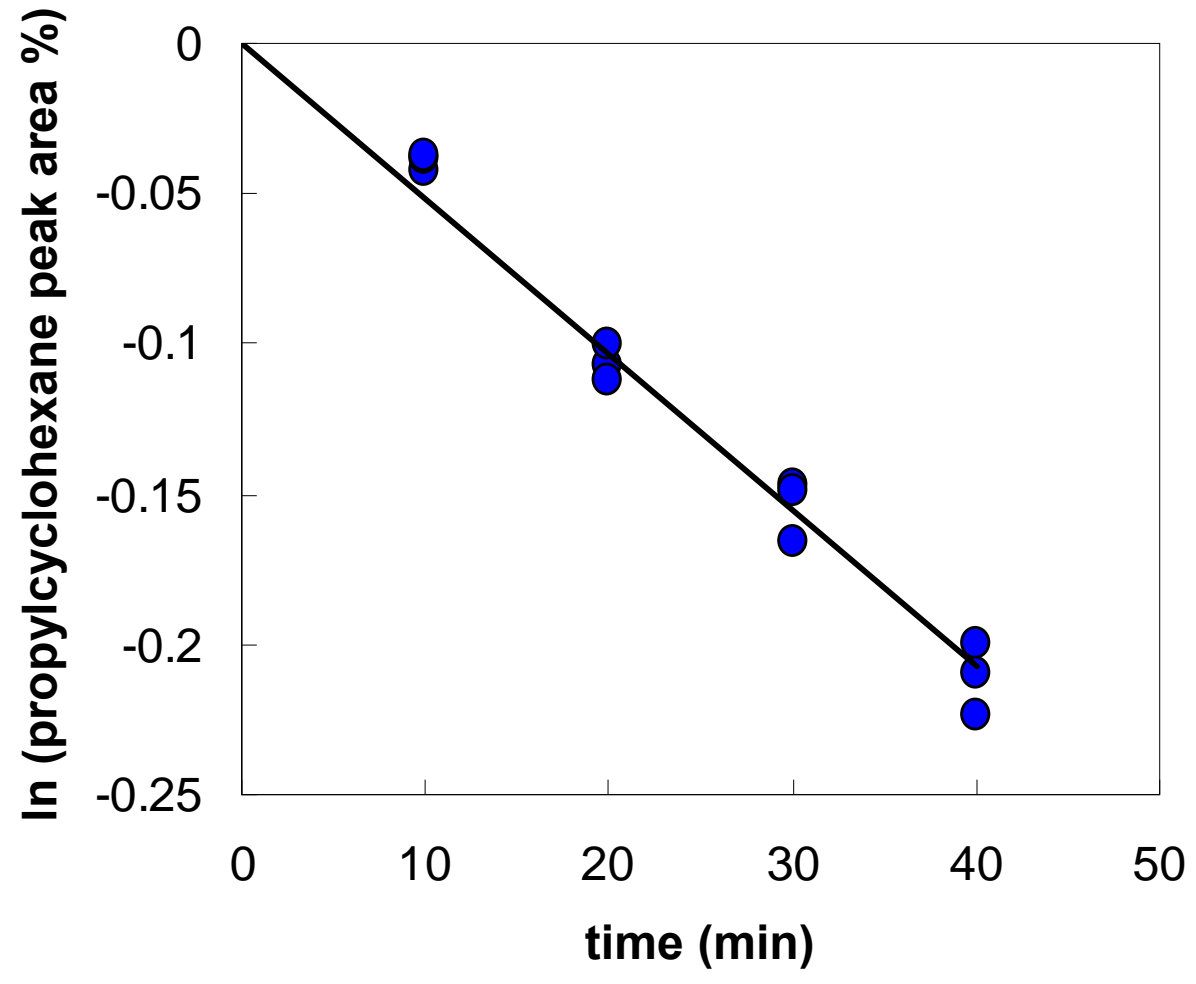

Figure 7: A plot of the $\ln$ (propylcyclohexane peak area \%) as a function of time at 450 ${ }^{\circ} \mathrm{C}$. The first-order rate constant for the decomposition reaction was determined from the slope of the linear fit to the data.

Table 7: Kinetic data for the thermal decomposition of propylcyclohexane.

\begin{tabular}{|c|c|c|c|c|}
\hline$\underline{T} /{ }^{\circ} \mathrm{C}$ & $\underline{k} / \mathbf{s}^{-1}$ & Uncertainty in $k / s^{-1}$ & $\underline{t}_{0.5} / \mathrm{h}$ & $\underline{t}_{0.01} / \mathrm{min}$ \\
\hline 375 & $3 . \overline{66 \times 10^{-7}}$ & $0.12 \times 10^{-7}$ & 526 & 458 \\
\hline 400 & $2.67 \times 10^{-6}$ & $0.09 \times 10^{-6}$ & 72.2 & 62.8 \\
\hline 425 & $1.59 \times 10^{-5}$ & $0.04 \times 10^{-5}$ & 12.1 & 10.5 \\
\hline 450 & $8.63 \times 10^{-5}$ & $0.18 \times 10^{-5}$ & 2.23 & 1.94 \\
\hline
\end{tabular}




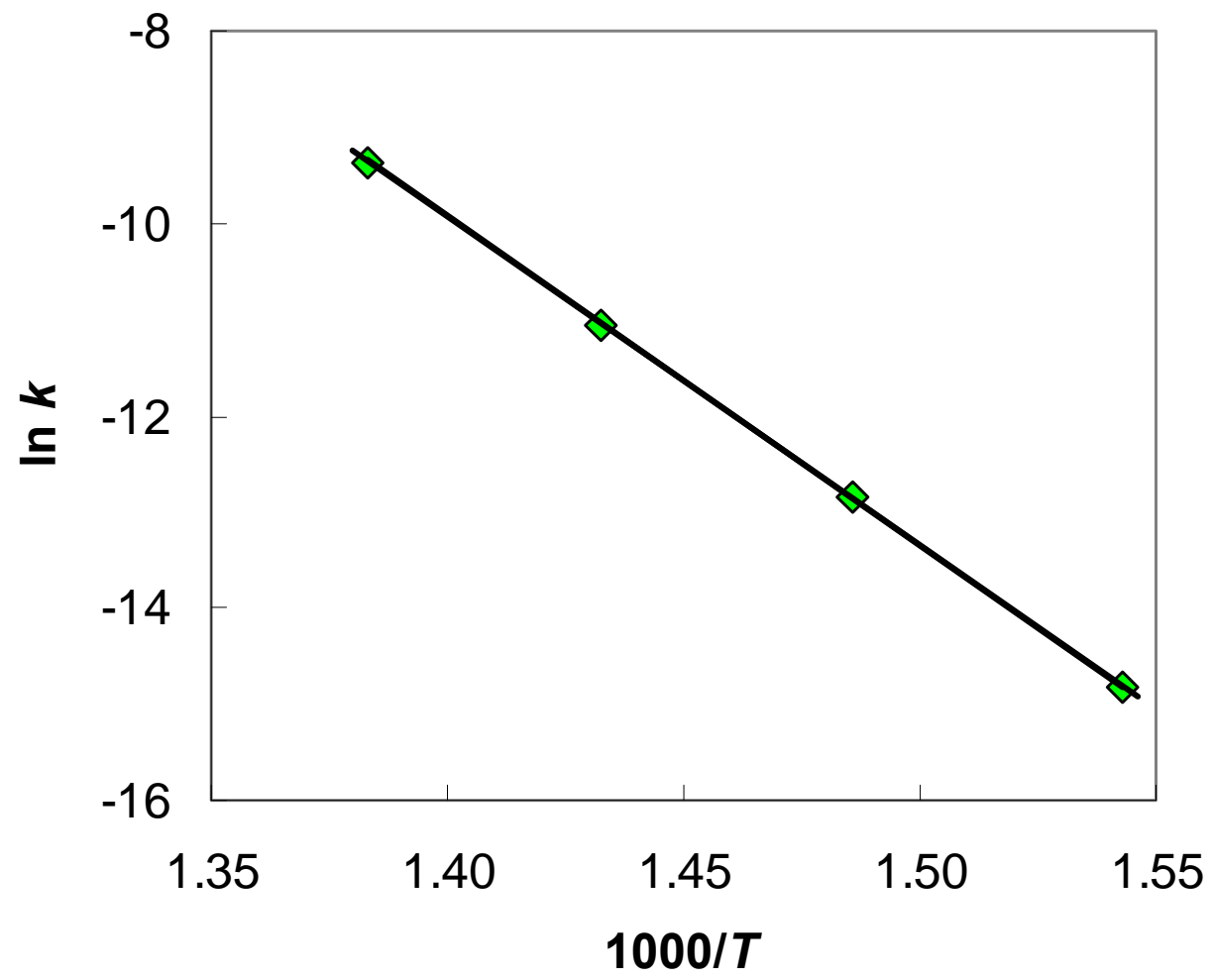

Figure 8: The Arrhenius plot for the decomposition of propylcyclohexane. The Arrhenius parameters determined from the linear fit are $\mathrm{A}=2.56 \times 10^{16} \mathrm{~s}^{-1}$ and $E_{\mathrm{a}}=283 \mathrm{~kJ} \cdot \mathrm{mol}^{-1}$.

Thermophysical Property Measurements on Methylcyclohexane and Propylcyclohexane:

Compressed Liquid Density Measurements for Methyl- and Propylcyclohexane:

A schematic of the apparatus used to measure compressed liquid densities over the temperature range of $270 \mathrm{~K}$ to $470 \mathrm{~K}$ and to pressures of $50 \mathrm{MPa}$ is illustrated in Figure 9. The heart of the apparatus is a commercial vibrating tube densimeter, however, several physical and procedural improvements have been implemented beyond that of the commercial instrument operated in a stand-alone mode. The densimeter is housed in a specially designed two-stage thermostat for improved temperature control. The uncertainty in the temperature is $0.02 \mathrm{~K}$ with short-term stability of $0.005 \mathrm{~K}$. Pressures are measured with an oscillating quartz crystal pressure transducer with an uncertainty of $10 \mathrm{kPa}$. The densimeter is calibrated with measurements of vacuum, propane and toluene, over the temperature and pressure range of the apparatus to achieve an uncertainty in density of $1 \mathrm{~kg} / \mathrm{m}^{3}$.

The apparatus has been designed, and software has been written so that the operation and data acquisition are fully automated. Data are taken along isotherms over a temperature/pressure matrix programmed by the operator prior to the start of measurements. Electronically actuated pneumatic valves, and a programmable syringe pump are used to move from one pressure to the next and/or flush fresh sample through 
the system. Operation of the densimeter in this manner allows for measurements to be made 24 hours a day.

Compressed liquid densities of methylcyclohexane have been measured along eleven isotherms from $270 \mathrm{~K}$ to $470 \mathrm{~K}$ at pressures from $0.5 \mathrm{MPa}$ to $40 \mathrm{MPa}$. A total of 140 points are reported in Table 8 and shown graphically in Figure $10 .^{9}$

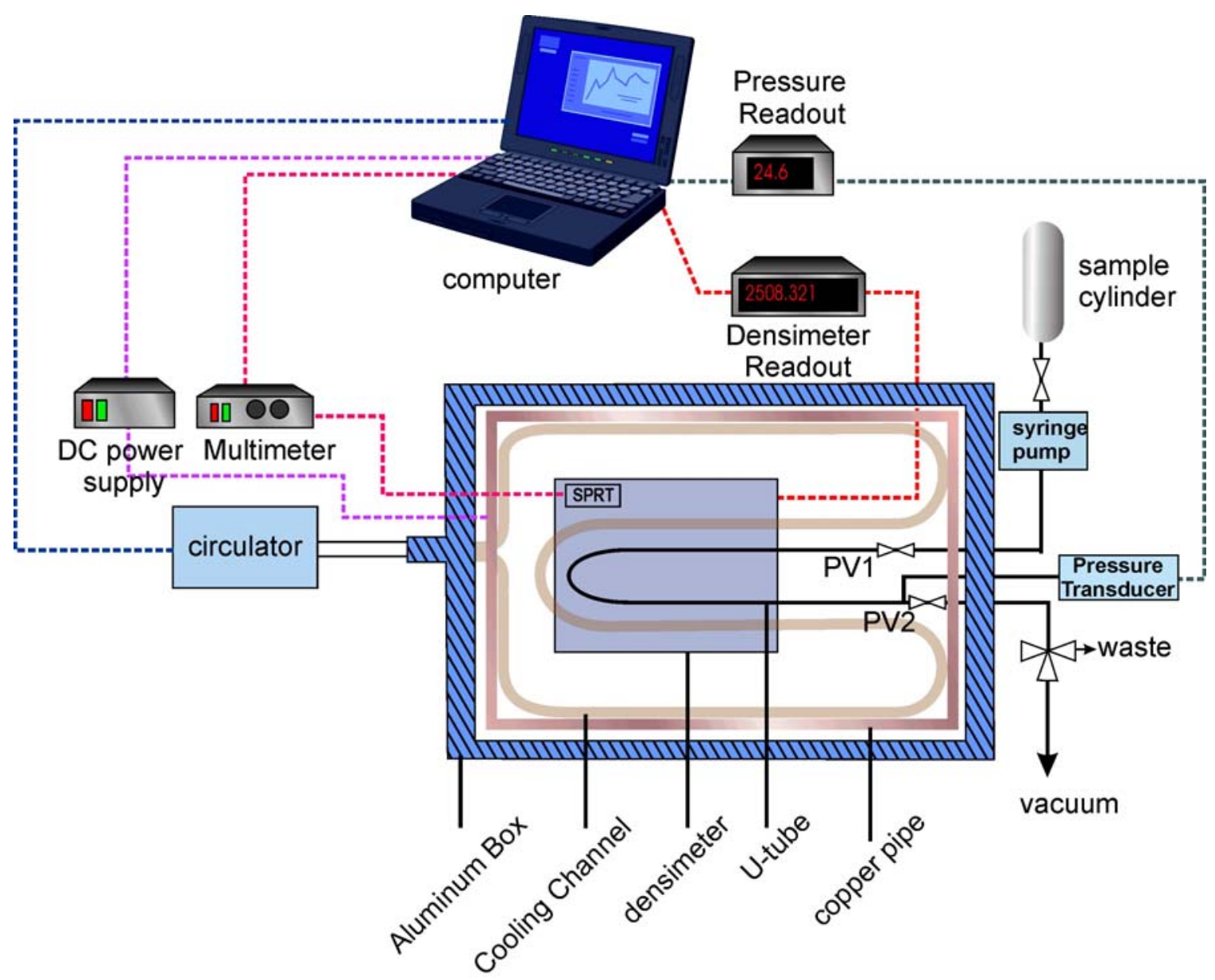

Figure 9. Schematic of the Compressed Liquid Density Apparatus.

Table 8. Compressed liquid densities of methylcyclohexane

$\begin{array}{cccccc}\begin{array}{c}\text { Temperature } \\ (\mathrm{K})\end{array} & \begin{array}{c}\text { Pressure } \\ (\mathrm{MPa})\end{array} & \begin{array}{c}\text { Density } \\ (\mathrm{kg} / \mathrm{m} 3)\end{array} & \begin{array}{c}\text { Temperature } \\ (\mathrm{K})\end{array} & \begin{array}{c}\text { Pressure } \\ (\mathrm{MPa})\end{array} & \begin{array}{c}\text { Density } \\ (\mathrm{kg} / \mathrm{m} 3)\end{array} \\ 270.00 & 40.007 & 814.61 & 390.00 & 40.003 & 731.07 \\ 270.00 & 35.009 & 811.80 & 390.00 & 35.004 & 726.33 \\ 270.00 & 30.008 & 808.90 & 390.00 & 29.996 & 721.31\end{array}$




\begin{tabular}{|c|c|c|c|c|c|}
\hline 270.00 & 25.004 & 805.91 & 390.00 & 25.009 & 715.97 \\
\hline 270.00 & 20.008 & 802.83 & 390.00 & 20.007 & 710.24 \\
\hline 270.00 & 15.006 & 799.63 & 390.00 & 15.001 & 704.06 \\
\hline 270.00 & 10.005 & 796.31 & 390.00 & 10.003 & 697.32 \\
\hline 270.00 & 5.007 & 792.85 & 390.00 & 5.011 & 689.86 \\
\hline 270.00 & 4.004 & 792.13 & 390.00 & 4.003 & 688.24 \\
\hline 270.00 & 2.998 & 791.41 & 390.00 & 3.004 & 686.61 \\
\hline 270.00 & 2.005 & 790.68 & 390.00 & 2.008 & 684.95 \\
\hline 270.00 & 1.003 & 789.96 & 390.00 & 0.999 & 683.2 \\
\hline 270.00 & 0.502 & 789.59 & 390.00 & 0.502 & 682.32 \\
\hline 290.00 & 39.998 & 800.66 & 410.00 & 39.999 & 717.45 \\
\hline 290.00 & 34.996 & 797.59 & 410.00 & 35.003 & 712.28 \\
\hline 290.00 & 29.996 & 794.41 & 410.00 & 30.002 & 706.79 \\
\hline 290.00 & 24.995 & 791.12 & 410.00 & 25.002 & 700.89 \\
\hline 290.00 & 20.007 & 787.71 & 410.00 & 19.997 & 694.5 \\
\hline 290.00 & 14.995 & 784.14 & 410.00 & 15.004 & 687.54 \\
\hline 290.00 & 9.999 & 780.43 & 410.00 & 10.006 & 679.84 \\
\hline 290.00 & 5.004 & 776.54 & 410.00 & 5.002 & 671.17 \\
\hline 290.00 & 3.994 & 775.73 & 410.00 & 4.003 & 669.29 \\
\hline 290.00 & 3.007 & 774.91 & 410.00 & 3.000 & 667.35 \\
\hline 290.00 & 2.000 & 774.08 & 410.00 & 2.003 & 665.35 \\
\hline 290.00 & 1.003 & 773.25 & 410.00 & 1.000 & 663.27 \\
\hline 290.00 & 0.497 & 772.82 & 410.00 & 0.507 & 662.23 \\
\hline 310.00 & 40.034 & 786.33 & 430.00 & 40.017 & 703.89 \\
\hline 310.00 & 34.999 & 782.89 & 430.00 & 34.998 & 698.25 \\
\hline 310.00 & 30.014 & 779.38 & 430.00 & 30.000 & 692.21 \\
\hline 310.00 & 25.007 & 775.73 & 430.00 & 25.005 & 685.69 \\
\hline 310.00 & 20.006 & 771.95 & 430.00 & 19.999 & 678.55 \\
\hline 310.00 & 15.009 & 767.98 & 430.00 & 14.997 & 670.67 \\
\hline 310.00 & 10.007 & 763.81 & 430.00 & 10.006 & 661.83 \\
\hline 310.00 & 5.016 & 759.43 & 430.00 & 4.999 & 651.64 \\
\hline 310.00 & 3.997 & 758.50 & 430.00 & 3.997 & 649.38 \\
\hline 310.00 & 2.999 & 757.59 & 430.00 & 3.003 & 647.06 \\
\hline 310.00 & 2.005 & 756.66 & 430.00 & 2.002 & 644.62 \\
\hline 310.00 & 1.009 & 755.72 & 430.00 & 0.493 & 640.64 \\
\hline 310.00 & 0.500 & 755.22 & 450.00 & 39.991 & 690.35 \\
\hline 330.00 & 40.011 & 772.18 & 450.00 & 34.996 & 684.22 \\
\hline 330.00 & 35.006 & 768.48 & 450.00 & 29.995 & 677.59 \\
\hline 330.00 & 30.003 & 764.63 & 450.00 & 24.995 & 670.36 \\
\hline 330.00 & 25.001 & 760.61 & 450.00 & 20.003 & 662.4 \\
\hline 330.00 & 20.006 & 756.40 & 450.00 & 15.001 & 653.46 \\
\hline 330.00 & 15.009 & 752.00 & 450.00 & 10.004 & 643.22 \\
\hline 330.00 & 10.001 & 747.31 & 450.00 & 4.999 & 631.1 \\
\hline 330.00 & 5.003 & 742.35 & 450.00 & 4.000 & 628.37 \\
\hline 330.00 & 4.000 & 741.29 & 450.00 & 3.001 & 625.51 \\
\hline 330.00 & 3.012 & 740.25 & 450.00 & 1.999 & 622.5 \\
\hline
\end{tabular}




\begin{tabular}{|c|c|c|c|c|c|}
\hline 330.00 & 2.002 & 739.17 & 450.00 & 1.000 & 619.32 \\
\hline 330.00 & 1.000 & 738.08 & 470.00 & 39.994 & 676.99 \\
\hline 330.00 & 0.501 & 737.54 & 470.00 & 35.000 & 670.31 \\
\hline 350.00 & 40.000 & 758.41 & 470.00 & 30.009 & 663.05 \\
\hline 350.00 & 35.003 & 754.41 & 470.00 & 25.005 & 655.04 \\
\hline 350.00 & 30.011 & 750.22 & 470.00 & 19.995 & 646.07 \\
\hline 350.00 & 25.004 & 745.82 & 470.00 & 14.995 & 635.87 \\
\hline 350.00 & 20.001 & 741.17 & 470.00 & 9.995 & 623.93 \\
\hline 350.00 & 15.005 & 736.24 & 470.00 & 5.001 & 609.33 \\
\hline 350.00 & 10.006 & 730.97 & 470.00 & 4.003 & 605.94 \\
\hline 350.00 & 5.000 & 725.31 & 470.00 & 2.999 & 602.32 \\
\hline 350.00 & 4.007 & 724.13 & 470.00 & 1.999 & 598.46 \\
\hline 350.00 & 3.009 & 722.92 & 470.00 & 1.002 & 594.33 \\
\hline 350.00 & 2.003 & 721.69 & & & \\
\hline 350.00 & 1.004 & 720.45 & & & \\
\hline 350.00 & 0.500 & 719.79 & & & \\
\hline 370.00 & 39.999 & 744.71 & & & \\
\hline 370.00 & 34.994 & 740.36 & & & \\
\hline 370.00 & 29.997 & 735.78 & & & \\
\hline 370.00 & 25.005 & 730.95 & & & \\
\hline 370.00 & 19.994 & 725.79 & & & \\
\hline 370.00 & 15.007 & 720.28 & & & \\
\hline 370.00 & 10.006 & 714.34 & & & \\
\hline 370.00 & 5.000 & 707.86 & & & \\
\hline 370.00 & 3.995 & 706.48 & & & \\
\hline 370.00 & 3.000 & 705.08 & & & \\
\hline 370.00 & 2.001 & 703.65 & & & \\
\hline 370.00 & 0.994 & 702.17 & & & \\
\hline 370.00 & 0.499 & 701.44 & & & \\
\hline
\end{tabular}




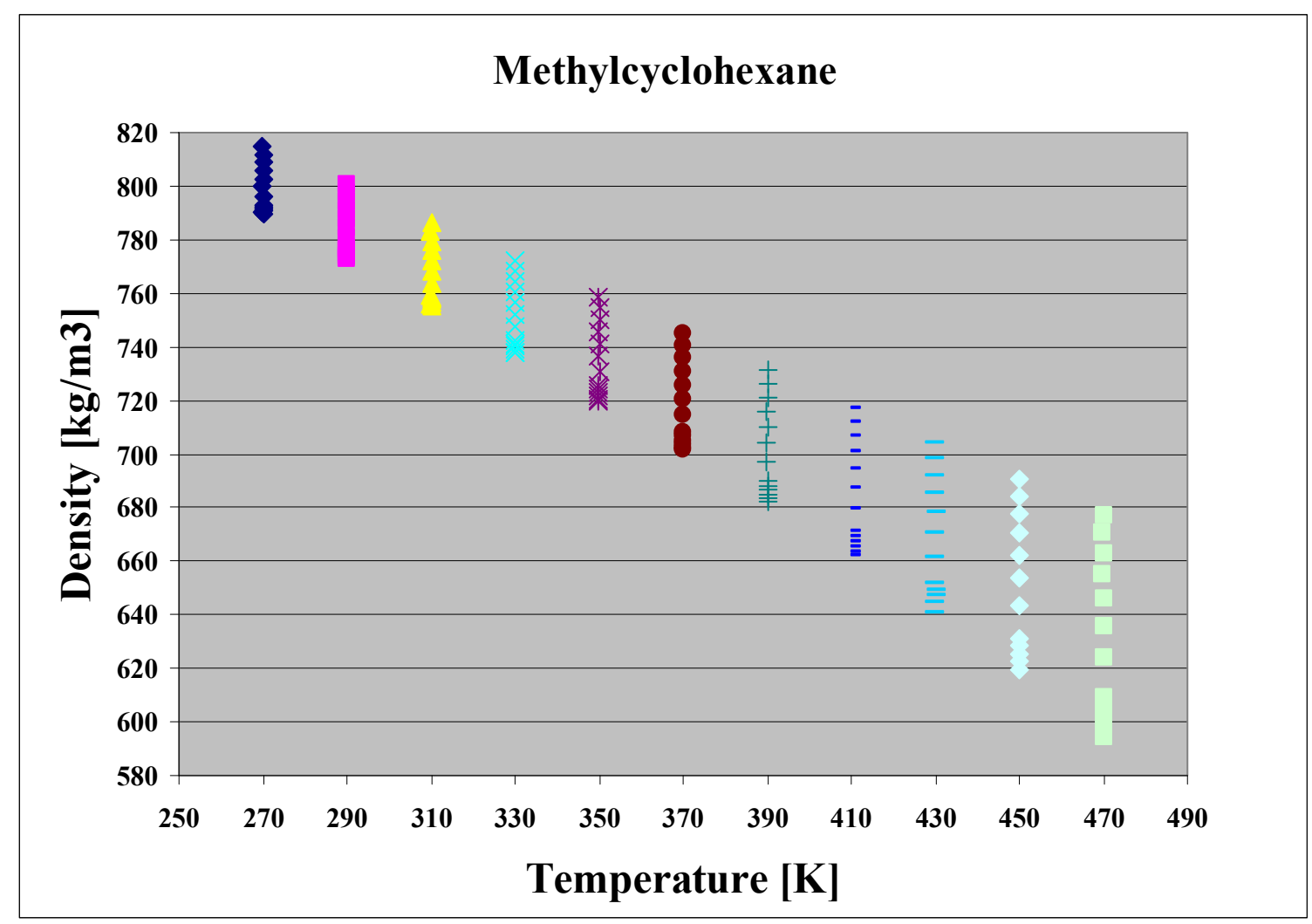

Figure 10. Compressed liquid densities of methylcyclohexane as a function of temperature.

Compressed liquid densities of propylcyclohexane have been measured along eleven isotherms from $270 \mathrm{~K}$ to $470 \mathrm{~K}$ at pressures from $0.5 \mathrm{MPa}$ to $40 \mathrm{MPa}$. A total of 143 points are reported in Table 9 and are shown graphically in Figure 11.

Table 9. Compressed liquid densities of propylcyclohexane.

$\begin{array}{cccccc}\begin{array}{c}\text { Temperature } \\ (\mathrm{K})\end{array} & \begin{array}{c}\text { Pressure } \\ (\mathrm{MPa})\end{array} & \begin{array}{c}\text { Density } \\ (\mathrm{kg} / \mathrm{m} 3)\end{array} & \begin{array}{c}\text { Temperature } \\ (\mathrm{K})\end{array} & \begin{array}{c}\text { Pressure } \\ (\mathrm{MPa})\end{array} & \begin{array}{c}\text { Density } \\ (\mathrm{kg} / \mathrm{m} 3)\end{array} \\ 270.00 & 39.959 & 834.41 & 390.00 & 39.989 & 756.91 \\ 270.00 & 35.005 & 831.91 & 390.00 & 35.002 & 752.82 \\ 270.00 & 30.003 & 829.32 & 390.00 & 29.998 & 748.51 \\ 270.00 & 25.001 & 826.66 & 390.00 & 25.002 & 743.97 \\ 270.00 & 19.995 & 823.91 & 390.00 & 20.002 & 739.14 \\ 270.00 & 15.004 & 821.08 & 390.00 & 15.000 & 734.00 \\ 270.00 & 10.003 & 818.11 & 390.00 & 10.005 & 728.48 \\ 270.00 & 5.009 & 815.01 & 390.00 & 5.003 & 722.49 \\ 270.00 & 4.004 & 814.35 & 390.00 & 4.003 & 721.22 \\ 270.00 & 2.987 & 813.68 & 390.00 & 3.003 & 719.93 \\ 270.00 & 2.001 & 813.03 & 390.00 & 2.009 & 718.64 \\ 270.00 & 1.001 & 812.37 & 390.00 & 1.002 & 717.29 \\ 270.00 & 0.497 & 812.02 & 390.00 & 0.504 & 716.61\end{array}$




\begin{tabular}{|c|c|c|c|c|c|}
\hline 290.00 & 40.005 & 821.46 & 410.00 & 39.998 & 744.41 \\
\hline 290.00 & 35.005 & 818.73 & 410.00 & 35.005 & 739.97 \\
\hline 290.00 & 29.995 & 815.90 & 410.00 & 30.003 & 735.27 \\
\hline 290.00 & 25.004 & 812.98 & 410.00 & 25.002 & 730.28 \\
\hline 290.00 & 19.998 & 809.96 & 410.00 & 19.998 & 724.97 \\
\hline 290.00 & 15.011 & 806.81 & 410.00 & 14.998 & 719.26 \\
\hline 290.00 & 10.002 & 803.50 & 410.00 & 10.008 & 713.07 \\
\hline 290.00 & 5.002 & 800.04 & 410.00 & 5.008 & 706.29 \\
\hline 290.00 & 4.007 & 799.31 & 410.00 & 4.003 & 704.83 \\
\hline 290.00 & 3.003 & 798.58 & 410.00 & 2.994 & 703.34 \\
\hline 290.00 & 2.013 & 797.84 & 410.00 & 2.005 & 701.86 \\
\hline 290.00 & 1.000 & 797.09 & 410.00 & 0.994 & 700.28 \\
\hline 290.00 & 0.506 & 796.73 & 410.00 & 0.506 & 699.52 \\
\hline 310.00 & 39.979 & 807.65 & 430.00 & 39.996 & 731.95 \\
\hline 310.00 & 35.008 & 804.71 & 430.00 & 35.004 & 727.15 \\
\hline 310.00 & 29.997 & 801.64 & 430.00 & 30.006 & 722.05 \\
\hline 310.00 & 24.999 & 798.47 & 430.00 & 24.999 & 716.59 \\
\hline 310.00 & 20.004 & 795.18 & 430.00 & 19.996 & 710.74 \\
\hline 310.00 & 14.996 & 791.73 & 430.00 & 15.011 & 704.40 \\
\hline 310.00 & 10.004 & 788.15 & 430.00 & 10.005 & 697.42 \\
\hline 310.00 & 5.013 & 784.41 & 430.00 & 4.999 & 689.66 \\
\hline 310.00 & 3.999 & 783.61 & 430.00 & 3.993 & 687.98 \\
\hline 310.00 & 3.004 & 782.83 & 430.00 & 3.002 & 686.29 \\
\hline 310.00 & 2.007 & 782.04 & 430.00 & 1.988 & 684.51 \\
\hline 310.00 & 0.999 & 781.23 & 430.00 & 0.998 & 682.73 \\
\hline 310.00 & 0.505 & 780.83 & 430.00 & 0.516 & 681.83 \\
\hline 330.00 & 39.988 & 794.75 & 450.00 & 39.992 & 719.57 \\
\hline 330.00 & 35.002 & 791.53 & 450.00 & 35.009 & 714.38 \\
\hline 330.00 & 30.000 & 788.17 & 450.00 & 30.007 & 708.83 \\
\hline 330.00 & 25.001 & 784.69 & 450.00 & 25.013 & 702.87 \\
\hline 330.00 & 20.004 & 781.06 & 450.00 & 19.999 & 696.38 \\
\hline 330.00 & 15.009 & 777.27 & 450.00 & 15.008 & 689.31 \\
\hline 330.00 & 10.001 & 773.27 & 450.00 & 9.999 & 681.42 \\
\hline 330.00 & 5.001 & 769.08 & 450.00 & 4.999 & 672.53 \\
\hline 330.00 & 3.994 & 768.20 & 450.00 & 3.995 & 670.59 \\
\hline 330.00 & 3.000 & 767.32 & 450.00 & 3.001 & 668.60 \\
\hline 330.00 & 2.004 & 766.43 & 450.00 & 1.993 & 666.53 \\
\hline 330.00 & 0.999 & 765.52 & 450.00 & 0.999 & 664.39 \\
\hline 330.00 & 0.498 & 765.06 & 450.00 & 0.506 & 663.31 \\
\hline 350.00 & 40.001 & 782.15 & 470.00 & 40.004 & 707.37 \\
\hline 350.00 & 35.003 & 778.64 & 470.00 & 35.004 & 701.75 \\
\hline 350.00 & 30.001 & 774.98 & 470.00 & 30.002 & 695.70 \\
\hline 350.00 & 25.007 & 771.17 & 470.00 & 25.001 & 689.15 \\
\hline 350.00 & 20.005 & 767.18 & 470.00 & 20.004 & 682.01 \\
\hline 350.00 & 15.006 & 762.98 & 470.00 & 14.994 & 674.08 \\
\hline 350.00 & 10.006 & 758.54 & 470.00 & 10.006 & 665.17 \\
\hline
\end{tabular}




$\begin{array}{lccccc}350.00 & 4.999 & 753.83 & 470.00 & 5.003 & 654.87 \\ 350.00 & 4.003 & 752.86 & 470.00 & 4.003 & 652.59 \\ 350.00 & 2.996 & 751.85 & 470.00 & 3.000 & 650.21 \\ 350.00 & 1.992 & 750.83 & 470.00 & 2.002 & 647.76 \\ 350.00 & 1.000 & 749.82 & 470.00 & 0.991 & 645.18 \\ 350.00 & 0.500 & 749.30 & 470.00 & 0.496 & 643.86 \\ 370.00 & 39.998 & 769.44 & & & \\ 370.00 & 34.998 & 765.65 & & & \\ 370.00 & 30.001 & 761.68 & & & \\ 370.00 & 25.001 & 757.53 & & & \\ 370.00 & 20.007 & 753.15 & & & \\ 370.00 & 15.011 & 748.51 & & & \\ 370.00 & 10.006 & 743.56 & & & \\ 370.00 & 5.003 & 738.27 & & & \\ 370.00 & 4.003 & 737.16 & & & \\ 370.00 & 3.002 & 736.02 & & & \\ 370.00 & 2.005 & 734.87 & & & \\ 370.00 & 1.006 & 733.71 & & & \\ 370.00 & 0.496 & 733.11 & & & \end{array}$




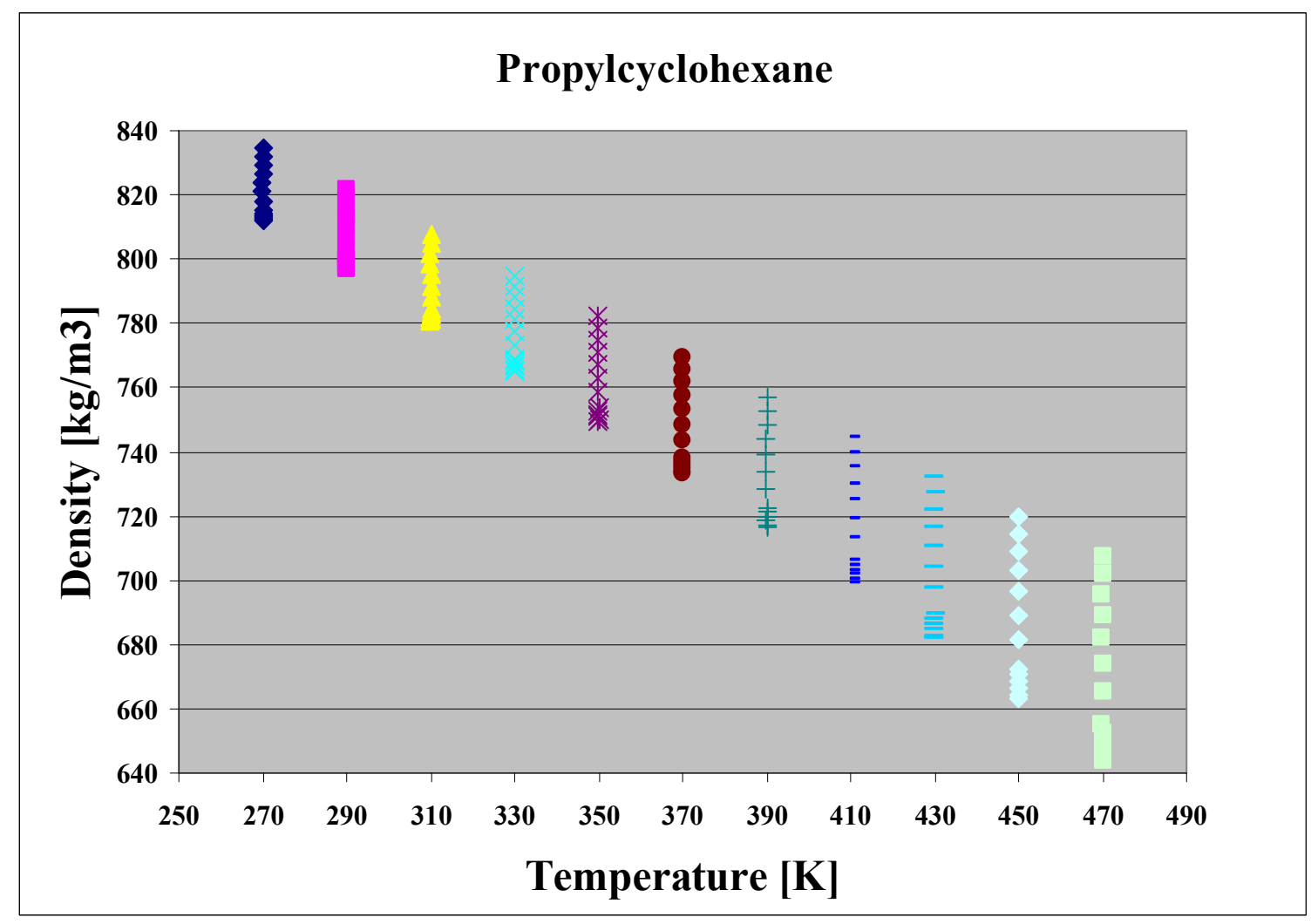

Figure 11. Compressed liquid densities of propylcyclohexane as a function of temperature.

Viscosity Measurements of Methyl- and Propylcyclohexane:

Viscosity measurements of methyl- and propylcyclohexane were carried out at ambient pressure in the temperature range $293.15 \mathrm{~K}$ to $373.15 \mathrm{~K}$. These measurements are presented in Table 10. The instrument used was a commercial device consisting of an automated open gravitational flow viscometer with a suspended-level Ubbelohde glass capillary of $200 \mathrm{~mm}$ length with upper reservoir bulbs for a kinematic viscosity range from $0.3 \mathrm{~mm}^{2} \cdot \mathrm{s}^{-1}$ to $30 \mathrm{~mm}^{2} \cdot \mathrm{s}^{-1}$. As shown in the photograph of Figure 12, the glass capillary is mounted in a thermostatting bath filled with silicone oil. The thermostat includes a stirrer, a heat pipe to a thermoelectric Peltier cooler at the top of the instrument (not visible), and a platinum $100 \Omega$ resistance temperature probe (PRT). The bath temperature is set with the operating software that is an integral part of the viscosity measurement system and it is controlled within $0.02 \mathrm{~K}$ between $293.15 \mathrm{~K}$ and $373.15 \mathrm{~K}$. The resistance of the PRT is measured with an ac bridge. The calibration of the PRT on the International Temperature Scale of 1990 was checked by comparison with a water triple point cell. The estimated uncertainty of the temperature measurement system is $0.02 \mathrm{~K}$. 


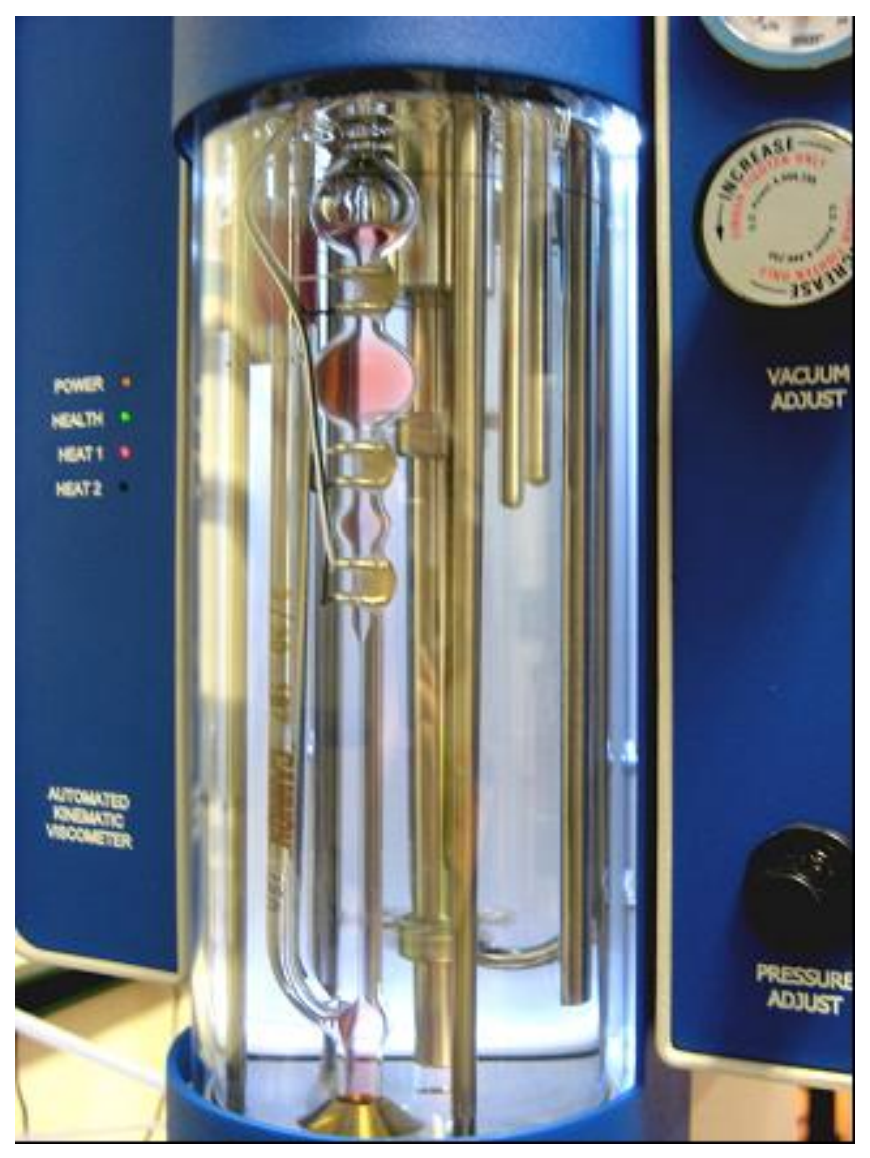

Figure 12: A photograph of the viscometer used for the measurement of methyl- and propylcyclohexane.

The instrument allows viscosity measurements relative to liquids with well known viscosities. Calibrations were performed with certified viscosity standards to determine the constants $C$ and $E$ of the working equation:

$v=C \cdot t-E / t^{2}$

The first term on the right hand side of this equation is the reformulated Hagen-Poiseuille expression for laminar flow in a circular tube whereas the second term is the Hagenbach correction for kinetic energy losses. Symbol $v$ denotes the kinematic viscosity in $\mathrm{mm}^{2} \cdot \mathrm{s}^{-1}$ and $t$ the efflux time in seconds of a known volume of liquid through the capillary. Efflux times are measured with three thermistor sensors on the outside of the capillary above and below the two measuring bulbs. The thermistors detect the passing of the liquid meniscus at their locations and trigger an internal stopwatch. Depending on the viscosity range the two upper or the two lower thermistors are used to time the efflux of the test liquid through the respective measuring bulb of known volume. 
The viscosity measurement system includes components to pump the test liquid into the upper measuring bulbs for repetitive efflux timings and to flush the capillary tube with two different solvents when the test liquid is changed. The operating software was set to perform five measurement runs at the most of which the three that agreed within $0.5 \%$ repeatability were averaged to calculate the viscosity. The uncertainty of the viscosity measurements reported here is estimated at $1.5 \%$ to account for variations in the constants $C$ and $E$ that occurred for calibrations with different viscosity standards and to a lesser degree for calibrations at different temperatures.

The ambient pressure during the measurements was $83 \mathrm{kPa}$. Due to this, methyl cyclohexane could not be measured at $373.15 \mathrm{~K}$ because it evaporated at that temperature.

The design of the instrument, its calibration, and operation conform to the following standards:

- $\quad$ ASTM D 445 Standard Test Method for Kinematic Viscosity of Transparent and Opaque Liquids (and the Calculation of Dynamic Viscosity),

- $\quad$ ASTM D 446 Standard Specifications and Operating Instructions for Glass Capillary Kinematic Viscometers,

- D 2162 Test Method for Basic Calibration of Master Viscometers and Viscosity Oil Standards, and the corresponding ISO standards 3104 and 3105. 
Table 10: Kinematic viscosity of methyl- and propylcyclohexane measured in the open gravitational capillary viscometer system.

\begin{tabular}{|c|c|c|c|}
\hline \multicolumn{2}{|c|}{ Methylcyclohexane } & \multicolumn{2}{c|}{ Propylcyclohexane } \\
\hline $\begin{array}{c}\text { Temperature } \\
T\end{array}$ & $\begin{array}{c}\text { Kinematic } \\
\text { viscosity } \\
v\end{array}$ & $\begin{array}{c}\text { Temperature } \\
T\end{array}$ & $\begin{array}{c}\text { Kinematic } \\
\text { viscosity } \\
v\end{array}$ \\
\hline $\mathrm{K}$ & $\mathrm{mm}^{2} \cdot \mathrm{s}^{-1}$ & $\mathrm{~K}$ & $\mathrm{~mm}^{2} \cdot \mathrm{s}^{-1}$ \\
\hline 363.15 & 0.4707 & 303.15 & 1.112 \\
353.16 & 0.5113 & 293.15 & 1.277 \\
343.15 & 0.5568 & 313.15 & 0.9830 \\
333.15 & 0.6107 & 373.15 & 0.5500 \\
323.15 & 0.6736 & 363.15 & 0.5966 \\
313.15 & 0.7488 & 353.15 & 0.6499 \\
303.21 & 0.8387 & 343.15 & 0.7140 \\
293.23 & 0.9480 & 333.15 & 0.7877 \\
& & 323.15 & 0.8759 \\
\hline
\end{tabular}


Sound Speed Measurements of Methyl- and Propylcyclohexane:

A commercial density and sound speed analyzer was used to determine the sound speed of methyl- and propylcyclohexane at ambient pressure. ${ }^{9}$ Temperature scans were programmed from $70{ }^{\circ} \mathrm{C}$ to $10^{\circ} \mathrm{C}$ in decrements of $10^{\circ} \mathrm{C}$ followed by a single measurement at $5{ }^{\circ} \mathrm{C}$. The device contains a sound speed cell and a vibrating quartz tube densimeter in series. Temperature is measured with an integrated Pt-100 thermometer with an estimated uncertainty of $0.01 \mathrm{~K}$. The sound speed cell has a circular cylindrical cavity of $8 \mathrm{~mm}$ diameter and $5 \mathrm{~mm}$ thickness that is sandwiched between the transmitter and receiver. The speed of sound is determined by measuring the time of flight of signals between the transmitter and receiver. The instrument was calibrated with air and deionized water at $20^{\circ} \mathrm{C}$. The reproducibility of the sound speed of water at $20^{\circ} \mathrm{C}$ to within $0.01 \%$ was checked before and after measurements of the test liquids. Careful cleaning of the sound speed cell with suitable solvents was found critical to avoid contaminations and to ensure this level of performance. For the same reason, fresh samples of test liquids were injected for each temperature scan instead of performing repetitive measurements on the same sample. At least four temperature scans were performed for each test liquid. The relative standard deviation of these repeated sound speed measurements was lower than $0.013 \%$. The manufacturer quoted uncertainty of sound speed measurements with this instrument is $0.1 \%$. The speeds of sound measured in this work (along with the density) are provided in Table 11, and shown graphically in Figure 13.

Table 11: Density, speed of sound, and adiabatic compressibility of methyl- and propylcyclohexane measured in the commercial density and sound speed analyzer. The ambient pressure during the measurements was $83 \mathrm{kPa}$.

\begin{tabular}{|c|c|c|c|c|c|c|}
\hline & \multicolumn{3}{|c|}{ Methylcyclohexane } & \multicolumn{3}{|c|}{ Propylcyclohexane } \\
\hline $\begin{array}{c}\text { Temp- } \\
\text { erature } T\end{array}$ & $\begin{array}{c}\text { Density } \\
\rho\end{array}$ & $\begin{array}{c}\text { Speed } \\
\text { of } \\
\text { sound } \\
w\end{array}$ & $\begin{array}{c}\text { Adiab. } \\
\text { compre } \\
\text { ssibility } \\
\kappa_{s}\end{array}$ & $\begin{array}{c}\text { Density } \\
\rho\end{array}$ & $\begin{array}{c}\text { Speed } \\
\text { of } \\
\text { sound } \\
w\end{array}$ & $\begin{array}{c}\text { Adiab. } \\
\text { compres- } \\
\text { sibility } \kappa_{S}\end{array}$ \\
\hline $\mathbf{K}$ & $\mathrm{kg} \cdot \mathrm{m}^{-3}$ & $\mathbf{m} \cdot \mathbf{s}^{-1}$ & $\mathrm{TPa}^{-1}$ & $\mathrm{~kg} \cdot \mathrm{m}^{-3}$ & $\mathbf{m} \cdot \mathbf{s}^{-1}$ & $\mathrm{TPa}^{-1}$ \\
\hline 278.15 & 782.3 & 1304.7 & 750.94 & 805.4 & 1371.3 & 660.26 \\
\hline 283.15 & 778.0 & 1281.9 & 782.27 & 801.5 & 1349.6 & 685.01 \\
\hline 293.15 & 769.3 & 1236.9 & 849.67 & 793.7 & 1307.1 & 737.38 \\
\hline 303.15 & 760.7 & 1192.9 & 923.93 & 785.9 & 1265.5 & 794.47 \\
\hline 313.15 & 751.9 & 1149.7 & 1006.1 & 778.1 & 1224.7 & 856.81 \\
\hline 323.15 & 743.1 & 1107.4 & 1097.4 & 770.2 & 1184.7 & 925.02 \\
\hline 333.15 & 734.3 & 1065.6 & 1199.3 & 762.3 & 1145.4 & 999.94 \\
\hline 343.15 & 725.3 & 1024.5 & 1313.6 & 754.4 & 1106.9 & 1081.9 \\
\hline
\end{tabular}




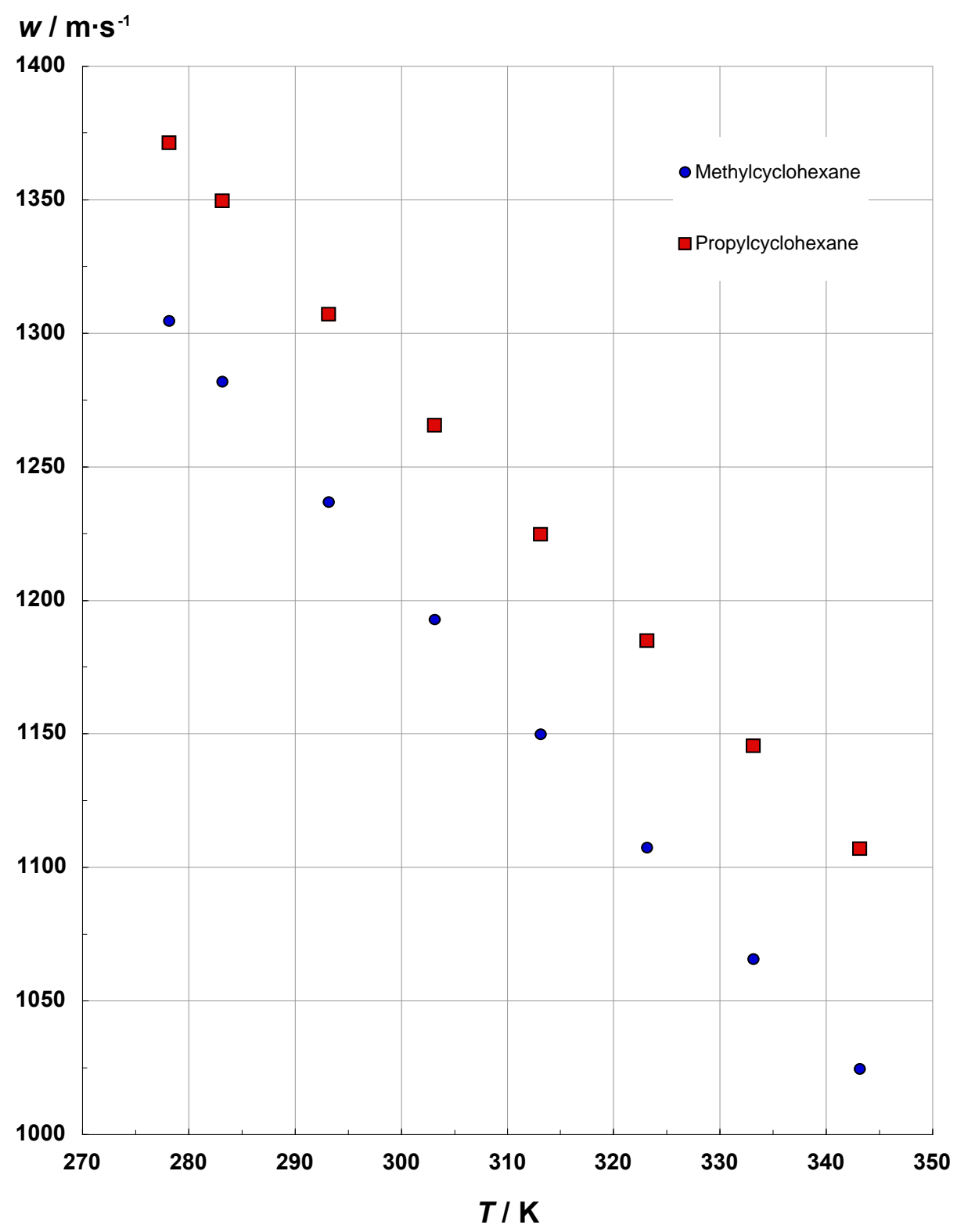

Figure 13: Measured speed of sound data for methyl- and propylcyclohexane

Adiabatic compressibilities at ambient pressure were obtained from the measured densities and speeds of sound via the thermodynamic relation $\kappa_{s}=-(\partial V / \partial p)_{s} / V=1 /\left(\rho w^{2}\right)$, where $V$ denotes volume, $p$ is pressure, $\rho$ is the density, and $w$ the speed of sound. Subscript $s$ indicates "at constant entropy $s$." For convenience, the calculated adiabatic compressibilities are included in Table 11.

The speed of sound and adiabatic compressibility data of the two liquids at ambient pressure are plotted in Figure 14 as a function of temperature. Comparing the plots illustrates how changing the molecular structure of methylcyclohexane by adding an ethyl-group $-\mathrm{CH}_{2}-\mathrm{CH}_{2}$ - to the aliphatic side chain to form propylcyclohexane influences the macroscopic properties of the two compounds. The speed of sound increases between 
$5.1 \%$ at $273.15 \mathrm{~K}$ and $8.1 \%$ at $343.15 \mathrm{~K}$ whereas the adiabatic compressibility increases between $13.8 \%$ and $21.4 \%$. The densities of the test liquids at these two state points differ only by $3 \%$ and $4 \%$, respectively. Thus, the adiabatic compressibility appears to reflect structural changes on the molecular scale with higher resolution than the other two properties.

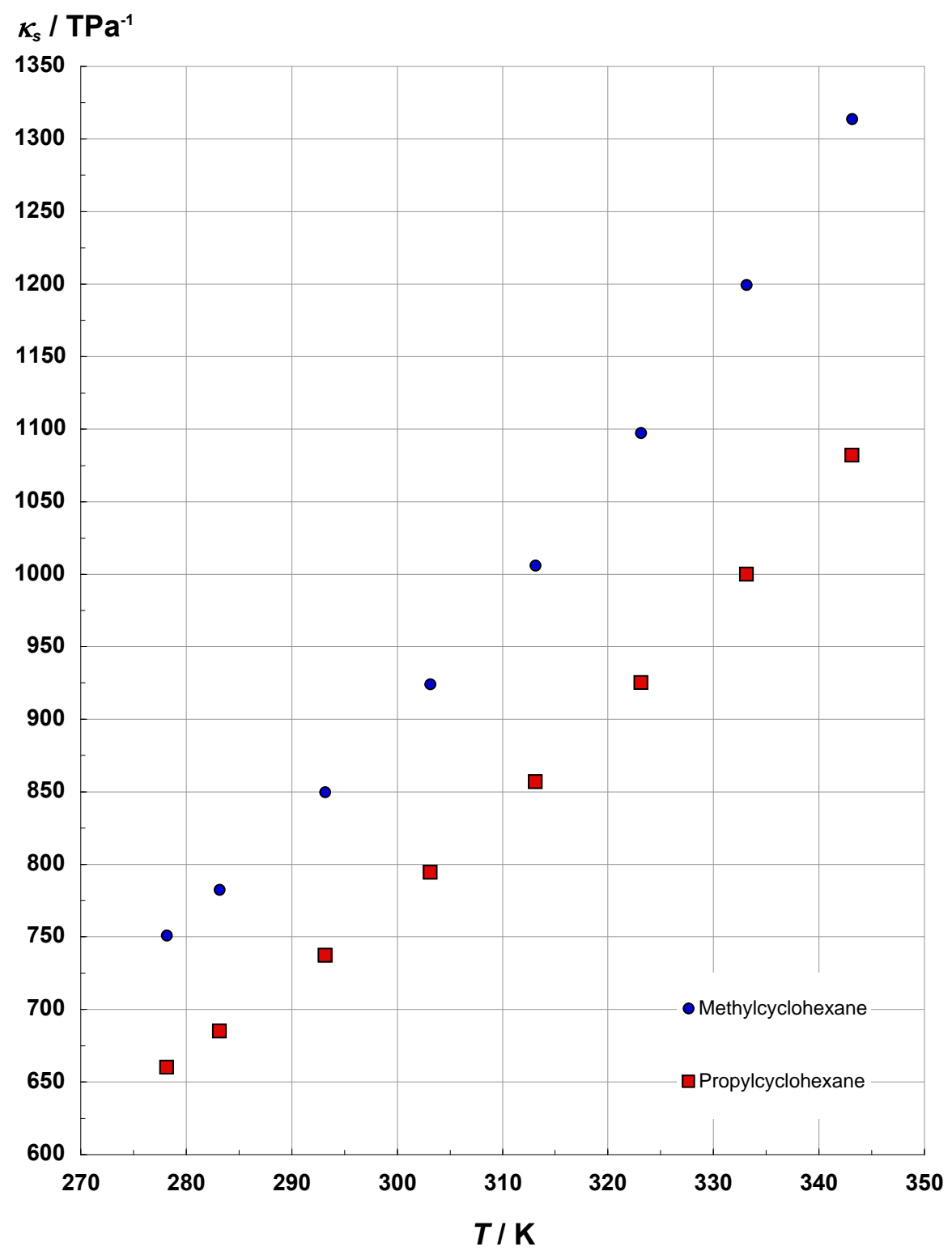

Figure 14: Measured adiabatic compressibility of methyl- and propylcyclohexane as a function of temperature at ambient pressure 
Thermal Conductivity of Methyl- and Propylcyclohexane:

Transient hot-wire measurements of the thermal conductivity of the samples of methylcyclohexane and propylcyclohexane were made in the liquid and vapor phases; up to $600 \mathrm{~K}$ for propylcyclohexane. In addition, a supercritical isotherm at $593 \mathrm{~K}$ was measured for methylcyclohexane. Measurements for both fluids cover temperatures from 300 to $600 \mathrm{~K}$ with pressures up to $70 \mathrm{MPa}$. The transient hot-wire instrument has been described in detail elsewhere. ${ }^{10,11}$ The measurement cell is designed to closely approximate transient heating from a line source into an infinite fluid medium. The ideal (line source) temperature rise $\Delta T_{\text {id }}$ is given by:

$$
\Delta T_{\mathrm{id}}=\frac{q}{4 \pi \lambda}\left[\ln (t)+\ln \left(\frac{4 a}{r_{0}^{2} C}\right)\right]=\Delta T_{\mathrm{w}}+\sum_{i=1}^{10} \delta T_{i},
$$

where $q$ is the power applied per unit length, $\lambda$ is the thermal conductivity of the fluid, $t$ is the elapsed time, $a=\lambda / \rho C_{\mathrm{p}}$ is the thermal diffusivity of the fluid, $\rho$ is the density of the fluid, $C_{\mathrm{p}}$ is the isobaric specific heat capacity of the fluid, $r_{0}$ is the radius of the hot wire, $C=1.781 \ldots$ is the exponential of Euler's constant, $\Delta T_{\mathrm{w}}$ is the measured temperature rise of the wire, and $\delta T_{i}$ are corrections to account for deviations from ideal line-source conduction. The only significant correction for the measurements is for the finite wire dimensions. A plot of ideal temperature rise versus logarithm of elapsed time should be linear, such that thermal conductivity can be found from the slope and thermal diffusivity can be found from the intercept of a line fit to the data.

At time zero, a fixed voltage is applied to heat the small diameter wire that is immersed in the fluid of interest. The wire is used as an electrical heat source while its resistance increase allows determination of the transient temperature rise as a function of elapsed time. Two platinum wires of $12.7 \mu \mathrm{m}$ diameter were used for most of the measurements. The two wires, one about $18 \mathrm{~cm}$ long and one about $4 \mathrm{~cm}$ long, were used with a differential technique to eliminate axial conduction errors. A similar cell with anodized tantalum hot wires of $25 \mu \mathrm{m}$ diameter was used for some measurements on liquid methylcyclohexane at temperatures from $300 \mathrm{~K}$ to $400 \mathrm{~K}$. Short experiment times (nominally $1 \mathrm{~s}$ ) and small temperature rises (nominally 1 to $4 \mathrm{~K}$ ) were selected to eliminate heat transfer by free convection. Experiments at several different heating powers (and temperature rises) provide verification that free convection is not significant. Heat transfer due to thermal radiation is more difficult to detect and correct when the fluid can absorb and re-emit infrared radiation as these hydrocarbons do. Thermal radiation heat transfer will increase roughly in proportion to the absolute temperature cubed and can be characterized from an increase in the apparent thermal conductivity as experiment time increases since radiation emission from the fluid increases as the thermal wave diffuses outward.

At very low pressures, the steady-state hot-wire technique has the advantage of not requiring significant corrections. The working equation for the steady-state mode is based on a 
different solution of Fourier's law but the geometry is still that of concentric cylinders. This equation can be solved for the thermal conductivity of the fluid, $\lambda$,

$$
\lambda=\frac{q \ln \left(\frac{r_{2}}{r_{1}}\right)}{2 \pi\left(T_{1}-T_{2}\right)},
$$

where $q$ is the applied power per unit length, $r_{2}$ is the internal radius of the outer cylinder, $r_{1}$ is the external radius of the inner cylinder (hot wire), and $\Delta T=\left(T_{1}-T_{2}\right)$ is the measured temperature difference between the hot wire and its surrounding cavity.

A total of 1389 points are reported in Appendix I (the lengths of these tables preclude inclusion within the body of the report) for the thermal conductivity of methylcyclohexane in the liquid, vapor and supercritical regions at pressures to $60 \mathrm{MPa}$. These data for methylcyclohexane are shown in Figure 15. A total of 668 points are reported in appendix I for the thermal conductivity of propylcyclohexane in the liquid and vapor regions at pressures to $60 \mathrm{MPa}$. Note that within the appendix, the thermal conductivity tables are divided into vapor and liquid, and by wire material. These data for propylcyclohexane are shown in Figure 16. Each experiment is characterized by the initial cell temperature $T_{0}$ and the mean experiment temperature $T_{\mathrm{e}}$. There are generally 5 experiments at each initial cell temperature to verify that convection was not significant, since convection depends strongly on the temperature rise $\left(\Delta T=T_{\mathrm{e}}-T_{0}\right)$. The conditions of the fluid during each measurement are given by the experimental temperature $T_{\mathrm{e}}$, pressure $P_{\mathrm{e}}$, and density $\rho_{\mathrm{e}}$. The thermal conductivity without correction for thermal radiation is given by $\lambda_{\mathrm{e}}$.

The thermal conductivity data for these fluids have an uncertainty of less than $1 \%$ for measurements removed from the critical point and for gas at pressures above $1 \mathrm{MPa}$, increasing to $3 \%$ at the highest temperatures (near $600 \mathrm{~K}$ ) and for gas at low pressures $(<1 \mathrm{MPa})$ at a $95 \%$ confidence level. A significant critical enhancement is observed in the thermal conductivity data near the critical point. There is likely a residual contribution due to emission of thermal radiation by the fluid that increases in proportion to temperature cubed up to $2 \%$ to $3 \%$ near $600 \mathrm{~K}$. 


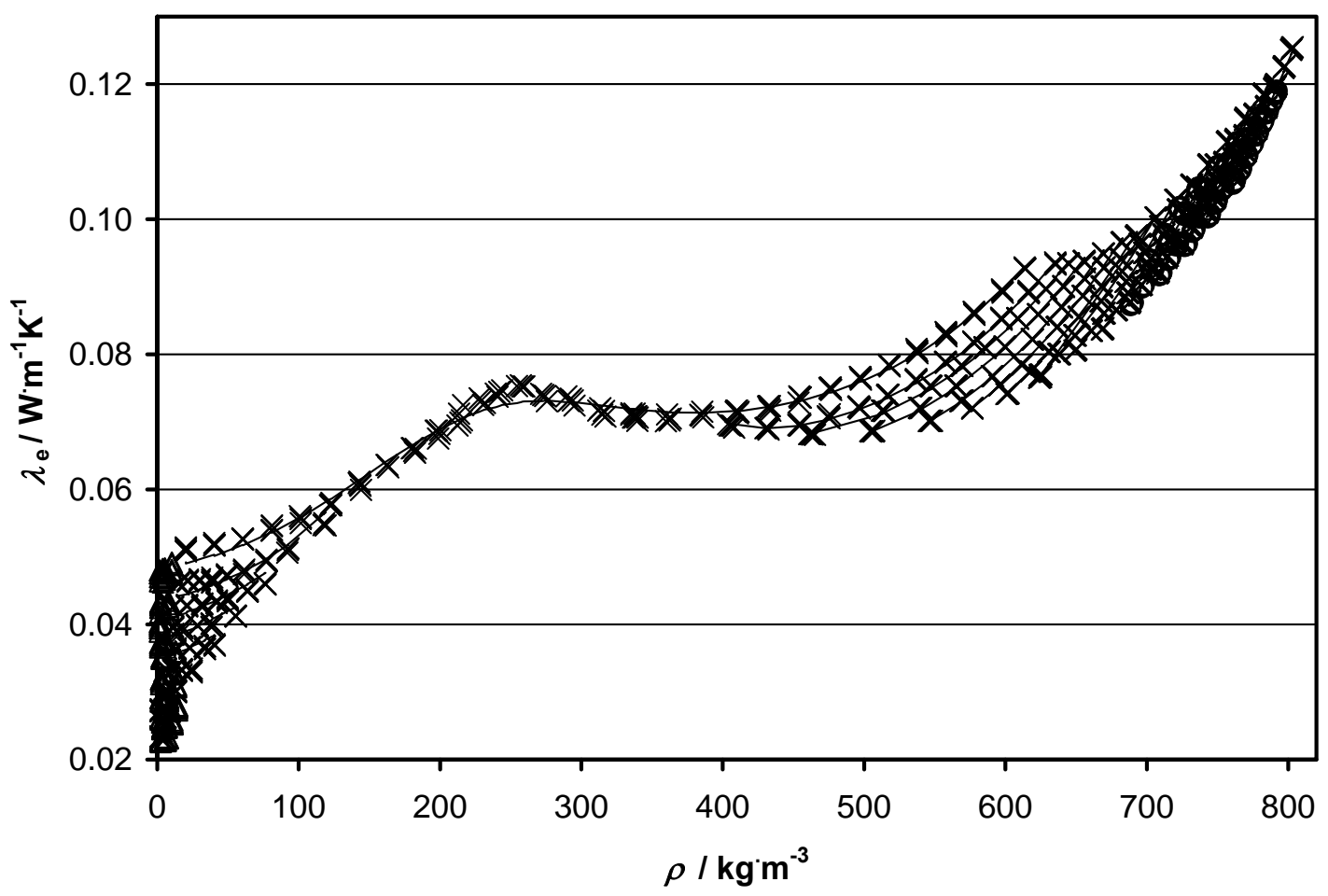

Figure 15: Thermal conductivity of methylcyclohexane at temperatures from $300 \mathrm{~K}$ to $595 \mathrm{~K}$ and pressures up to $60 \mathrm{MPa}: \times$, transient $(\mathrm{Pt})$; $\mathrm{O}$, transient $(\mathrm{Ta}) ; \triangle$, steady state $(\mathrm{Pt})$; solid line given by the correlation developed in this work. 


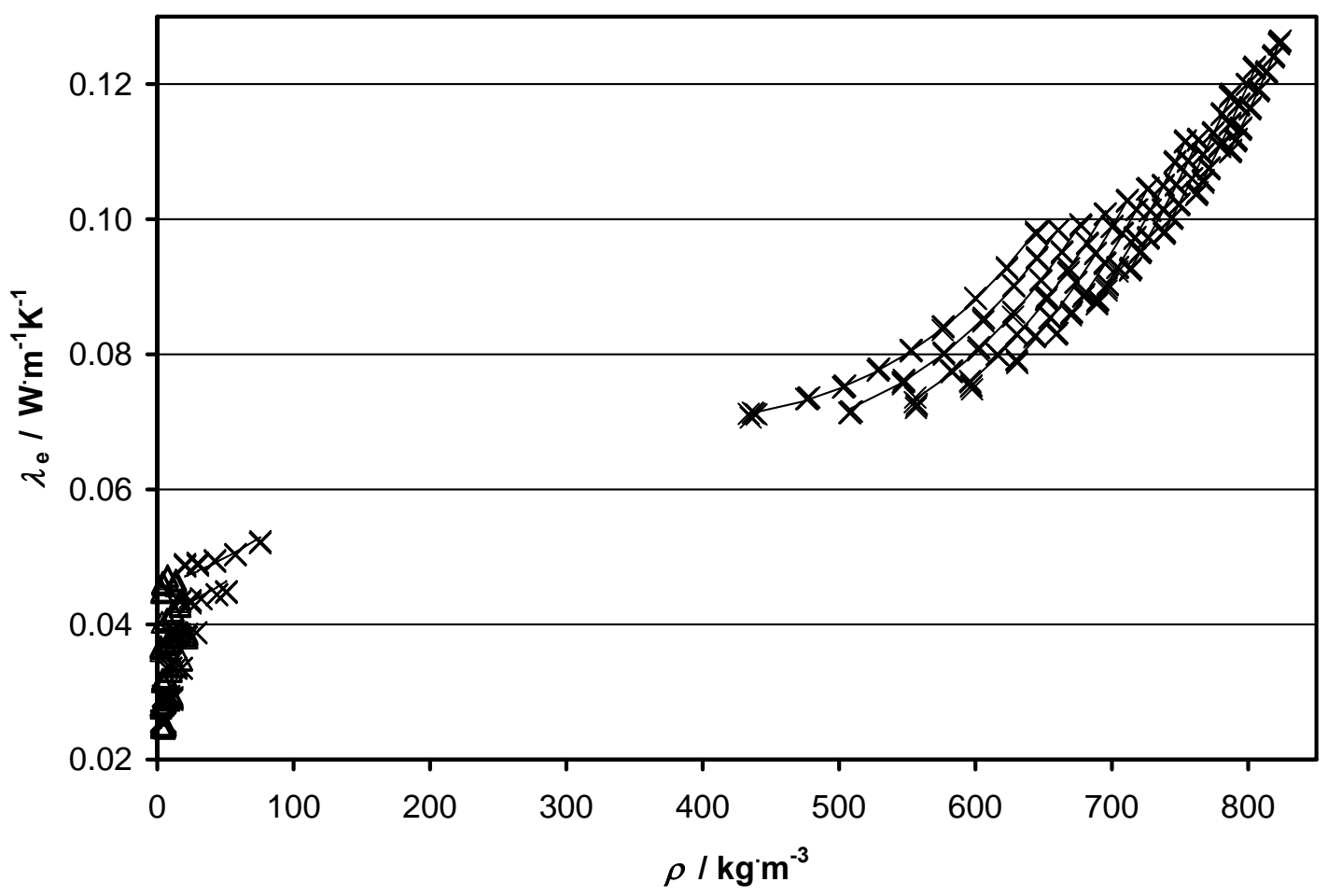

Figure 16: Thermal conductivity of propylcyclohexane at temperatures from $300 \mathrm{~K}$ to $600 \mathrm{~K}$ and pressures up to $60 \mathrm{MPa}: \times$, transient $(\mathrm{Pt}) ; \triangle$, steady state $(\mathrm{Pt})$; solid line given by the correlation developed in this work.

Thermophysical Property Measurements on Jet-A, JP-8 and S-8:

\section{Distillation Curves of Jet-A, JP-8 and S-8:}

A new advanced method for the measurement of distillation curves of complex fluids has recently been introduced. The modifications to the classical measurement provide for (1) temperature and volume measurements of low uncertainty, (2) temperature control based upon fluid behavior, and most important, (3) a composition-explicit data channel in addition to the usual temperature-volume relationship ${ }^{12-14}$. This latter modification is achieved with a new sampling approach that allows precise qualitative as well as quantitative analyses of each fraction, on the fly. Any composition dependent property can be enhanced by combining it with the distillation curve information. For example, and especially relevant to fuels, we have shown that it is possible to obtain heat of combustion data for each distillate fraction ${ }^{15}$. In the advanced method, the temperature is logged in two locations. First, the temperature is measured directly in the fluid, which provides a true thermodynamic state point and true initial boiling temperature. This temperature is referred to as $T_{k}$. Second, the temperature is also measured in the distillation head, referred to at $T_{h}$. This temperature is directly comparable to historical 
data. We have applied this method to a wide variety of fuels and complex fluids ${ }^{16-31}$. A schematic diagram of the advanced apparatus is provided in Figures 17 - 19.

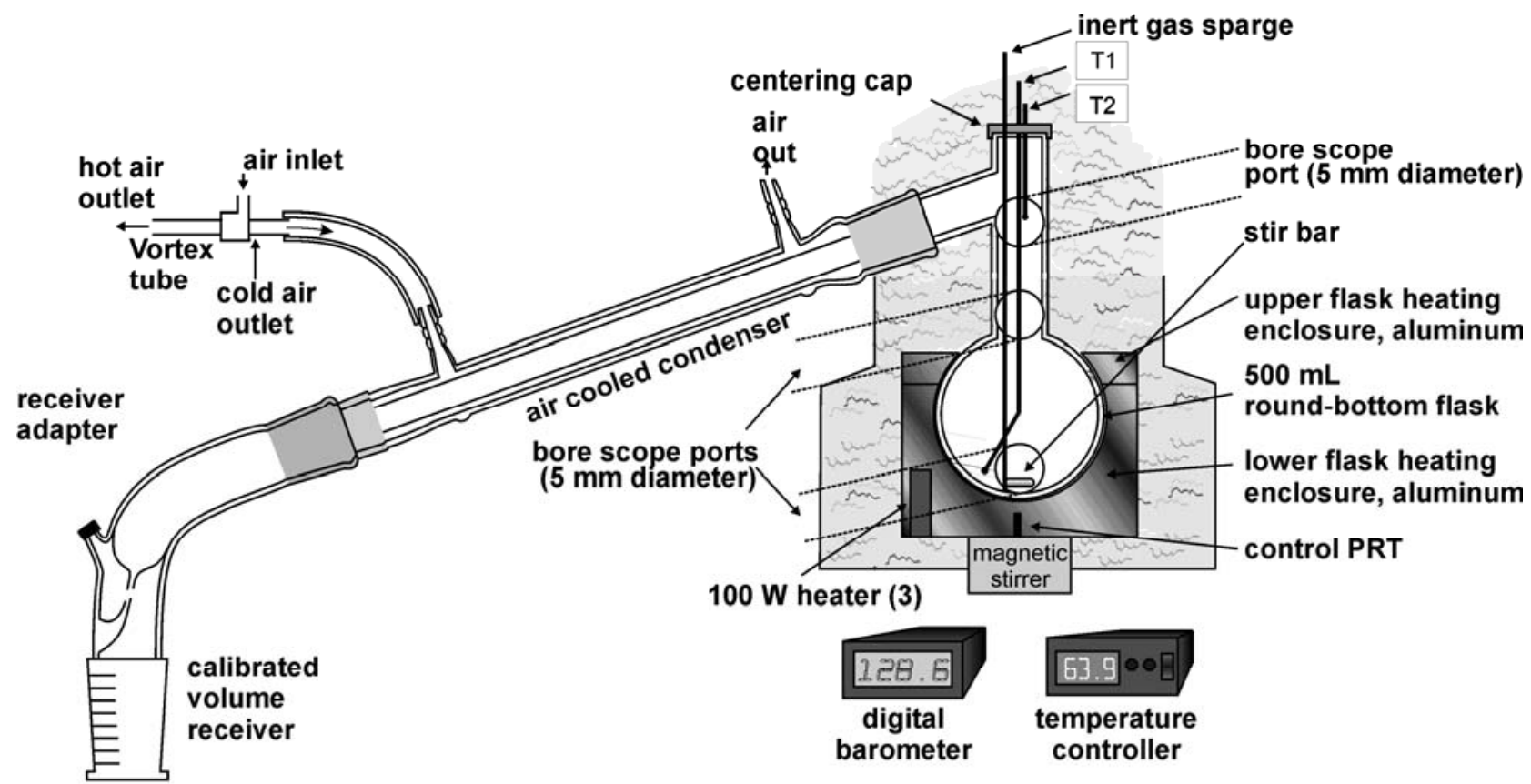

Figure 17: Schematic diagram of the overall apparatus used for the measurement of distillation curves. 


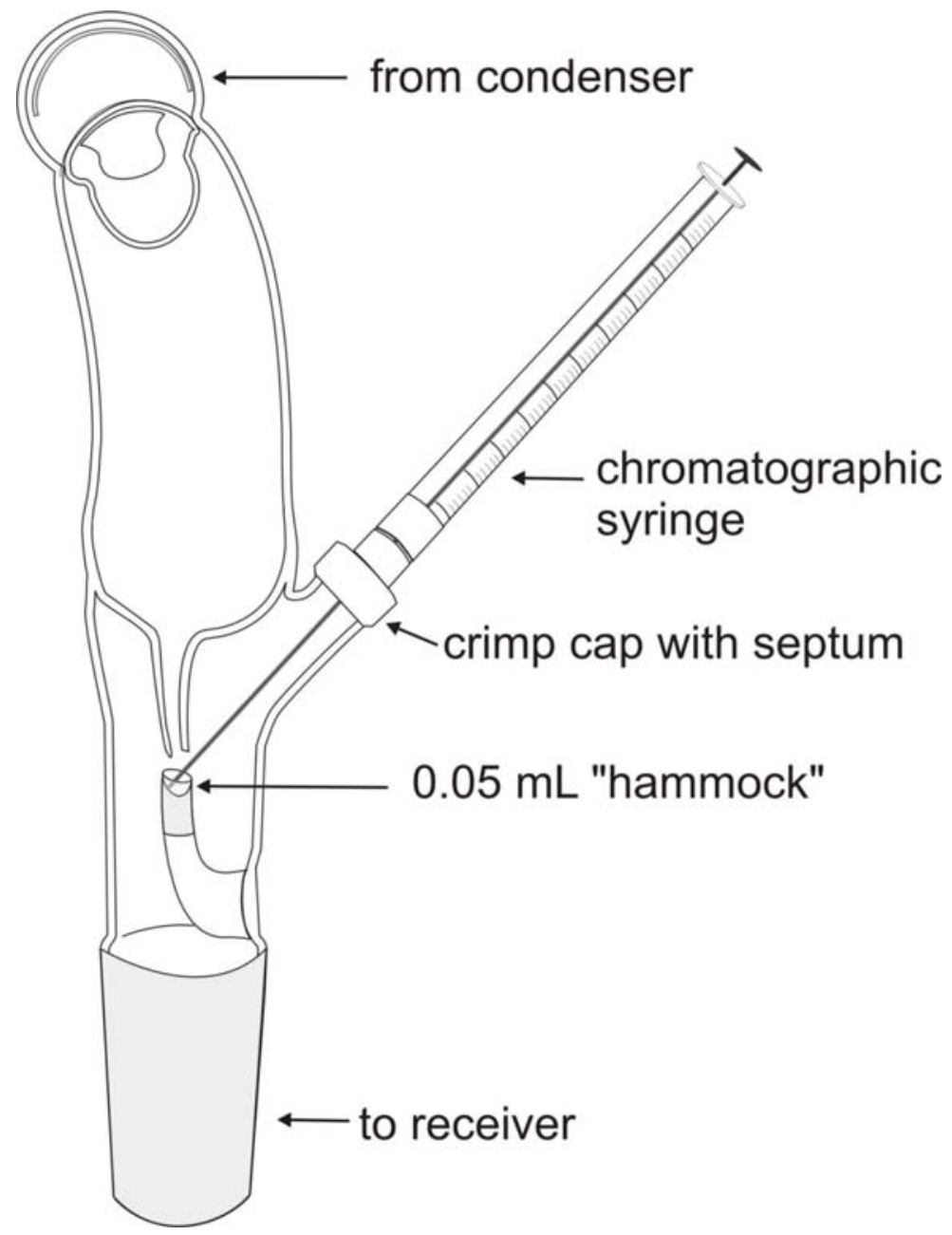

Figure 18: Schematic diagram of the receiver adapter to provide on-the-fly sampling of distillate cuts for subsequent analysis. 


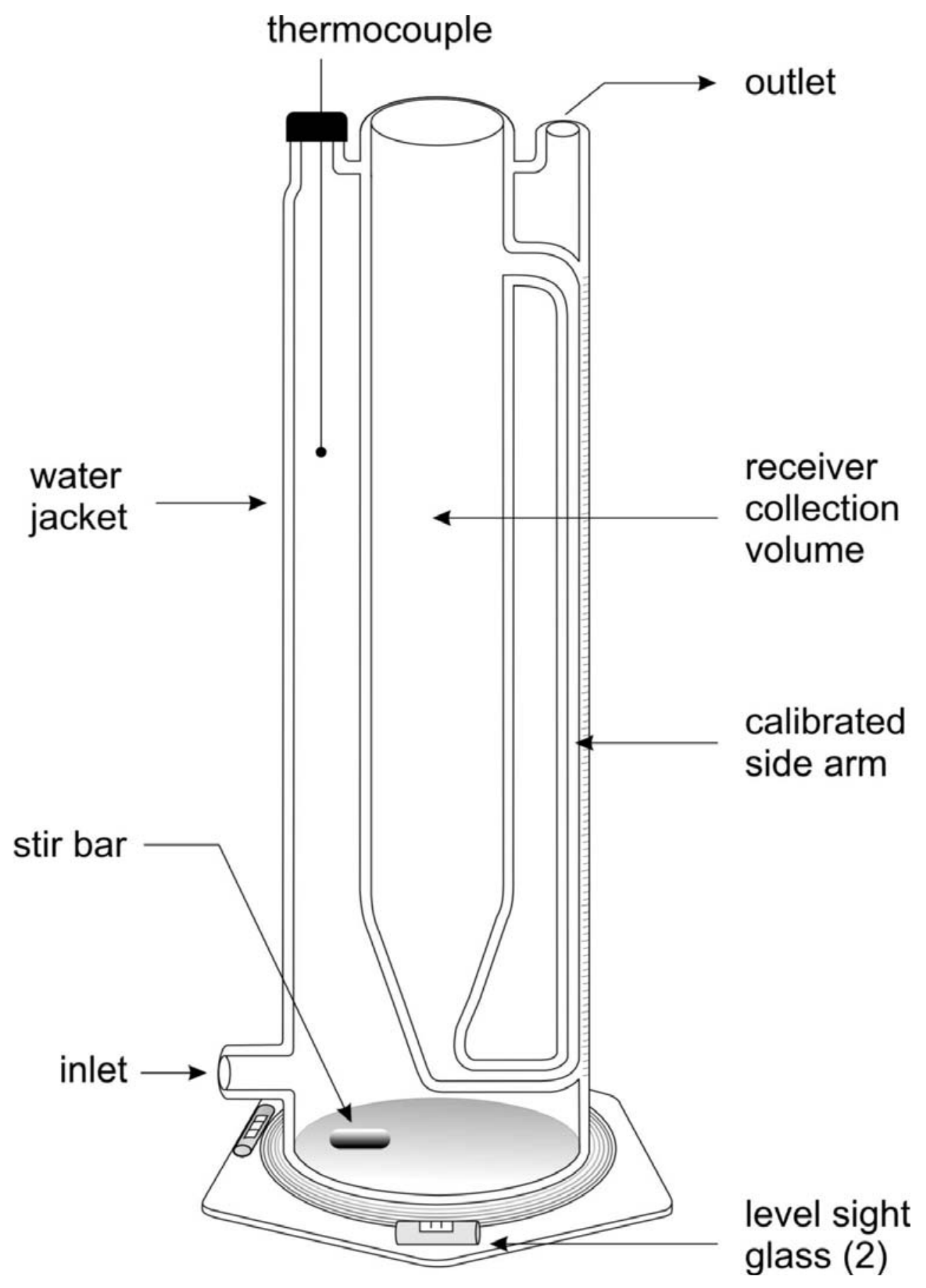

Figure 19: Schematic diagram of the level-stabilized receiver for distillation curve measurement. 
During the initial heating of each sample in the distillation instrument, the behavior of the fluid was observed. Direct observation through the flask window or through the illuminated bore scope allowed measurement of the onset of boiling for each of the mixtures. Typically, during the early stages of a measurement the first bubbles will appear intermittently, and this action will quell if the stirrer is stopped momentarily. Sustained vapor bubbling is then observed. In the context of the advanced distillation curve measurement, sustained bubbling is also somewhat intermittent, but it is observable even when the stirrer is momentarily stopped. Finally, the temperature at which vapor is first observed to rise into the distillation head is observed. This is termed the vapor rise temperature. These observations are important because they are the initial boiling temperatures (IBT) of each fluid. The initial behaviors of three samples of Jet-A and the synthetic S-8 are provided in Table 12. These temperatures have been corrected to $1 \mathrm{~atm}$. with the modified Sydney Young equation. ${ }^{32}$

Table 12: A summary of the initial behavior of the three individual samples of Jet-A, and the sample of S-8. In keeping with our advanced distillation curve protocol, the onset temperature is the temperature at which the first bubbles are observed. The sustained bubbling temperature is that at which the bubbling persists. The vapor rise temperature is that at which vapor is observed to rise into the distillation head, considered to be the initial boiling temperature of the fluid (highlighted in bold print). The temperatures have been adjusted to $1 \mathrm{~atm}$ with the modified Sydney Young equation; uncertainties are discussed in the text.

\begin{tabular}{|c|c|c|c|c|}
\hline $\begin{array}{c}\text { Observed } \\
\text { Temperature }\end{array}$ & $\begin{array}{c}\text { Jet-A-3602, } \\
{ }^{\circ} \mathbf{C}, \mathbf{8 2 . 8 2} \mathbf{~ k P a}\end{array}$ & $\begin{array}{c}\text { Jet-A-3638, } \\
{ }^{\circ} \mathbf{C}, \mathbf{8 2 . 1 1} \mathbf{~ k P a}\end{array}$ & $\begin{array}{c}\text { Jet-A-4658, } \\
{ }^{\circ} \mathbf{C}, \mathbf{8 3 . 6 3 ~ k P a}\end{array}$ & $\begin{array}{c}\mathbf{S - 8 ,}, \\
{ }^{\circ} \mathbf{C}, \mathbf{8 3 . 2 7} \mathbf{~ k P a}\end{array}$ \\
\hline onset & 150.9 & 148.4 & 139.9 & 163.0 \\
\hline sustained & 183.6 & 176.9 & 185.6 & 168.6 \\
\hline vapor rising & $\mathbf{1 9 1 . 0}$ & $\mathbf{1 8 4 . 2}$ & $\mathbf{1 9 0 . 5}$ & $\mathbf{1 8 1 . 9}$ \\
\hline
\end{tabular}

Representative distillation curve data for the three samples of Jet-A, presented in both $\mathrm{T}_{\mathrm{k}}$ and $T_{h}$, are provided in Table 13. In this table, the estimated uncertainty (with a coverage factor $\mathrm{k}=2$ ) in the temperatures is $0.1^{\circ} \mathrm{C}$. Note that the experimental uncertainty of $\mathrm{T}_{\mathrm{k}}$ is somewhat lower than that of $\mathrm{T}_{\mathrm{h}}$, but as a conservative position, we use the higher value for both temperatures. The uncertainty in the volume measurement that is used to obtain the distillate volume fraction is $0.05 \mathrm{~mL}$ in each case. The same data are provided graphically in Figure 20. 
Table 13: Representative distillation curve data for the three individual samples of Jet-A and the sample of S-8 measured in this work. The temperatures have been adjusted to 1 atm. with the modified Sydney Young equation; uncertainties are discussed in the text. These data are plotted in Figure 20.

\begin{tabular}{|c|c|c|c|c|c|c|c|c|}
\hline \multirow{2}{*}{$\begin{array}{c}\text { Distillate } \\
\text { Volume } \\
\text { Fraction, } \\
\%\end{array}$} & \multicolumn{2}{|c|}{$\begin{array}{c}\text { Jet-A-3602 } \\
82.82 \mathrm{kPa} \\
\end{array}$} & \multicolumn{2}{|c|}{$\begin{array}{c}\text { Jet-A-3638 } \\
82.11 \mathrm{kPa}\end{array}$} & \multicolumn{2}{|c|}{$\begin{array}{c}\text { Jet-A-4658 } \\
83.63 \mathrm{kPa}\end{array}$} & \multicolumn{2}{|c|}{$\begin{array}{c}\text { S-8 } \\
\text { 83.27 kPa }\end{array}$} \\
\hline & $\mathrm{T}_{\mathrm{k}},{ }^{\circ} \mathrm{C}$ & $\mathrm{T}_{\mathrm{h}},{ }^{\circ} \mathrm{C}$ & $\mathrm{T}_{\mathrm{k}},{ }^{\circ} \mathrm{C}$ & $\mathrm{T}_{\mathrm{h}},{ }^{\circ} \mathrm{C}$ & $\mathrm{T}_{\mathrm{k}},{ }^{\circ} \mathrm{C}$ & $\mathrm{T}_{\mathrm{h}},{ }^{\circ} \mathrm{C}$ & $\mathrm{T}_{\mathrm{k}},{ }^{\circ} \mathrm{C}$ & $\mathrm{T}_{\mathrm{h}},{ }^{\circ} \mathrm{C}$ \\
\hline 5 & 194.8 & 179.3 & 186.8 & 179.9 & 195.4 & 174.7 & 183.6 & 169.2 \\
\hline 10 & 197.7 & 186.7 & 188.7 & 184.2 & 198.5 & 183.3 & 185.0 & 173.9 \\
\hline 15 & 200.7 & 189.9 & 191.1 & 187.0 & 201.5 & 187.0 & 187.7 & 179.1 \\
\hline 20 & 203.5 & 194.7 & 192.9 & 185.8 & 204.7 & 189.1 & 190.2 & 173.6 \\
\hline 25 & 206.4 & 196.9 & 194.9 & 189.5 & 208.1 & 190.6 & 193.0 & 175.5 \\
\hline 30 & 209.7 & 198.7 & 196.6 & 191.6 & 211.3 & 192.8 & 196.2 & 181.9 \\
\hline 35 & 212.1 & 199.2 & 198.5 & 193.9 & 214.3 & 194.6 & 199.5 & 187.7 \\
\hline 40 & 214.8 & 201.5 & 200.3 & 196.0 & 217.6 & 199.1 & 202.9 & 192.0 \\
\hline 45 & 217.3 & 204.5 & 202.1 & 197.9 & 220.7 & 202.6 & 207.1 & 196.2 \\
\hline 50 & 220.1 & 206.4 & 204.0 & 199.8 & 224.2 & 205.4 & 211.0 & 200.3 \\
\hline 55 & 222.5 & 208.8 & 205.9 & 202.4 & 227.6 & 208.6 & 215.3 & 205.2 \\
\hline 60 & 225.1 & 213.6 & 208.0 & 204.0 & 231.2 & 212.4 & 219.6 & 209.3 \\
\hline 65 & 227.9 & 213.7 & 210.5 & 205.1 & 234.7 & 214.9 & 224.2 & 213.6 \\
\hline 70 & 230.7 & 218.4 & 213.6 & 207.6 & 239.4 & 216.6 & 229.4 & 219.1 \\
\hline 75 & 233.9 & 223.2 & 216.2 & 210.6 & 243.3 & 218.7 & 235.2 & 224.3 \\
\hline 80 & 237.9 & 226.4 & 219.4 & 210.2 & 247.9 & 220.8 & 240.1 & 231.4 \\
\hline 85 & 242.7 & 225.6 & 222.9 & 215.3 & 253.6 & 224.1 & 246.8 & 236.8 \\
\hline
\end{tabular}




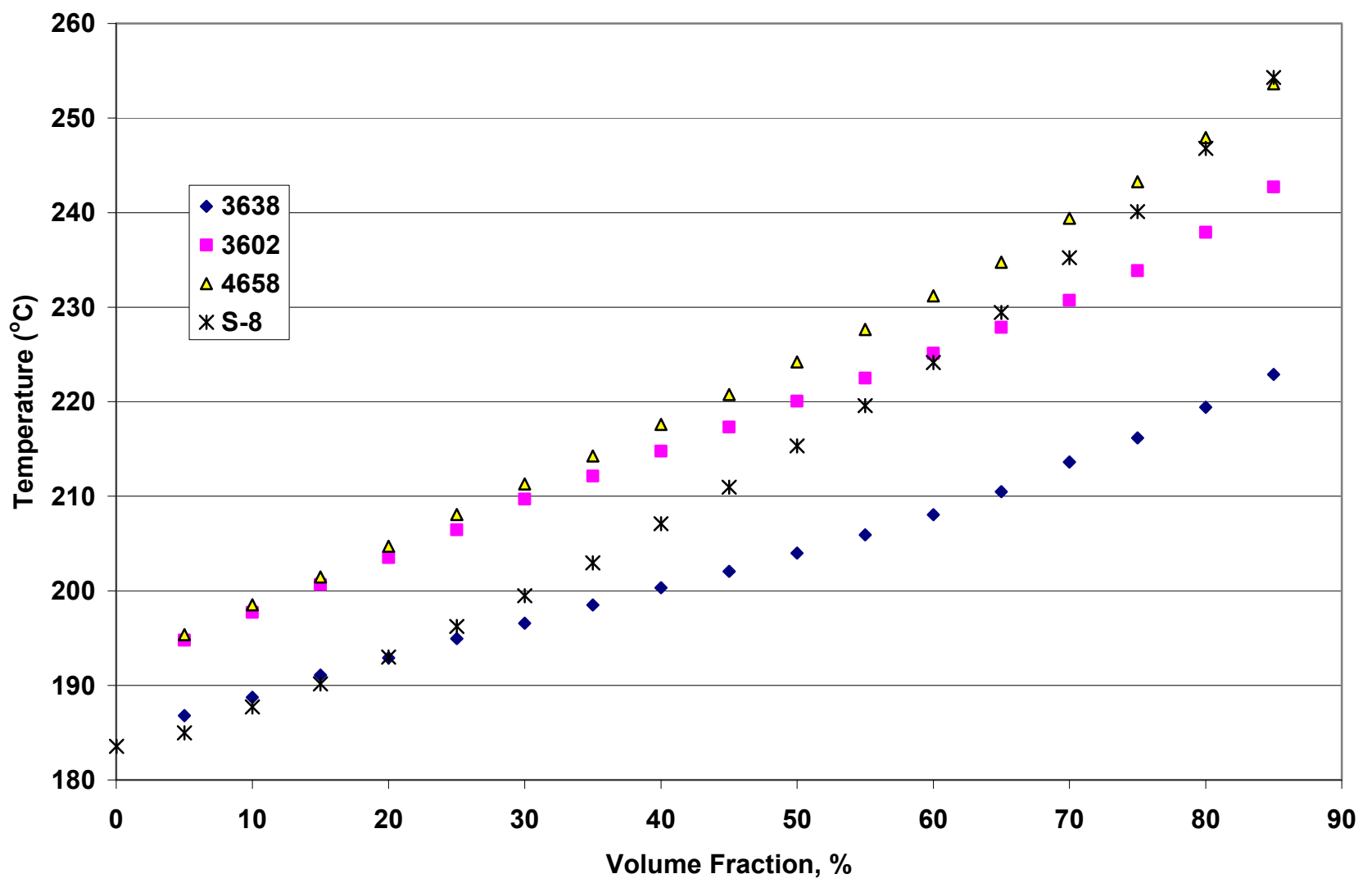

Figure 20: Representative distillation curves for each of the three samples of Jet-A and the sample of S-8 that have been measured as part of this work. The temperatures have been adjusted to $1 \mathrm{~atm}$ with the modified Sydney Young equation; uncertainties are discussed in the text.

The shapes of all of the curves are of the subtle sigmoid or growth curve type that one would expect for a highly complex fluid with many components, distributed over a large range of relative molecular mass. There is no indication of the presence of azeotropic constituents, since there is an absence of multiple inflections and curve flattening. As an example of typical repeatability of these curves, we show in Figure 21 six curves measured for Jet-A-4658. We note that in the latter stages of the distillations, the repeatability suffers slightly. 


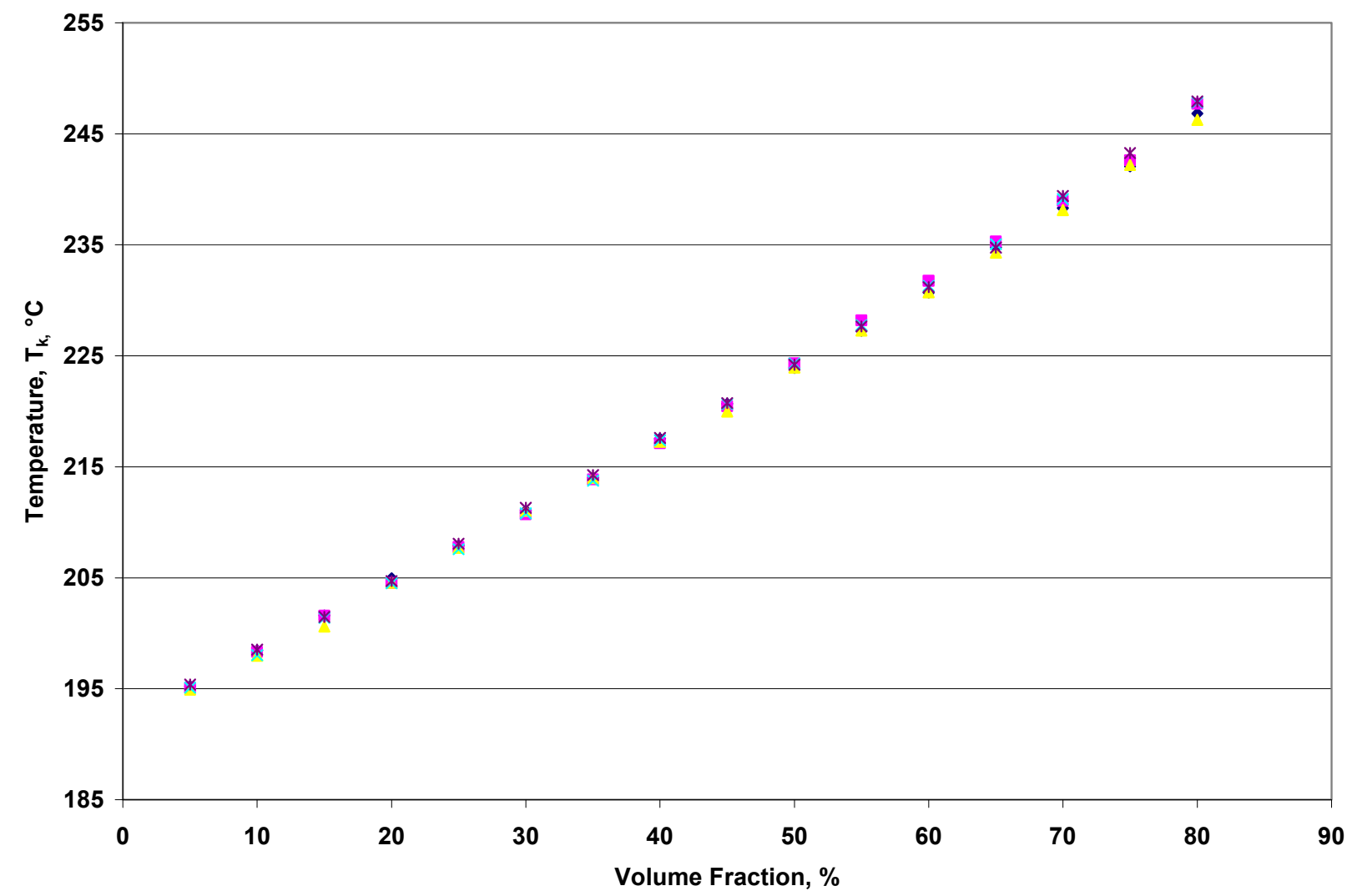

Figure 21: Plot showing the repeatability of the distillation curve measurement. Here, six measurements of the curve for Jet-A-4658 are provided. The uncertainty bars of the individual temperatures are of the same size as the plotting symbols.

The plotted curves are particularly instructive since the difference presented by Jet-A3838 with respect to Jet-A-3602 and Jet-A-4658 is clearly shown. It is also clear from the curves that the differences are not merely in the early parts of the curves, but rather the difference persists throughout the curve and is in fact magnified at higher distillate volume fraction values. This behavior is indicative of fluids that differ in overall composition or chemical family throughout the entire composition range of the fluid. This is in contrast to differences that result from one fluid merely having somewhat more volatile constituents that boil off in the early stages of the distillation curve measurement, and is often caused by the presence of a different distribution of components within a chemical family. Indeed, this observation was found to be consistent with a gas chromatographic analysis of the three fuel samples (the procedure for which was described in the experimental section), since Jet-A-3602 and Jet-A-4658 appear to contain much higher concentrations of heavier components. This can be shown by examining the total area of chromatographic peaks that elute subsequent to the emergence of n-tetradecane, for each sample. For Jet-A-3638, this comprises $2.47 \%$ of the total peak areas, while for Jet-A-3602 and Jet-A-4658, this comprises 12.07 and $17.57 \%$, respectively. Note that these peak areas are the raw, uncalibrated values, and are used only for comparison among the three fluids. 
The rather consistent difference in the distillation curves of Jet-A-3638 and the other two Jet-A fluids is not seen when one examines the behavior of S-8. With this fluid, the curve rises much more sharply than do the Jet-A curves. This is typically observed when a fluid has somewhat more volatile constituents that boil off in the early stages of the distillation curve measurement. While the fluid initially begins to vaporize at a relatively lower temperature (especially when compared to Jet-A-3602 and Jet-A-4658), by a distillate volume fraction of $45 \%$, the curve of this fluid is approaching those of Jet-A3602 and Jet-A-4658. By a distillate volume fraction of $60 \%$, the curve of S-8 and those of Jet-A-3602 and Jet-A-4658 have essentially merged. Note that this is consistent with the onset behaviors and chromatographic analyses presented in the discussion of the initial temperatures.

The relationship between $T_{k}$ and $T_{h}$ is presented in Figure 22, in which both temperatures are presented for the data shown in Table 13. We note that $T_{k}$ always leads $T_{h}$. This behavior is consistent with a complex mixture with a continually changing composition. Note that when these two temperatures converge, it is evidence of either a single component being generated (by vaporization) in the kettle, or the presence of an azeotrope that controls the composition of both phases. The absence of such a convergence can be interpreted as further evidence of the absence of azeotropic behavior. It is clear that an examination of the initial temperatures and the detailed structures of the distillation curves (presented in $T_{k}$ and $T_{h}$ ) can serve as method to evaluate the loose specifications that can sometimes characterize gas turbine fuels.

For comparison, the distillation curve was measured for JP-8-3773, a sample of which was obtained directly from the flight line at Wright Patterson Air Force Base. The distillation curve was measured for six aliquots of this fluid. The initial temperatures for this fluid are provided in Table 14, while representative distillation curve measurements presented in $T_{k}$ and $T_{h}$ are provided in Table 15. A graphical depiction of the distillation curve is provided in Figure 23. Since this fluid has all the additives typically present in JP-8 relative to Jet-A, the very minor differences between JP-8 and Jet-A reflected in these distillation curves may be indicative of these additives. Additional work would be needed to confirm this, especially considering the wide specifications allowable for Jet-A and JP-8. 

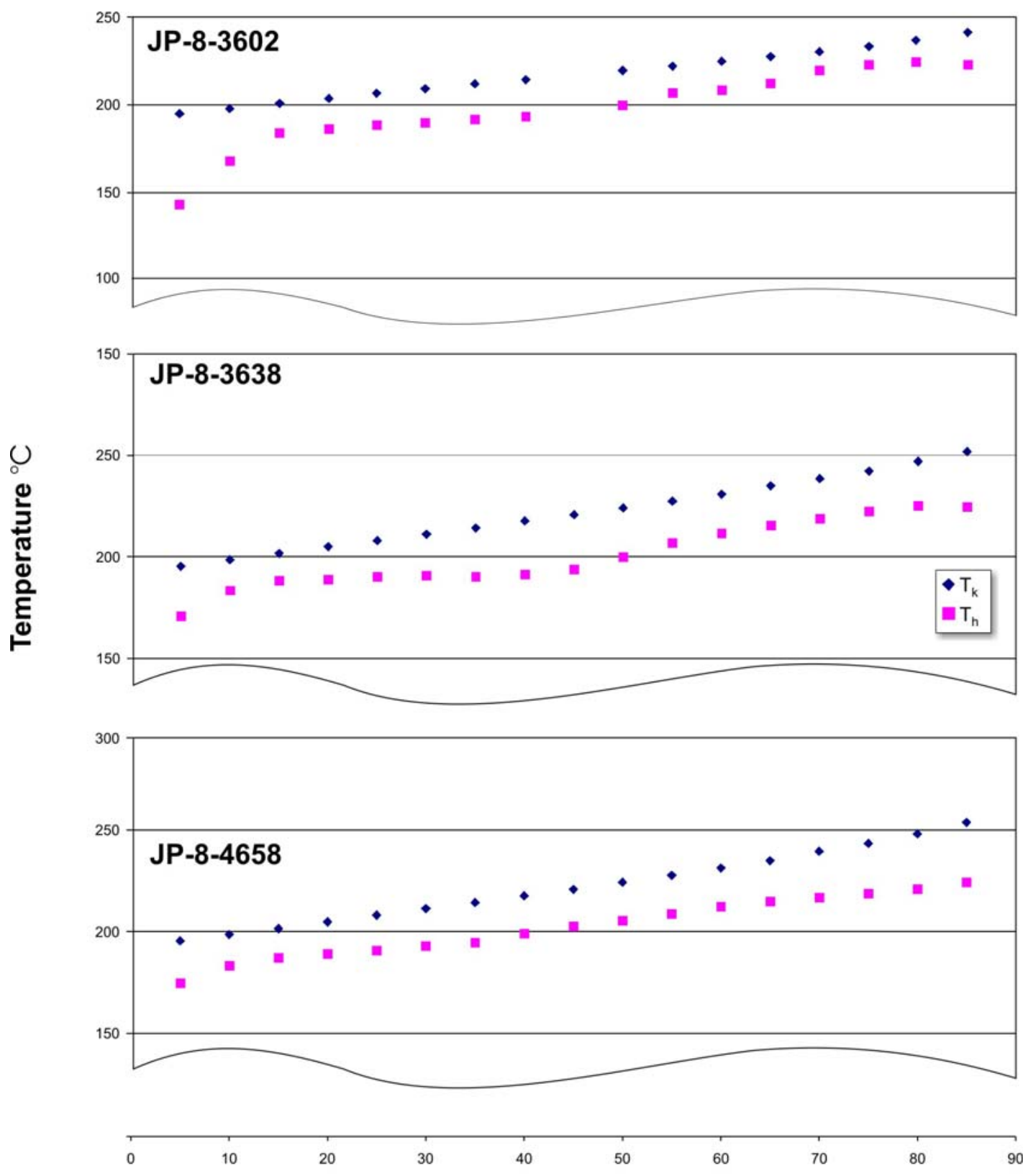

Volume Fraction, \%

Figure 22: The relationship of $\mathrm{T}_{\mathrm{k}}$ and $\mathrm{T}_{\mathrm{h}}$ for the three Jet-A fluids measured in this work. The uncertainty is discussed in the text. 
Table 14: A summary of the initial behavior of JP-8-3773, obtained directly from the flight line of Wright Patterson Air Force Base. In keeping with our advanced distillation curve protocol, the onset temperature is the temperature at which the first bubbles are observed. The sustained bubbling temperature is that at which the bubbling persists. The vapor rise temperature is that at which vapor is observed to rise into the distillation head, considered to be the initial boiling temperature of the fluid (highlighted in bold print). These temperatures have been corrected to $1 \mathrm{~atm}$. with the Sidney Young equation. The uncertainties are discussed in the text.

\begin{tabular}{|c|c|}
\hline $\begin{array}{c}\text { Observed } \\
\text { Temperature }\end{array}$ & $\begin{array}{c}\mathbf{J P - 8 - 3 7 7 3 ,} \\
{ }^{\circ} \mathbf{C , ~ 8 3 . 8 6} \\
\mathbf{k P a}\end{array}$ \\
\hline onset & 132.4 \\
\hline sustained & 179.9 \\
\hline vapor rising & 182.8 \\
\hline
\end{tabular}

Table 15: Distillation curve data of JP-8-3773, obtained directly from the flight line of Wright Patterson Air Force Base. The temperatures have been adjusted to $1 \mathrm{~atm}$ with the modified Sydney Young equation; uncertainties are discussed in the text.

\begin{tabular}{|c|c|c|}
\hline Distillate & \multicolumn{2}{|c|}{ JP-8-3773 } \\
Volume & \multicolumn{2}{|c|}{$\mathbf{8 3 . 8 6}$ kPa } \\
\cline { 2 - 3 } $\begin{array}{c}\text { Fraction, } \\
\text { \% }\end{array}$ & $\begin{array}{c}\mathrm{T}_{\mathrm{k}}, \\
{ }^{\circ} \mathrm{C}\end{array}$ & $\begin{array}{c}\mathrm{T}_{\mathrm{h}}, \\
{ }^{\circ} \mathrm{C}\end{array}$ \\
\hline 5 & 185.6 & 174.7 \\
\hline 10 & 187.9 & 179.2 \\
\hline 15 & 190.3 & 182.2 \\
\hline 20 & 192.7 & 184.8 \\
\hline 25 & 195.1 & 186.7 \\
\hline 30 & 197.6 & 185.1 \\
\hline 35 & 200.4 & 188.7 \\
\hline 40 & 203.3 & 194.1 \\
\hline 45 & 206.1 & 196.2 \\
\hline 50 & 209.3 & 199.9 \\
\hline 55 & 213.5 & 201.2 \\
\hline 60 & 216.4 & 203.8 \\
\hline 65 & 220.6 & 209.4 \\
\hline 70 & 224.8 & 212.1 \\
\hline 75 & 229.4 & 215.8 \\
\hline 80 & 234.6 & 219.3 \\
\hline 85 & 240.3 & 225.5 \\
\hline
\end{tabular}




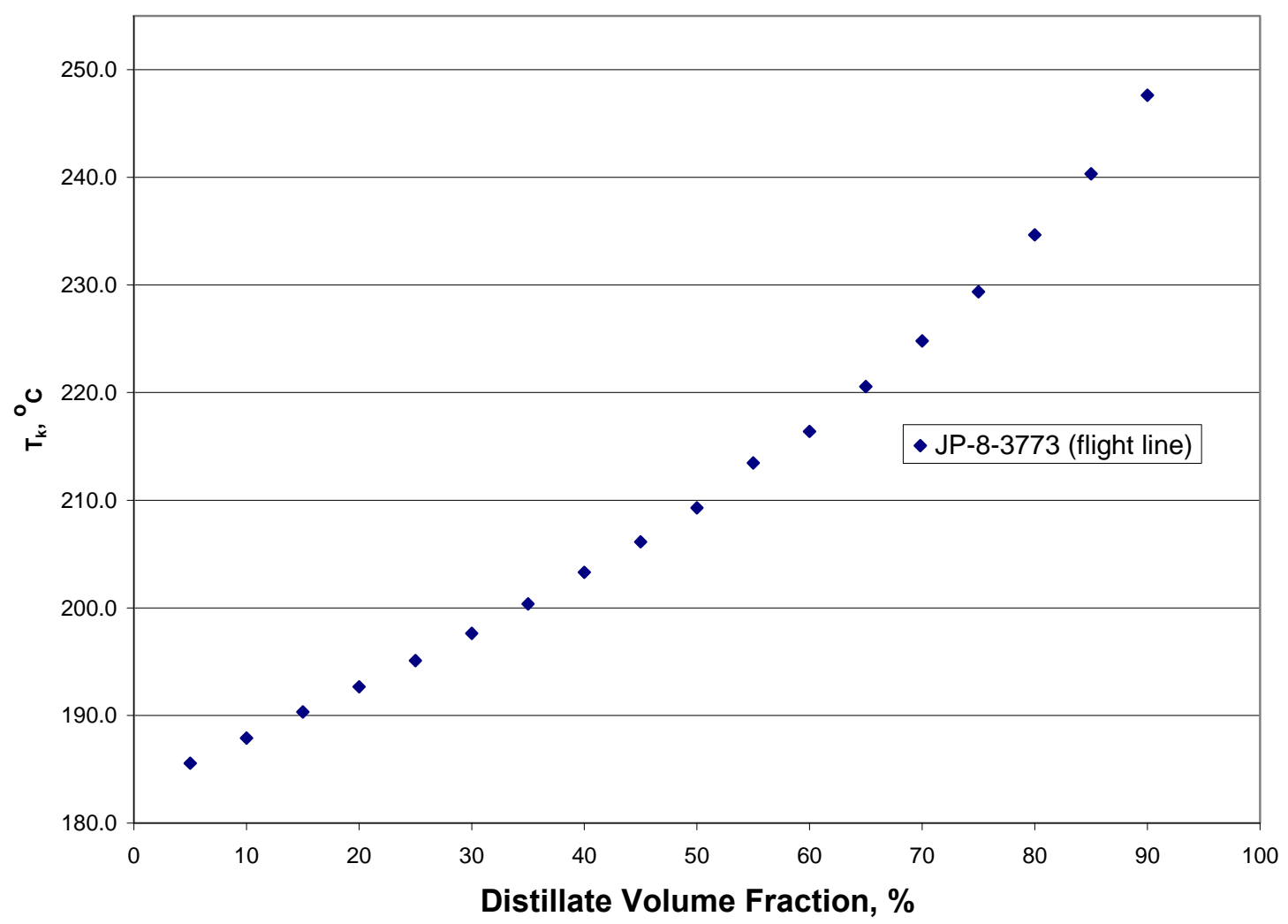

Figure 23: Distillation curve of JP-8-3773, obtained directly from the flight line of Wright Patterson Air Force Base. The temperatures have been adjusted to $1 \mathrm{~atm}$ with the modified Sydney Young equation; uncertainties are discussed in the text.

While the gross examination of the distillation curves is instructive and valuable for many design purposes, the composition channel of the advanced approach can provide even greater understanding and information content. One can sample and examine the individual fractions as they emerge from the condenser, as discussed in the introduction. Following the analytical procedure described, samples were collected and prepared for analysis. Chemical analyses of each fraction were done by gas chromatography with flame ionization detection and mass spectrometric detection. Representative chromatograms (measured by flame ionization detection) for each fraction of Jet-A-4658 are shown in Figure 24. The time axis is from 0 to 12 minutes for each chromatogram, and the abundance axis is presented in arbitrary units of area counts. It is clear that although there are many peaks on each chromatogram ( $30-40$ major peaks, and $60-80$ minor and trace peaks), these chromatograms are much simpler than those of the neat fluids, which can contain 300 - 400 peaks. At the very start of each chromatogram is the solvent front, which does not interfere with the sample. One can follow the progression of the chromatograms in Figure 24 as the distillate fraction becomes richer in the heavier components. This figure illustrates just one chemical analysis strategy that can be 
applied to the distillate fractions. It is possible to use any analytical technique that is applicable to solvent born liquid samples that might be desirable for a given application.
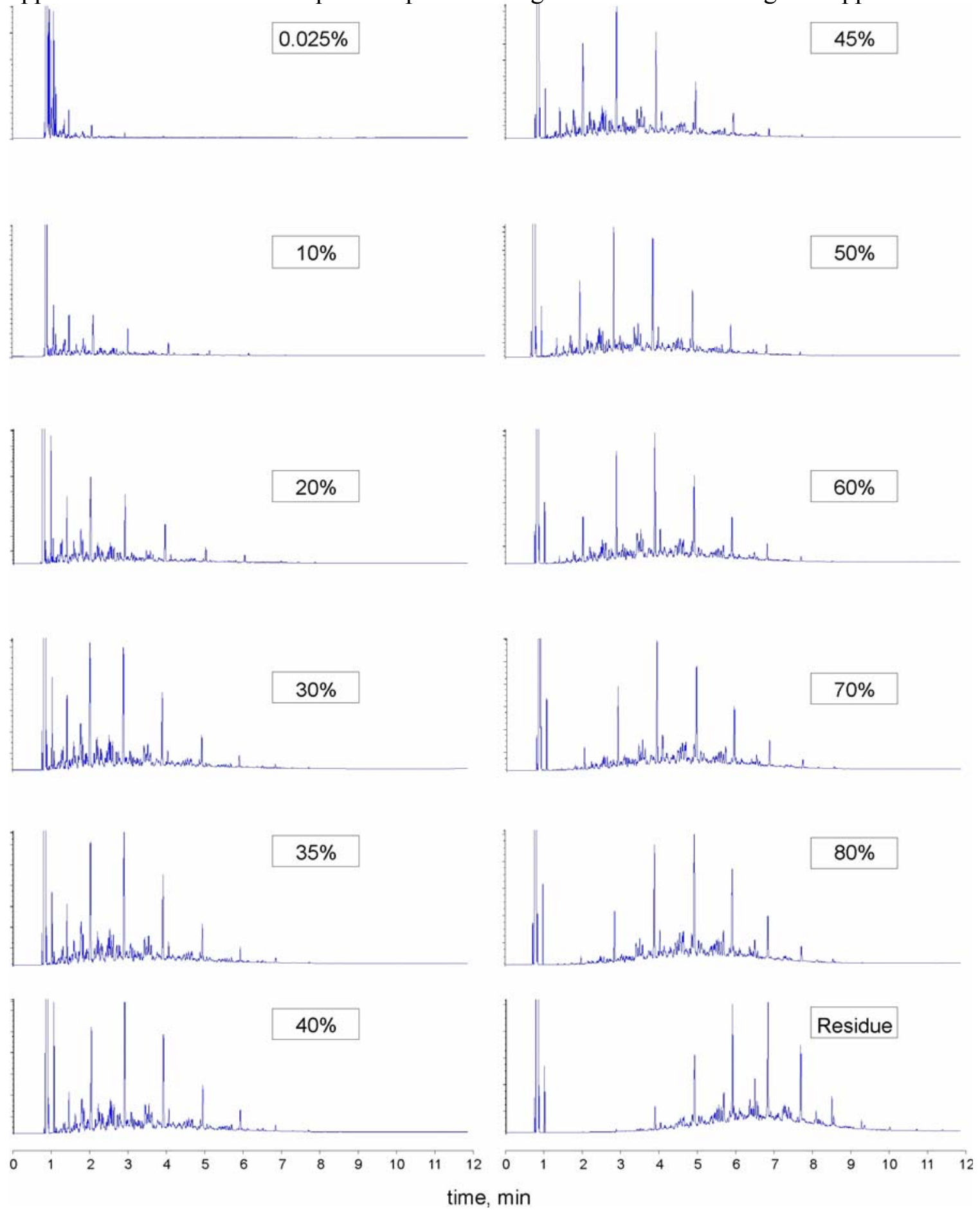

Figure 24: Chromatograms of distillate fractions of a typical Jet-A sample, in this case Jet-A-4658, presented in arbitrary units of intensity (from a flame ionization detector) plotted against time. One can see the solvent peaks very early in the chromatograms. The details of the chromatography are discussed in the text. 
The distillate fractions of the three Jet-A samples and the S-8 sample were examined for hydrocarbon types by use of a mass spectrometric classification method summarized in ASTM Method D-2789 ${ }^{33}$. In this method, one uses mass spectrometry (or gas chromatography - mass spectrometry) to characterize hydrocarbon samples into six types. The six types or families are paraffins, monocycloparaffins, dicycloparaffins, alkylbenzenes (or aromatics), indanes and tetralins (grouped as one classification), and naphthalenes. Although the method is specified only for application to low olefinic gasolines, and is subject to numerous interferences and uncertainties, it is of practical relevance to many complex fluid analyses, and is often applied to gas turbine fuels, rocket propellants and missile fuels. For the hydrocarbon type analysis of the distillate fraction samples, $1 \mu \mathrm{L}$ injections were made into the GC-MS. Because of this consistent injection volume, no corrections were needed for sample volume.

The results of these hydrocarbon type analyses for the Jet-A and S-8 samples are presented in Tables 16a to 16e, and plotted in Figure 25. The first line in each of the tables reports the results of the analysis as applied to the entire sample (called the composite) rather than to distillate fractions. The data listed in this line are actually an average of two separate determinations; one done with a neat sample of the fuel (that is, with no added solvent) and the other with the sample in n-hexane. The volume of the neat sample was $0.2 \mu \mathrm{L}$, and only these mass spectra were corrected for sample volume. All of the distillate fractions presented in the table were measured in the same way as the composite ( $\mathrm{m} / \mathrm{z}$ range from 15 to 550 relative molecular mass units gathered in scanning mode, each spectrum corrected by subtracting trace air and water peaks).

In general, the hydrocarbon type fractions for the composite (the first row in each table) are consistent with the compositions obtained for the distillate fractions (the remaining rows of each table). Thus, taking the $\mathrm{S}-8$ fluid as an example, the paraffin fraction for the composite sample was found to be 80.0 percent, while that of the distillate fractions ranged from 79.1 to 87.8. We have noted, however, that with the composite samples (which naturally produce a much more complex total ion chromatogram), one obtains many more non-integral $\mathrm{m} / \mathrm{z}$ peaks on the mass spectrum. Thus, for a distillate fraction, one might obtain a peak at $\mathrm{m} / \mathrm{z}=43.0$, while for the composite one might obtain $\mathrm{m} / \mathrm{z}=$ $43.0,43.15$, etc., despite the resolution of the instrument being only 1 unit of mass. Our practice has been to round the fractional masses to the nearest integral mass, a practice that can sometimes cause bias. This is an unavoidable vagary of the instrument that can potentially be remedied with a higher resolution mass spectrometer. We maintain that the comparability among the distillate fractions is not affected by this characteristic, although the intercomparability between the distillate fractions and the composite should be approached with a bit more caution. 
Table 16: Summary of the results of hydrocarbon family calculations based on the method of ASTM D-2789. The first three tables are for the individual lots of Jet-A, while the last is for the synthetic S-8.

Table 16a: Jet-A-3602:

\begin{tabular}{|c|c|c|c|c|c|c|}
\hline $\begin{array}{c}\text { Distillate } \\
\text { Volume } \\
\text { Fraction, } \\
\%\end{array}$ & Paraffins & $\begin{array}{c}\text { Monocyclo- } \\
\text { paraffins }\end{array}$ & $\begin{array}{c}\text { Dicyclo- } \\
\text { paraffins }\end{array}$ & $\begin{array}{c}\text { Alkyl- } \\
\text { aromatics }\end{array}$ & $\begin{array}{c}\text { Indanes } \\
\text { and } \\
\text { Tetralins } \\
\text { Vol \% }\end{array}$ & $\begin{array}{c}\text { Naphth- } \\
\text { alenes }\end{array}$ \\
\hline Vol \% \\
\hline composite & 36.0 & 26.9 & 4.5 & 20.6 & 6.9 & 1.7 \\
\hline 0.025 & 25.5 & 30.3 & 6.1 & 34.7 & 2.9 & 0.4 \\
\hline 10 & 27.5 & 27.0 & 7.4 & 33.2 & 4.3 & 0.7 \\
\hline 20 & 27.5 & 26.7 & 10.4 & 28.4 & 5.9 & 1.0 \\
\hline 30 & 28.2 & 26.6 & 10.8 & 27.0 & 6.3 & 1.1 \\
\hline 35 & 30.0 & 26.4 & 9.6 & 26.4 & 6.5 & 1.2 \\
\hline 40 & 29.1 & 26.6 & 11.6 & 24.3 & 7.0 & 1.4 \\
\hline 45 & 30.1 & 26.9 & 11.0 & 23.4 & 7.2 & 1.5 \\
\hline 50 & 32.9 & 26.6 & 8.8 & 22.8 & 7.4 & 1.5 \\
\hline 60 & 28.9 & 26.8 & 13.3 & 19.9 & 9.0 & 2.1 \\
\hline 70 & 31.0 & 28.3 & 12.4 & 17.1 & 9.1 & 2.2 \\
\hline 80 & 31.5 & 29.0 & 12.8 & 14.0 & 10.0 & 2.8 \\
\hline Residue & 34.3 & 32.5 & 13.9 & 6.8 & 7.9 & 4.5 \\
\hline
\end{tabular}

Table 16b: Jet-A-3638:

\begin{tabular}{|c|c|c|c|c|c|c|}
\hline $\begin{array}{c}\text { Distillate } \\
\text { Volume } \\
\text { Fraction, } \\
\%\end{array}$ & Paraffins & $\begin{array}{c}\text { Monocyclo- } \\
\text { paraffins }\end{array}$ & $\begin{array}{c}\text { Dicyclo- } \\
\text { paraffins }\end{array}$ & $\begin{array}{c}\text { Alkyl- } \\
\text { aromatics }\end{array}$ & $\begin{array}{c}\text { Indanes } \\
\text { and } \\
\text { Tetralins } \\
\text { Vol \% }\end{array}$ & $\begin{array}{c}\text { Naphth- } \\
\text { alenes }\end{array}$ \\
\hline Vol \% & Vol \% & Vol \% & 12.5 & 2.9 & 2.8 \\
\hline 0.025 & 36.9 & 30.0 & 6.2 & 24.6 & 1.3 & 1.0 \\
\hline 10 & 42.6 & 26.1 & 4.2 & 25.0 & 0.9 & 1.3 \\
\hline 20 & 45.4 & 25.0 & 4.1 & 23.3 & 0.8 & 1.4 \\
\hline 30 & 42.2 & 26.6 & 6.7 & 21.0 & 1.7 & 1.9 \\
\hline 35 & 42.9 & 26.4 & 7.1 & 19.1 & 1.8 & 2.6 \\
\hline 40 & 41.0 & 26.7 & 8.4 & 19.5 & 2.2 & 2.2 \\
\hline 45 & 40.9 & 27.0 & 9.0 & 18.5 & 2.4 & 2.3 \\
\hline 50 & 42.0 & 27.0 & 8.7 & 17.6 & 2.3 & 2.5 \\
\hline 60 & 42.5 & 27.3 & 9.0 & 15.8 & 2.5 & 2.9 \\
\hline 70 & 44.8 & 27.4 & 8.1 & 13.7 & 2.5 & 3.5 \\
\hline 80 & 44.6 & 27.6 & 9.5 & 11.1 & 2.9 & 4.3 \\
\hline Residue & 43.2 & 27.7 & 12.0 & 3.9 & 3.1 & 10.1 \\
\hline
\end{tabular}


Table 16c: Jet-A-4658:

\begin{tabular}{|c|c|c|c|c|c|c|}
\hline $\begin{array}{c}\text { Distillate } \\
\text { Volume } \\
\text { Fraction, } \\
\%\end{array}$ & Paraffins & $\begin{array}{c}\text { Monocyclo- } \\
\text { paraffins }\end{array}$ & $\begin{array}{c}\text { Dicyclo- } \\
\text { paraffins }\end{array}$ & $\begin{array}{c}\text { Alkyl- } \\
\text { aromatics }\end{array}$ & $\begin{array}{c}\text { Indanes } \\
\text { and } \\
\text { Tetralins } \\
\text { Vol \% }\end{array}$ & $\begin{array}{c}\text { Naphth- } \\
\text { alenes }\end{array}$ \\
\hline Vol \% \\
\hline composite & 46.5 & 22.5 & 5.4 & 18.4 & 4.5 & 2.4 \\
\hline 0.025 & 40.4 & 27.3 & 3.4 & 27.3 & 1.2 & 0.5 \\
\hline 10 & 39.8 & 25.1 & 4.5 & 27.2 & 2.6 & 0.8 \\
\hline 20 & 41.2 & 24.6 & 4.4 & 25.6 & 3.1 & 1.1 \\
\hline 30 & 40.9 & 25.2 & 5.8 & 22.1 & 4.3 & 1.6 \\
\hline 35 & 43.2 & 24.5 & 4.3 & 21.9 & 4.2 & 1.8 \\
\hline 40 & 43.3 & 25.3 & 4.8 & 20.0 & 4.6 & 2.0 \\
\hline 45 & 41.7 & 25.9 & 6.4 & 18.7 & 5.0 & 2.3 \\
\hline 50 & 42.9 & 25.8 & 5.6 & 18.1 & 5.1 & 2.4 \\
\hline 60 & 43.1 & 26.4 & 6.7 & 15.0 & 5.9 & 2.9 \\
\hline 70 & 43.8 & 27.1 & 7.4 & 11.8 & 6.3 & 3.6 \\
\hline 80 & 48.7 & 29.9 & 7.0 & 6.3 & 4.6 & 3.3 \\
\hline Residue & 49.7 & 31.9 & 7.0 & 3.4 & 3.4 & 4.5 \\
\hline
\end{tabular}

Table 16d: S-8:

\begin{tabular}{|c|c|c|c|c|c|c|}
\hline $\begin{array}{c}\text { Distillate } \\
\text { Volume } \\
\text { Fraction, } \\
\%\end{array}$ & Paraffins & $\begin{array}{c}\text { Monocyclo- } \\
\text { paraffins }\end{array}$ & $\begin{array}{c}\text { Dicyclo- } \\
\text { paraffins }\end{array}$ & $\begin{array}{c}\text { Alkyl- } \\
\text { aromatics }\end{array}$ & $\begin{array}{c}\text { Indanes } \\
\text { and } \\
\text { Tetralins } \\
\text { Vol \% }\end{array}$ & $\begin{array}{c}\text { Naphth- } \\
\text { alenes }\end{array}$ \\
\hline Vol \% & Vol \% & Vol \% & 0.1 & 0 & 1.9 \\
\hline 0.025 & 79.1 & 18.4 & 0.1 & 1.8 & 0.0 & 0.6 \\
\hline 10 & 81.2 & 16.4 & 0.0 & 1.9 & 0.0 & 0.5 \\
\hline 20 & 81.0 & 18.0 & 0.1 & 0.0 & 0.0 & 0.9 \\
\hline 30 & 80.8 & 17.9 & 0.3 & 0.0 & 0.0 & 1.1 \\
\hline 35 & 82.0 & 16.8 & 0.1 & 0.0 & 0.0 & 1.1 \\
\hline 40 & 85.8 & 13.7 & 0.0 & 0.0 & 0.0 & 0.5 \\
\hline 45 & 87.8 & 11.9 & 0.0 & 0.0 & 0.0 & 0.3 \\
\hline 50 & 85.3 & 13.8 & 0.0 & 0.0 & 0.0 & 0.9 \\
\hline 60 & 85.1 & 13.9 & 0.0 & 0.0 & 0.0 & 1.1 \\
\hline 70 & 85.1 & 13.7 & 0.0 & 0.0 & 0.0 & 1.2 \\
\hline 80 & 83.6 & 15.0 & 0.0 & 0.0 & 0.0 & 1.4 \\
\hline Residue & 84.8 & 14.7 & 0.0 & 0.0 & 0.0 & 0.5 \\
\hline
\end{tabular}


Table 16e: JP-8 3773:

\begin{tabular}{|c|r|r|r|r|r|r|}
\hline $\begin{array}{c}\text { Distillate } \\
\text { Volume } \\
\text { Fraction, } \\
\%\end{array}$ & Pol \% & \multicolumn{1}{c|}{$\begin{array}{c}\text { Vol \% } \\
\text { paraffins }\end{array}$} & $\begin{array}{c}\text { Dicyclo- } \\
\text { paraffins }\end{array}$ & $\begin{array}{c}\text { Alkyl- } \\
\text { aromatics }\end{array}$ & $\begin{array}{c}\text { Indanes } \\
\text { and } \\
\text { Tetralins } \\
\text { Vol \% }\end{array}$ & $\begin{array}{c}\text { Naphth- } \\
\text { alenes }\end{array}$ \\
\hline & & & & & & Vol \% \\
\hline 0.025 & 40.8 & 30.3 & 11.4 & 16.8 & 0.5 & 0.3 \\
\hline 10 & 49.0 & 27.0 & 2.3 & 20.7 & 0.7 & 0.3 \\
\hline 20 & 45.9 & 28.1 & 4.7 & 18.0 & 1.9 & 1.3 \\
\hline 30 & 47.4 & 27.4 & 3.6 & 19.2 & 1.5 & 1.0 \\
\hline 35 & 48.6 & 26.8 & 3.1 & 19.4 & 1.3 & 0.7 \\
\hline 40 & 52.1 & 24.8 & 2.1 & 18.8 & 1.2 & 0.9 \\
\hline 45 & 57.6 & 21.8 & 1.0 & 18.4 & 0.2 & 1.0 \\
\hline 50 & 56.1 & 23.5 & 1.6 & 17.0 & 0.8 & 1.1 \\
\hline 60 & 57.2 & 23.5 & 1.7 & 14.9 & 1.0 & 1.8 \\
\hline 70 & 61.4 & 22.2 & 1.0 & 11.0 & 1.7 & 2.6 \\
\hline 80 & 56.3 & 26.6 & 2.5 & 8.0 & 2.5 & 4.0 \\
\hline Residue & 56.0 & 30.9 & 4.0 & 1.2 & 0.5 & 7.3 \\
\hline
\end{tabular}




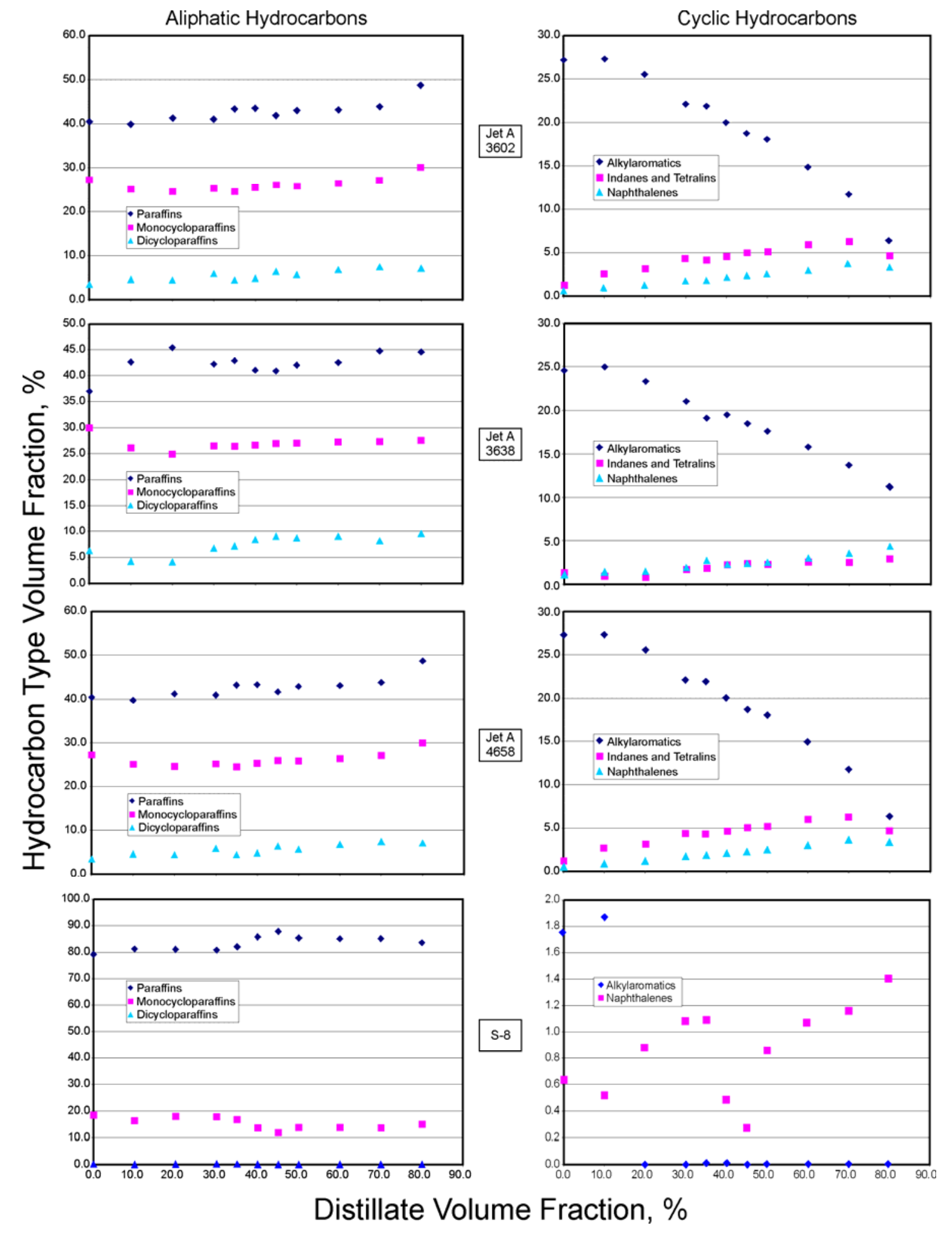

Figure 25: A plot of the hydrocarbon types resulting from the ASTM D-2789 analysis performed on Jet-A-3602, Jet-A-3638, Jet-A-4658 and S-8. The left side of the figure presents the aliphatic constituents, while the right side presents the cyclic constituents. The uncertainties are discussed in the text. 

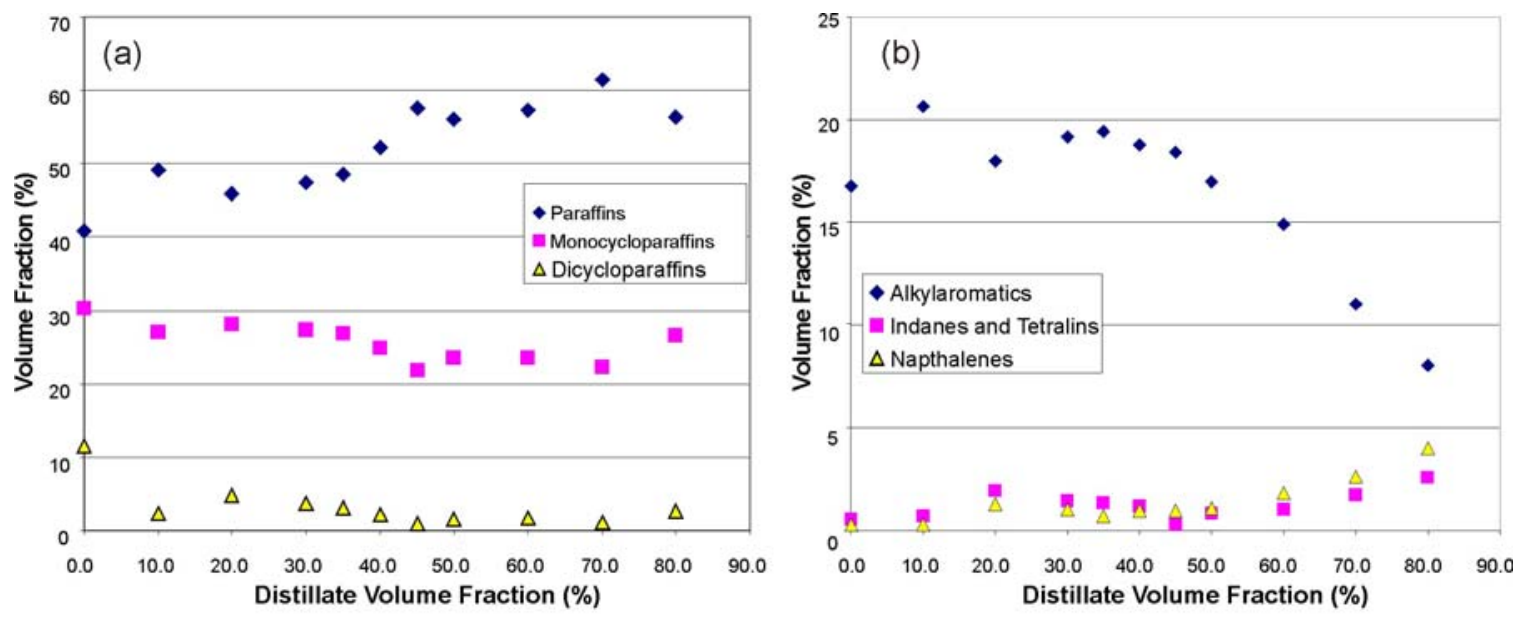

Figure 26: A plot of the hydrocarbon types resulting from the ASTM D-2789 analysis performed on JP-8-3773. The left side of the figure presents the aliphatic constituents, while the right side presents the cyclic constituents. The uncertainties are discussed in the text.

The distribution of hydrocarbon type as a function of distillate fraction is particularly instructive among the different Jet-A samples and with reference to Jet-A as compared to the synthetic S-8. We note from the data of Table 16a - 16d that Jet-A-3638 and Jet-A4658 have very similar hydrocarbon family distributions. Moreover, the paraffin fractions of these fluids are significantly higher than those of Jet-A-3602. We also note that for Jet-A-3638 and Jet-A-4658, the alkylaromatic content is relatively close, while for the Jet-A-3602 it is much higher. This behavior is in striking contrast to the behavior apparent on the distillation curves, in which the curves of Jet-A-3602 and Jet-A-4658 appeared to be very similar, and the curve for Jet-A-3638 was at a lower temperature. This observation illustrates the importance of the composition channel of our distillation curve approach. Note also that this does not represent an inconsistency, since it is clear that differing distributions of hydrocarbon types can give rise to different volatilities. Despite having very similar volatility characteristics, Jet-A-3602 and Jet-A-4658 are very different chemically, a fact that would not be noted without the composition channel.

As a function of distillate volume fraction, one can see from Figure 25 that in general for the Jet-A fluids, the paraffin, monocycloparaffin and dicycloparaffin content remains essentially constant or increases very slightly. The alkylaromatic content decreases markedly, while the concentrations of the indanes and tetralins, and the naphthalenics compounds increase.

When one compares the Jet-A fluids with the synthetic S-8, the difference is very significant. Table $16 \mathrm{~d}$ clearly shows that $\mathrm{S}-8$ has a much higher paraffinic content than any of the Jet-A fluids. Moreover, the alkylaromatic content is very small. Indeed, the only aromatic constituents could be found in the very early emerging distillate fractions. 
These two facts are consistent with the composition of the synthetic feed stock of this fluid, namely natural gas. One also notes the clear similarity of the Jet-A fluids with the JP-8, shown in Figure 26. These fluids differ only in the additive package, and this is not reflected in the volatility behavior.

Distillation Curve Measurements on Mixtures of Jet-A and S-8:

As part of the property measurement program for aviation fuels, we prepared mixtures of Jet-A-4658 with S-8, and made distillation curve measurements to examine how the properties would change. ${ }^{18,29}$ Mixtures were prepared volumetrically in mixing cylinders at ambient temperature and pressure. Mixtures of 25/75, 50/50, and 75/25 (vol/vol) of Jet-A with S-8 were prepared and measured. Typically, between four and six distillation curves were measured for each mixture with the same apparatus and approach as has been described in detail earlier. In Table 17, we present the initial boiling behaviors for these mixtures and in Table 18 we present the distillation curve data. The distillation curves are presented graphically in Figure 27.

Table 17: A summary of the initial behavior of the three mixtures (prepared on a volume basis) of Jet-A + S-8, along with the initial behaviors of the starting fluids. The temperatures have been adjusted to $1 \mathrm{~atm}$ with the modified Sydney Young equation; uncertainties are discussed in the text.

\begin{tabular}{|c|c|c|c|c|c|}
\hline $\begin{array}{c}\text { Observed } \\
\text { Temperature, } \\
{ }^{\circ} \mathrm{C} \\
\end{array}$ & $\begin{array}{c}\text { S-8 } \\
83.27 \mathrm{kPa} \\
\end{array}$ & $\begin{array}{c}75 / 25 \mathrm{~S}-8 \\
+ \text { Jet-A } \\
83.67 \mathrm{kPa} \\
\end{array}$ & $\begin{array}{c}50 / 50 \text { S-8 } \\
+ \text { Jet-A } \\
82.38 \mathrm{kPa} \\
\end{array}$ & $\begin{array}{c}25 / 75 \mathrm{~S}-8+ \\
\text { Jet-A } \\
83.51 \mathrm{kPa} \\
\end{array}$ & $\begin{array}{l}\text { Jet-A } 4658 \\
83.63 \mathrm{kPa} \\
\end{array}$ \\
\hline Onset & 163.0 & 160.9 & 154.9 & 161.8 & 139.9 \\
\hline Sustained & 168.6 & 182.3 & 178.6 & 178.9 & 185.6 \\
\hline Vapor Rising & 181.9 & 184.8 & 186.6 & 189.1 & 190.5 \\
\hline
\end{tabular}

These data are presented graphically in Figure 27.

As with the as-delivered aviation fuels discussed earlier, the composition explicit data channel provided a chemical analysis of selected distillate cuts. The hydrocarbon type breakdown resulting from the ASTM D-2789 type analysis is presented in Table 19a-d and Figure 28. 
Table 18: Representative distillation curve data for the three mixtures (prepared on a volume basis) of S-8 + Jet-A-4658 measured in this work. For reference, the data for the individual components, S-8 and Jet-A-4658, are also provided. These data are plotted in Figure 27. The temperatures have been adjusted to $1 \mathrm{~atm}$ with the modified Sydney Young equation; uncertainties are discussed in the text.

\begin{tabular}{|c|c|c|c|c|c|c|c|c|c|c|}
\hline \multirow{2}{*}{$\begin{array}{c}\text { Distillate } \\
\text { Volume } \\
\text { Fraction, } \\
\% \\
\end{array}$} & \multicolumn{2}{|c|}{$\begin{array}{c}\text { S-8 } \\
\text { 83.27 kPa }\end{array}$} & \multicolumn{2}{|c|}{$\begin{array}{c}\text { 75/25 S-8 } \\
\text { Jet-A } \\
83.67 \mathrm{kPa}\end{array}$} & \multicolumn{2}{|c|}{$\begin{array}{c}\text { 50/50 S-8 + } \\
\text { Jet-A } \\
82.38 \mathrm{kPa}\end{array}$} & \multicolumn{2}{|c|}{$\begin{array}{c}\text { 25/75 S-8 + } \\
\text { Jet-A } \\
83.51 \text { kPa }\end{array}$} & \multicolumn{2}{|c|}{$\begin{array}{c}\text { Jet-A } 4658 \\
83.63 \mathrm{kPa}\end{array}$} \\
\hline & $\mathrm{T}_{\mathrm{k}},{ }^{\circ} \mathrm{C}$ & $\begin{array}{l}\mathrm{T}_{\mathrm{h}}, \\
{ }^{\circ} \mathrm{C}\end{array}$ & $\begin{array}{l}\mathrm{T}_{\mathrm{k}}, \\
{ }^{\circ} \mathrm{C}\end{array}$ & $\begin{array}{l}\mathrm{T}_{\mathrm{h}}, \\
{ }^{\circ} \mathrm{C}\end{array}$ & $\begin{array}{l}\mathrm{T}_{\mathrm{k}}, \\
{ }^{\circ} \mathrm{C}\end{array}$ & $\begin{array}{l}\mathrm{T}_{\mathrm{h}}, \\
{ }^{\circ} \mathrm{C}\end{array}$ & $\begin{array}{l}\mathrm{T}_{\mathrm{k}}, \\
{ }^{\circ} \mathrm{C}\end{array}$ & $\begin{array}{l}\mathrm{T}_{\mathrm{h}}, \\
{ }^{\circ} \mathrm{C}\end{array}$ & $\begin{array}{l}\mathrm{T}_{\mathrm{k}}, \\
{ }^{\circ} \mathrm{C}\end{array}$ & $\begin{array}{l}\mathrm{T}_{\mathrm{h}}, \\
{ }^{\circ} \mathrm{C}\end{array}$ \\
\hline 5 & 183.6 & 169.2 & 187.8 & 176.2 & 190.2 & 171.0 & 193.3 & 174.7 & 195.4 & 174.7 \\
\hline 10 & 85.0 & 173.9 & 190.4 & 180.8 & 92.8 & 177.6 & 196.4 & 183.2 & 98.5 & 183.3 \\
\hline 15 & 187.7 & & 193.4 & 184.2 & 196.4 & 183.6 & 199.9 & 189.3 & & 187.0 \\
\hline 20 & & & 196.3 & 182.6 & 199.9 & & 202.9 & 192.5 & & 189.1 \\
\hline & & & & & & & 206.6 & 189.6 & & 0.6 \\
\hline & 6.2 & & 202.8 & & 06.3 & 192.7 & 209.6 & 193.1 & & 92.8 \\
\hline 3 & 199.5 & & 206.3 & 194 & 209.9 & 193.3 & 212.7 & 196.5 & 214 & 194.6 \\
\hline 4 & 22.9 & & 209.9 & 197.5 & 213.3 & 193.8 & 216.4 & 198.4 & 217.6 & 199.1 \\
\hline 45 & 207.1 & 96.2 & 213.7 & 198.1 & 217.1 & 196.6 & 219.7 & 200.8 & 20.7 & 202.6 \\
\hline 50 & 211.0 & 200.3 & 218.2 & 205.8 & 221.1 & 201.8 & 223.6 & 207.2 & 224.2 & 205.4 \\
\hline 55 & 215.3 & 205.2 & 222.4 & 210.4 & 225.1 & 206.9 & 227.5 & 211.3 & 227.6 & 208.6 \\
\hline 60 & 9.6 & 20 & 226.6 & 214.6 & 228.8 & 208.1 & 231.0 & 215.3 & 1.2 & 212.4 \\
\hline 65 & & & 231.6 & & 233.3 & 213.1 & 235.0 & 219.9 & 234.7 & 214.9 \\
\hline & & & 236.4 & 22 & 237.2 & 220.0 & 238.9 & 221.2 & 239.4 & 216.6 \\
\hline & & 224.3 & 241.8 & 229.2 & 242.3 & 221.1 & 243.7 & 226.5 & 243.3 & 218.7 \\
\hline & & & 247.5 & 233.9 & 247.2 & 225.8 & 248.8 & 233.2 & 247.9 & 220.8 \\
\hline 85 & 246.8 & 236.8 & 255.4 & 240.7 & 254.4 & 231.5 & 255.7 & 235.5 & 253.6 & 224.1 \\
\hline
\end{tabular}




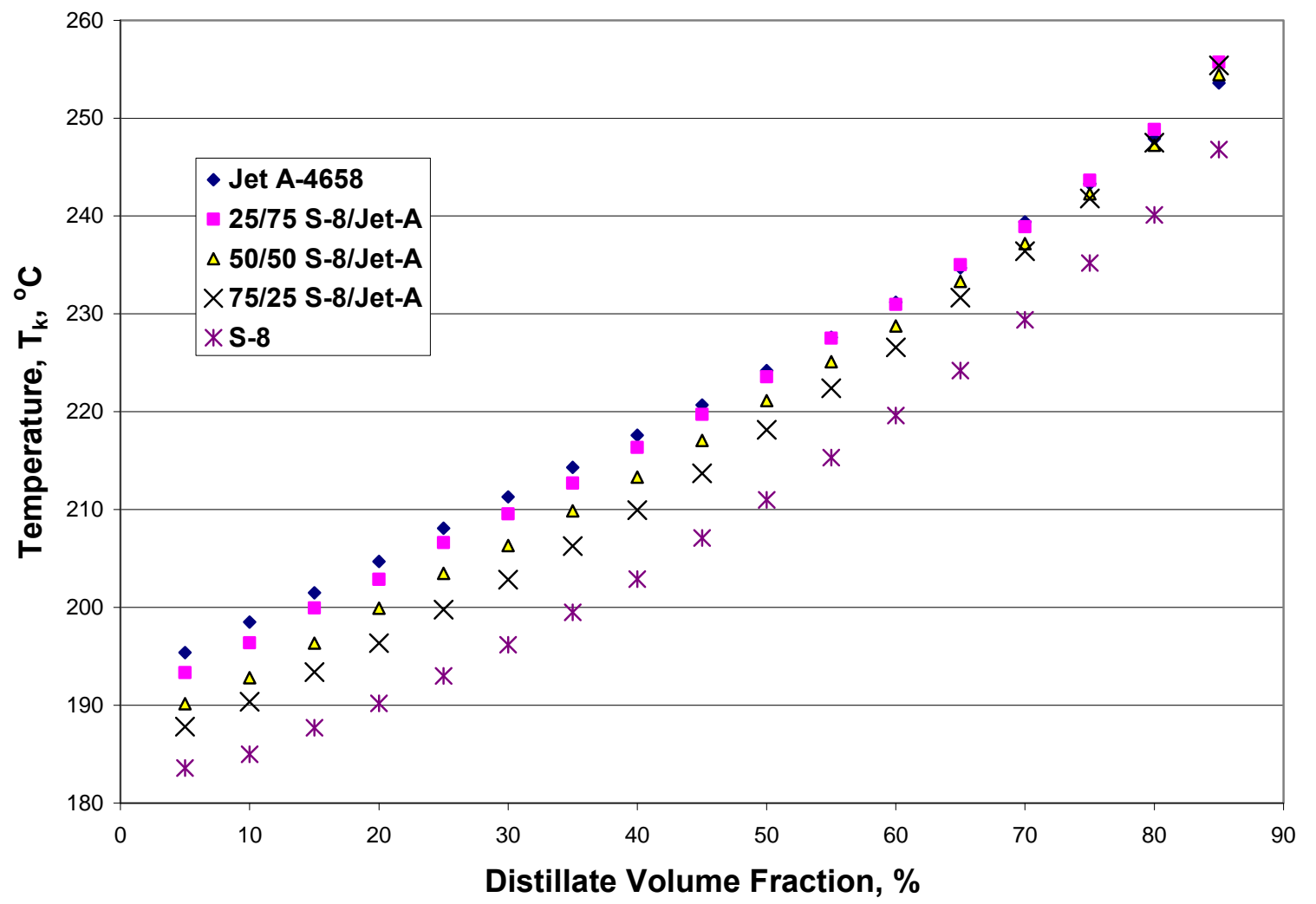

Figure 27: Representative distillation curves for each of the three mixtures of S-8 + JetA-4658 (prepared on a volume basis) measured in this work. For reference, the curves for the individual components, S-8 and Jet-A-4658, are also provided. The temperatures have been adjusted to $1 \mathrm{~atm}$ with the modified Sydney Young equation; uncertainties are discussed in the text.

Table 19: Summary of the results of hydrocarbon family calculations based on the method of ASTM D-2789.

Table 19a: 75/25 S-8/Jet-A:

\begin{tabular}{|c|c|c|c|c|c|c|}
\hline $\begin{array}{c}\text { Distillate } \\
\text { Volume } \\
\text { Fraction, } \\
\%\end{array}$ & Paraffins & $\begin{array}{c}\text { Monocyclo- } \\
\text { paraffins } \\
\text { Vol \% }\end{array}$ & $\begin{array}{c}\text { Dicyclo- } \\
\text { paraffins } \\
\text { Vol \% }\end{array}$ & $\begin{array}{c}\text { Alkyl- } \\
\text { aromatics } \\
\text { Vol \% }\end{array}$ & $\begin{array}{l}\text { Indanes } \\
\text { and } \\
\text { Tetralins } \\
\text { Vol \% }\end{array}$ & $\begin{array}{c}\text { Naphth- } \\
\text { alenes } \\
\text { Vol \% }\end{array}$ \\
\hline composite & 75.3 & 22.0 & 0.4 & 1.2 & 0.2 & 0.9 \\
\hline 0.025 & 74.1 & 22.2 & 0.2 & 3.2 & 0.0 & 0.3 \\
\hline 10 & 77.9 & 19.1 & 0.1 & 2.6 & 0.0 & 0.3 \\
\hline 20 & 76.7 & 19.9 & 0.1 & 2.9 & 0.0 & 0.4 \\
\hline 30 & 76.6 & 20.0 & 0.1 & 2.9 & 0.0 & 0.5 \\
\hline 35 & 77.6 & 19.2 & 0.1 & 2.7 & 0.0 & 0.4 \\
\hline 40 & 75.9 & 20.1 & 0.3 & 3.0 & 0.2 & 0.6 \\
\hline
\end{tabular}




\begin{tabular}{|c|c|c|c|c|c|c|}
\hline 45 & 81.5 & 16.3 & 0.0 & 1.9 & 0.0 & 0.2 \\
\hline 50 & 78.1 & 18.9 & 0.2 & 2.3 & 0.1 & 0.5 \\
\hline 60 & 78.9 & 18.4 & 0.1 & 1.7 & 0.1 & 0.7 \\
\hline 70 & 72.3 & 21.6 & 1.4 & 2.3 & 0.8 & 1.6 \\
\hline 80 & 84.1 & 15.2 & 0.0 & 0.1 & 0.0 & 0.6 \\
\hline Residue & 83.1 & 16.5 & 0.0 & 0.0 & 0.0 & 0.4 \\
\hline
\end{tabular}

Table 19b: 50/50 S-8/Jet-A:

\begin{tabular}{|c|c|c|c|c|c|c|}
\hline $\begin{array}{c}\text { Distillate } \\
\text { Volume } \\
\begin{array}{c}\text { Fraction, } \\
\%\end{array}\end{array}$ & Paraffins & $\begin{array}{c}\text { Monocyclo- } \\
\text { paraffins }\end{array}$ & $\begin{array}{c}\text { Dicyclo- } \\
\text { paraffins }\end{array}$ & $\begin{array}{c}\text { Alkyl- } \\
\text { aromatics }\end{array}$ & $\begin{array}{c}\text { Indanes } \\
\text { and } \\
\text { Tetralins } \\
\text { Vol \% }\end{array}$ & $\begin{array}{c}\text { Naphth- } \\
\text { alenes }\end{array}$ \\
\hline composite & 56.4 & 23.5 & 6.1 & 8.8 & 3.0 & 2.3 \\
\hline 0.025 & 66.7 & 22.9 & 0.4 & 9.6 & 0.0 & 0.3 \\
\hline 10 & 67.9 & 23.3 & 0.5 & 7.8 & 0.2 & 0.4 \\
\hline 20 & 68.9 & 22.3 & 0.5 & 7.7 & 0.2 & 0.4 \\
\hline 30 & 70.6 & 20.9 & 0.3 & 7.4 & 0.3 & 0.5 \\
\hline 35 & 70.8 & 20.9 & 0.4 & 7.1 & 0.3 & 0.4 \\
\hline 40 & 71.3 & 20.5 & 0.4 & 6.8 & 0.4 & 0.6 \\
\hline 45 & 73.2 & 19.3 & 0.3 & 6.4 & 0.3 & 0.5 \\
\hline 50 & 71.9 & 20.0 & 0.4 & 6.2 & 0.8 & 0.8 \\
\hline 60 & 70.4 & 21.7 & 0.6 & 5.2 & 1.1 & 1.0 \\
\hline 70 & 73.1 & 20.9 & 0.4 & 3.4 & 1.0 & 1.2 \\
\hline 80 & 76.9 & 19.4 & 0.1 & 1.5 & 0.9 & 1.2 \\
\hline Residue & 72.3 & 25.9 & 0.3 & 0.2 & 0.1 & 1.2 \\
\hline
\end{tabular}

Table 19c: $25 / 75$ S-8/Jet-A:

\begin{tabular}{|c|c|c|c|c|c|c|}
\hline $\begin{array}{c}\text { Distillate } \\
\text { Volume } \\
\begin{array}{c}\text { Fraction, } \\
\%\end{array}\end{array}$ & Paraffins & $\begin{array}{c}\text { Monocyclo- } \\
\text { paraffins }\end{array}$ & $\begin{array}{c}\text { Dicyclo- } \\
\text { paraffins }\end{array}$ & $\begin{array}{c}\text { Alkyl- } \\
\text { aromatics }\end{array}$ & $\begin{array}{c}\text { Indanes } \\
\text { and } \\
\text { Tetralins } \\
\text { Vol \% }\end{array}$ & $\begin{array}{c}\text { Naphth- } \\
\text { alenes }\end{array}$ \\
\hline composite & 48.1 & 25.6 & 8.5 & 11.3 & 4.2 & 2.5 \\
\hline 0.025 & 56.2 & 26.5 & 1.3 & 15.3 & 0.4 & 0.3 \\
\hline 10 & 56.7 & 25.1 & 1.5 & 15.5 & 0.7 & 0.5 \\
\hline 20 & 60.9 & 22.3 & 0.7 & 15.2 & 0.5 & 0.5 \\
\hline 30 & 56.7 & 24.6 & 1.8 & 14.5 & 1.6 & 0.8 \\
\hline 35 & 58.1 & 23.9 & 1.5 & 14.1 & 1.6 & 0.8 \\
\hline 40 & 57.0 & 24.9 & 1.9 & 13.3 & 1.9 & 1.0 \\
\hline 45 & 59.9 & 23.6 & 1.2 & 12.4 & 1.8 & 1.1 \\
\hline 50 & 60.7 & 23.4 & 1.3 & 11.5 & 1.9 & 1.2 \\
\hline 60 & 65.5 & 21.5 & 0.6 & 8.9 & 2.1 & 1.4 \\
\hline 70 & 62.4 & 24.9 & 1.3 & 6.9 & 2.6 & 1.9 \\
\hline 80 & 59.9 & 27.1 & 2.7 & 4.9 & 3.0 & 2.4 \\
\hline Residue & & & & & & \\
\hline
\end{tabular}


Table 19d: Jet-A 4658:

\begin{tabular}{|c|c|c|c|c|c|c|}
\hline $\begin{array}{c}\text { Distillate } \\
\text { Volume } \\
\begin{array}{c}\text { Fraction, } \\
\%\end{array}\end{array}$ & Paraffins & $\begin{array}{c}\text { Monocyclo- } \\
\text { paraffins }\end{array}$ & $\begin{array}{c}\text { Dicyclo- } \\
\text { paraffins }\end{array}$ & $\begin{array}{c}\text { Alkyl- } \\
\text { aromatics }\end{array}$ & $\begin{array}{c}\text { Indanes } \\
\text { and } \\
\text { Tetralins } \\
\text { Vol \% }\end{array}$ & $\begin{array}{c}\text { Naphth- } \\
\text { alenes }\end{array}$ \\
\hline composite & 46.5 & 22.5 & 5.4 & 18.4 & 4.5 & 2.4 \\
\hline 0.025 & 40.4 & 27.3 & 3.4 & 27.3 & 1.2 & 0.5 \\
\hline 10 & 39.8 & 25.1 & 4.5 & 27.2 & 2.6 & 0.8 \\
\hline 20 & 41.2 & 24.6 & 4.4 & 25.6 & 3.1 & 1.1 \\
\hline 30 & 40.9 & 25.2 & 5.8 & 22.1 & 4.3 & 1.6 \\
\hline 35 & 43.2 & 24.5 & 4.3 & 21.9 & 4.2 & 1.8 \\
\hline 40 & 43.3 & 25.3 & 4.8 & 20.0 & 4.6 & 2.0 \\
\hline 45 & 41.7 & 25.9 & 6.4 & 18.7 & 5.0 & 2.3 \\
\hline 50 & 42.9 & 25.8 & 5.6 & 18.1 & 5.1 & 2.4 \\
\hline 60 & 43.1 & 26.4 & 6.7 & 15.0 & 5.9 & 2.9 \\
\hline 70 & 43.8 & 27.1 & 7.4 & 11.8 & 6.3 & 3.6 \\
\hline 80 & 48.7 & 29.9 & 7.0 & 6.3 & 4.6 & 3.3 \\
\hline Residue & 49.7 & 31.9 & 7.0 & 3.4 & 3.4 & 4.5 \\
\hline
\end{tabular}



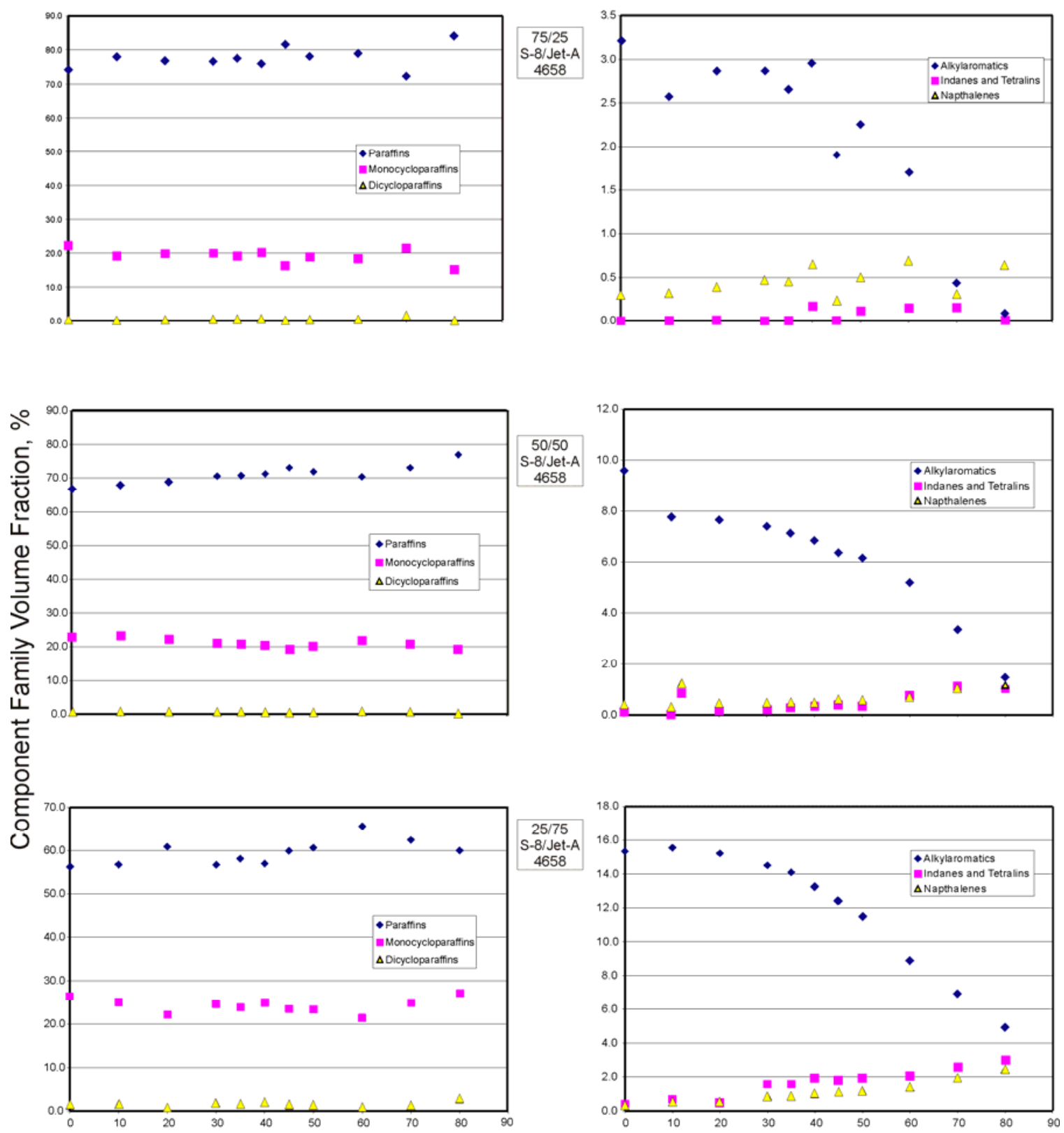

Distillate Volume Fraction, \%

Figure 28: A plot of the hydrocarbon types resulting from the ASTM D-2789 analysis performed on three mixtures of Jet-A-4658 and S-8. The left side of the figure presents the aliphatic constituents, while the right side presents the cyclic constituents. The uncertainties are discussed in the text. 
Density Measurements of Compressed Liquid Jet-A, JP-8 and S-8:

The apparatus described earlier ${ }^{8}$ for the compressed liquid density measurements on methyl- and propylcyclohexane was used to measure the compressed liquid density for Jet-A, JP- 8 and S- $8 .{ }^{34}$ these measurements were made over the temperature range of 270 $\mathrm{K}$ to $470 \mathrm{~K}$ and pressures to $50 \mathrm{MPa}$. We present these measurements in Tables $20-24$, and Figures 29 - 33, which follow. Tables list compressed liquid densities of Jet-A-3602, Jet-A-3638 and Jet-A-4658, JP-8-3773 and S-8, respectively. The density measurements have an estimated uncertainty of $1.0 \mathrm{~kg} / \mathrm{m}^{3}$ which includes the uncertainty in temperature $0.03 \mathrm{~K}$ and pressure $0.01 \mathrm{MPa}$.

Table 20: Compressed liquid densities of Jet-A-3602

$\begin{array}{cccccc}\text { Temperature } & \text { Pressure } & \begin{array}{c}\text { Density } \\ {[\mathrm{K}]}\end{array} & \begin{array}{c}\text { Temperature } \\ {[\mathrm{MPa}]}\end{array} & \begin{array}{c}\text { Pressure } \\ {\left[\mathrm{kg} / \mathrm{m}^{3}\right]}\end{array} & \begin{array}{c}\text { Density } \\ {\left[\mathrm{Kg} / \mathrm{m}^{3}\right]}\end{array} \\ 270.00 & 30.770 & 850.67 & 350.00 & 4.478 & 779.05 \\ 270.00 & 25.606 & 848.05 & 350.00 & 3.281 & 777.97 \\ 270.00 & 20.663 & 845.45 & 350.00 & 2.206 & 776.98 \\ 270.00 & 15.925 & 842.88 & 350.00 & 1.095 & 775.96 \\ 270.00 & 11.308 & 840.33 & 350.00 & 0.555 & 775.45 \\ 270.00 & 6.061 & 837.34 & 370.00 & 31.929 & 787.77 \\ 270.00 & 4.923 & 836.67 & 370.00 & 25.704 & 783.1 \\ 270.00 & 3.742 & 835.97 & 370.00 & 20.960 & 779.32 \\ 270.00 & 2.518 & 835.23 & 370.00 & 16.114 & 775.28 \\ 270.00 & 1.319 & 834.5 & 370.00 & 11.021 & 770.78 \\ 290.00 & 31.570 & 838.62 & 370.00 & 5.488 & 765.55 \\ 290.00 & 25.590 & 835.32 & 370.00 & 4.354 & 764.42 \\ 290.00 & 20.646 & 832.51 & 370.00 & 3.228 & 763.26 \\ 290.00 & 15.967 & 829.77 & 370.00 & 2.162 & 762.17 \\ 290.00 & 11.244 & 826.91 & 370.00 & 1.090 & 761.05 \\ 290.00 & 5.974 & 823.62 & 370.00 & 0.589 & 760.53 \\ 290.00 & 4.779 & 822.84 & 390.00 & 31.808 & 775.21 \\ 290.00 & 3.597 & 822.07 & 390.00 & 25.736 & 770.24 \\ 290.00 & 2.423 & 821.3 & 390.00 & 21.012 & 766.14 \\ 310.00 & 31.934 & 826.25 & 390.00 & 16.082 & 761.61 \\ 310.00 & 25.572 & 822.48 & 390.00 & 10.876 & 756.53 \\ 310.00 & 20.758 & 819.48 & 390.00 & 5.410 & 750.78 \\ 310.00 & 16.002 & 816.47 & 390.00 & 4.277 & 749.52 \\ 310.00 & 11.259 & 813.25 & 390.00 & 3.239 & 748.33 \\ 310.00 & 5.758 & 809.31 & 390.00 & 2.163 & 747.09 \\ 310.00 & 4.674 & 808.51 & 390.00 & 1.255 & 746.02 \\ 310.00 & 3.500 & 807.64 & 390.00 & 0.659 & 745.28 \\ 310.00 & 2.304 & 806.68 & 410.00 & 31.747 & 762.63 \\ 310.00 & 1.720 & 806.26 & 410.00 & 25.841 & 757.38 \\ 330.00 & 31.638 & 812.73 & 410.00 & 21.034 & 752.82 \\ 330.00 & 25.593 & 808.76 & 410.00 & 16.035 & 747.76\end{array}$




\begin{tabular}{|c|c|c|c|c|c|}
\hline 330.00 & 20.805 & 805.48 & 410.00 & 10.778 & 742.08 \\
\hline 330.00 & 16.082 & 802.16 & 410.00 & 5.328 & 735.65 \\
\hline 330.00 & 11.178 & 798.57 & 410.00 & 4.280 & 734.33 \\
\hline 330.00 & 5.765 & 794.42 & 410.00 & 3.214 & 732.96 \\
\hline 330.00 & 4.589 & 793.49 & 410.00 & 2.188 & 731.62 \\
\hline 330.00 & 3.413 & 792.51 & 410.00 & 1.192 & 730.3 \\
\hline 330.00 & 2.261 & 791.6 & 430.00 & 31.659 & 749.98 \\
\hline 330.00 & 1.117 & 790.66 & 430.00 & 25.868 & 744.41 \\
\hline 330.00 & 0.541 & 790.17 & 430.00 & 21.038 & 739.44 \\
\hline 330.00 & 31.638 & 812.73 & 430.00 & 15.970 & 733.81 \\
\hline 330.00 & 25.593 & 808.76 & 430.00 & 10.651 & 727.39 \\
\hline 330.00 & 20.805 & 805.48 & 430.00 & 5.308 & 720.29 \\
\hline 330.00 & 16.082 & 802.16 & 430.00 & 4.261 & 718.79 \\
\hline 330.00 & 11.178 & 798.57 & 430.00 & 3.256 & 717.32 \\
\hline 330.00 & 5.765 & 794.42 & 430.00 & 2.238 & 715.8 \\
\hline 330.00 & 4.589 & 793.49 & 430.00 & 1.268 & 714.32 \\
\hline 330.00 & 3.413 & 792.51 & 450.00 & 31.665 & 737.5 \\
\hline 330.00 & 2.261 & 791.6 & 450.00 & 25.929 & 731.48 \\
\hline 330.00 & 1.117 & 790.66 & 450.00 & 21.027 & 725.93 \\
\hline 330.00 & 0.541 & 790.17 & 450.00 & 15.895 & 719.64 \\
\hline 330.00 & 31.754 & 812.44 & 450.00 & 10.572 & 712.47 \\
\hline 330.00 & 25.641 & 808.49 & 450.00 & 5.322 & 704.58 \\
\hline 330.00 & 20.858 & 805.25 & 450.00 & 4.325 & 702.96 \\
\hline 330.00 & 16.096 & 801.93 & 450.00 & 3.330 & 701.3 \\
\hline 330.00 & 11.218 & 798.35 & 450.00 & 2.348 & 699.62 \\
\hline 330.00 & 5.762 & 794.14 & 450.00 & 1.337 & 697.84 \\
\hline 330.00 & 4.609 & 793.21 & 470.00 & 31.633 & 725.24 \\
\hline 330.00 & 3.479 & 792.29 & 470.00 & 26.007 & 718.83 \\
\hline 330.00 & 2.315 & 791.32 & 470.00 & 20.979 & 712.57 \\
\hline 330.00 & 1.147 & 790.36 & 470.00 & 15.846 & 705.6 \\
\hline 330.00 & 0.599 & 789.91 & 470.00 & 10.523 & 697.56 \\
\hline 350.00 & 32.101 & 800.44 & 470.00 & 5.390 & 688.79 \\
\hline 350.00 & 25.629 & 795.91 & 470.00 & 4.388 & 686.91 \\
\hline 350.00 & 20.879 & 792.4 & 470.00 & 3.404 & 685.03 \\
\hline 350.00 & 16.081 & 788.74 & 470.00 & 2.407 & 683.05 \\
\hline 350.00 & 11.105 & 784.74 & 470.00 & 1.434 & 681.07 \\
\hline 350.00 & 5.598 & 780.05 & & & \\
\hline
\end{tabular}

Table 21: Compressed liquid densities of Jet-A-3638

$\begin{array}{cccccc}\begin{array}{c}\text { Temperature } \\ {[\mathrm{K}]}\end{array} & \begin{array}{c}\text { Pressure } \\ {[\mathrm{MPa}]}\end{array} & \begin{array}{c}\text { Density } \\ {\left[\mathrm{kg} / \mathrm{m}^{3}\right]}\end{array} & \begin{array}{c}\text { Temperature } \\ {[\mathrm{K}]}\end{array} & \begin{array}{c}\text { Pressure } \\ {[\mathrm{MPa}]}\end{array} & \begin{array}{c}\text { Density } \\ {\left[\mathrm{kg} / \mathrm{m}^{3}\right]}\end{array} \\ 270.00 & 30.045 & 827.22 & 370.00 & 5.088 & 740.92 \\ 270.00 & 25.104 & 824.61 & 370.00 & 4.066 & 739.86 \\ 270.00 & 20.148 & 821.94 & 370.00 & 3.048 & 738.73\end{array}$




\begin{tabular}{|c|c|c|c|c|c|}
\hline 270.00 & 15.155 & 819.16 & 370.00 & 2.027 & 737.62 \\
\hline 270.00 & 10.128 & 816.28 & 370.00 & 1.006 & 736.51 \\
\hline 270.00 & 5.058 & 813.27 & 390.00 & 30.017 & 750.57 \\
\hline 270.00 & 4.043 & 812.66 & 390.00 & 25.082 & 746.29 \\
\hline 270.00 & 3.019 & 812.03 & 390.00 & 20.133 & 741.78 \\
\hline 270.00 & 1.994 & 811.40 & 390.00 & 15.156 & 736.95 \\
\hline 270.00 & 0.971 & 810.76 & 390.00 & 10.141 & 731.75 \\
\hline 290.00 & 30.076 & 814.46 & 390.00 & 5.075 & 726.09 \\
\hline 290.00 & 25.140 & 811.64 & 390.00 & 4.062 & 724.89 \\
\hline 290.00 & 20.184 & 808.73 & 390.00 & 3.047 & 723.67 \\
\hline 290.00 & 15.201 & 805.71 & 390.00 & 2.027 & 722.43 \\
\hline 290.00 & 10.175 & 802.55 & 390.00 & 1.006 & 721.17 \\
\hline 290.00 & 5.109 & 799.24 & 410.00 & 30.020 & 738.07 \\
\hline 290.00 & 4.093 & 798.55 & 410.00 & 25.080 & 733.42 \\
\hline 290.00 & 3.072 & 797.86 & 410.00 & 20.128 & 728.48 \\
\hline 290.00 & 2.050 & 797.16 & 410.00 & 15.147 & 723.16 \\
\hline 290.00 & 1.028 & 796.45 & 410.00 & 10.131 & 717.38 \\
\hline 310.00 & 30.079 & 801.81 & 410.00 & 5.066 & 711.01 \\
\hline 310.00 & 25.134 & 798.75 & 410.00 & 4.050 & 709.64 \\
\hline 310.00 & 20.174 & 795.57 & 410.00 & 3.029 & 708.24 \\
\hline 310.00 & 15.187 & 792.26 & 410.00 & 2.008 & 706.81 \\
\hline 310.00 & 10.159 & 788.77 & 410.00 & 0.985 & 705.36 \\
\hline 310.00 & 5.090 & 785.07 & 430.00 & 30.008 & 725.40 \\
\hline 310.00 & 4.075 & 784.30 & 430.00 & 25.067 & 720.35 \\
\hline 310.00 & 3.053 & 783.51 & 430.00 & 20.112 & 714.93 \\
\hline 310.00 & 2.031 & 782.73 & 430.00 & 15.129 & 709.05 \\
\hline 310.00 & 1.009 & 781.93 & 430.00 & 10.111 & 702.59 \\
\hline 330.00 & 30.043 & 788.77 & 430.00 & 5.049 & 695.38 \\
\hline 330.00 & 25.110 & 785.43 & 430.00 & 4.028 & 693.82 \\
\hline 330.00 & 20.156 & 781.94 & 430.00 & 3.009 & 692.23 \\
\hline 330.00 & 15.172 & 778.28 & 430.00 & 1.984 & 690.59 \\
\hline 330.00 & 10.148 & 774.42 & 430.00 & 0.960 & 688.90 \\
\hline 330.00 & 5.084 & 770.34 & 450.00 & 29.957 & 712.75 \\
\hline 330.00 & 4.069 & 769.48 & 450.00 & 25.019 & 707.25 \\
\hline 330.00 & 3.050 & 768.61 & 450.00 & 20.073 & 701.31 \\
\hline 330.00 & 2.031 & 767.74 & 450.00 & 15.096 & 694.80 \\
\hline 330.00 & 1.010 & 766.85 & 450.00 & 10.079 & 687.56 \\
\hline 350.00 & 30.055 & 775.92 & 450.00 & 5.020 & 679.37 \\
\hline 350.00 & 25.118 & 772.28 & 450.00 & 4.003 & 677.59 \\
\hline 350.00 & 20.163 & 768.48 & 450.00 & 2.985 & 675.74 \\
\hline 350.00 & 15.181 & 764.48 & 450.00 & 1.964 & 673.84 \\
\hline 350.00 & 10.159 & 760.23 & 450.00 & 0.939 & 671.87 \\
\hline 350.00 & 5.092 & 755.70 & 470.00 & 29.936 & 700.26 \\
\hline
\end{tabular}




$\begin{array}{lccccc}350.00 & 4.073 & 754.74 & 470.00 & 25.002 & 694.28 \\ 350.00 & 3.059 & 753.78 & 470.00 & 20.051 & 687.75 \\ 350.00 & 2.037 & 752.80 & 470.00 & 15.078 & 680.53 \\ 350.00 & 1.017 & 751.81 & 470.00 & 10.062 & 672.39 \\ 370.00 & 30.053 & 763.11 & 470.00 & 4.997 & 662.99 \\ 370.00 & 25.114 & 759.16 & 470.00 & 3.981 & 660.92 \\ 370.00 & 20.159 & 755.03 & 470.00 & 2.957 & 658.76 \\ 370.00 & 15.176 & 750.65 & 470.00 & 1.941 & 656.54 \\ 370.00 & 10.157 & 745.98 & 470.00 & 0.922 & 654.23\end{array}$

Table 22: Compressed liquid densities of Jet-A-4658

$\begin{array}{cccccc}\text { Temperature } & \text { Pressure } & \text { Density } & \text { Temperature } & \text { Pressure } & \text { Density } \\ {[\mathrm{K}]} & {[\mathrm{MPa}]} & {\left[\mathrm{kg} / \mathrm{m}^{3}\right]} & {[\mathrm{K}]} & {[\mathrm{MPa}]} & {\left[\mathrm{kg} / \mathrm{m}^{3}\right]} \\ 270.00 & 30.015 & 837.52 & 370.00 & 4.010 & 751.72 \\ 270.00 & 25.010 & 834.93 & 370.00 & 3.011 & 750.70 \\ 270.00 & 20.002 & 832.28 & 370.00 & 2.006 & 749.66 \\ 270.00 & 15.007 & 829.56 & 370.00 & 1.013 & 748.61 \\ 270.00 & 10.007 & 826.76 & 370.00 & 0.499 & 748.06 \\ 270.00 & 4.999 & 823.86 & 390.00 & 30.008 & 761.81 \\ 270.00 & 4.010 & 823.27 & 390.00 & 25.012 & 757.62 \\ 270.00 & 2.999 & 822.67 & 390.00 & 20.018 & 753.21 \\ 270.00 & 2.005 & 822.07 & 390.00 & 15.007 & 748.52 \\ 270.00 & 1.007 & 821.46 & 390.00 & 10.009 & 743.54 \\ 270.00 & 0.508 & 821.16 & 390.00 & 5.007 & 738.18 \\ 290.00 & 30.001 & 824.78 & 390.00 & 4.008 & 737.05 \\ 290.00 & 25.002 & 822.00 & 390.00 & 3.008 & 735.91 \\ 290.00 & 19.999 & 819.11 & 390.00 & 2.001 & 734.74 \\ 290.00 & 15.002 & 816.15 & 390.00 & 1.009 & 733.55 \\ 290.00 & 10.004 & 813.08 & 390.00 & 0.503 & 732.93 \\ 290.00 & 5.005 & 809.92 & 410.00 & 30.004 & 749.32 \\ 290.00 & 4.005 & 809.26 & 410.00 & 25.012 & 744.75 \\ 290.00 & 3.009 & 808.60 & 410.00 & 20.013 & 739.94 \\ 290.00 & 2.009 & 807.94 & 410.00 & 15.000 & 734.79 \\ 290.00 & 1.010 & 807.27 & 410.00 & 10.009 & 729.27 \\ 290.00 & 0.507 & 806.93 & 410.00 & 5.007 & 723.26 \\ 310.00 & 30.013 & 811.77 & 410.00 & 4.008 & 721.99 \\ 310.00 & 25.011 & 808.70 & 410.00 & 3.008 & 720.69 \\ 310.00 & 20.013 & 805.54 & 410.00 & 2.002 & 719.37 \\ 310.00 & 15.010 & 802.27 & 410.00 & 1.013 & 718.05 \\ 310.00 & 10.009 & 798.88 & 410.00 & 0.516 & 717.36 \\ 310.00 & 5.006 & 795.34 & 430.00 & 29.999 & 736.86 \\ 310.00 & 3.999 & 794.61 & 430.00 & 25.007 & 731.93 \\ 310.00 & 3.006 & 793.87 & 430.00 & 20.009 & 726.68 \\ 310.00 & 2.009 & 793.13 & 430.00 & 15.005 & 721.00\end{array}$




\begin{tabular}{|c|c|c|c|c|c|}
\hline 310.00 & 1.009 & 792.38 & 430.00 & 10.023 & 714.88 \\
\hline 310.00 & 0.508 & 792.00 & 430.00 & 5.012 & 708.11 \\
\hline 330.00 & 29.999 & 799.02 & 430.00 & 4.017 & 706.66 \\
\hline 330.00 & 25.010 & 795.71 & 430.00 & 3.004 & 705.17 \\
\hline 330.00 & 20.007 & 792.28 & 430.00 & 2.010 & 703.68 \\
\hline 330.00 & 15.012 & 788.72 & 430.00 & 1.012 & 702.13 \\
\hline 330.00 & 10.013 & 784.99 & 430.00 & 0.508 & 701.34 \\
\hline 330.00 & 5.006 & 781.09 & 450.00 & 29.996 & 724.54 \\
\hline 330.00 & 4.015 & 780.29 & 450.00 & 25.003 & 719.19 \\
\hline 330.00 & 3.008 & 779.48 & 450.00 & 20.006 & 713.44 \\
\hline 330.00 & 2.005 & 778.65 & 450.00 & 15.002 & 707.18 \\
\hline 330.00 & 1.014 & 777.81 & 450.00 & 10.002 & 700.31 \\
\hline 330.00 & 0.513 & 777.39 & 450.00 & 5.018 & 692.70 \\
\hline 350.00 & 29.995 & 786.59 & 450.00 & 4.002 & 691.02 \\
\hline 350.00 & 25.009 & 783.03 & 450.00 & 3.010 & 689.34 \\
\hline 350.00 & 20.013 & 779.32 & 450.00 & 2.013 & 687.61 \\
\hline 350.00 & 15.006 & 775.43 & 450.00 & 1.006 & 685.81 \\
\hline 350.00 & 10.005 & 771.34 & 450.00 & 0.508 & 684.89 \\
\hline 350.00 & 5.012 & 767.03 & 470.00 & 29.993 & 712.33 \\
\hline 350.00 & 4.010 & 766.12 & 470.00 & 25.002 & 706.52 \\
\hline 350.00 & 3.005 & 765.20 & 470.00 & 20.012 & 700.22 \\
\hline 350.00 & 2.007 & 764.28 & 470.00 & 15.020 & 693.32 \\
\hline 350.00 & 1.005 & 763.34 & 470.00 & 10.016 & 685.63 \\
\hline 350.00 & 0.504 & 762.87 & 470.00 & 5.005 & 676.93 \\
\hline 370.00 & 30.005 & 774.22 & 470.00 & 4.002 & 675.03 \\
\hline 370.00 & 25.011 & 770.35 & 470.00 & 3.001 & 673.07 \\
\hline 370.00 & 20.009 & 766.29 & 470.00 & 2.008 & 671.06 \\
\hline 370.00 & 15.010 & 762.03 & 470.00 & 1.014 & 668.98 \\
\hline 370.00 & 10.015 & 757.53 & 470.00 & 0.514 & 667.89 \\
\hline 370.00 & 5.007 & 752.72 & & & \\
\hline
\end{tabular}

Table 23: Compressed-liquid densities of JP-8-3773

$\begin{array}{cccccc}\begin{array}{c}\text { Temperature } \\ {[\mathrm{K}]}\end{array} & \begin{array}{c}\text { Pressure } \\ {[\mathrm{MPa}]}\end{array} & \begin{array}{c}\text { Density } \\ {\left[\mathrm{kg} / \mathrm{m}^{3}\right]}\end{array} & \begin{array}{c}\text { Temperature } \\ {[\mathrm{K}]}\end{array} & \begin{array}{c}\text { Pressure } \\ {[\mathrm{MPa}]}\end{array} & \begin{array}{c}\text { Density } \\ {\left[\mathrm{kg} / \mathrm{m}^{3}\right]}\end{array} \\ 270.0 & 39.99 & 833.2 & 330.0 & 5.01 & 771.1 \\ 270.0 & 35.00 & 830.8 & 330.0 & 4.00 & 770.3 \\ 270.0 & 30.00 & 828.2 & 330.0 & 2.99 & 769.4 \\ 270.0 & 24.99 & 825.6 & 330.0 & 1.99 & 768.6 \\ 270.0 & 20.00 & 823.0 & 330.0 & 1.00 & 767.7 \\ 270.0 & 15.00 & 820.2 & 330.0 & 0.49 & 767.2 \\ 270.0 & 10.00 & 817.4 & 350.0 & 40.00 & 783.9 \\ 270.0 & 4.99 & 814.4 & 350.0 & 35.00 & 780.5 \\ 270.0 & 3.99 & 813.8 & 350.0 & 30.00 & 777.0 \\ 270.0 & 3.00 & 813.2 & 350.0 & 25.00 & 773.3\end{array}$




\begin{tabular}{|c|c|c|c|c|c|}
\hline 270.0 & 1.99 & 812.6 & 350.0 & 19.99 & 769.5 \\
\hline 270.0 & 1.01 & 812.0 & 350.0 & 15.00 & 765.5 \\
\hline 270.0 & 0.50 & 811.6 & 350.0 & 9.99 & 761.2 \\
\hline 290.0 & 39.97 & 821.0 & 350.0 & 5.00 & 756.7 \\
\hline 290.0 & 35.00 & 818.3 & 350.0 & 3.99 & 755.8 \\
\hline 290.0 & 30.00 & 815.6 & 350.0 & 2.99 & 754.8 \\
\hline 290.0 & 24.98 & 812.7 & 350.0 & 2.00 & 753.9 \\
\hline 290.0 & 20.00 & 809.8 & 350.0 & 1.01 & 752.9 \\
\hline 290.0 & 15.00 & 806.8 & 350.0 & 0.50 & 752.4 \\
\hline 290.0 & 9.99 & 803.7 & 370.0 & 40.00 & 771.8 \\
\hline 290.0 & 5.00 & 800.4 & 370.0 & 35.00 & 768.2 \\
\hline 290.0 & 3.99 & 799.7 & 370.0 & 30.00 & 764.4 \\
\hline 290.0 & 3.00 & 799.0 & 370.0 & 24.99 & 760.4 \\
\hline 290.0 & 1.99 & 798.4 & 370.0 & 19.99 & 756.2 \\
\hline 290.0 & 1.00 & 797.7 & 370.0 & 14.99 & 751.7 \\
\hline 290.0 & 0.49 & 797.3 & 370.0 & 10.01 & 747.0 \\
\hline 310.0 & 39.99 & 808.7 & 370.0 & 4.99 & 742.0 \\
\hline 310.0 & 35.00 & 805.7 & 370.0 & 3.99 & 740.9 \\
\hline 310.0 & 29.99 & 802.7 & 370.0 & 2.99 & 739.9 \\
\hline 310.0 & 25.00 & 799.5 & 370.0 & 1.99 & 738.8 \\
\hline 310.0 & 20.00 & 796.2 & 370.0 & 0.99 & 737.7 \\
\hline 310.0 & 14.99 & 792.8 & 370.0 & 0.49 & 737.1 \\
\hline 310.0 & 10.00 & 789.3 & 390.0 & 39.99 & 759.9 \\
\hline 310.0 & 4.99 & 785.7 & 390.0 & 35.00 & 755.9 \\
\hline 310.0 & 4.00 & 784.9 & 390.0 & 29.99 & 751.8 \\
\hline 310.0 & 3.00 & 784.2 & 390.0 & 25.00 & 747.5 \\
\hline 310.0 & 1.99 & 783.4 & 390.0 & 20.00 & 742.9 \\
\hline 310.0 & 1.00 & 782.6 & 390.0 & 14.99 & 738.0 \\
\hline 310.0 & 0.50 & 782.2 & 390.0 & 10.00 & 732.6 \\
\hline 330.0 & 40.00 & 796.0 & 390.0 & 4.99 & 727.0 \\
\hline 330.0 & 35.00 & 792.9 & 390.0 & 4.00 & 725.8 \\
\hline 330.0 & 29.99 & 789.6 & 390.0 & 3.00 & 724.6 \\
\hline 330.0 & 24.99 & 786.2 & 390.0 & 2.00 & 723.4 \\
\hline 330.0 & 19.99 & 782.7 & 390.0 & 1.00 & 722.1 \\
\hline 330.0 & 14.98 & 779.0 & 390.0 & 0.49 & 721.5 \\
\hline 330.0 & 10.00 & 775.2 & 410.0 & 39.99 & 747.9 \\
\hline 410.0 & 35.00 & 743.7 & 450.0 & 34.99 & 719.2 \\
\hline 410.0 & 29.98 & 739.2 & 450.0 & 29.99 & 714.0 \\
\hline 410.0 & 25.01 & 734.5 & 450.0 & 24.99 & 708.4 \\
\hline 410.0 & 20.00 & 729.5 & 450.0 & 19.99 & 702.3 \\
\hline 410.0 & 14.99 & 724.1 & 450.0 & 15.00 & 695.7 \\
\hline 410.0 & 10.00 & 718.2 & 450.0 & 10.00 & 688.4 \\
\hline 410.0 & 4.99 & 711.9 & 450.0 & 5.00 & 680.3 \\
\hline 410.0 & 3.99 & 710.5 & 450.0 & 4.00 & 678.5 \\
\hline 410.0 & 2.99 & 709.1 & 450.0 & 3.00 & 676.7 \\
\hline 410.0 & 1.99 & 707.7 & 450.0 & 1.99 & 674.8 \\
\hline
\end{tabular}




$\begin{array}{lccccc}410.0 & 0.99 & 706.3 & 450.0 & 0.99 & 672.9 \\ 410.0 & 0.49 & 705.5 & 450.0 & 0.49 & 671.9 \\ 430.0 & 39.98 & 736.0 & 470.0 & 40.01 & 712.5 \\ 430.0 & 34.99 & 731.4 & 470.0 & 34.99 & 707.2 \\ 430.0 & 29.99 & 726.6 & 470.0 & 29.99 & 701.5 \\ 430.0 & 25.00 & 721.4 & 470.0 & 24.99 & 695.4 \\ 430.0 & 19.99 & 715.9 & 470.0 & 20.01 & 688.7 \\ 430.0 & 15.00 & 709.9 & 470.0 & 15.00 & 681.4 \\ 430.0 & 10.00 & 703.4 & 470.0 & 9.99 & 673.3 \\ 430.0 & 5.00 & 696.2 & 470.0 & 4.99 & 664.0 \\ 430.0 & 4.00 & 694.7 & 470.0 & 4.00 & 661.9 \\ 430.0 & 2.99 & 693.1 & 470.0 & 2.99 & 659.8 \\ 430.0 & 2.00 & 691.5 & 470.0 & 1.99 & 657.6 \\ 430.0 & 0.99 & 689.9 & 470.0 & 0.99 & 655.3 \\ 430.0 & 0.49 & 689.0 & 470.0 & 0.49 & 654.2 \\ 450.0 & 40.02 & 724.2 & & & \end{array}$

Table 24: Compressed-liquid densities of S-8

$\begin{array}{cccccc}\text { Temperature } & \text { Pressure } & \begin{array}{c}\text { Density } \\ {[\mathrm{K}]}\end{array} & \begin{array}{c}\text { Temperature } \\ {[\mathrm{MPa}]}\end{array} & \begin{array}{c}\text { Pressure } \\ {\left[\mathrm{kg} / \mathrm{m}^{3}\right]}\end{array} & \begin{array}{c}\mathrm{K}] \\ {[\mathrm{MPa}]}\end{array} \\ 270.0 & 30.09 & 786.2 & 330.0 & 1.01 & \begin{array}{c}\text { Density } \\ {\left[\mathrm{kg} / \mathrm{m}^{3}\right]}\end{array} \\ 270.0 & 25.15 & 783.6 & 330.0 & 0.51 & 725.1 \\ 270.0 & 20.20 & 780.9 & 350.0 & 30.01 & 735.5 \\ 270.0 & 15.21 & 778.1 & 350.0 & 25.01 & 731.7 \\ 270.0 & 10.19 & 775.1 & 350.0 & 20.01 & 727.7 \\ 270.0 & 5.12 & 772.1 & 350.0 & 15.00 & 723.5 \\ 270.0 & 4.10 & 771.4 & 350.0 & 10.01 & 719.1 \\ 270.0 & 3.07 & 770.8 & 350.0 & 5.00 & 714.3 \\ 270.0 & 2.05 & 770.1 & 350.0 & 4.01 & 713.4 \\ 270.0 & 1.02 & 769.5 & 350.0 & 3.01 & 712.3 \\ 270.0 & 0.51 & 769.1 & 350.0 & 2.00 & 711.3 \\ 290.0 & 30.04 & 773.6 & 350.0 & 1.01 & 710.3 \\ 290.0 & 25.10 & 770.7 & 350.0 & 0.50 & 709.8 \\ 290.0 & 20.14 & 767.7 & 370.0 & 30.02 & 723.2 \\ 290.0 & 15.15 & 764.6 & 370.0 & 25.02 & 719.0 \\ 290.0 & 10.13 & 761.3 & 370.0 & 20.01 & 714.7 \\ 290.0 & 5.06 & 757.8 & 370.0 & 15.02 & 710.1 \\ 290.0 & 4.05 & 757.1 & 370.0 & 10.00 & 705.1 \\ 290.0 & 3.02 & 756.4 & 370.0 & 5.01 & 699.9 \\ 290.0 & 2.00 & 755.6 & 370.0 & 4.01 & 698.8 \\ 290.0 & 0.97 & 754.9 & 370.0 & 3.01 & 697.6 \\ 290.0 & 0.46 & 754.5 & 370.0 & 2.00 & 696.4 \\ 310.0 & 29.97 & 760.5 & 370.0 & 1.01 & 695.3 \\ 310.0 & 25.03 & 757.3 & 370.0 & 0.50 & 694.7\end{array}$




\begin{tabular}{|c|c|c|c|c|c|}
\hline 310.0 & 20.07 & 754.0 & 390.0 & 30.02 & 711.0 \\
\hline 310.0 & 15.09 & 750.6 & 390.0 & 25.00 & 706.5 \\
\hline 310.0 & 10.07 & 747.0 & 390.0 & 20.01 & 701.7 \\
\hline 310.0 & 5.00 & 743.1 & 390.0 & 15.01 & 696.6 \\
\hline 310.0 & 3.98 & 742.3 & 390.0 & 10.00 & 691.1 \\
\hline 310.0 & 2.96 & 741.5 & 390.0 & 5.00 & 685.2 \\
\hline 310.0 & 1.94 & 740.7 & 390.0 & 4.00 & 683.9 \\
\hline 310.0 & 0.92 & 739.8 & 390.0 & 3.00 & 682.6 \\
\hline 310.0 & 0.40 & 739.4 & 390.0 & 2.01 & 681.3 \\
\hline 310.0 & 2.99 & 741.4 & 390.0 & 1.00 & 680.0 \\
\hline 310.0 & 2.01 & 740.5 & 390.0 & 0.50 & 679.3 \\
\hline 310.0 & 1.01 & 739.7 & 410.0 & 30.01 & 698.7 \\
\hline 310.0 & 0.51 & 739.3 & 410.0 & 25.01 & 693.8 \\
\hline 330.0 & 30.00 & 747.9 & 410.0 & 20.01 & 688.6 \\
\hline 330.0 & 25.01 & 744.4 & 410.0 & 15.00 & 683.0 \\
\hline 330.0 & 20.01 & 740.8 & 410.0 & 10.01 & 676.9 \\
\hline 330.0 & 15.01 & 737.0 & 410.0 & 5.00 & 670.1 \\
\hline 330.0 & 10.01 & 733.0 & 410.0 & 4.00 & 668.7 \\
\hline 330.0 & 5.01 & 728.7 & 410.0 & 3.00 & 667.2 \\
\hline 330.0 & 4.01 & 727.9 & 410.0 & 2.01 & 665.7 \\
\hline 330.0 & 3.01 & 727.0 & 410.0 & 1.00 & 664.1 \\
\hline 330.0 & 2.01 & 726.1 & 410.0 & 0.50 & 663.3 \\
\hline 430.0 & 29.99 & 686.4 & 450.0 & 4.00 & 636.9 \\
\hline 430.0 & 25.02 & 681.1 & 450.0 & 3.00 & 634.9 \\
\hline 430.0 & 20.00 & 675.3 & 450.0 & 2.01 & 632.9 \\
\hline 430.0 & 15.00 & 669.1 & 450.0 & 1.01 & 630.8 \\
\hline 430.0 & 10.01 & 662.2 & 450.0 & 0.50 & 629.7 \\
\hline 430.0 & 5.00 & 654.6 & 470.0 & 30.01 & 662.2 \\
\hline 430.0 & 4.01 & 653.0 & 470.0 & 25.01 & 655.9 \\
\hline 430.0 & 3.01 & 651.3 & 470.0 & 20.01 & 649.0 \\
\hline 430.0 & 2.00 & 649.5 & 470.0 & 15.01 & 641.3 \\
\hline 430.0 & 1.01 & 647.7 & 470.0 & 10.01 & 632.6 \\
\hline 430.0 & 0.49 & 646.8 & 470.0 & 5.01 & 622.7 \\
\hline 450.0 & 30.02 & 674.3 & 470.0 & 4.02 & 620.5 \\
\hline 450.0 & 25.01 & 668.4 & 470.0 & 3.01 & 618.1 \\
\hline 450.0 & 20.02 & 662.1 & 470.0 & 2.00 & 615.7 \\
\hline 450.0 & 15.00 & 655.2 & 470.0 & 1.00 & 613.2 \\
\hline 450.0 & 10.00 & 647.5 & 470.0 & 0.50 & 611.9 \\
\hline 450.0 & 5.01 & 638.8 & & & \\
\hline
\end{tabular}




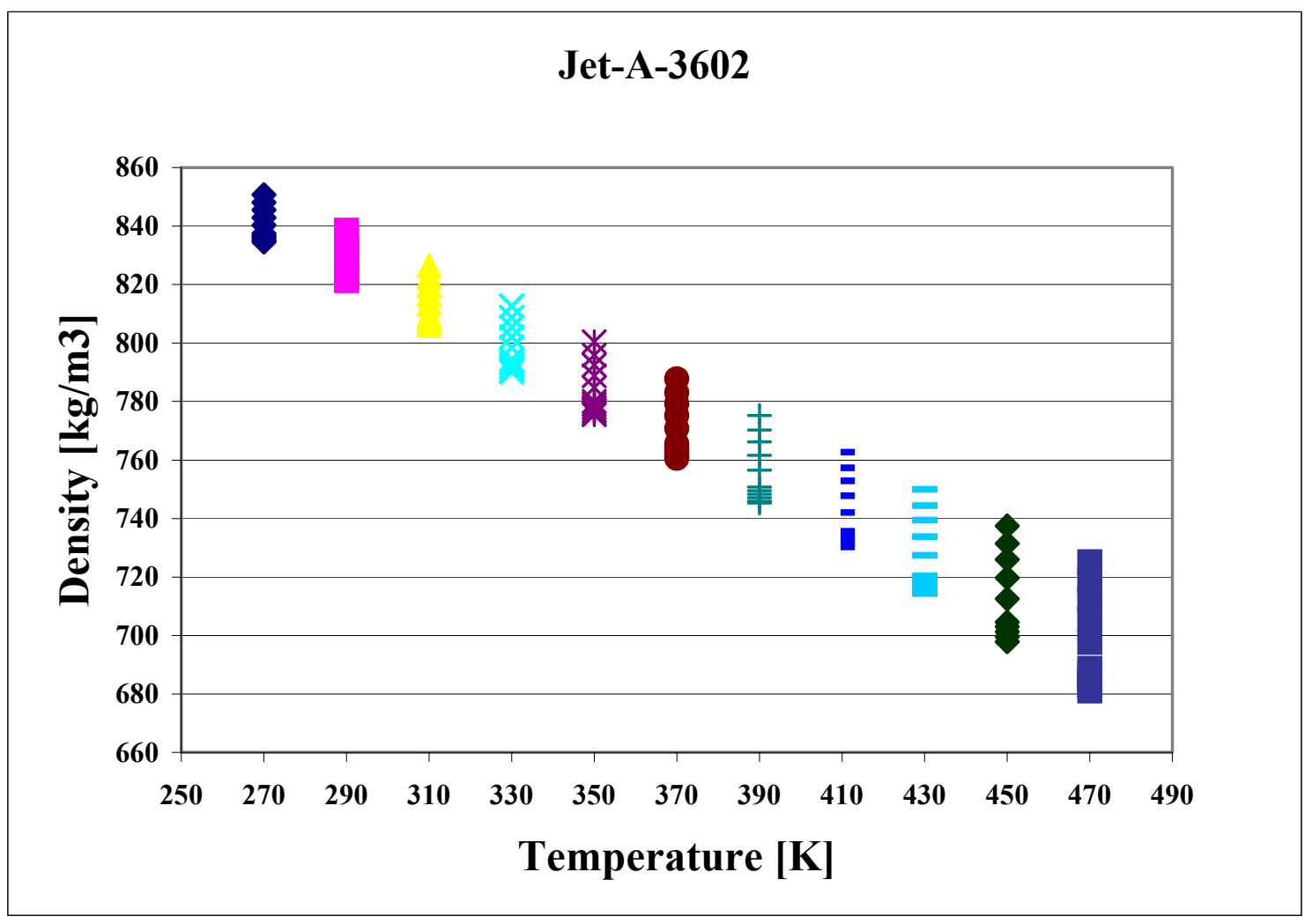

Figure 29: Compressed liquid densities of Jet A-3602. 


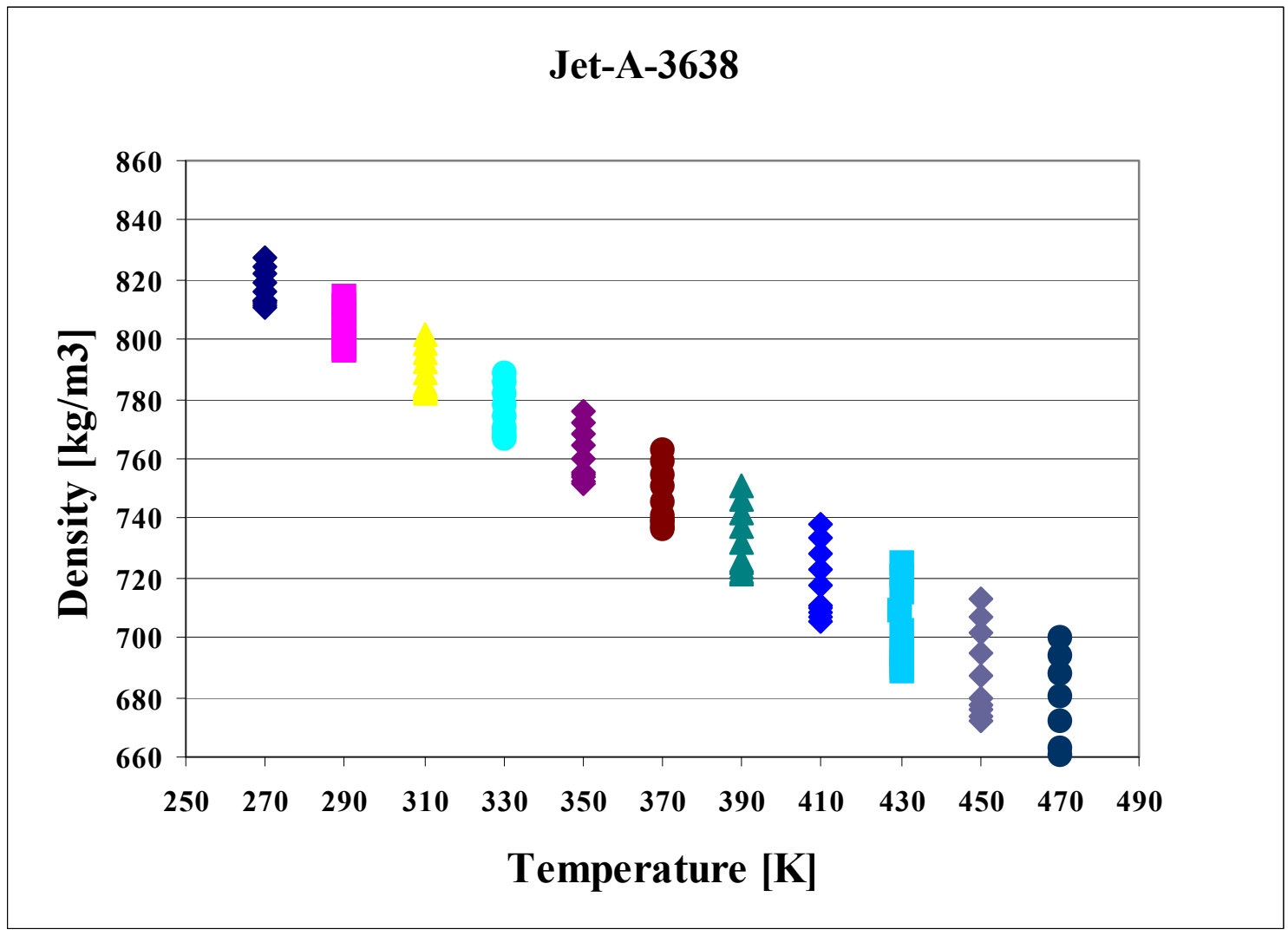

Figure 30: Compressed liquid densities of Jet A-3638. 


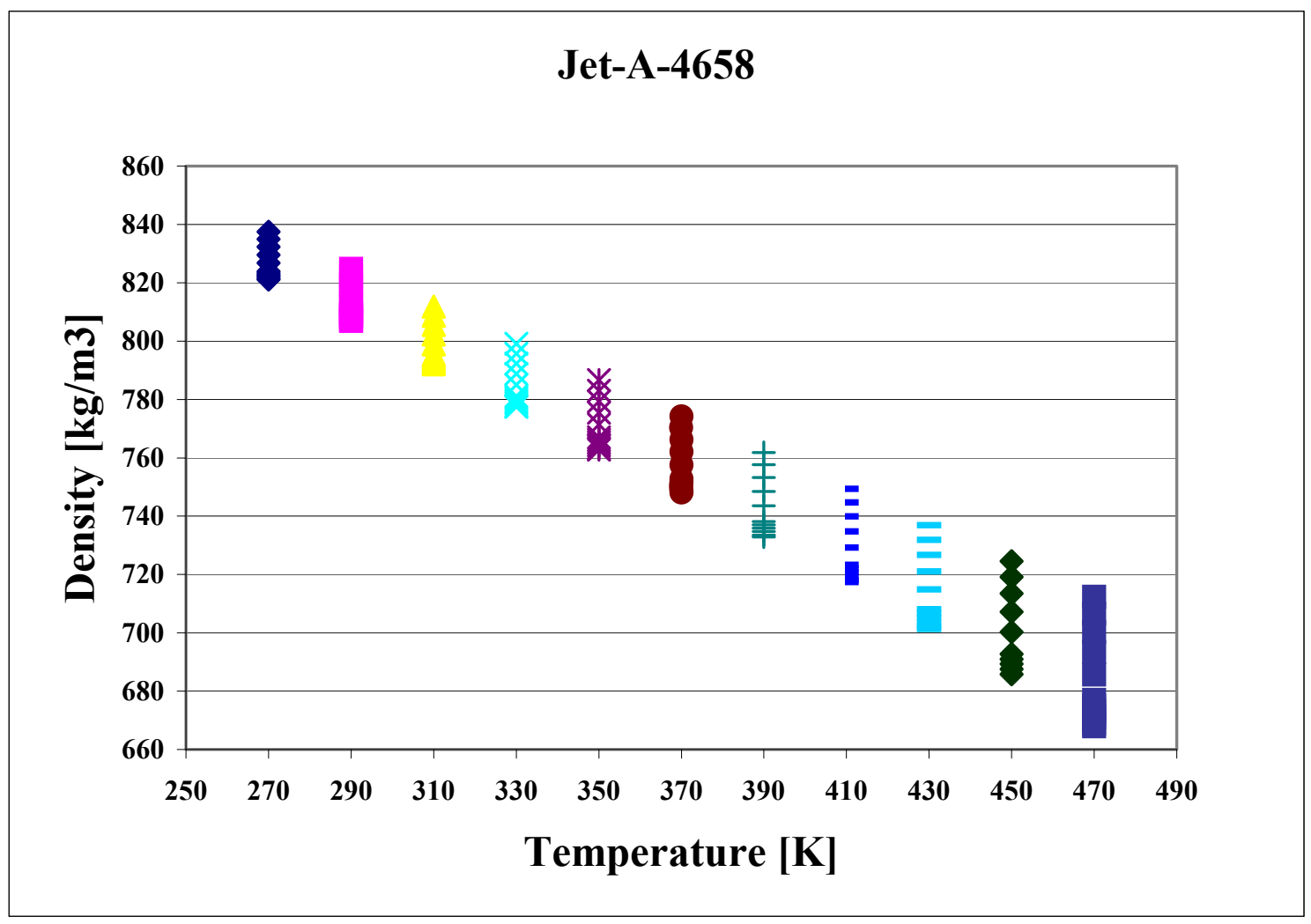

Figure 31: Compressed liquid densities of Jet A-3638. 


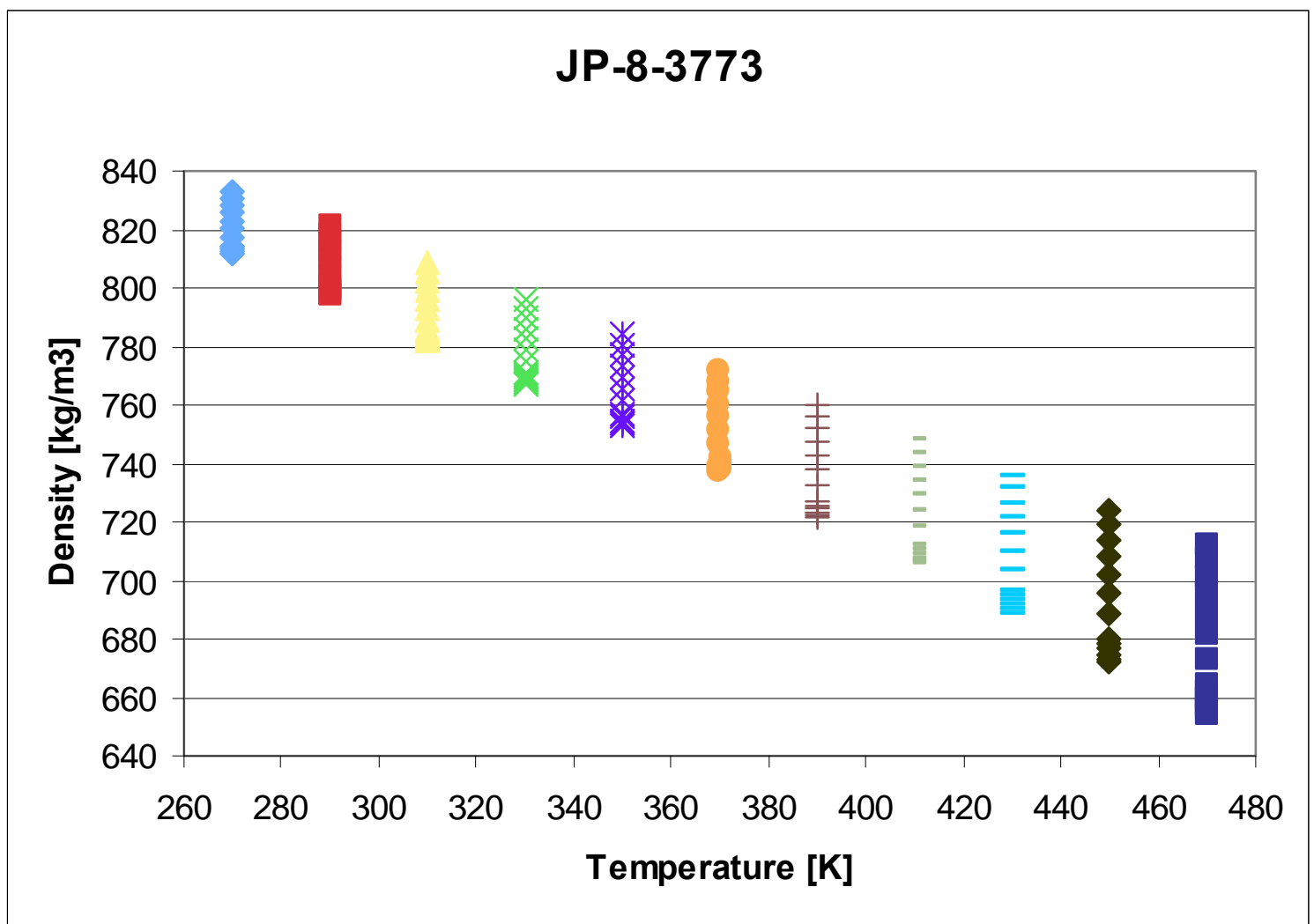

Figure 32: Compressed liquid densities of JP-8-3773. 


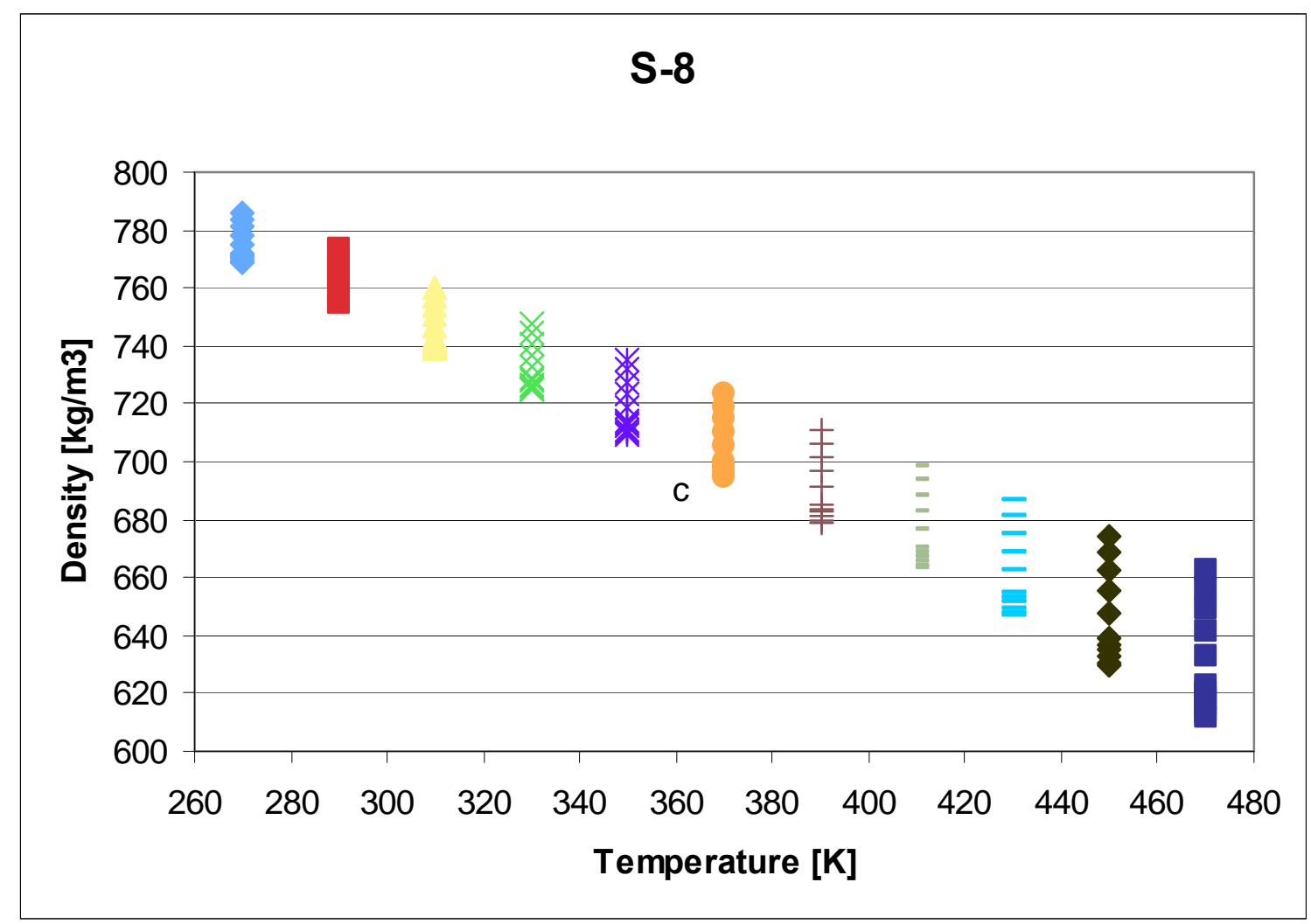

Figure 33: Compressed liquid densities of S-8.

Viscosity Measurements of Jet-A Fuels at Ambient Pressure:

The viscosities of two samples of Jet-A (3638 and 4658) was measured with a commercial viscodensimeter in the temperature range from $263.15 \mathrm{~K}$ to $373.15 \mathrm{~K}$. The performance of the instrument hardware and firmware was examined by comparisons with certified viscosity standard liquids. The reference viscosities of two appropriate calibration liquids were reproduced by the instrument within $0.4 \%$ and $0.8 \%$, respectively. Together, these two viscosity standards span the entire range of measured Jet-A fuel samples. The estimated uncertainty of the Jet-A fuel measurements reported here is deduced from this comparison. Above a viscosity of $0.94 \mathrm{mPa} \cdot \mathrm{s}$ the reported uncertainty is $0.4 \%$; however, below this viscosity threshold the reported uncertainty is expanded to $1 \%$ to match the more conservative manufacturer's estimate. We note that the reported uncertainty estimates are not derived from a strict statistical treatment. The measured absolute and kinematic viscosities of Jet-A-3638 and Jet-A-4658 are tabulated in Tables 25 and 26, respectively. Also included in Tables 25 and 26 are the measured densities and the estimated uncertainty value for each measured quantity. In addition to the tabulated data, the measured absolute and kinematic viscosities are illustrated in Figures 34 - 37. 
Table 25: Viscosity Measurements for Jet-A-3638.

\begin{tabular}{|c|c|c|c|c|c|c|}
\hline $\begin{array}{c}\text { Temperature } \\
\text { K }\end{array}$ & $\begin{array}{c}\eta \\
\mathbf{m P a} \cdot \mathbf{s}\end{array}$ & $\begin{array}{l}\mathbf{u}[\eta] \\
\mathbf{m P a} \cdot \mathbf{s}\end{array}$ & $\begin{array}{c}\mathrm{v} \\
\mathrm{mm}^{2} \cdot \mathrm{s}^{-1}\end{array}$ & $\begin{array}{c}\mathbf{u}[v] \\
\mathrm{mm}^{2} \cdot \mathrm{s}^{-1}\end{array}$ & $\begin{array}{c}\rho \\
\mathrm{kg} \cdot \mathrm{m}^{-3}\end{array}$ & $\begin{array}{c}\mathbf{u}[\rho] \\
\mathbf{k g} \cdot \mathbf{m}^{-3}\end{array}$ \\
\hline 373.150 & 0.47418 & 0.00474 & 0.64796 & 0.00648 & 731.78 & 0.51 \\
\hline 368.150 & 0.49836 & 0.00498 & 0.67746 & 0.00678 & 735.64 & 0.50 \\
\hline 363.150 & 0.52412 & 0.00524 & 0.70877 & 0.00709 & 739.46 & 0.50 \\
\hline 358.150 & 0.55200 & 0.00552 & 0.74261 & 0.00743 & 743.32 & 0.50 \\
\hline 353.150 & 0.58223 & 0.00582 & 0.77927 & 0.00779 & 747.14 & 0.50 \\
\hline 348.150 & 0.61503 & 0.00615 & 0.81899 & 0.00819 & 750.94 & 0.50 \\
\hline 343.150 & 0.65078 & 0.00651 & 0.86223 & 0.00862 & 754.74 & 0.50 \\
\hline 338.150 & 0.68986 & 0.00690 & 0.90944 & 0.00910 & 758.54 & 0.50 \\
\hline 333.150 & 0.73269 & 0.00733 & 0.96111 & 0.00961 & 762.34 & 0.50 \\
\hline 328.150 & 0.77984 & 0.00780 & 1.0179 & 0.0102 & 766.10 & 0.50 \\
\hline 323.150 & 0.83198 & 0.00832 & 1.0807 & 0.0046 & 769.90 & 0.50 \\
\hline 318.150 & 0.88983 & 0.00890 & 1.1502 & 0.0049 & 773.64 & 0.50 \\
\hline 313.150 & 0.95426 & 0.00392 & 1.2275 & 0.0052 & 777.38 & 0.50 \\
\hline 308.150 & 1.0264 & 0.0042 & 1.3140 & 0.0056 & 781.14 & 0.50 \\
\hline 303.150 & 1.1076 & 0.0046 & 1.4112 & 0.0060 & 784.90 & 0.50 \\
\hline 298.150 & 1.1995 & 0.0050 & 1.5210 & 0.0065 & 788.62 & 0.50 \\
\hline 293.150 & 1.3041 & 0.0054 & 1.6458 & 0.0071 & 792.36 & 0.50 \\
\hline 288.150 & 1.4240 & 0.0059 & 1.7887 & 0.0077 & 796.10 & 0.50 \\
\hline 283.150 & 1.5624 & 0.0065 & 1.9535 & 0.0084 & 799.82 & 0.50 \\
\hline 278.150 & 1.7235 & 0.0072 & 2.1449 & 0.0093 & 803.56 & 0.50 \\
\hline 273.150 & 1.9134 & 0.0081 & 2.3703 & 0.0104 & 807.26 & 0.50 \\
\hline 268.150 & 2.1393 & 0.0090 & 2.6380 & 0.0116 & 810.96 & 0.51 \\
\hline 263.150 & 2.4106 & 0.0102 & 2.9590 & 0.0130 & 814.68 & 0.51 \\
\hline
\end{tabular}


Table 26: Viscosity Measurements for Jet-A-4658

\begin{tabular}{|c|c|c|c|c|c|c|}
\hline $\begin{array}{c}\text { Temperature } \\
\text { K }\end{array}$ & $\begin{array}{c}\eta \\
\mathbf{m P a} \cdot \mathbf{s}\end{array}$ & $\begin{array}{l}\mathbf{u}[\eta] \\
\mathbf{m P a} \cdot \mathbf{s}\end{array}$ & $\begin{array}{c}\mathrm{v} \\
\mathrm{mm}^{2} \cdot \mathrm{s}^{-1}\end{array}$ & $\begin{array}{c}\mathbf{u}[v] \\
\mathbf{m m}^{2} \cdot \mathbf{s}^{-1}\end{array}$ & $\begin{array}{c}\rho \\
\mathrm{kg} \cdot \mathrm{m}^{-3}\end{array}$ & $\begin{array}{c}\mathbf{u}[\rho] \\
\mathbf{k g} \cdot \mathbf{m}^{-3}\end{array}$ \\
\hline 373.150 & 0.53287 & 0.00533 & 0.71680 & 0.00717 & 743.38 & 0.51 \\
\hline 368.150 & 0.56121 & 0.00561 & 0.75113 & 0.00751 & 747.16 & 0.50 \\
\hline 363.150 & 0.59165 & 0.00592 & 0.78785 & 0.00788 & 750.96 & 0.50 \\
\hline 358.150 & 0.62466 & 0.00625 & 0.82765 & 0.00828 & 754.74 & 0.50 \\
\hline 353.150 & 0.66055 & 0.00661 & 0.87086 & 0.00871 & 758.50 & 0.50 \\
\hline 348.150 & 0.69968 & 0.00700 & 0.91789 & 0.00919 & 762.26 & 0.50 \\
\hline 343.150 & 0.74245 & 0.00743 & 0.96926 & 0.00970 & 765.98 & 0.51 \\
\hline 338.150 & 0.78941 & 0.00790 & 1.0256 & 0.0103 & 769.76 & 0.50 \\
\hline 333.150 & 0.84115 & 0.00842 & 1.0876 & 0.0109 & 773.46 & 0.50 \\
\hline 328.150 & 0.89844 & 0.00900 & 1.1561 & 0.0116 & 777.16 & 0.50 \\
\hline 323.150 & 0.96220 & 0.00397 & 1.2322 & 0.0053 & 780.88 & 0.51 \\
\hline 318.150 & 1.0335 & 0.0043 & 1.3172 & 0.0056 & 784.56 & 0.50 \\
\hline 313.150 & 1.1136 & 0.0046 & 1.4126 & 0.0061 & 788.26 & 0.50 \\
\hline 308.150 & 1.2041 & 0.0050 & 1.5203 & 0.0065 & 791.98 & 0.50 \\
\hline 303.150 & 1.3070 & 0.0054 & 1.6426 & 0.0071 & 795.68 & 0.50 \\
\hline 298.150 & 1.4249 & 0.0059 & 1.7825 & 0.0077 & 799.38 & 0.50 \\
\hline 293.150 & 1.5608 & 0.0065 & 1.9436 & 0.0084 & 803.06 & 0.50 \\
\hline 288.150 & 1.7188 & 0.0072 & 2.1306 & 0.0092 & 806.72 & 0.51 \\
\hline 283.150 & 1.9043 & 0.0079 & 2.3498 & 0.0101 & 810.40 & 0.50 \\
\hline 278.150 & 2.1239 & 0.0088 & 2.6089 & 0.0112 & 814.10 & 0.50 \\
\hline 273.150 & 2.3878 & 0.0100 & 2.9199 & 0.0127 & 817.78 & 0.50 \\
\hline 268.150 & 2.7078 & 0.0113 & 3.2966 & 0.0143 & 821.40 & 0.50 \\
\hline 263.150 & 3.1011 & 0.0130 & 3.7586 & 0.0163 & 825.08 & 0.50 \\
\hline
\end{tabular}




\section{$\eta / \mathrm{mPa} \cdot \mathrm{s}$}

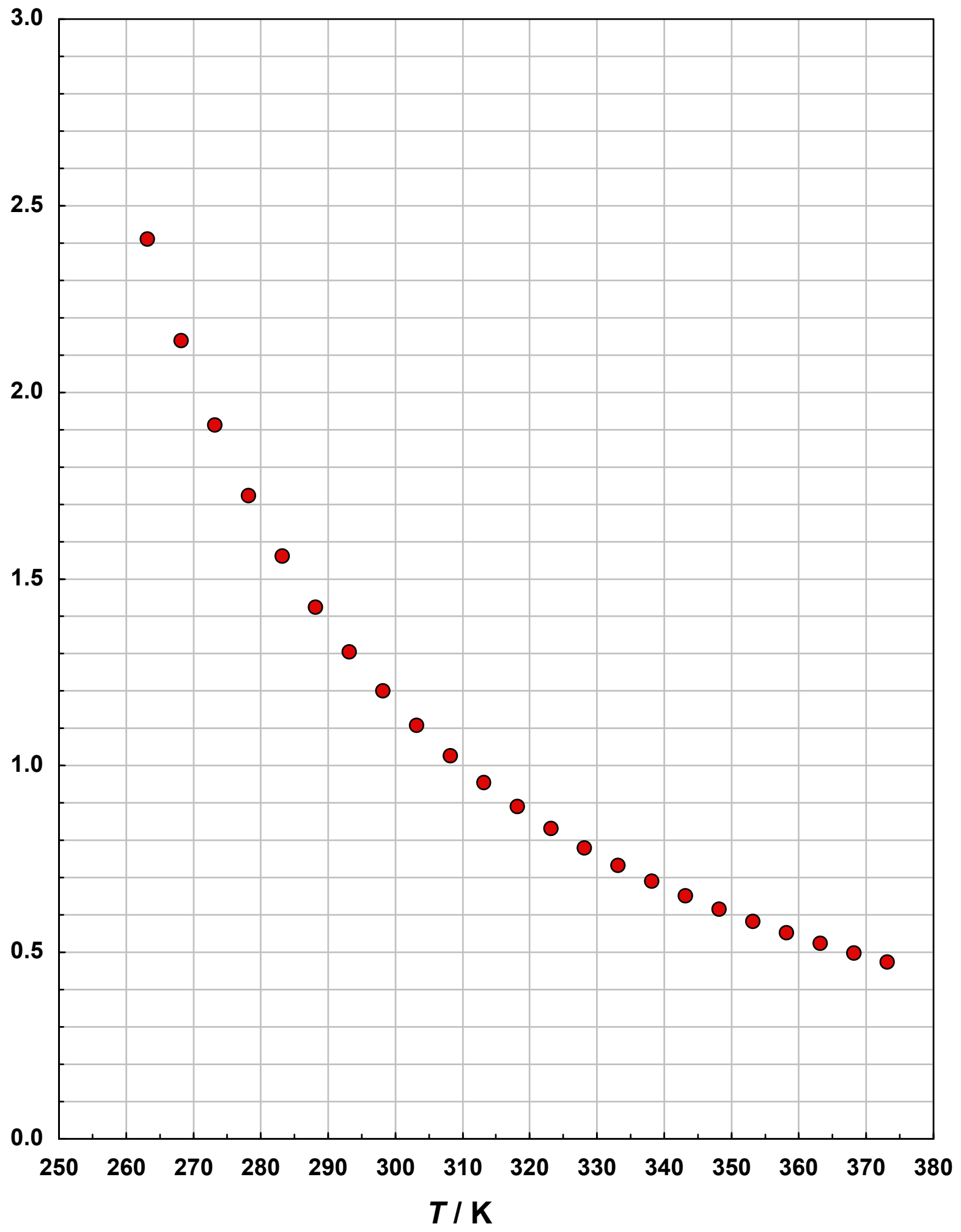

Figure 34: Measurements of the absolute viscosity of Jet-A-3638. The uncertainty is discussed in the text. 
$v / \mathrm{mm}^{2} \cdot \mathrm{s}^{-1}$

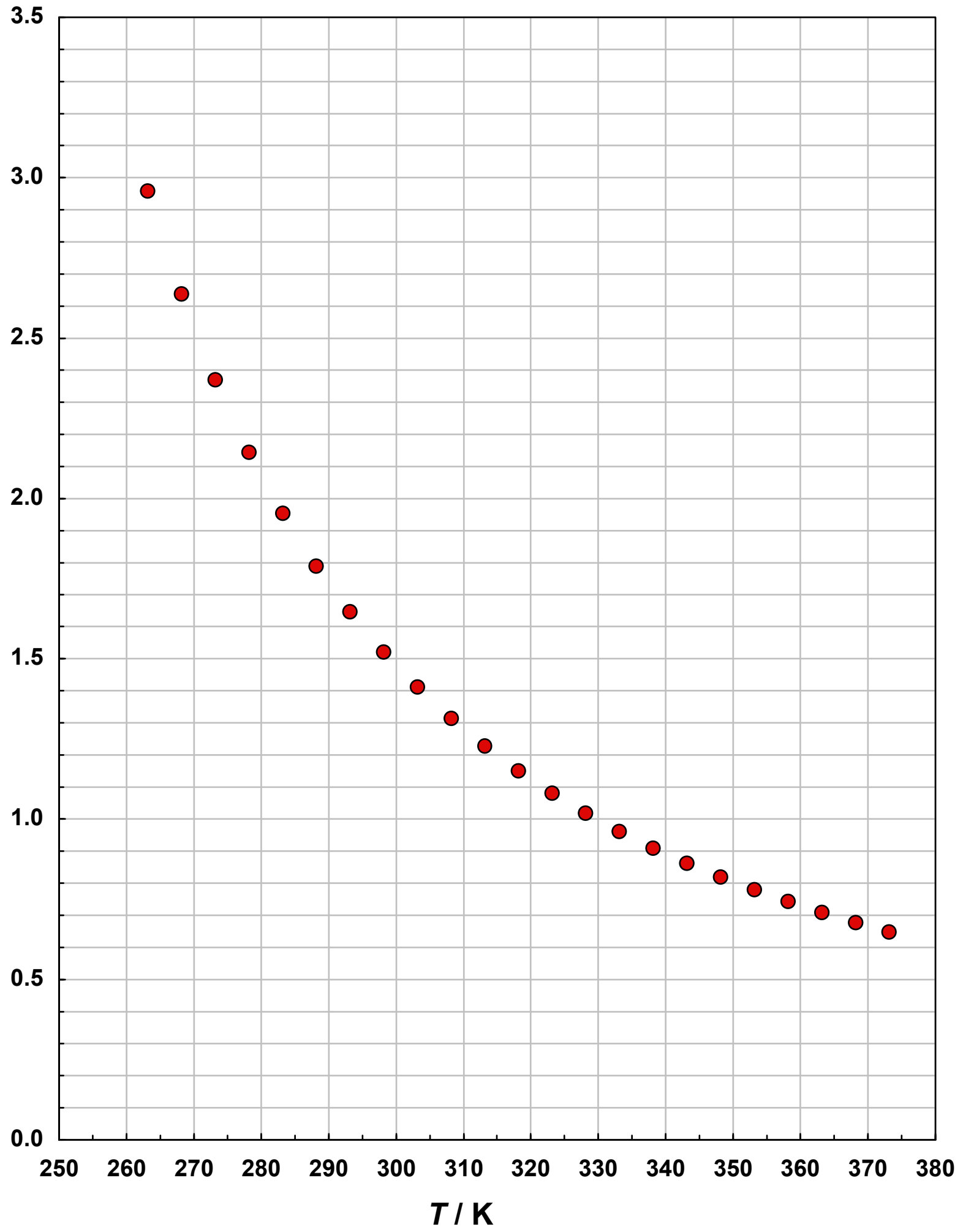

Figure 35: Measurements of the kinematic viscosity of Jet-A-3638. The uncertainty is discussed in the text. 
$\eta / \mathrm{mPa} \cdot \mathrm{s}$

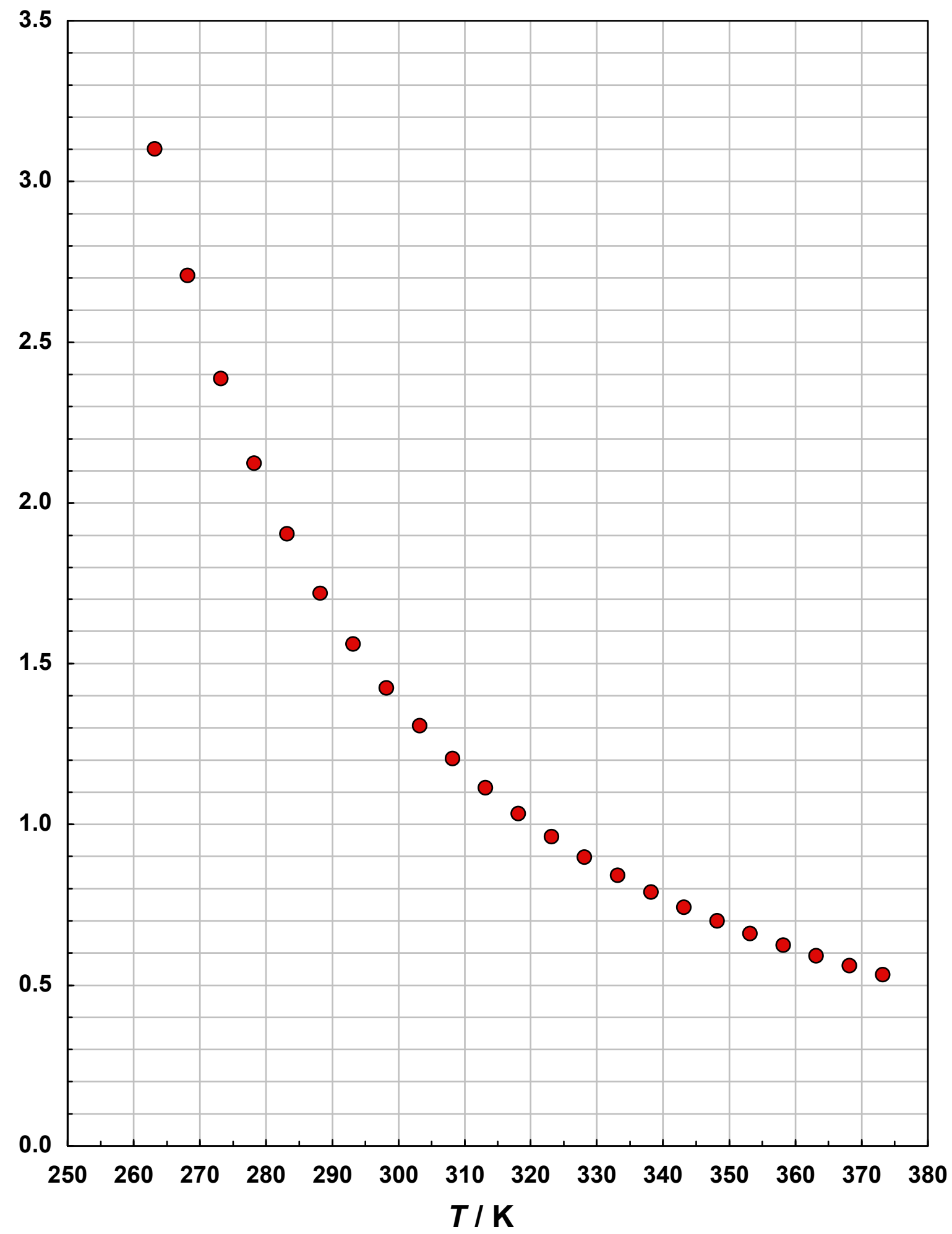

Figure 36: Measurements of the absolute viscosity of Jet-A-4648. The uncertainty is discussed in the text. 


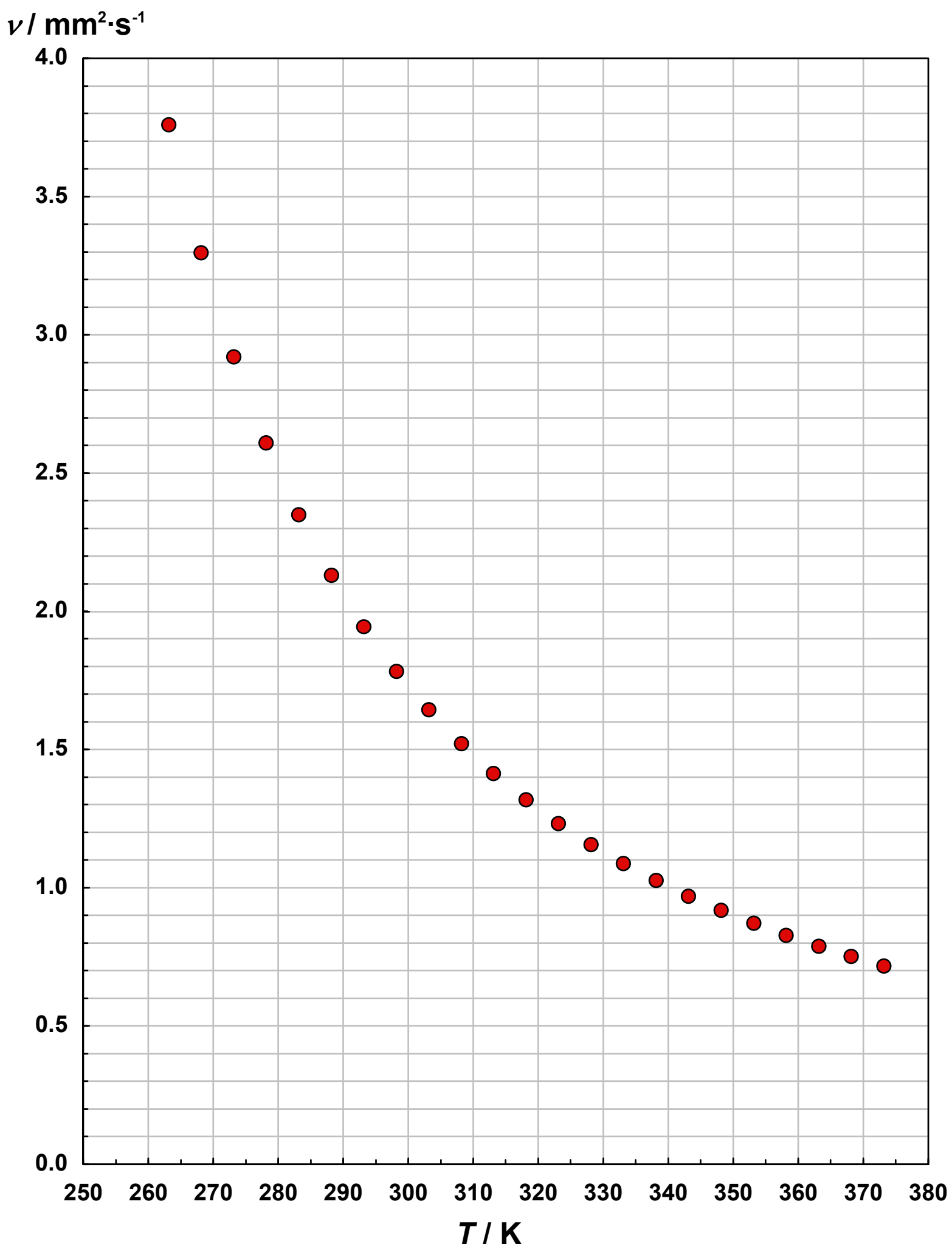

Figure 37: Measurements of the kinematic viscosity of Jet-A-4648. The uncertainty is discussed in the text. 
The kinematic viscosity of JP-8-3773 was measured at ambient pressure in the temperature range $293.15 \mathrm{~K}$ to $373.15 \mathrm{~K}$. These measurements are presented in Table 27. The instrument used was a commercial automated open gravitational flow viscometer with a suspended-level Ubbelohde glass capillary of $200 \mathrm{~mm}$ length with upper reservoir bulbs for a kinematic viscosity range from $0.3 \mathrm{~mm}^{2} \cdot \mathrm{s}^{-1}$ to $30 \mathrm{~mm}^{2} \cdot \mathrm{s}^{-1}$. This instrument was described earlier for the measurements done on methyl- and propylcyclohexane. These data are presented graphically in Figure 38.

Table 27: The kinematic viscosity of JP-8-3773 at an ambient pressure of $83 \mathrm{kPa}$.

\begin{tabular}{|c|c|}
\hline \multicolumn{2}{|c|}{ JP-8 3773 } \\
\hline $\boldsymbol{T}$ & $\begin{array}{c}\text { Kinematic } \\
\text { viscosity } \\
\boldsymbol{\nu}\end{array}$ \\
\hline K & $\mathbf{m m}^{\mathbf{2}} \cdot \mathbf{s}^{-1}$ \\
\hline 293.15 & 1.692 \\
303.15 & 1.442 \\
313.15 & 1.250 \\
323.15 & 1.099 \\
333.15 & 0.9775 \\
343.15 & 0.8768 \\
353.15 & 0.7889 \\
363.15 & 0.7172 \\
373.15 & 0.6559 \\
\hline
\end{tabular}




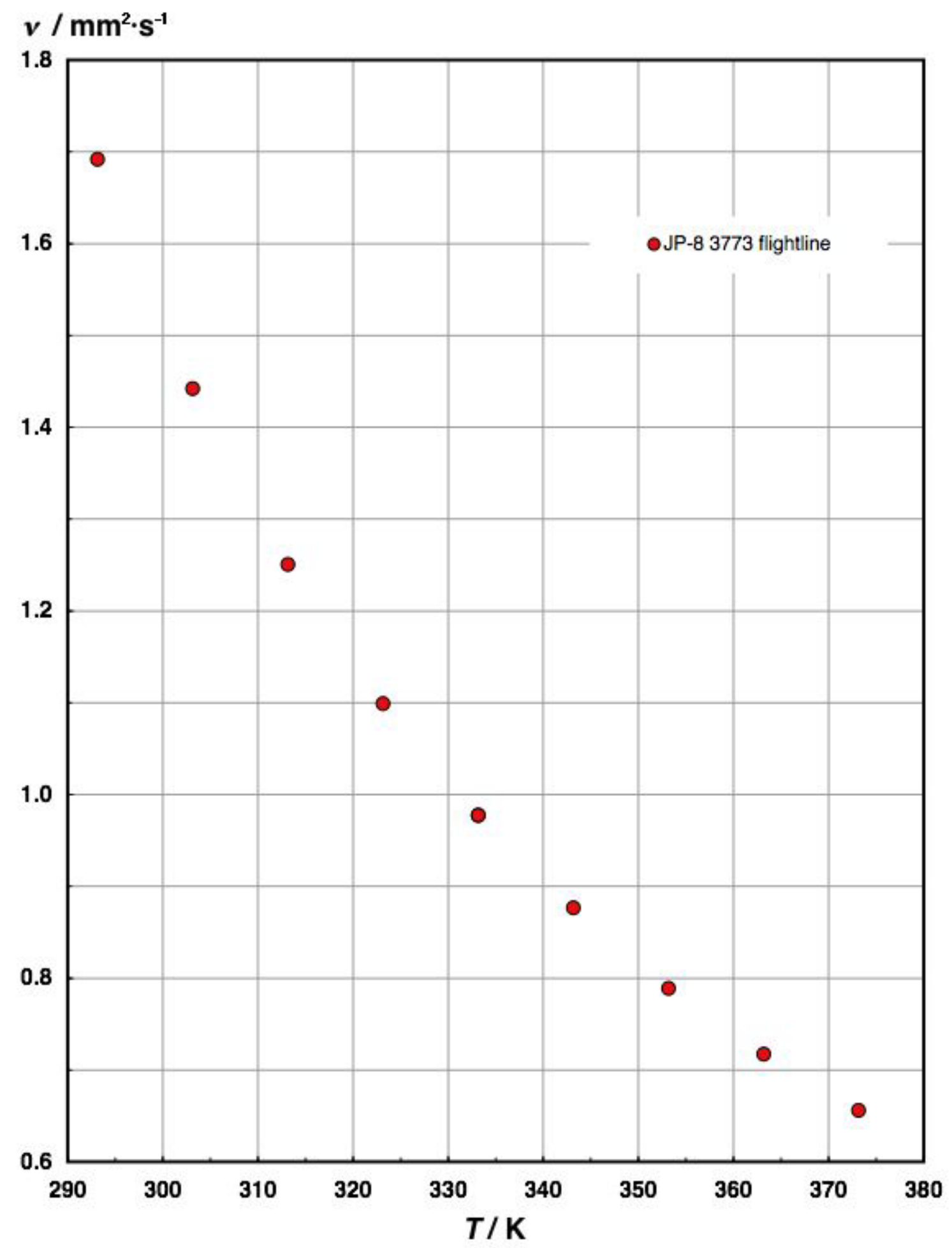

Figure 38: Measurements of the kinematic viscosity of JP-8-3773. The uncertainty is discussed in the text. 
Thermal Conductivity Measurements of the Compressed Liquid Aviation Fuels:

Transient hot-wire measurements of the thermal conductivity were made on each of the three liquid samples of Jet-A-3602, Jet-A-3638, Jet-A-4658, JP-8-3773 and S-8. For each sample, measurements were made along 11 isotherms at temperatures from 300 to $500 \mathrm{~K}$ with pressures up to $70 \mathrm{MPa}$. The transient hot-wire instrument has been described in detail above in the treatment of the measurements on methyl- and propylcyclohexane. The tabulated thermal conductivity measurements are extensive and are therefore provided in Appendix I. The measurements are depicted graphically in Figures 39 - 43.

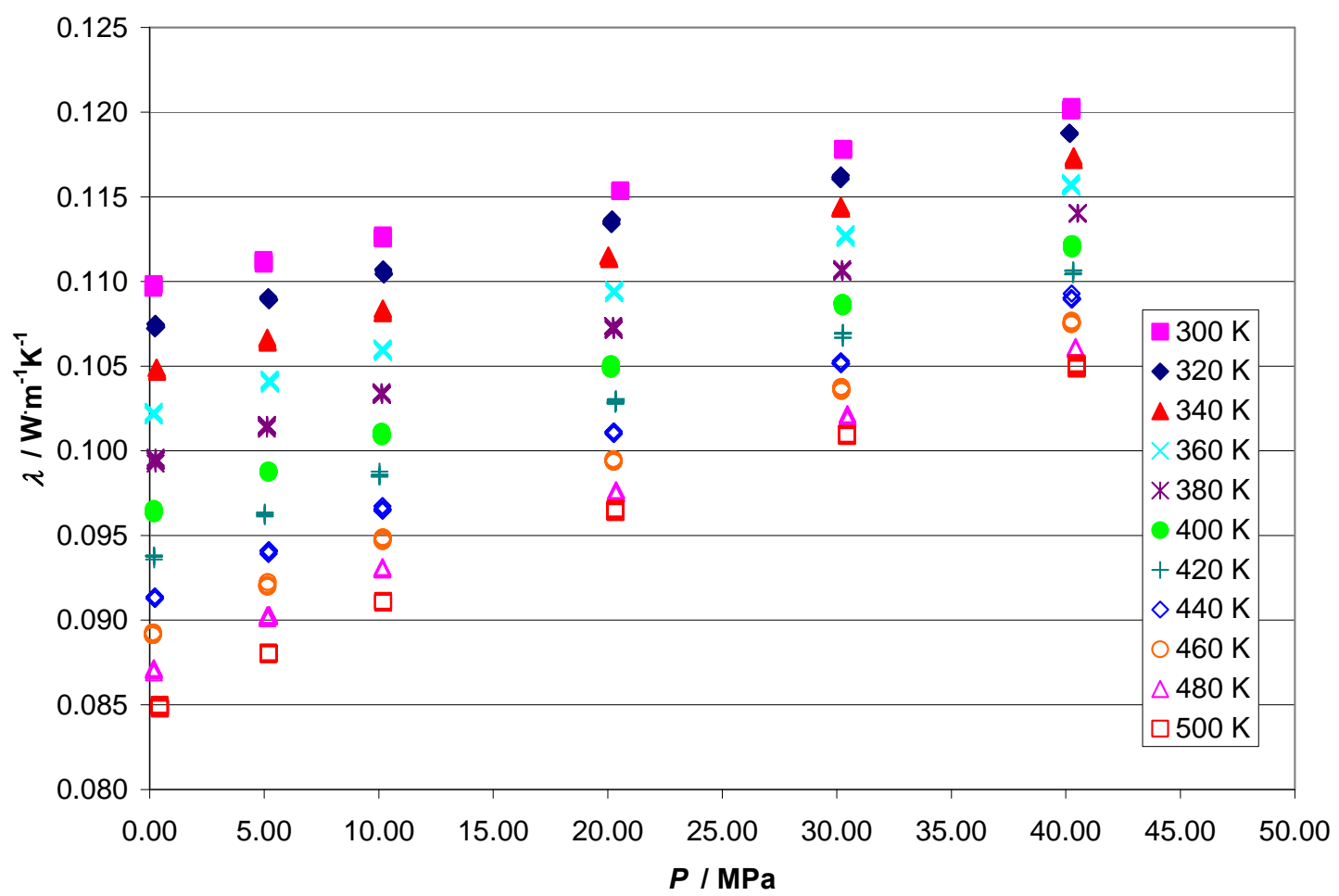

Figure 39: Thermal conductivity of Jet-A-3602 in the liquid phase. 


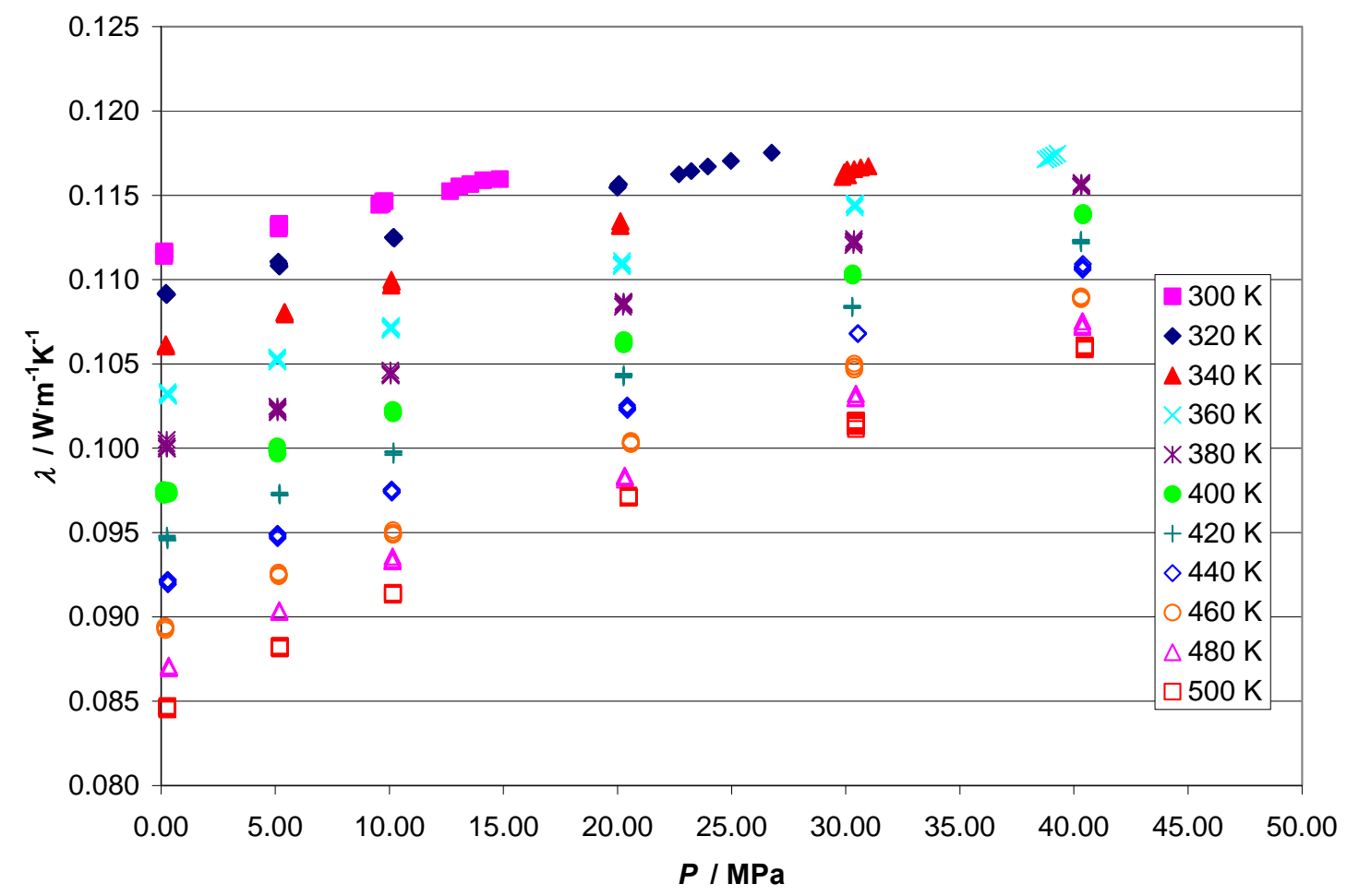

Figure 40: Thermal conductivity of Jet-A-3638 in the liquid phase.

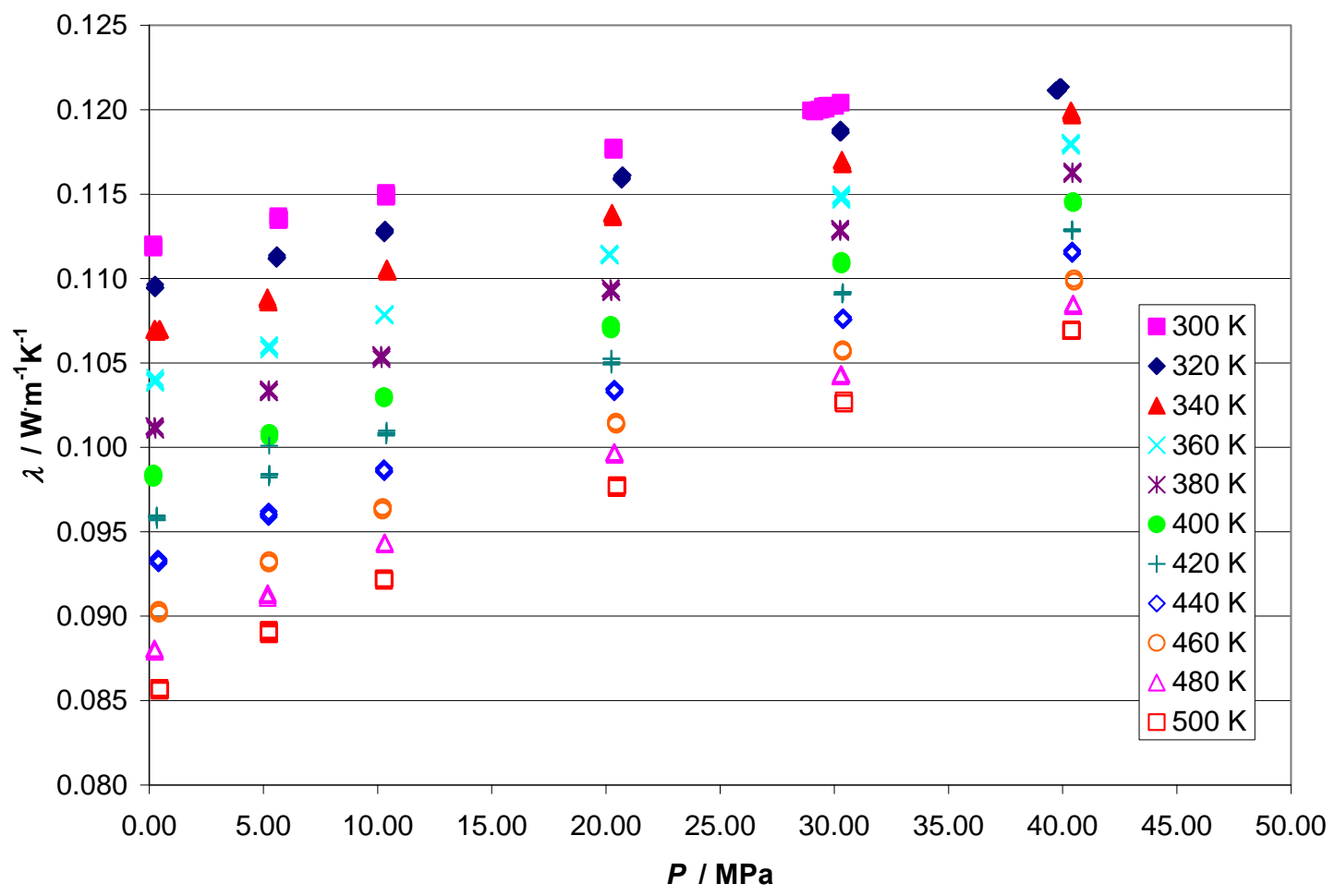

Figure 41: Thermal conductivity of Jet-A-4658 in the liquid phase. 


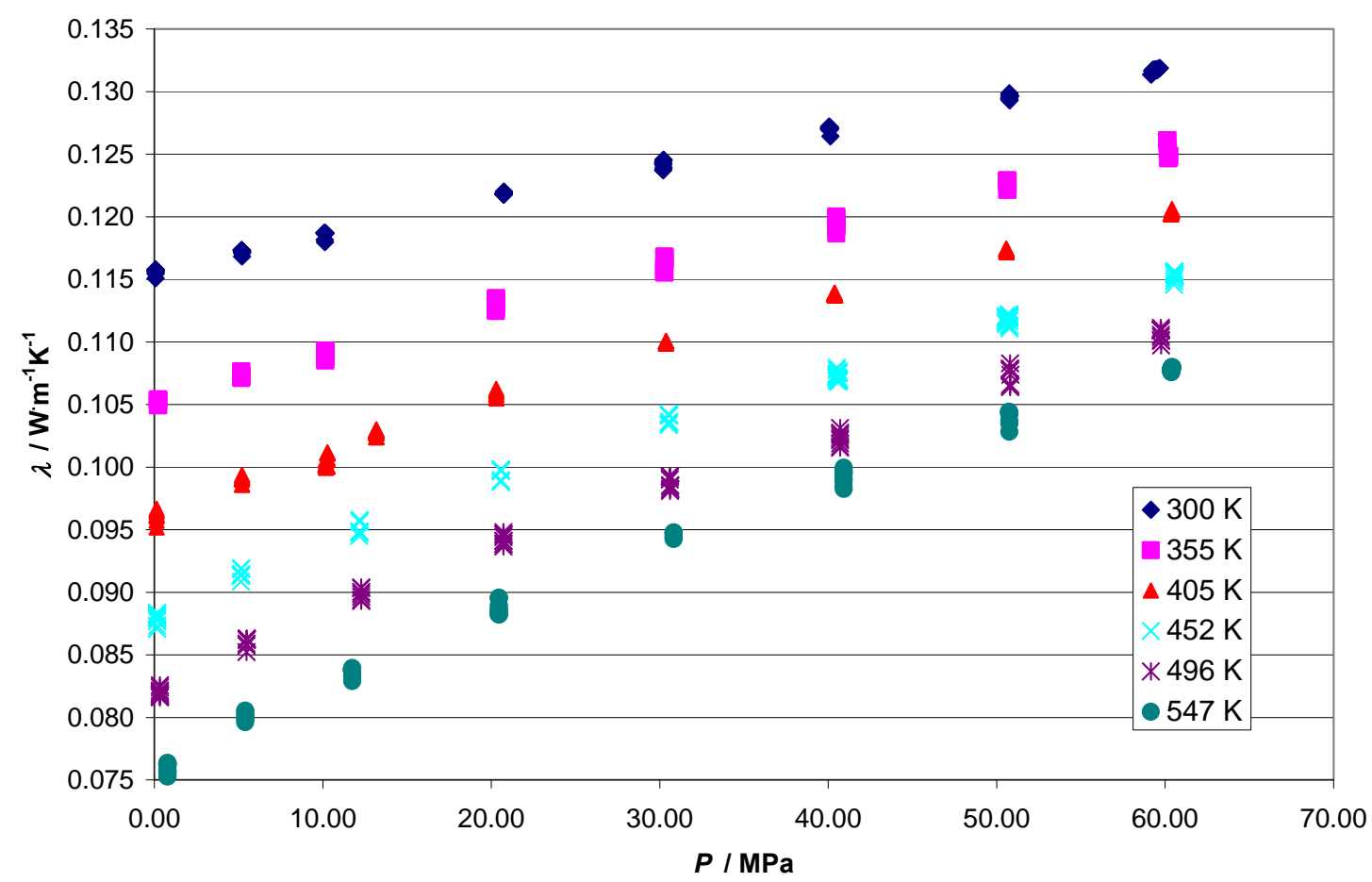

Figure 42: Thermal conductivity of JP-8-3773 from $0.1 \mathrm{MPa}$ to $70 \mathrm{MPa}$.

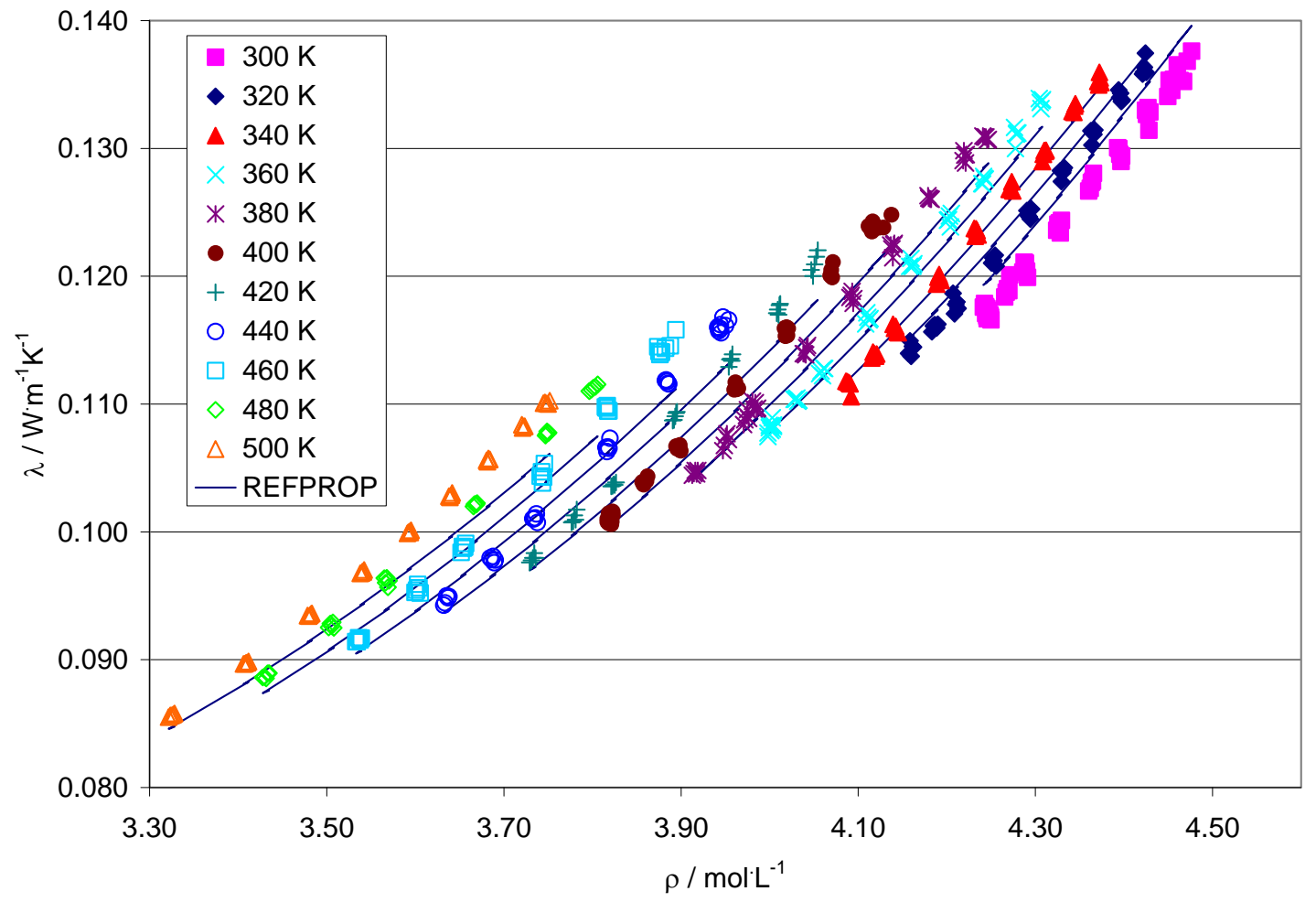

Figure 43: Thermal conductivity of S-8 at pressures from $0.1 \mathrm{MPa}$ to $70 \mathrm{MPa}$. 
Heat Capacities of Jet Fuels S-8 and JP-8:

The heat capacities of jet fuels JP-8-3373 and S-8 were measured with a commercial differential scanning calorimeter. Samples were contained in high-pressure sample containers during the measurements. These high-pressure containers are constructed of stainless steel, and are plated with gold on internal surfaces. These containers are sealed with a gold disk sandwiched between the upper lid and the lower portion of the vessel. The cells are rated for pressures of approximately $15 \mathrm{MPa}$. The internal volumes of these cells are approximately $30 \mu$ l. The high-pressure cells were used because the heat capacity measurements extended to above the normal boiling point of the jet fuels. In practice, measurements can be made at different filled fractions of the internal volume of the cells and these values can be extrapolated to complete filling to eliminate contributions from the vaporization of the liquid in the cells. The vaporization enthalpy was sufficiently negligible throughout the temperature range, that the larger fractions-filled measurements could be taken as being free of vapor-space. The capsules were filled and sealed within a glove bag that had been swept with dry nitrogen gas for at least an hour prior to cell filling. The sealed vessels were weighed on a microbalance with resolution of $1 \mu \mathrm{g}$.

Crushed pieces of SRM 720, synthetic sapphire, were used to calibrate the heat flux of the calorimeter with the same high-pressure cell that was used for the fluid heat capacity measurements. The mass of fluid sealed in the high-pressure cell was always much smaller than the mass of the cell. The empty cell parts had a mass of approximately 0.66 $\mathrm{g}$ and the sample masses ranged from $5 \mathrm{mg}$ to $19 \mathrm{mg}$.

If vaporization enthalpies are significant, then the observed specific heat capacity of the two phase system will decrease with a decrease of vapor space in the sample vessel; or equivalently, the observed two phase heat capacity would decrease with increasing filled fraction of the sample cell. This behavior was not observed to temperatures of up to $473 \mathrm{~K}$. In fact slight increases in the observed two phase heat capacity were observed with increasing filled fraction of the vessel.

Using a vapor volume of $5 \mu$, the ideal gas law, a representative enthalpy of vaporization of $50 \mathrm{~kJ} \cdot \mathrm{mol}^{-1}$, and a hypothetical increase in pressure of $0.1 \mathrm{MPa}$ over $50 \mathrm{~K}$, the contribution of the vaporization enthalpy to the observed two-phase heat capacity would be $0.0074 \mathrm{~J} \cdot \mathrm{K}^{-1} \cdot \mathrm{g}^{-1}$, which is less than the run-to-run irreproducibility. Observed heat capacities were obtained by equilibrating the calorimeter at $223 \mathrm{~K}$ for 10 min or longer, scanning at $5 \mathrm{~K} \cdot \mathrm{min}^{-1}$ to $473 \mathrm{~K}$ and equilibrating at $473 \mathrm{~K}$ for $10 \mathrm{~min}$. The equilibration periods were used to establish a baseline that was subtracted from the heat-flux against time thermal curve. Heat flux curves for the empty high-pressure cells in the reference and sample sides of the calorimeter were determined and averaged. The average heat flux curve for the empty vessel was subtracted from baseline-adjusted heat flux curves for the vessel filled with either sapphire or one of the jet fuels. 
A correction factor for the heat flux was determined as a ratio of the true heat capacity of SRM 720 to that obtained from the average of several heat flux curves. This ratio was then multiplied by the observed heat capacity for the jet fuels to correct for heat-flux error (as in ASTM International Standard Method E968). The calorimeter obtains approximately 3000 readings for each thermal scan, not including the equilibration periods. With four or five replicates per filling and an average over three fillings, close to half a million data points might be processed to obtain a heat capacity curve. These are shown for JP-8-3773 and S-8 in figures 44 and 45 . In order to reduce this number individual data points were collated near nominal temperatures. A single curve was then fitted to all these collated readings to obtain the heat capacity of each of the jet fuels. The statistics calculated for the fitted curve thus include the variances due to: 1) irreproducibility in vessel filling and sealing; 2) calorimetric noise; 3) run-to-run variability for the same vessel filling; 4) vessel placement irreproducibilities. The last two are the largest contributors to imprecision.

The least-squares generated equation for the heat capacity at ambient pressure of JP-8 is:

$\mathrm{Cp} / \mathrm{Cp}^{\circ}=(2.193 \pm 0.0055)+(3.996 \pm 0.0011) \times 10^{-3}\left(\mathrm{~T} / \mathrm{T}^{\circ}-\right.$ $363.15)$

The least-squares generated equation for the heat capacity of S-8 at ambient pressure is:

$\mathrm{Cp} / \mathrm{Cp}^{\circ}=(2.527 \pm 0.0118)+(2.804 \pm 0.0024) \times 10^{-3}\left(\mathrm{~T} / \mathrm{T}^{\circ}-\right.$

$363.15)$

where $\mathrm{T}^{\circ}$ is $1 \mathrm{~K}, \mathrm{Cp}^{\circ}$ is $1\left(\mathrm{~J} \cdot \mathrm{K}^{-1} \cdot \mathrm{g}^{1}\right)$, and the difference between the saturation heat capacity and the constant pressure heat capacity was assumed to be negligible. The uncertainties attached to the parameters are 1 standard deviation. The random factors that contribute to those uncertainties of the parameters were stated in a previous paragraph. 


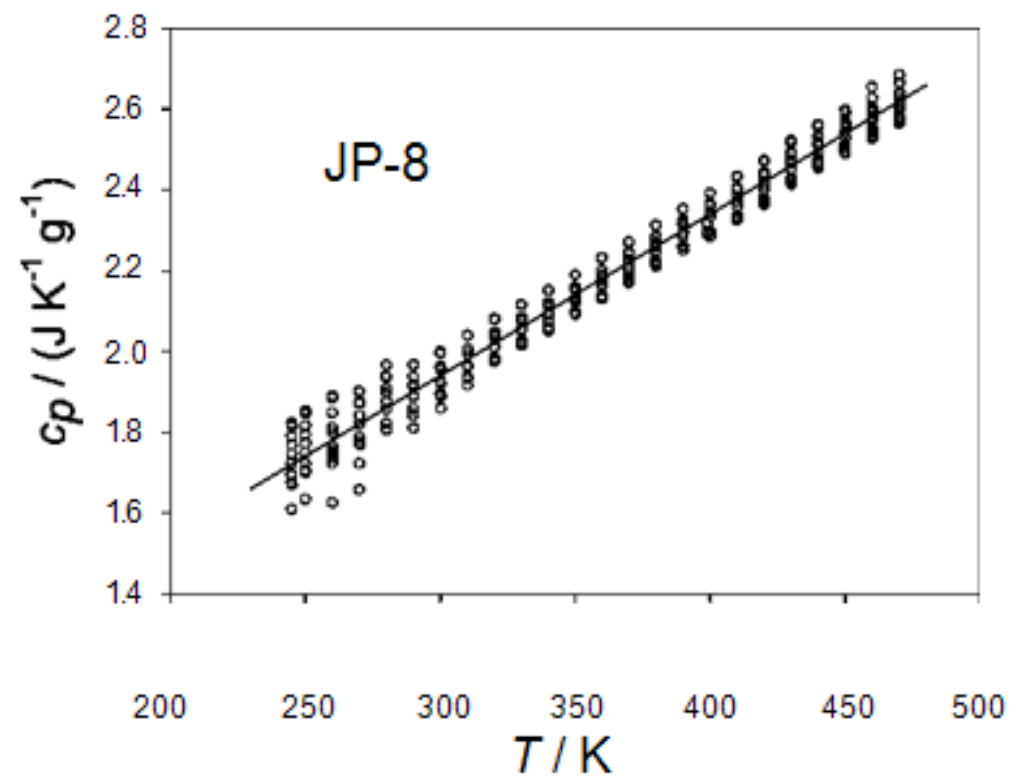

Figure 44: Heat capacity at constant pressure of JP-8-3773 as a function of temperature.

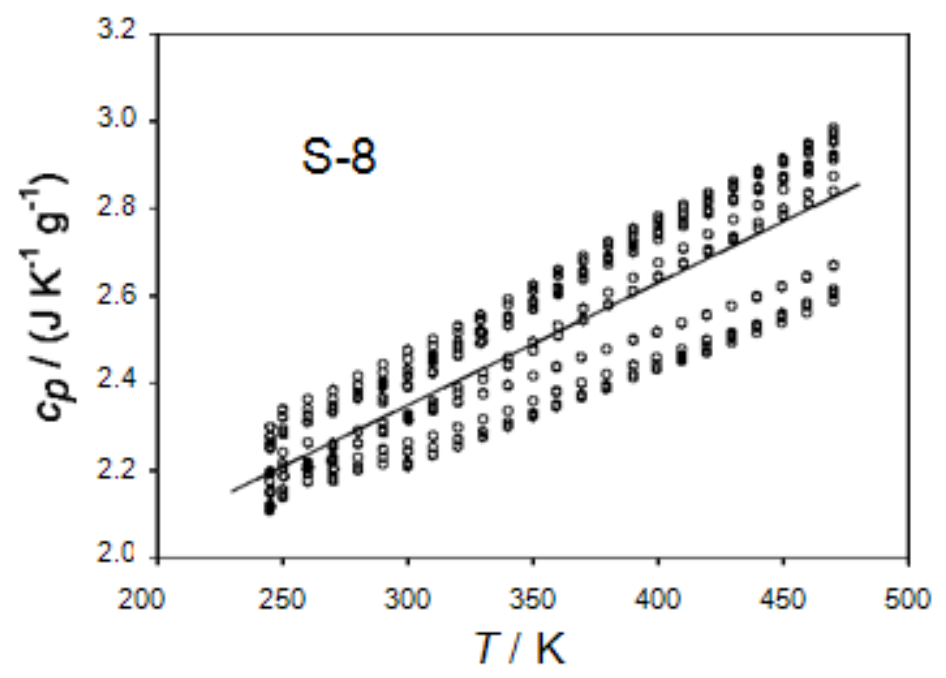

Figure 45: Heat capacity at constant pressure of JP-8-3773 as a function of temperature. 


\section{Development of the Thermodynamic and Transport Model:}

The procedure for developing a surrogate mixture can be summarized as follows. First, a chemical analysis is performed to identify the composition of the fuel sample. From this analysis, a list of candidate fluids is constructed, including compounds representative of the various chemical families (branched or linear paraffins, alkenes, aromatics, mono or polycyclic paraffins, etc.) found in the sample. For each of these possible pure-fluid constituents, an equation of state, a viscosity surface and a thermal conductivity surface are developed, and a mixture model is used that incorporates the pure-fluid equations for both thermodynamic and transport properties. The fluids in the surrogate mixture and their compositions are then chosen by determining the composition that minimizes the difference between the predicted and experimental data for the distillation curve, density, sound speed, viscosity and thermal conductivity.

From the gas chromatography and mass spectrometry analysis of the Jet-A samples, we compiled a list of potential candidate fluids for a surrogate model. These fluids are listed in Table 28, along with their normal boiling point and their boiling points at an atmospheric pressure of $83 \mathrm{kPa}$ (the typical local pressure of our laboratory, located at $1655 \mathrm{~m}$ above sea level). The list contains fluids used in our earlier work on RP-1, RP-2, and $\mathrm{S}-8$, but in addition includes aromatic compounds such as toluene, o-xylene and tetralin that were not used in model for either S-8 or RP-1 and RP-2. ${ }^{35,36}$ For each monobranched alkane identified in the chemical analysis, a representative species was selected as a candidate constituent fluid for the surrogates. In other words, for our purposes, all $x$ methylnonanes are represented as a single methylnonane. Similarly, we used a particular $x, y$-dimethylnonane to represent the dimethylnonane family. A major factor governing the specific choice of compound to represent a moiety was the availability of property data: priority was given to compounds for which the most abundant and reliable experimental measurements were available. For each possible constituent fluid, we searched the open literature as well as databases such as the NIST TDE program, DIPPR, and Landolt-Börnstein for experimental physical property data. For some of the fluids, the data were sparse and were supplemented with predicted values from the TDE and DIPPR Diadem programs ${ }^{37}$.

Because our modeling approach requires thermophysical property models for all pure constituent fluids, it was necessary to have available equations of state and surfaces for the viscosity and thermal conductivity for each of the potential constituent pure fluids. Details of this procedure are available in other work, so we provide only a brief summary here $^{35,36,38,39}$. With the available experimental data supplemented with predictions obtained from the TDE program, we developed Helmholtz-form equations of state similar to the form developed by Span and Wagner that can represent not only the vapor pressure and density, but also other properties such as the speed of sound and heat capacity ${ }^{40}$. For viscosity and thermal conductivity, we primarily used an extended corresponding-states model, with n-dodecane as a reference fluid. When sufficient data were available, the representation of the viscosity or thermal conductivity was improved by fitting the data to correction functions for the shape factors. In the absence of experimental data, we used the predictive method of Van Velzen for viscosity, and the method of Baroncini for thermal conductivity (as implemented in the DIPPR Diadem program). Additionally, we 
incorporated earlier work on the thermal conductivity of methyl and propylcyclohexane to represent the alkyl cyclohexane family in terms of a scaled form of the thermal conductivity correlation developed for propylcyclohexane.

For calculations of the thermodynamic properties of mixtures, we used the mixture model incorporated into the REFPROP ${ }^{41}$ computer program. This model includes an algorithm for estimating binary interaction parameters when data are unavailable for a particular fluid pair. The model for calculating the transport properties of a mixture is an extended corresponding-states method. In addition, we used an algorithm developed in earlier work to compute the distillation curve; this procedure incorporates data from an improved advanced distillation curve metrology. ${ }^{35,36,38,39}$

The properties measurements discussed earlier formed the basis of the experimental data set used to obtain the surrogate models. We then used a multi-property, nonlinear regression procedure to minimize the differences between the experimental data and the predictions of the model. This is used to determine the components and their relative abundances to define the surrogate fluid mixtures for each aviation fuel sample. The objective function was the sum of the squared percentage differences between the experimental data and the predicted value. The independent variables were the compositions of the fluid mixture. Our initial guess included all of the components in Table 28. Successive calculations gave very small concentrations of some components. These were removed from the mixture and the minimization process was repeated until further reductions in the number of components resulted in unacceptably large deviations with the experimental data.

The final compositions of the surrogate mixtures are summarized in Table 29. Each surrogate model contains eight components. The surrogate for the composite Jet-A-4658 contains more of the heavier cycloalkanes than the Jet-A-3638 sample, and also contains hexadecane. The Jet-A-3638 sample contains some propylcyclohexane, and more of the lighter components. This is not unexpected because the distillation curves indicate that the Jet-A-4658 sample contains more of the higher boiling components.

In Figures 46 to 52, we present comparisons of our surrogate models with experimental data. Figure 46 shows the density as a function of temperature at atmospheric pressure $(83 \mathrm{kPa})$. The models agree with the data to within their experimental uncertainty $(0.1$ $\%$. The density of the two different samples differs from each other by approximately $1.5 \%$. Figures 47 and 48 show the deviations in density between the experimental measurements as a function of pressure, over the temperature range $270 \mathrm{~K}$ to $470 \mathrm{~K}$ for the Jet-A-3638 and the Jet-A-4658 samples. The experimental uncertainty of these data is $0.1 \%$. The models both show increasing deviations as the pressure increases, but remain within $0.5 \%$. 
Table 28. Potential constituent fluids for the surrogate fuel mixtures

\begin{tabular}{|c|c|c|c|c|c|}
\hline Compound & CAS no. & Class & $\begin{array}{l}\text { No. of } \\
\text { carbon } \\
\text { atoms }\end{array}$ & $\begin{array}{c}\text { Boiling } \\
\text { point at } 83 \\
\text { kPa }(K) \\
\end{array}$ & $\begin{array}{c}\text { Normal } \\
\text { boiling } \\
\text { point (K) }\end{array}$ \\
\hline heptane & $142-82-5$ & linear paraffin & 7 & 364.90 & 371.53 \\
\hline toluene & $108-88-3$ & aromatic & 7 & 376.87 & 383.75 \\
\hline octane & $111-65-9$ & linear paraffin & 8 & 391.75 & 398.77 \\
\hline ortho-xylene & $95-47-6$ & aromatic & 8 & 410.16 & 417.54 \\
\hline nonane & $111-84-2$ & linear paraffin & 9 & 416.54 & 423.81 \\
\hline propylcyclohexane & $1678-92-8$ & $\begin{array}{c}\text { monocyclic } \\
\text { paraffin }\end{array}$ & 9 & 422.13 & 429.86 \\
\hline 5-methylnonane & $15869-85-9$ & branched paraffin & 10 & 430.7 & 438.3 \\
\hline decane & $124-18-5$ & linear paraffin & 10 & 439.6 & 447.3 \\
\hline trans-decalin & $493-02-7$ & dicyclic paraffin & 10 & 452.0 & 460.4 \\
\hline tetralin & $119-64-2$ & aromatic & 10 & 472.31 & 480.75 \\
\hline 2-methyldecane & $6975-98-0$ & branched paraffin & 11 & 454.4 & 462.3 \\
\hline $\begin{array}{c}2,4- \\
\text { dimethylnonane }\end{array}$ & $17302-24-8$ & branched paraffin & 11 & 437.6 & 445.4 \\
\hline undecane & $1120-21-4$ & linear paraffin & 11 & 461.1 & 469.0 \\
\hline pentylcyclohexane & $4292-92-6$ & $\begin{array}{c}\text { monocyclic } \\
\text { paraffin }\end{array}$ & 11 & 468.3 & 476.7 \\
\hline 1-methyldecalin & $2958-75-0$ & dicyclic paraffin & 11 & 469.6 & 478.2 \\
\hline 3-methylundecane & $1002-43-3$ & branched paraffin & 12 & 478.1 & 486.3 \\
\hline dodecane & $112-40-3$ & linear paraffin & 12 & 481.2 & 489.4 \\
\hline hexylcyclohexane & $4292-75-5$ & $\begin{array}{c}\text { monocyclic } \\
\text { paraffin }\end{array}$ & 12 & 489.7 & 498.4 \\
\hline 5-methyldodecane & 17453-93-9 & branched paraffin & 13 & 494.7 & 503.2 \\
\hline tridecane & $629-50-5$ & linear paraffin & 13 & 500.2 & 508.7 \\
\hline heptylcyclohexane & $5617-41-4$ & $\begin{array}{c}\text { monocyclic } \\
\text { paraffin }\end{array}$ & 13 & 509.2 & 517.9 \\
\hline 2-methyltridecane & $1560-96-9$ & branched paraffin & 14 & 512.7 & 521.1 \\
\hline tetradecane & $629-59-4$ & linear paraffin & 14 & 518.1 & 526.7 \\
\hline pentadecane & $629-62-9$ & linear paraffin & 15 & 535.0 & 543.8 \\
\hline hexadecane & $544-76-3$ & linear paraffin & 16 & 551.0 & 560.1 \\
\hline
\end{tabular}


Table 29. Composition of the Surrogate Mixtures

\begin{tabular}{|c|c|c|}
\hline Fluid Name & $\begin{array}{c}\text { Jet-A-4658 surrogate } \\
\text { composition, mole } \\
\text { fraction }\end{array}$ & $\begin{array}{c}\text { Jet-A-3638 surrogate } \\
\text { composition, mole } \\
\text { fraction }\end{array}$ \\
\hline propylcylcohexane & 0.000 & 0.009 \\
\hline hexylcyclohexane & 0.000 & 0.275 \\
\hline heptylcyclohexane & 0.255 & 0.000 \\
\hline methyldecalin & 0.081 & 0.014 \\
\hline 5-methylnonane & 0.148 & 0.068 \\
\hline 2-methyldecane & 0.164 & 0.347 \\
\hline n-tetradecane & 0.068 & 0.000 \\
\hline n-hecadecane & 0.030 & 0.120 \\
\hline ortho-xylene & 0.055 & 0.140 \\
\hline tetralin & 0.199 & \\
\hline
\end{tabular}




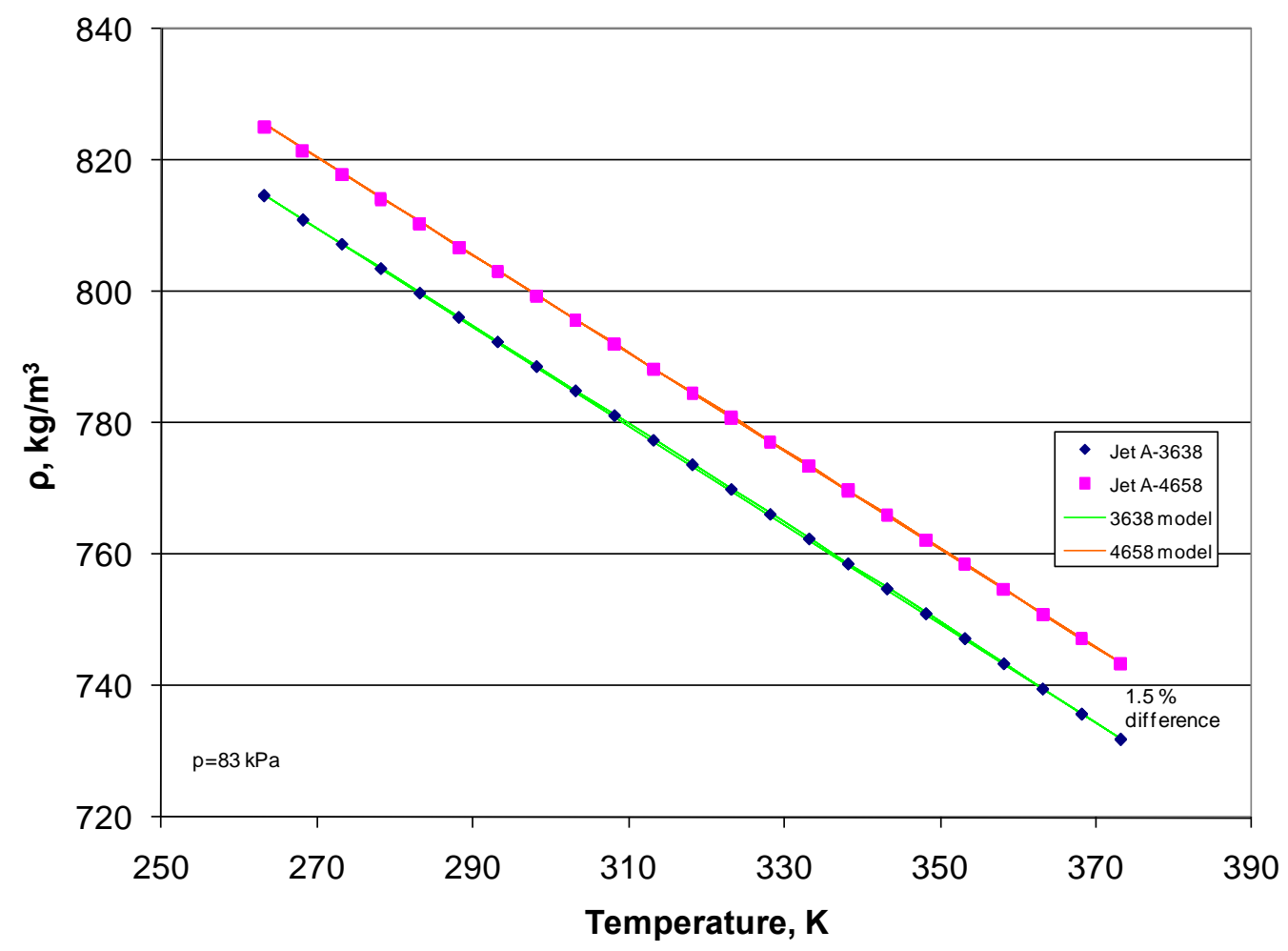

Figure 46: Plot of density as a function of temperature for the Jet-A samples at $83 \mathrm{kPa}$.

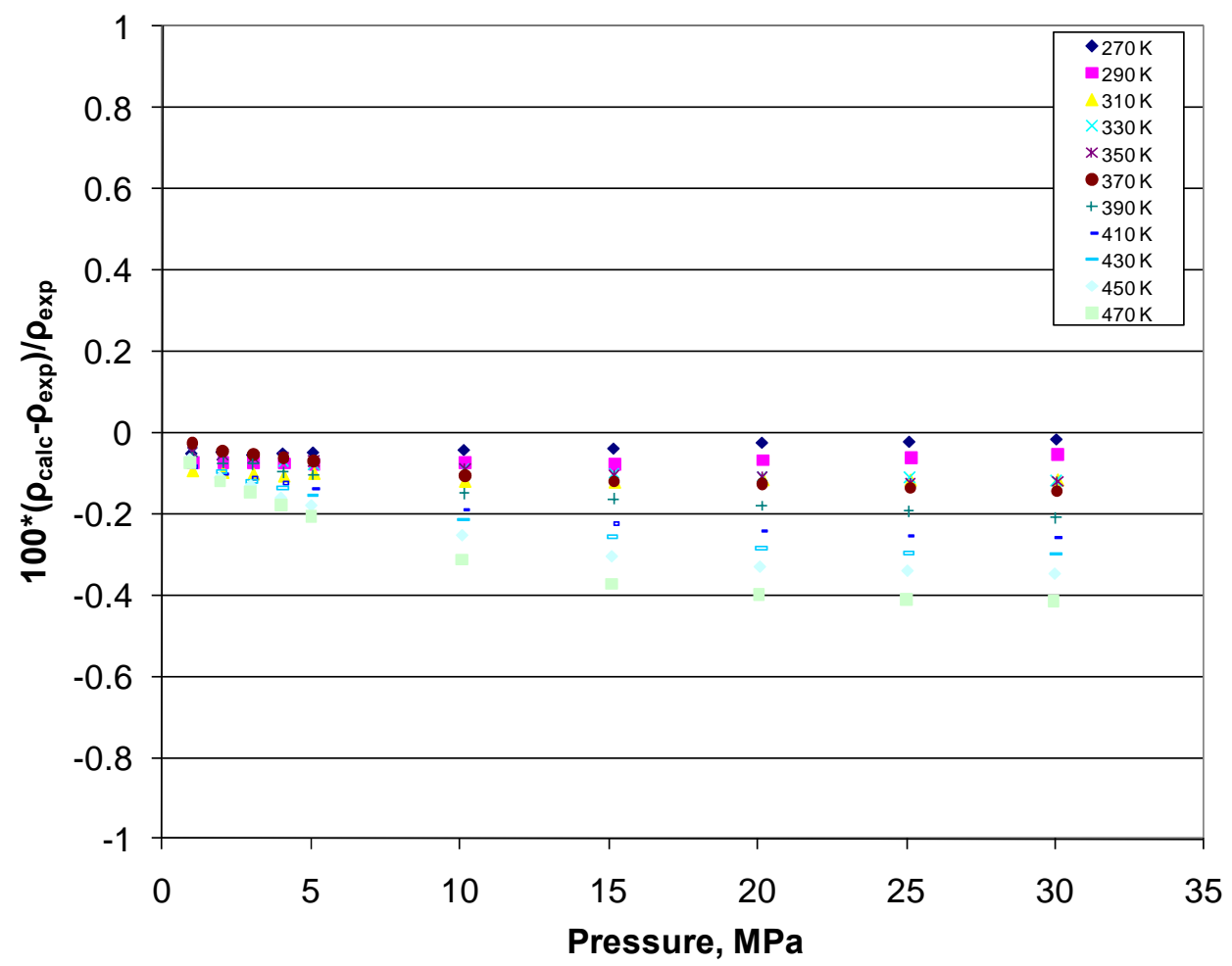

Figure 47: Deviation plot for density as a function of pressure for sample Jet-A-3638. 


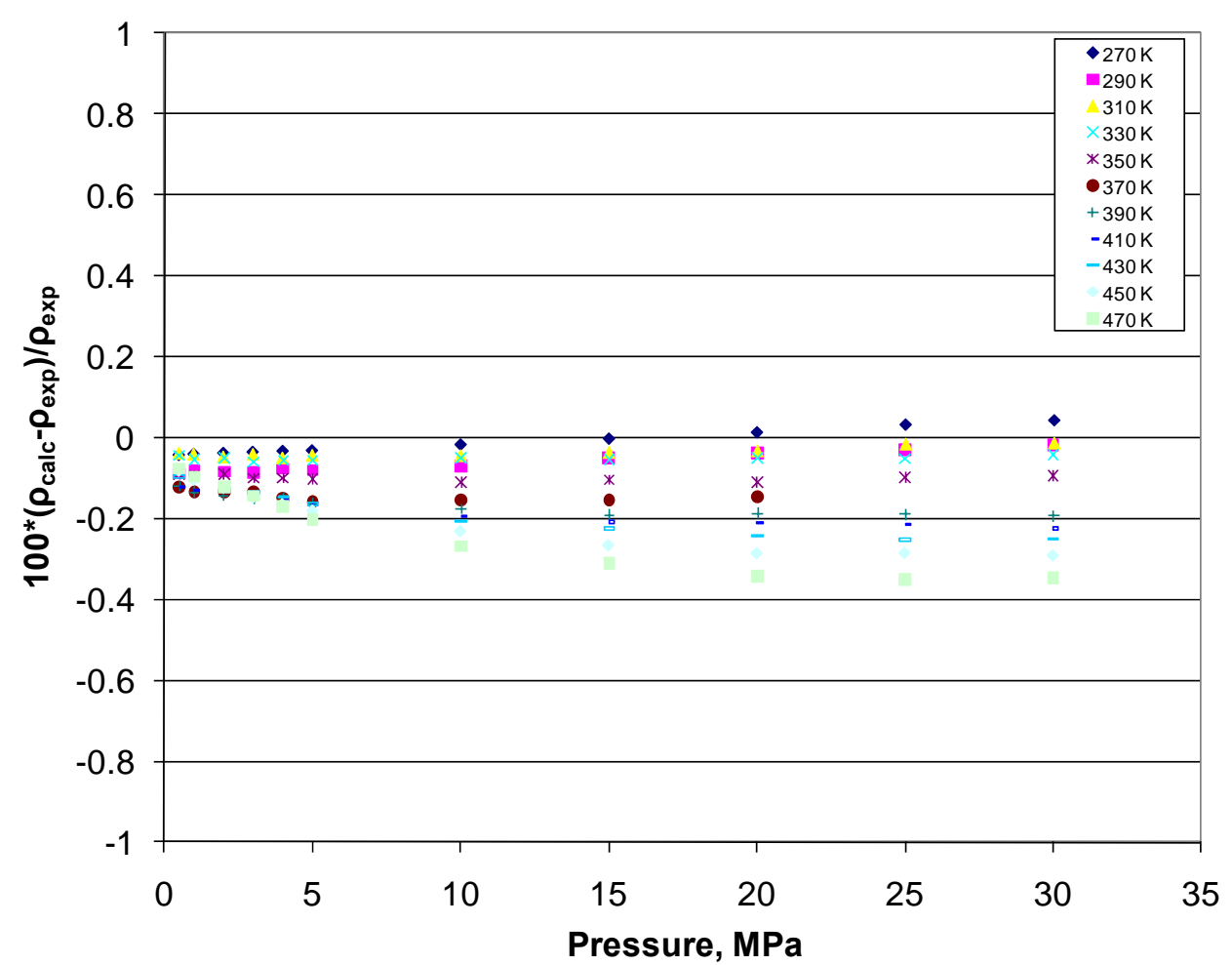

Figure 48: Deviation plot for density as a function of pressure for sample Jet-A-4658

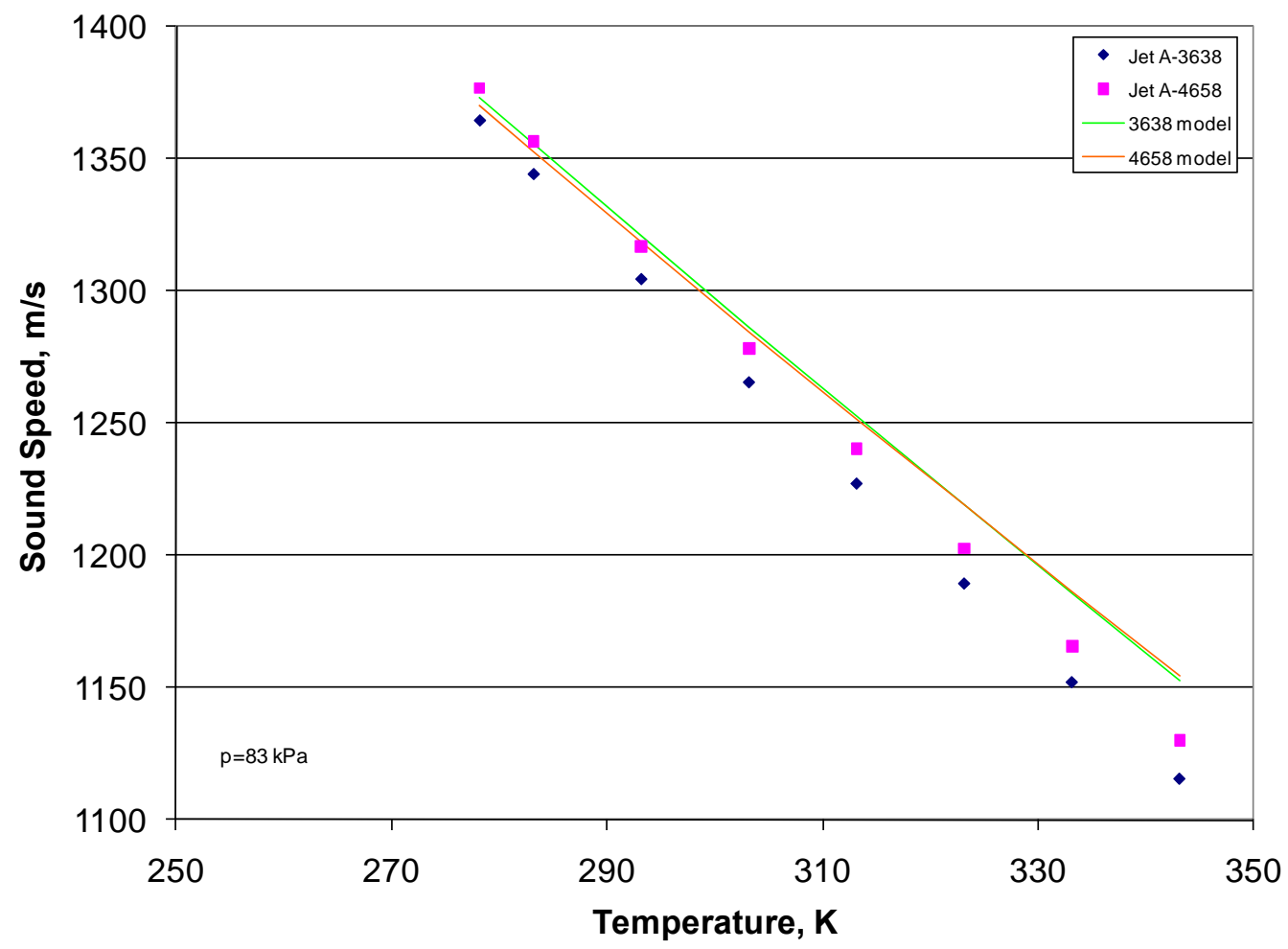

Figure 49: Calculated and experimental speed of sound for the Jet-A samples at $83 \mathrm{kPa}$ 


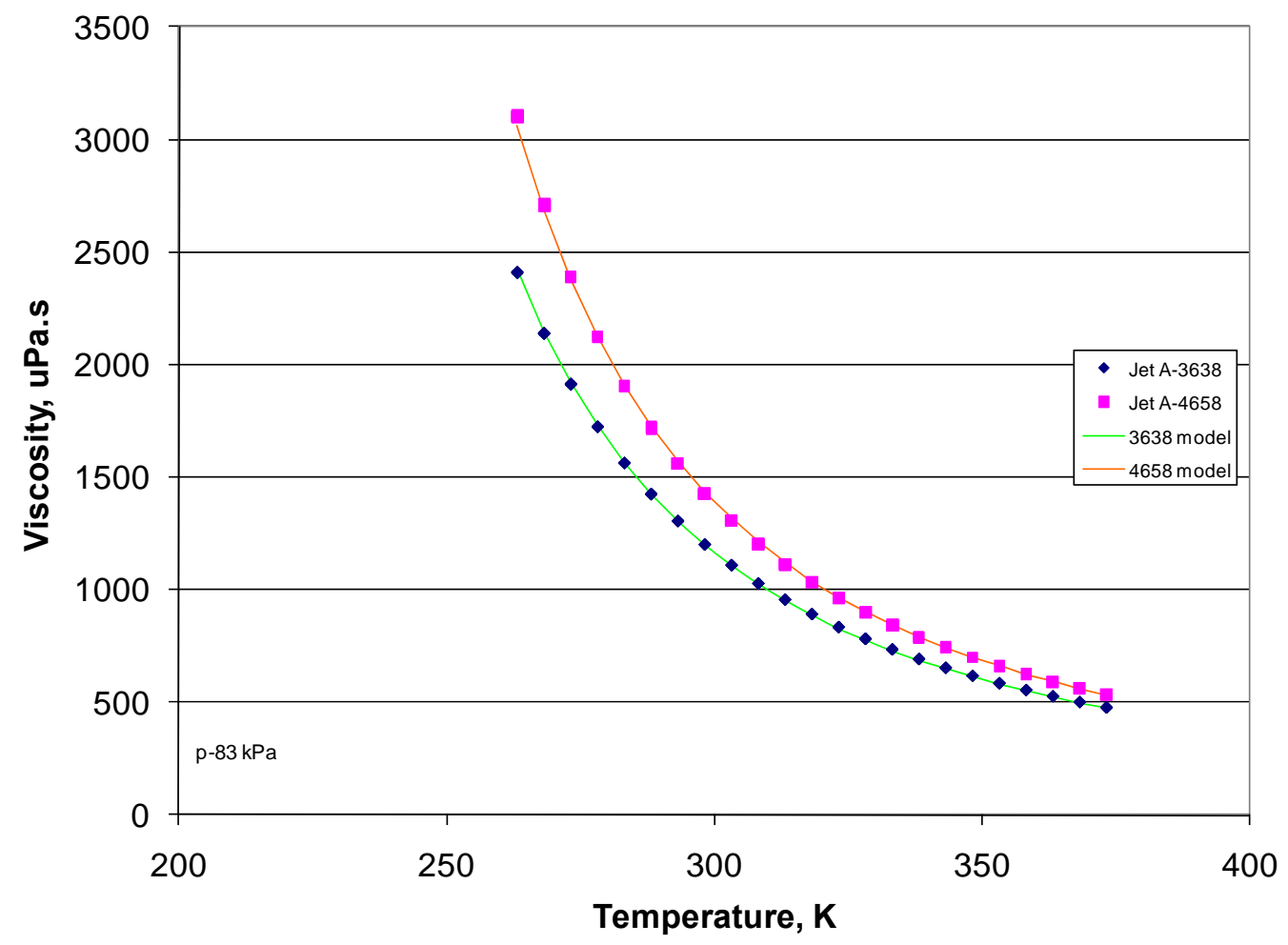

Figure 50: Plot of calculated and experimental viscosity for the Jet-A samples at $83 \mathrm{kPa}$.

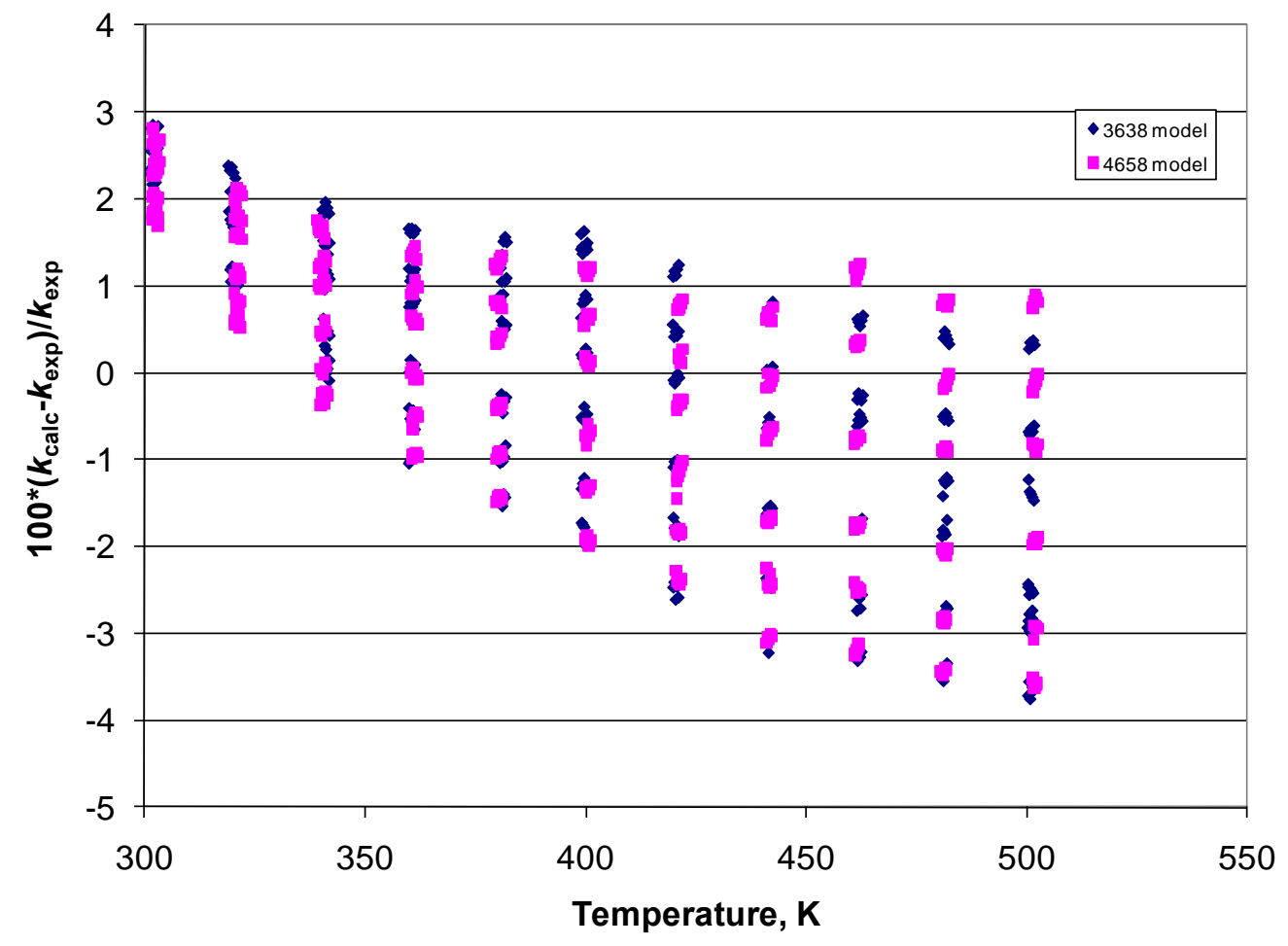

Figure 51: Deviation plot of calculated and experimental thermal conductivity for the Jet-

A samples at pressures to $40 \mathrm{MPa}$ 


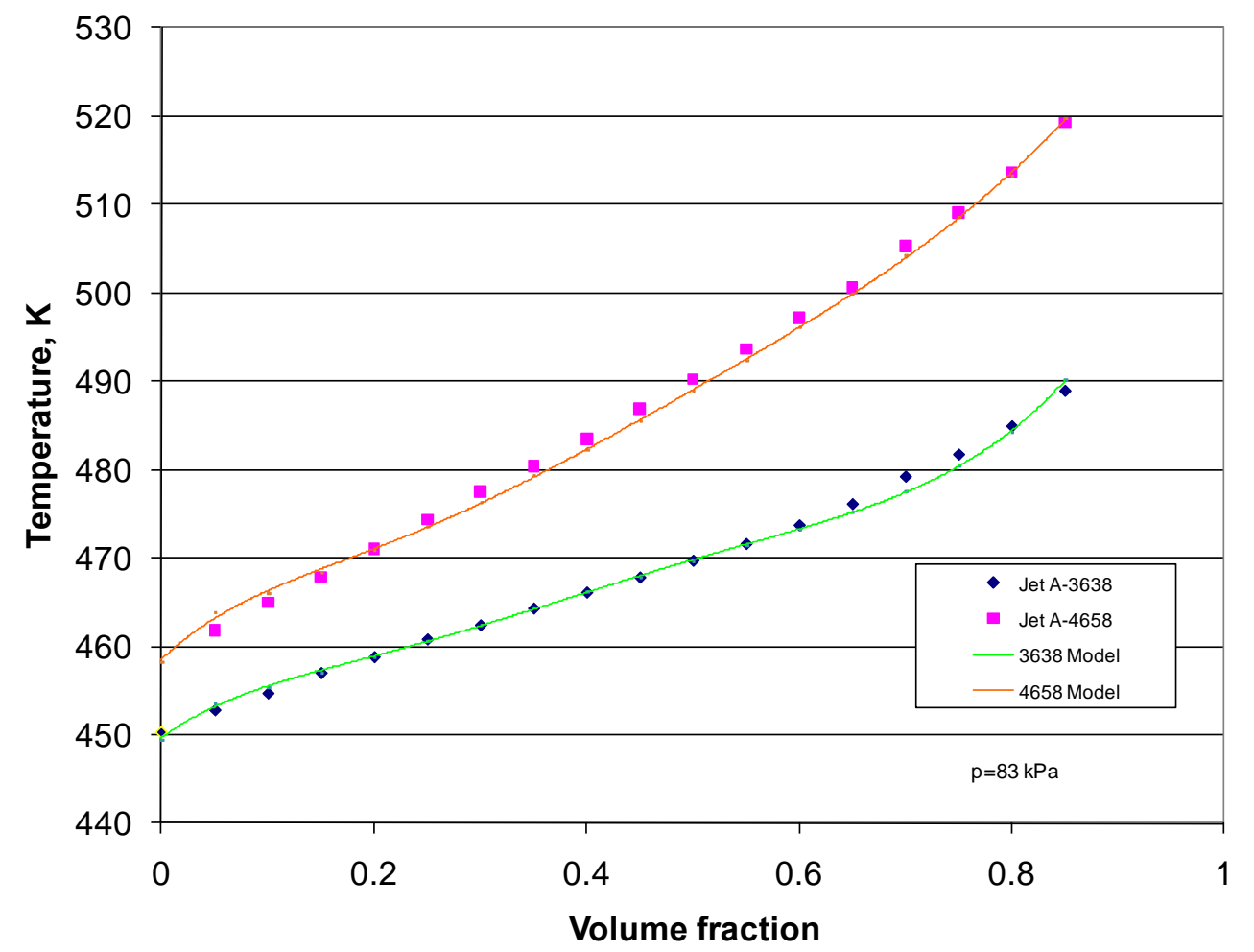

Figure 52: Distillation curves for the Jet-A samples, measured and calculated from the model.

The experimental values of the speed of sound and those calculated from the surrogate models are presented in Figure 49. All measurements were taken at ambient atmospheric pressure, and have an estimated uncertainty of $0.1 \%$. Neither of the models is able to represent the data to within their experimental uncertainty and systematically over predict the speed of sound; however, all models have deviations within $3.5 \%$.

Figure 50 is a plot of the calculated and experimental viscosity at atmospheric pressure as a function of temperature. This property is very sensitive to changes in composition, as indicated by an approximately $20 \%$ difference in viscosity of the two samples at $270 \mathrm{~K}$. The model was tuned so that the viscosity is represented by the model to within $3 \%$.

Figure 51 demonstrates the performance of the surrogate models for the thermal conductivity. The measurements covered temperatures from approximately $300 \mathrm{~K}$ to a maximum of $500 \mathrm{~K}$, at pressures up to $40 \mathrm{MPa}$ and were obtained from a transient hotwire apparatus with an estimated uncertainty of $1 \%$. The present surrogate models represent the data to within $4 \%$ over the range of conditions studied

Our final comparison with experimental data is presented in Figure 52, which shows the calculated and experimental advanced distillation curves. The distillation curves of the Jet-A-3638 and Jet-A-4658 sample differ significantly; at the end of the distillation they differ by $30{ }^{\circ} \mathrm{C}$. The surrogate models are able to capture the behavior of each sample. 
The volatility, as indicated by the advanced distillation curve, and the viscosity are very sensitive to changes in composition of the fuels.

Our surrogate models represent the thermophysical properties of the two samples studied. Work is in progress to develop a methodology to represent the Jet-A fuels as a single model that will characterize the fuels in terms of compositionally sensitive properties such as points on the distillation curve and viscosities. In addition, comparisons with existing surrogate models are in progress, and also further development of the equation of state models to improve the representation of the properties.

The composition of the surrogate mixture model for S-8, containing seven components, is summarized in Table 30. The computed distillation curve and the experimental data are shown in Figure 53. The difference between the calculated and experimental distillation temperatures is always within $1 \%$. The lightest (n-nonane) and heaviest fluids (nhexadecane) are present only in small amounts and determine the initial boiling behavior and the tail of the distillation curve. The overall shape of the distillation curve is due primarily to only four major components: 2,6-dimethyloctane, 3-methyldecane, ntridecane and n-tetradecane.

In Figures 54 to 57, we present comparisons of the S-8 surrogate model with experimental data. Figure 54 shows deviations of experimental and calculated surrogate density for S-8. The measurements cover the temperature range $233 \mathrm{~K}$ to $470 \mathrm{~K}$ at pressures to $30 \mathrm{MPa}$, and have an average absolute deviation (AAD) of $1.5 \%$

Figure 55 shows the deviations of experimental and calculated sound speeds for S-8. All of the sound speed measurements were made at local atmospheric pressure. The deviations are within $2.5 \%$, which exceeds the experimental uncertainty but is acceptable given the uncertainties in the constituent fluids and the mixture model.

Figure 56 shows the deviations of experimental and calculated viscosity at atmospheric pressure for S-8. The deviations are within about $5 \%$ over the temperature range investigated.

Figure 57 shows the deviations of experimental and calculated thermal conductivity over pressures from atmospheric to $70 \mathrm{MPa}$ at temperatures to $500 \mathrm{~K}$. The predictions from the surrogate model are within $6 \%$, with the largest deviations at the lower temperatures. 
Table 30. Composition of surrogate mixture for S-8

\begin{tabular}{|c|c|}
\hline Fluid & $\begin{array}{c}\text { S-8 surrogate composition, mole } \\
\text { fraction }\end{array}$ \\
\hline n-nonane & 0.03 \\
\hline 2,6-dimethyloctane & 0.28 \\
\hline 3-methyldecane & 0.34 \\
\hline n-tridecane & 0.13 \\
\hline n-tetradecane & 0.20 \\
\hline n-pentadecane & 0.015 \\
\hline n-hexadecane & 0.005 \\
\hline
\end{tabular}

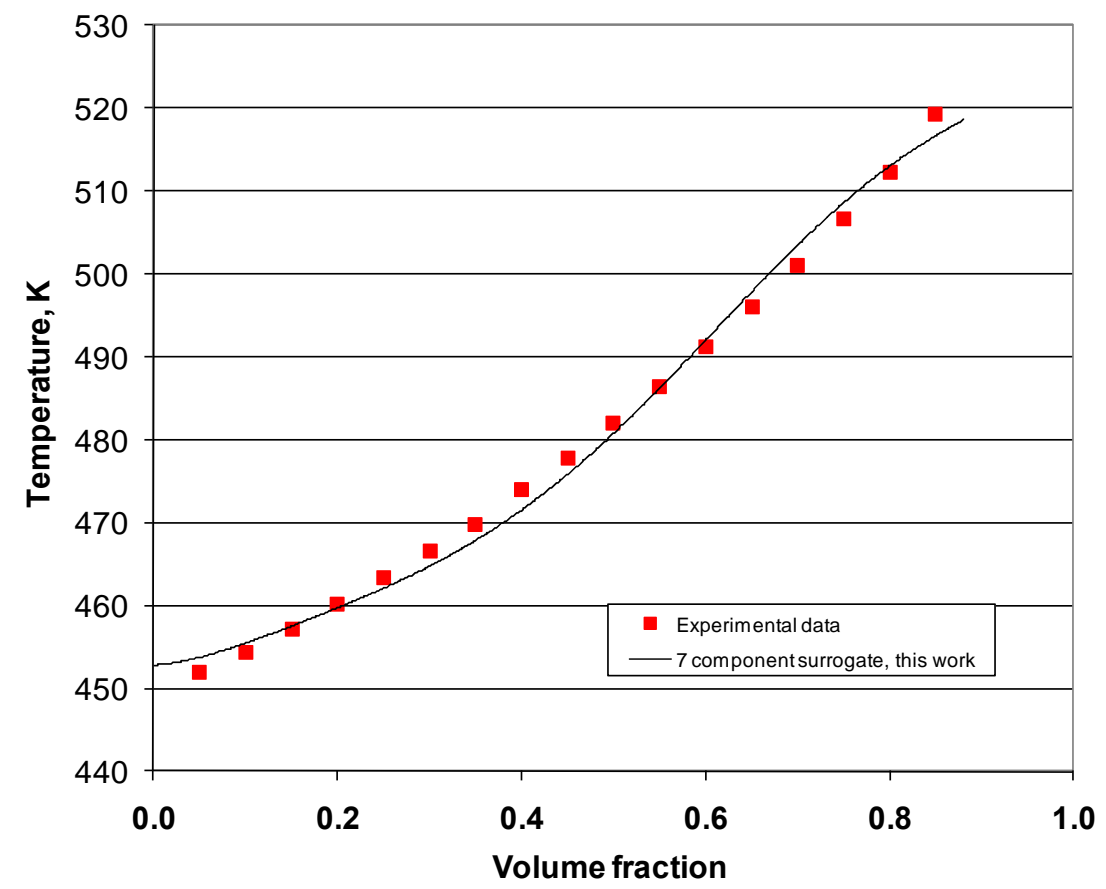

Figure 53. Distillation curve for S-8, showing the experimental and modeled curves. 


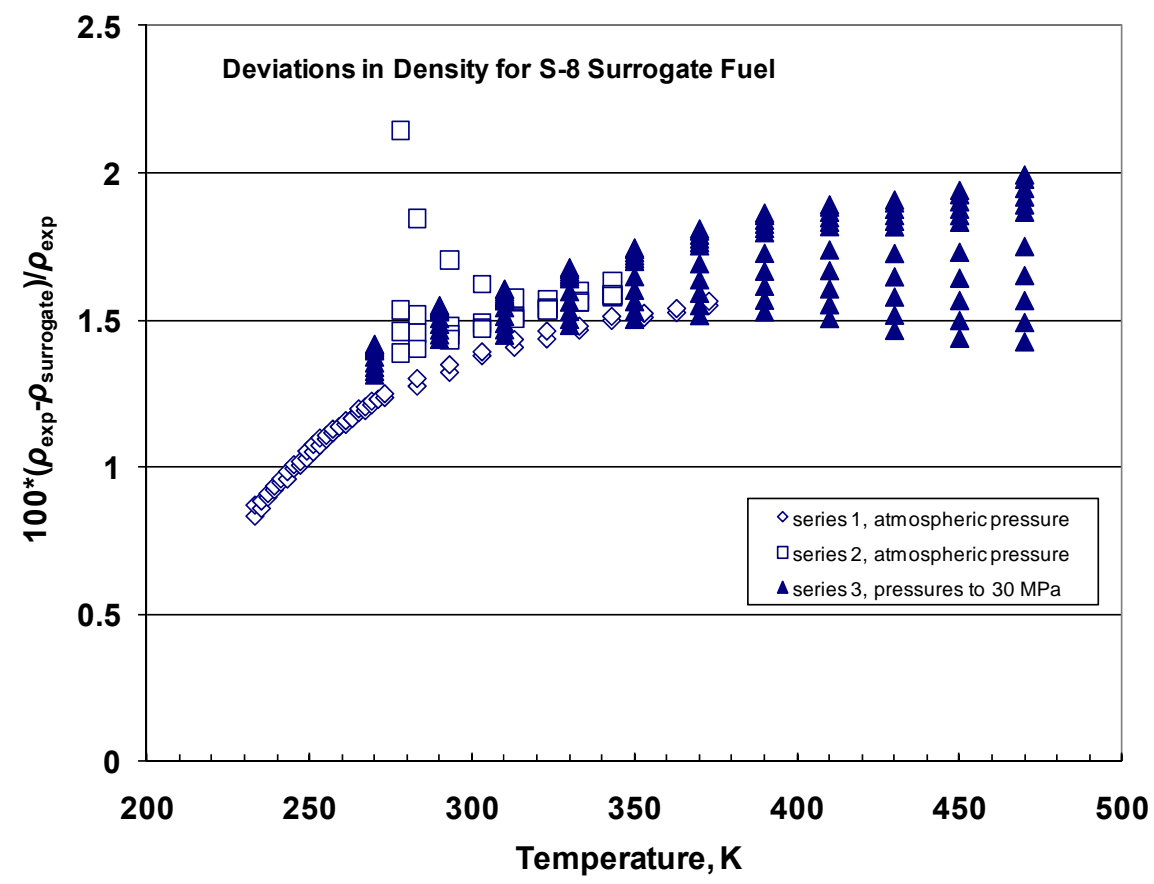

Figure 54: Deviations of experimental and calculated surrogate density for S-8.

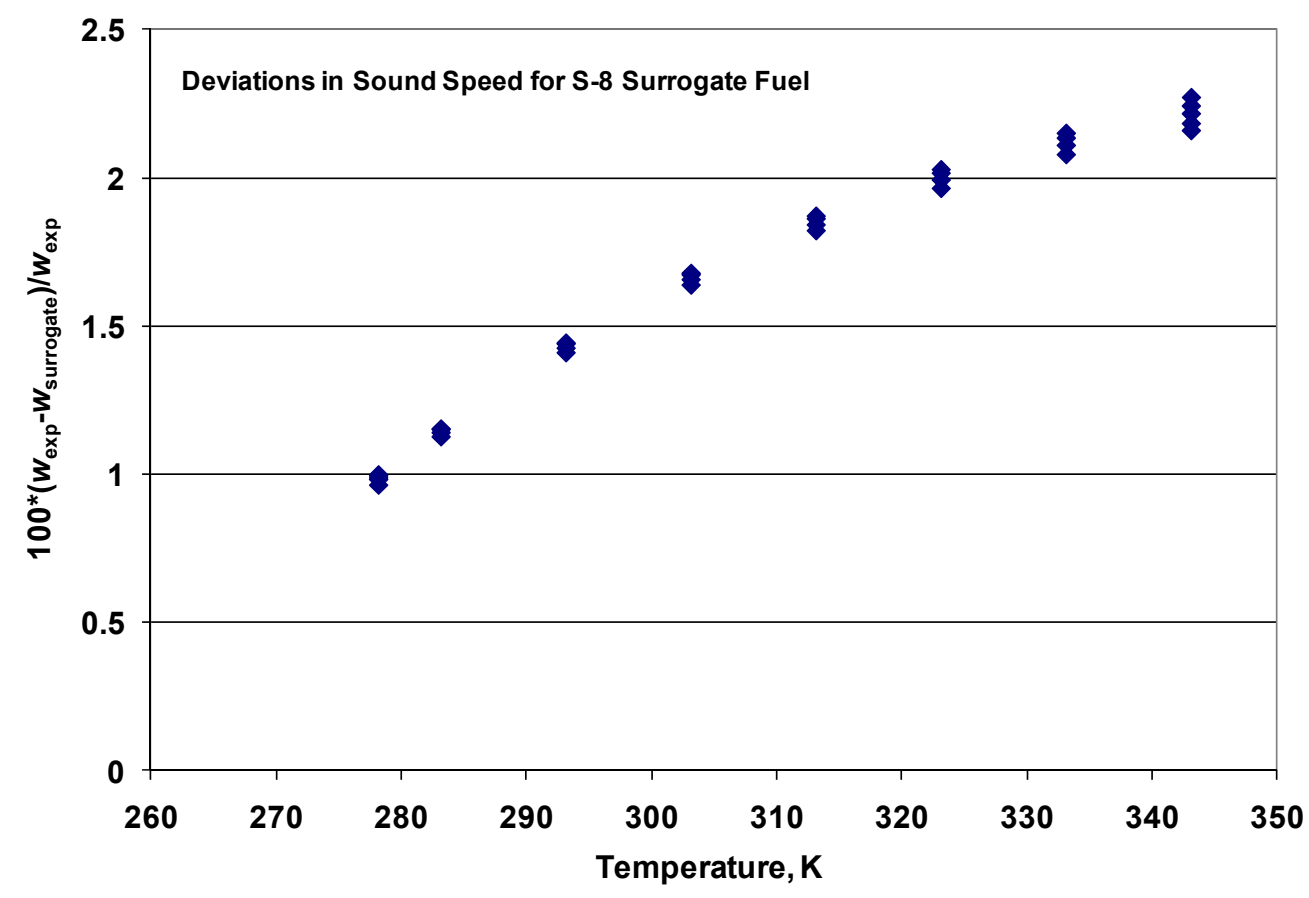

Figure 55: Deviations of experimental and calculated surrogate sound speed for S-8. 


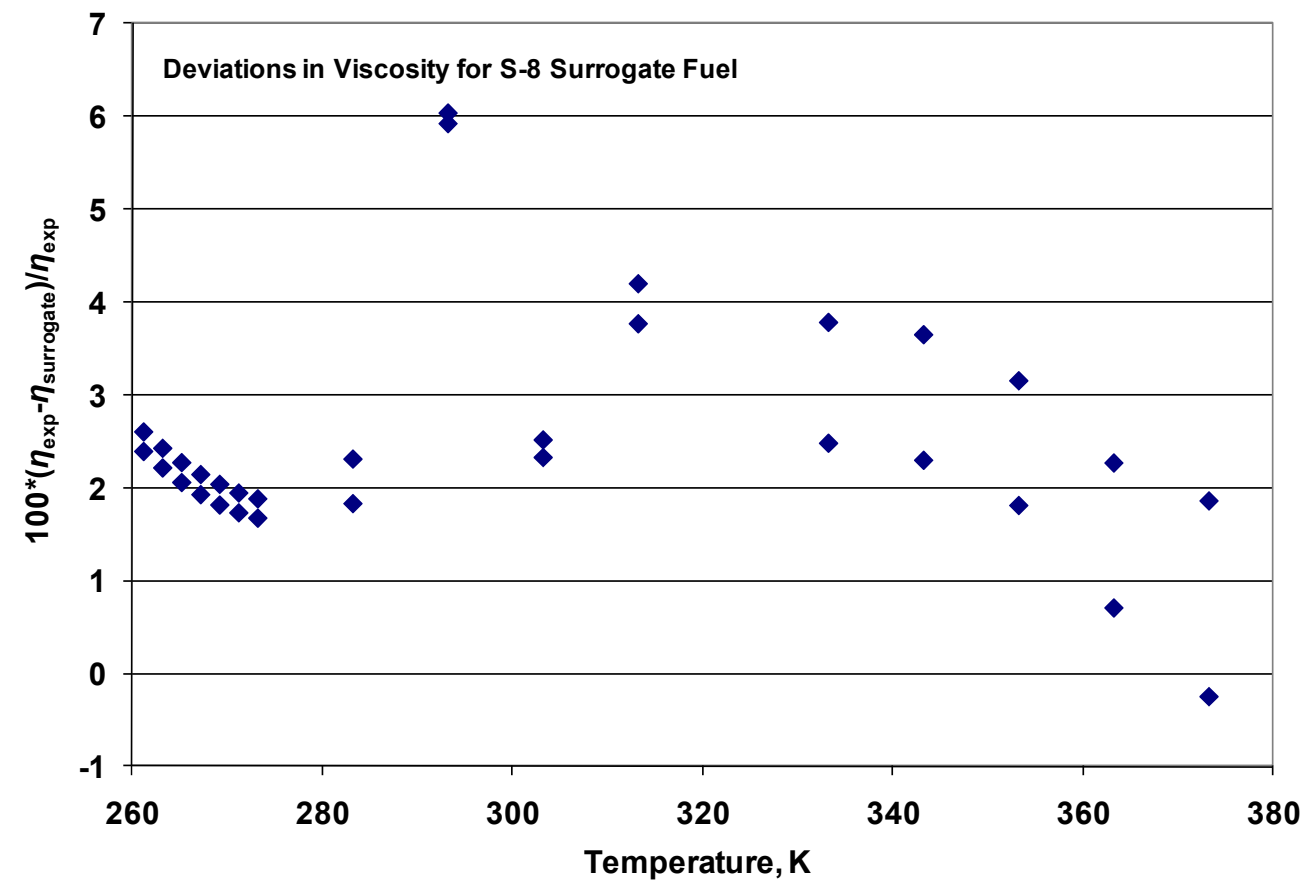

Figure 56: Deviations of experimental and calculated viscosity for S-8.

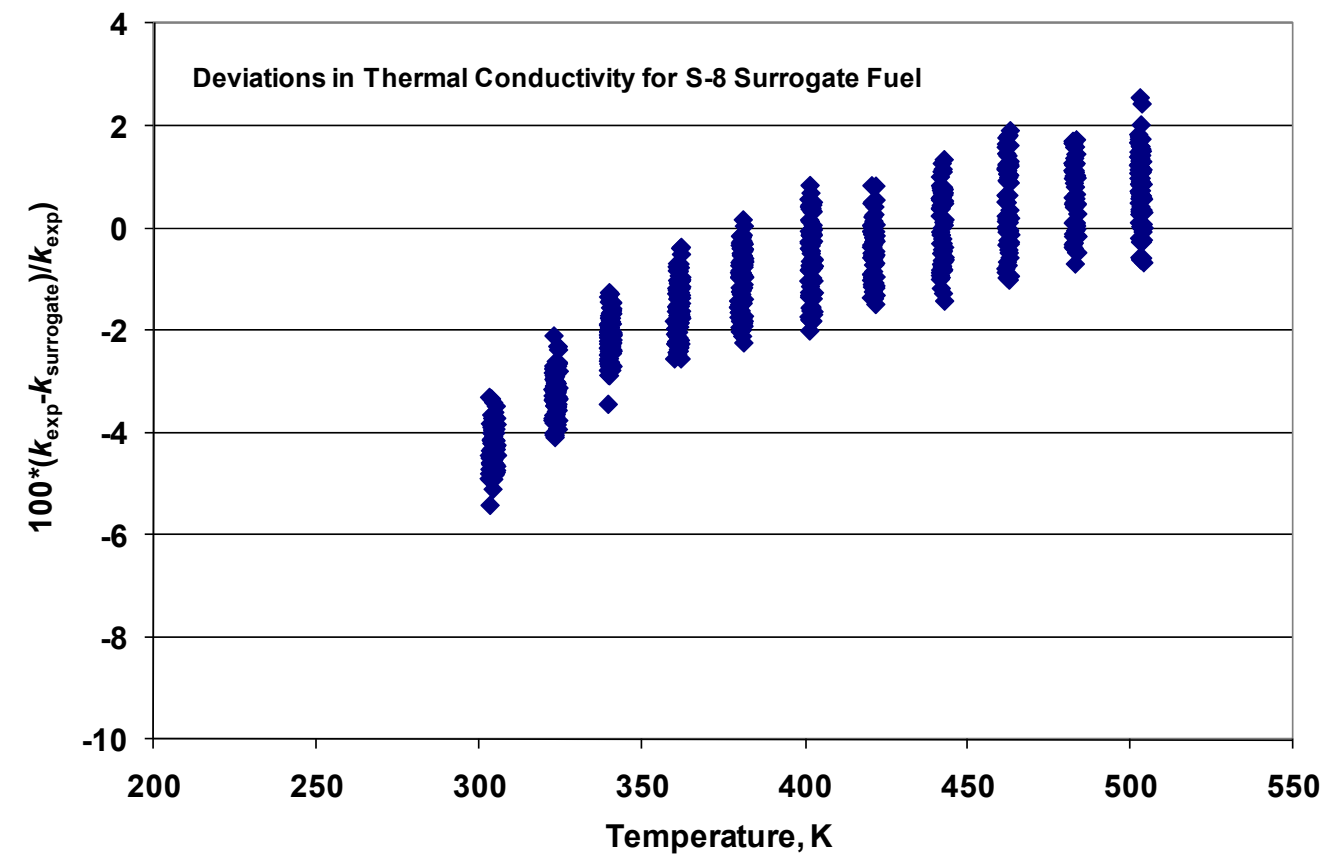

Figure 57: Deviations of experimental and calculated thermal conductivity for S-8. 


\section{References:}

1. Bruno, T. J., Svoronos, P.D.N., CRC Handbook of Basic Tables for Chemical Analysis, 2nd. ed. Taylor and Francis CRC Press: Boca Raton, 2004.

2. Bruno, T. J., Svoronos, P.D.N., CRC Handbook of Fundamental Spectroscopic Correlation Charts. Taylor and Francis CRC Press: Boca Raton, 2005.

3. Andersen, P. C., Bruno, T.J., Thermal decomposition kinetics of RP-1 rocket propellant. Ind. Eng. Chem. Res. 2005, 44, (6), 1670-1676.

4. Andersen, W. A., Bruno, T.J., Rapid screening of fluids for chemical stability in organic Rankine cycle applications. Ind. Eng. Chem. Res. 2005, 44, 5560-5566.

5. Widegren, J. A., Bruno, T.J., Thermal decomposition kinetics of the aviation fuel Jet-A. Ind. Eng. Chem. Res. 2008, 47, (13), 4342-4348.

6. Widegren, J. A., Bruno, T.J., Thermal decomposition kinetics of propylcyclohexane. Ind. Eng. Chem. Res. 2009, 48, (2), 654-659.

7. Bruno, T. J., Conditioning of flowing multiphase samples for chemical analysis. Sep. Sci. Technol. 2005, 40, (8), 1720-1732.

8. Outcalt, S. L., McLinden, M.O., Automated densimeter for the rapid characterization of industrial fluids. Ind. Eng. Chem. Res. 2007, 46, 8264 - 8269.

9. Laesecke, A., Outcalt, S.L. and Brumback, K., Density and Speed of Sound Measurements of Methyl- and Propylcyclohexane. Energy and Fuels 2008, 22, 2629 2636.

10. Perkins, R. A.; Huber, M. L., Measurement and correlation of the thermal conductivity of pentafluoroethane (R125) from $190 \mathrm{~K}$ to $512 \mathrm{~K}$ at pressures to $70 \mathrm{MPa}$. Journal of Chemical and Engineering Data 2006, 51, (3), 898-904.

11. Perkins, R. A.; Laesecke, A.; Nieto de Castro, C. A., Polarized Transient Hot Wire Thermal Conductivity Measurements. Fluid Phase Equilibria 1992, 80, 275-286.

12. Bruno, T. J., Improvements in the measurement of distillation curves - part 1: a composition-explicit approach. Ind. Eng. Chem. Res. 2006, 45, 4371-4380.

13. Bruno, T. J., Method and apparatus for precision in-line sampling of distillate. Sep. Sci. Technol. 2006, 41, (2), 309-314.

14. Smith, B. L., Bruno, T.J., Advanced distillation curve measurement with a model predictive temperature controller. Int. J. Thermophys. 2006, 27, 1419-1434. 
15. Bruno, T. J.; Smith, B. L., Enthalpy of combustion of fuels as a function of distillate cut: application of an advanced distillation curve method. Energy \& Fuels 2006, 20, 2109-2116.

16. Bruno, T. J., Thermodynamic, transport and chemical properties of "reference" JP-8. Book of Abstracts, Army Research Office and Air Force Office of Scientific Research, 2006 Contractor's meeting in Chemical Propulsion 2006, 15-18.

17. Bruno, T. J., The properties of S-8. In Final Report for MIPR F4FBEY6237G001, Air Force Research Laboratory: 2006.

18. Bruno, T. J., Laesecke, A., Outcalt, S.L., Seelig, H-D, Smith, B.L., Properties of a 50/50 Mixture of Jet-A + S-8, NIST-IR-6647. 2007.

19. Bruno, T. J., Wolk, A., Naydich, A., Stabilization of biodiesel fuel at elevated Temperature with Hydrogen Donors: evaluation with the advanced distillation curve method. Energy \& Fuels 2008, in press.

20. Bruno, T. J., Wolk, A., Naydich, A., Composition-explicit distillation curves for mixtures of gasoline with four-carbon alcohols (butanols). Energy \& Fuels 2008, in press.

21. Ott, L. S., Smith, B.L., Bruno, T.J., Advanced distillation curve measurements for corrosive fluids: application to two crude oils. Fuel 2008, 87, 3055-3064.

22. Ott, L. S., Smith, B.L., Bruno, T.J., Advanced distillation curve measurement: application to a bio-derived crude oil prepared from swine manure. Fuel 2008, 87, 33793387.

23. Ott, L. S., Smith, B.L., Bruno, T.J., Composition-explicit distillation curves of mixtures of diesel fuel with biomass-derived glycol ester oxygenates: a fuel design tool for decreased particulate emissions. Energy and Fuels 2008, 22, 2518-2526.

24. Ott, L. S., Hadler, A., Bruno, T.J., Variability of the rocket propellants RP-1, RP2, and TS-5: application of a composition- and enthalpy-explicit distillation curve method. Ind. Eng. Chem. Res. 2008, 47 (23), 9225-9233.

25. Ott, L. S., Bruno, T.J., Variability of biodiesel fuel and comparison to petroleumderived diesel fuel: application of a composition and enthalpy explicit distillation curve method. Energy \& Fuels 2008, 22, 2861-2868.

26. Smith, B. L., Bruno, T.J., Improvements in the measurement of distillation curves: part 3 - application to gasoline and gasoline + methanol mixtures. Ind. Eng. Chem. Res. 2007, 46, 297-309.

27. Smith, B. L., Bruno, T.J., Improvements in the measurement of distillation curves: part 4- application to the aviation turbine fuel Jet-A. Ind. Eng. Chem. Res. 2007, $46,310-320$. 
28. Smith, B. L., Bruno, T.J., Composition-explicit distillation curves of aviation fuel JP-8 and a coal based jet fuel. Energy \& Fuels 2007, 21, 2853-2862.

29. Smith, B. L., Bruno, T.J., Application of a Composition-Explicit Distillation Curve Metrology to Mixtures of Jet-A + Synthetic Fischer-Tropsch S-8. J. Propul. Power 2008, 24, (3), 619 - 623.

30. Smith, B. L., Ott, L.S., Bruno, T.J., Composition-explicit distillation curves of diesel fuel with glycol ether and glycol ester oxygenates: a design tool for decreased particulate emissions. Environ. Sci. Tech. 2008, 42, (20), 7682-7689.

31. Smith, B. L., Ott, L.S., Bruno, T.J., Composition-explicit distillation curves of commercial biodiesel fuels: comparison of petroleum derived fuel with B20 and B100. Ind. Eng. Chem. Res. 2008, 47, (16), 5832-5840.

32. Ott, L. S., Smith, B.L., Bruno, T.J., Experimental test of the Sydney Young equation for the presentation of distillation curves. J. Chem. Thermodynam. 2008, 40, 1352-1357.

33. Standard Test Method for Boiling Range Distribution of Petroleum Fractions by Gas Chromatography, ASTM Standard D2887-02, ASTM Annual Book of Standards, 2004. In 2004.

34. Outcalt, S. L., Laesecke, A., Freund, M.B., Density and speed of sound measurements of Jet A and S 8 aviation turbine fuels. Energy \& Fuels 2009, 23, (3), 1626-1633.

35. Huber, M. L., Smith, B.L., Ott, L.S., Bruno, T.J., Surrogate Mixture Model for the Thermophysical Properties of Synthetic Aviation Fuel S-8: Explicit Application of the Advanced Distillation Curve. Energy \& Fuels 2008, 22, 1104 - 1114.

36. Huber, M. L., Lemmon, E.W., Diky, V., Smith, B.L., Bruno, T.J., Chemically authentic surrogate mixture model for the thermophysical properties of a coal-derivedliquid fuel. Energy and Fuels 2008, 22, 3249-3257.

37. Rowley, R. L., Wilding, W.V., Oscarson, J.L., Zundel, N.A., Marshall, T.L., Daubert, T.E., Danner, R.P., , DIPPR Data Compilation of Pure Compound Properties, Design Institute for Physical Properties AIChE, New York, NY, 2004. In.

38. Huber, M. L., Lemmon, E., Ott, L.S., Bruno, T.J., Preliminary surrogate mixture models for rocket propellants RP-1 and RP-2. Energy \& Fuels 2009, 23, 3083-3088.

39. Huber, M. L., Lemmon, E., Bruno, T.J., Effect of RP-1 compositional variability on thermophysical properties. Energy \& Fuels 2009, 23, 5550-5555.

40. Span, R.; Wagner, W., Equations of state for technical applications. I. Simultaneously optimized functional forms for nonpolar and polar fluids. International Journal of Thermophysics 2003, 24, (1), 1-39. 
41. Lemmon, E. W., McLinden, M.O., Huber, M.L., REFPROP, Reference fluid thermodynamic and transport properties, NIST Standard Reference Database 23. National Institute of Standards and Technology, Gaithersburg, MD, 2005: 2005. 


\section{Appendix I: Thermal Conductivity Measurements for Aviation Fuels}


Table A1. Thermal conductivity of Jet-A-3602 in the liquid phase.

\begin{tabular}{|c|c|c|c|c|c|}
\hline Point ID & $\begin{array}{c}T_{0} \\
(\mathrm{~K})\end{array}$ & $\begin{array}{c}T_{\mathrm{e}} \\
(\mathrm{K})\end{array}$ & $\begin{array}{c}P_{\mathrm{e}} \\
(\mathrm{MPa})\end{array}$ & $\begin{array}{c}\lambda_{\mathrm{e}} \\
\left(\mathrm{W} \cdot \mathrm{m}^{-1} \mathrm{~K}^{-1}\right)\end{array}$ & $\begin{array}{c}q \\
\left(W \cdot m^{-1}\right)\end{array}$ \\
\hline 1001 & 298.295 & 296.274 & 1.984 & 0.1108 & 0.4694 \\
\hline 1003 & 298.672 & 296.292 & 1.968 & 0.1106 & 0.5496 \\
\hline 1005 & 299.099 & 296.325 & 1.961 & 0.1106 & 0.6375 \\
\hline 1007 & 299.543 & 296.349 & 1.948 & 0.1105 & 0.7320 \\
\hline 1009 & 300.022 & 296.374 & 1.939 & 0.1105 & 0.8329 \\
\hline 1011 & 301.639 & 299.624 & 0.174 & 0.1099 & 0.4651 \\
\hline 1013 & 301.987 & 299.627 & 0.174 & 0.1098 & 0.5446 \\
\hline 1015 & 302.367 & 299.627 & 0.175 & 0.1097 & 0.6317 \\
\hline 1017 & 302.774 & 299.622 & 0.170 & 0.1098 & 0.7254 \\
\hline 1019 & 303.214 & 299.627 & 0.163 & 0.1096 & 0.8254 \\
\hline 1021 & 301.619 & 299.634 & 4.975 & 0.1113 & 0.4651 \\
\hline 1023 & 301.964 & 299.636 & 4.980 & 0.1112 & 0.5446 \\
\hline 1025 & 302.346 & 299.639 & 4.984 & 0.1112 & 0.6316 \\
\hline 1027 & 302.750 & 299.642 & 4.983 & 0.1110 & 0.7252 \\
\hline 1029 & 303.180 & 299.640 & 4.971 & 0.1111 & 0.8253 \\
\hline 1031 & 301.609 & 299.651 & 10.178 & 0.1127 & 0.4654 \\
\hline 1033 & 301.951 & 299.654 & 10.176 & 0.1126 & 0.5450 \\
\hline 1035 & 302.316 & 299.651 & 10.187 & 0.1125 & 0.6320 \\
\hline 1037 & 302.713 & 299.650 & 10.197 & 0.1126 & 0.7254 \\
\hline 1039 & 303.138 & 299.649 & 10.198 & 0.1126 & 0.8253 \\
\hline 1041 & 301.570 & 299.672 & 20.550 & 0.1153 & 0.4651 \\
\hline 1043 & 301.900 & 299.670 & 20.553 & 0.1153 & 0.5446 \\
\hline 1045 & 302.265 & 299.672 & 20.554 & 0.1154 & 0.6317 \\
\hline 1047 & 302.653 & 299.670 & 20.555 & 0.1154 & 0.7253 \\
\hline 1049 & 303.070 & 299.672 & 20.549 & 0.1153 & 0.8253 \\
\hline 1051 & 301.529 & 299.686 & 30.277 & 0.1178 & 0.4651 \\
\hline 1053 & 301.859 & 299.689 & 30.274 & 0.1178 & 0.5447 \\
\hline 1055 & 302.206 & 299.683 & 30.275 & 0.1178 & 0.6317 \\
\hline 1057 & 302.590 & 299.682 & 30.278 & 0.1178 & 0.7253 \\
\hline 1059 & 303.003 & 299.685 & 30.282 & 0.1178 & 0.8252 \\
\hline 1061 & 301.527 & 299.694 & 40.263 & 0.1201 & 0.4653 \\
\hline 1063 & 301.842 & 299.688 & 40.266 & 0.1202 & 0.5448 \\
\hline 1065 & 302.199 & 299.693 & 40.251 & 0.1203 & 0.6320 \\
\hline 1067 & 302.576 & 299.694 & 40.236 & 0.1201 & 0.7258 \\
\hline 1069 & 302.972 & 299.689 & 40.224 & 0.1202 & 0.8259 \\
\hline 2001 & 321.196 & 319.226 & 0.225 & 0.1072 & 0.4427 \\
\hline 2003 & 321.505 & 319.239 & 0.249 & 0.1075 & 0.5181 \\
\hline 2005 & 321.891 & 319.253 & 0.261 & 0.1075 & 0.6009 \\
\hline 2007 & 322.305 & 319.266 & 0.273 & 0.1074 & 0.6899 \\
\hline 2009 & 322.750 & 319.280 & 0.290 & 0.1073 & 0.7849 \\
\hline 2011 & 321.338 & 319.407 & 5.164 & 0.1090 & 0.4424 \\
\hline 2013 & 321.693 & 319.425 & 5.179 & 0.1091 & 0.5179 \\
\hline 2015 & 322.008 & 319.426 & 5.194 & 0.1090 & 0.6006 \\
\hline 2017 & 322.419 & 319.441 & 5.207 & 0.1089 & 0.6895 \\
\hline 2019 & 322.853 & 319.454 & 5.218 & 0.1089 & 0.7845 \\
\hline 2021 & 321.614 & 319.717 & 10.194 & 0.1107 & 0.4420 \\
\hline 2023 & 321.952 & 319.724 & 10.206 & 0.1106 & 0.5174 \\
\hline 2025 & 322.320 & 319.731 & 10.216 & 0.1105 & 0.6002 \\
\hline 2027 & 322.722 & 319.745 & 10.222 & 0.1105 & 0.6891 \\
\hline 2029 & 323.143 & 319.750 & 10.228 & 0.1104 & 0.7840 \\
\hline 2031 & 321.722 & 319.865 & 20.180 & 0.1137 & 0.4419 \\
\hline
\end{tabular}




\begin{tabular}{|c|c|c|c|c|c|}
\hline 2033 & 322.056 & 319.876 & 20.156 & 0.1136 & 0.5177 \\
\hline 2035 & 322.403 & 319.872 & 20.157 & 0.1135 & 0.6005 \\
\hline 2037 & 322.796 & 319.885 & 20.158 & 0.1134 & 0.6895 \\
\hline 2039 & 323.204 & 319.887 & 20.169 & 0.1134 & 0.7844 \\
\hline 2041 & 321.702 & 319.958 & 30.172 & 0.1163 & 0.4417 \\
\hline 2043 & 322.025 & 319.967 & 30.161 & 0.1161 & 0.5174 \\
\hline 2045 & 322.366 & 319.966 & 30.155 & 0.1162 & 0.6002 \\
\hline 2047 & 322.745 & 319.978 & 30.158 & 0.1160 & 0.6891 \\
\hline 2049 & 323.148 & 319.980 & 30.154 & 0.1162 & 0.7841 \\
\hline 2051 & 321.861 & 320.074 & 40.148 & 0.1187 & 0.4418 \\
\hline 2053 & 322.169 & 320.078 & 40.154 & 0.1188 & 0.5173 \\
\hline 2055 & 322.514 & 320.084 & 40.161 & 0.1188 & 0.6000 \\
\hline 2057 & 322.883 & 320.088 & 40.170 & 0.1188 & 0.6889 \\
\hline 2059 & 323.263 & 320.086 & 40.178 & 0.1187 & 0.7837 \\
\hline 3001 & 341.527 & 339.564 & 0.293 & 0.1049 & 0.4213 \\
\hline 3003 & 341.762 & 339.569 & 0.303 & 0.1049 & 0.4932 \\
\hline 3005 & 342.136 & 339.581 & 0.312 & 0.1049 & 0.5720 \\
\hline 3007 & 342.535 & 339.593 & 0.320 & 0.1047 & 0.6567 \\
\hline 3009 & 342.953 & 339.599 & 0.327 & 0.1048 & 0.7472 \\
\hline 3011 & 341.537 & 339.694 & 5.129 & 0.1067 & 0.4211 \\
\hline 3013 & 341.871 & 339.700 & 5.135 & 0.1066 & 0.4931 \\
\hline 3015 & 342.231 & 339.708 & 5.142 & 0.1065 & 0.5719 \\
\hline 3017 & 342.624 & 339.717 & 5.150 & 0.1064 & 0.6566 \\
\hline 3019 & 343.036 & 339.724 & 5.154 & 0.1064 & 0.7471 \\
\hline 3021 & 341.610 & 339.798 & 10.188 & 0.1084 & 0.4210 \\
\hline 3023 & 341.932 & 339.803 & 10.183 & 0.1083 & 0.4930 \\
\hline 3025 & 342.286 & 339.805 & 10.173 & 0.1084 & 0.5720 \\
\hline 3027 & 342.669 & 339.815 & 10.171 & 0.1081 & 0.6569 \\
\hline 3029 & 343.081 & 339.822 & 10.170 & 0.1082 & 0.7474 \\
\hline 3031 & 341.664 & 339.918 & 20.026 & 0.1115 & 0.4212 \\
\hline 3033 & 341.980 & 339.921 & 20.019 & 0.1115 & 0.4934 \\
\hline 3035 & 342.323 & 339.928 & 20.050 & 0.1115 & 0.5718 \\
\hline 3037 & 342.688 & 339.930 & 20.056 & 0.1114 & 0.6565 \\
\hline 3039 & 343.084 & 339.935 & 20.066 & 0.1113 & 0.7469 \\
\hline 3041 & 341.704 & 339.991 & 30.148 & 0.1143 & 0.4212 \\
\hline 3043 & 342.013 & 339.996 & 30.153 & 0.1143 & 0.4932 \\
\hline 3045 & 342.347 & 340.000 & 30.179 & 0.1145 & 0.5717 \\
\hline 3047 & 342.703 & 339.998 & 30.188 & 0.1144 & 0.6564 \\
\hline 3049 & 343.088 & 340.005 & 30.194 & 0.1143 & 0.7468 \\
\hline 3051 & 341.750 & 340.067 & 40.334 & 0.1174 & 0.4209 \\
\hline 3053 & 342.047 & 340.068 & 40.339 & 0.1174 & 0.4928 \\
\hline 3055 & 342.372 & 340.071 & 40.336 & 0.1173 & 0.5717 \\
\hline 3057 & 342.724 & 340.073 & 40.341 & 0.1173 & 0.6564 \\
\hline 3059 & 343.098 & 340.080 & 40.349 & 0.1172 & 0.7468 \\
\hline 4001 & 360.637 & 358.790 & 0.166 & 0.1022 & 0.4031 \\
\hline 4003 & 360.911 & 358.795 & 0.175 & 0.1023 & 0.4719 \\
\hline 4005 & 361.273 & 358.804 & 0.171 & 0.1021 & 0.5474 \\
\hline 4007 & 361.655 & 358.810 & 0.167 & 0.1021 & 0.6287 \\
\hline 4009 & 362.064 & 358.817 & 0.169 & 0.1021 & 0.7154 \\
\hline 4011 & 360.656 & 358.894 & 5.232 & 0.1042 & 0.4031 \\
\hline 4013 & 360.979 & 358.902 & 5.238 & 0.1041 & 0.4719 \\
\hline 4015 & 361.327 & 358.908 & 5.242 & 0.1041 & 0.5474 \\
\hline 4017 & 361.704 & 358.912 & 5.247 & 0.1040 & 0.6285 \\
\hline 4019 & 362.105 & 358.921 & 5.251 & 0.1040 & 0.7151 \\
\hline 4021 & 360.745 & 358.982 & 10.164 & 0.1061 & 0.4030 \\
\hline 4023 & 361.062 & 358.988 & 10.169 & 0.1060 & 0.4719 \\
\hline
\end{tabular}




\begin{tabular}{|c|c|c|c|c|c|}
\hline 4025 & 361.405 & 358.992 & 10.175 & 0.1060 & 0.5474 \\
\hline 4027 & 361.774 & 359.000 & 10.182 & 0.1059 & 0.6285 \\
\hline 4029 & 362.163 & 359.000 & 10.190 & 0.1058 & 0.7150 \\
\hline 4031 & 360.798 & 359.072 & 20.275 & 0.1095 & 0.4029 \\
\hline 4033 & 361.097 & 359.074 & 20.279 & 0.1095 & 0.4718 \\
\hline 4035 & 361.433 & 359.079 & 20.278 & 0.1094 & 0.5472 \\
\hline 4037 & 361.789 & 359.079 & 20.267 & 0.1093 & 0.6285 \\
\hline 4039 & 362.173 & 359.087 & 20.268 & 0.1093 & 0.7152 \\
\hline 4041 & 360.765 & 359.136 & 30.385 & 0.1128 & 0.4028 \\
\hline 4043 & 361.111 & 359.137 & 30.390 & 0.1127 & 0.4718 \\
\hline 4045 & 361.438 & 359.143 & 30.392 & 0.1126 & 0.5472 \\
\hline 4047 & 361.785 & 359.145 & 30.380 & 0.1127 & 0.6285 \\
\hline 4049 & 362.149 & 359.143 & 30.372 & 0.1126 & 0.7152 \\
\hline 4051 & 360.846 & 359.196 & 40.225 & 0.1158 & 0.4030 \\
\hline 4053 & 361.133 & 359.200 & 40.223 & 0.1157 & 0.4720 \\
\hline 4055 & 361.443 & 359.199 & 40.234 & 0.1157 & 0.5473 \\
\hline 4057 & 361.786 & 359.205 & 40.246 & 0.1156 & 0.6283 \\
\hline 4059 & 362.149 & 359.211 & 40.250 & 0.1156 & 0.7148 \\
\hline 5001 & 380.967 & 379.179 & 0.263 & 0.0995 & 0.3856 \\
\hline 5003 & 381.285 & 379.183 & 0.259 & 0.0996 & 0.4516 \\
\hline 5005 & 381.632 & 379.192 & 0.257 & 0.0994 & 0.5239 \\
\hline 5007 & 382.008 & 379.199 & 0.258 & 0.0993 & 0.6015 \\
\hline 5009 & 382.401 & 379.203 & 0.258 & 0.0994 & 0.6845 \\
\hline 5011 & 380.987 & 379.257 & 5.121 & 0.1015 & 0.3855 \\
\hline 5013 & 381.303 & 379.264 & 5.115 & 0.1015 & 0.4516 \\
\hline 5015 & 381.644 & 379.268 & 5.114 & 0.1015 & 0.5238 \\
\hline 5017 & 382.011 & 379.272 & 5.116 & 0.1014 & 0.6014 \\
\hline 5019 & 382.397 & 379.278 & 5.117 & 0.1013 & 0.6842 \\
\hline 5021 & 381.059 & 379.335 & 10.120 & 0.1035 & 0.3857 \\
\hline 5023 & 381.369 & 379.345 & 10.123 & 0.1034 & 0.4516 \\
\hline 5025 & 381.697 & 379.346 & 10.132 & 0.1034 & 0.5237 \\
\hline 5027 & 382.053 & 379.348 & 10.136 & 0.1033 & 0.6012 \\
\hline 5029 & 382.431 & 379.351 & 10.143 & 0.1033 & 0.6840 \\
\hline 5031 & 381.064 & 379.398 & 20.233 & 0.1074 & 0.3857 \\
\hline 5033 & 381.357 & 379.402 & 20.245 & 0.1073 & 0.4514 \\
\hline 5035 & 381.683 & 379.406 & 20.250 & 0.1072 & 0.5236 \\
\hline 5037 & 382.022 & 379.406 & 20.255 & 0.1072 & 0.6011 \\
\hline 5039 & 382.385 & 379.405 & 20.260 & 0.1072 & 0.6840 \\
\hline 5041 & 381.066 & 379.457 & 30.226 & 0.1107 & 0.3855 \\
\hline 5043 & 381.351 & 379.458 & 30.231 & 0.1106 & 0.4514 \\
\hline 5045 & 381.660 & 379.459 & 30.236 & 0.1106 & 0.5235 \\
\hline 5047 & 381.996 & 379.464 & 30.236 & 0.1106 & 0.6011 \\
\hline 5049 & 382.353 & 379.466 & 30.239 & 0.1106 & 0.6840 \\
\hline 5051 & 381.067 & 379.512 & 40.517 & 0.1140 & 0.3855 \\
\hline 5053 & 381.341 & 379.514 & 40.520 & 0.1140 & 0.4513 \\
\hline 5055 & 381.646 & 379.516 & 40.523 & 0.1141 & 0.5235 \\
\hline 5057 & 381.963 & 379.513 & 40.527 & 0.1140 & 0.6011 \\
\hline 5059 & 382.314 & 379.516 & 40.511 & 0.1140 & 0.6841 \\
\hline 6001 & 401.768 & 399.994 & 0.177 & 0.0966 & 0.3696 \\
\hline 6003 & 402.070 & 399.990 & 0.180 & 0.0965 & 0.4328 \\
\hline 6005 & 402.405 & 399.993 & 0.182 & 0.0965 & 0.5019 \\
\hline 6007 & 402.761 & 399.991 & 0.183 & 0.0963 & 0.5763 \\
\hline 6009 & 403.144 & 399.993 & 0.175 & 0.0964 & 0.6558 \\
\hline 6011 & 401.679 & 400.005 & 5.188 & 0.0988 & 0.3695 \\
\hline 6013 & 401.979 & 400.006 & 5.189 & 0.0988 & 0.4327 \\
\hline 6015 & 402.306 & 400.008 & 5.189 & 0.0988 & 0.5018 \\
\hline
\end{tabular}




\begin{tabular}{|c|c|c|c|c|c|}
\hline 6017 & 402.656 & 400.007 & 5.190 & 0.0987 & 0.5762 \\
\hline 6019 & 403.022 & 400.004 & 5.193 & 0.0987 & 0.6556 \\
\hline 6021 & 401.697 & 400.022 & 10.130 & 0.1010 & 0.3696 \\
\hline 6023 & 401.986 & 400.019 & 10.134 & 0.1011 & 0.4327 \\
\hline 6025 & 402.304 & 400.017 & 10.137 & 0.1010 & 0.5019 \\
\hline 6027 & 402.655 & 400.022 & 10.139 & 0.1009 & 0.5763 \\
\hline 6029 & 403.013 & 400.016 & 10.141 & 0.1008 & 0.6556 \\
\hline 6031 & 401.635 & 400.041 & 20.129 & 0.1050 & 0.3698 \\
\hline 6033 & 401.916 & 400.040 & 20.139 & 0.1051 & 0.4330 \\
\hline 6035 & 402.219 & 400.038 & 20.144 & 0.1049 & 0.5021 \\
\hline 6037 & 402.550 & 400.036 & 20.145 & 0.1048 & 0.5765 \\
\hline 6039 & 402.906 & 400.039 & 20.149 & 0.1050 & 0.6558 \\
\hline 6041 & 401.612 & 400.056 & 30.252 & 0.1087 & 0.3697 \\
\hline 6043 & 401.880 & 400.053 & 30.252 & 0.1087 & 0.4329 \\
\hline 6045 & 402.178 & 400.052 & 30.255 & 0.1087 & 0.5020 \\
\hline 6047 & 402.500 & 400.052 & 30.257 & 0.1086 & 0.5764 \\
\hline 6049 & 402.845 & 400.056 & 30.258 & 0.1085 & 0.6558 \\
\hline 6051 & 401.546 & 400.067 & 40.273 & 0.1122 & 0.3699 \\
\hline 6053 & 401.823 & 400.072 & 40.275 & 0.1120 & 0.4331 \\
\hline 6055 & 402.108 & 400.067 & 40.273 & 0.1122 & 0.5023 \\
\hline 6057 & 402.416 & 400.068 & 40.276 & 0.1122 & 0.5767 \\
\hline 6059 & 402.751 & 400.066 & 40.287 & 0.1121 & 0.6560 \\
\hline 7001 & 421.914 & 420.177 & 0.184 & 0.0938 & 0.3547 \\
\hline 7003 & 422.223 & 420.186 & 0.188 & 0.0938 & 0.4153 \\
\hline 7005 & 422.558 & 420.190 & 0.190 & 0.0938 & 0.4817 \\
\hline 7007 & 422.914 & 420.191 & 0.188 & 0.0938 & 0.5532 \\
\hline 7009 & 423.301 & 420.201 & 0.188 & 0.0936 & 0.6294 \\
\hline 7011 & 421.903 & 420.239 & 5.025 & 0.0963 & 0.3546 \\
\hline 7013 & 422.192 & 420.238 & 5.029 & 0.0964 & 0.4152 \\
\hline 7015 & 422.525 & 420.246 & 5.031 & 0.0962 & 0.4815 \\
\hline 7017 & 422.866 & 420.244 & 5.030 & 0.0962 & 0.5529 \\
\hline 7019 & 423.244 & 420.251 & 5.032 & 0.0961 & 0.6291 \\
\hline 7021 & 421.997 & 420.334 & 10.039 & 0.0988 & 0.3547 \\
\hline 7023 & 422.291 & 420.340 & 10.040 & 0.0986 & 0.4153 \\
\hline 7025 & 422.609 & 420.341 & 10.039 & 0.0985 & 0.4817 \\
\hline 7027 & 422.946 & 420.345 & 10.039 & 0.0986 & 0.5531 \\
\hline 7029 & 423.299 & 420.340 & 10.036 & 0.0985 & 0.6293 \\
\hline 7031 & 422.289 & 420.384 & 20.334 & 0.1029 & 0.3542 \\
\hline 7033 & 422.558 & 420.382 & 20.336 & 0.1028 & 0.4147 \\
\hline 7035 & 422.860 & 420.382 & 20.337 & 0.1029 & 0.4810 \\
\hline 7037 & 423.187 & 420.387 & 20.337 & 0.1030 & 0.5523 \\
\hline 7039 & 423.531 & 420.386 & 20.331 & 0.1028 & 0.6285 \\
\hline 7041 & 422.000 & 420.422 & 20.356 & 0.1031 & 0.3538 \\
\hline 7043 & 422.277 & 420.423 & 20.354 & 0.1030 & 0.4144 \\
\hline 7045 & 422.580 & 420.424 & 20.348 & 0.1029 & 0.4807 \\
\hline 7047 & 422.904 & 420.427 & 20.345 & 0.1029 & 0.5520 \\
\hline 7049 & 423.252 & 420.429 & 20.340 & 0.1029 & 0.6282 \\
\hline 7051 & 421.974 & 420.463 & 30.268 & 0.1070 & 0.3540 \\
\hline 7053 & 422.237 & 420.462 & 30.265 & 0.1070 & 0.4145 \\
\hline 7055 & 422.531 & 420.464 & 30.265 & 0.1067 & 0.4808 \\
\hline 7057 & 422.842 & 420.464 & 30.262 & 0.1069 & 0.5521 \\
\hline 7059 & 423.171 & 420.461 & 30.259 & 0.1067 & 0.6282 \\
\hline 7061 & 421.925 & 420.484 & 40.327 & 0.1106 & 0.3540 \\
\hline 7063 & 422.180 & 420.482 & 40.327 & 0.1107 & 0.4144 \\
\hline 7065 & 422.512 & 420.483 & 40.330 & 0.1105 & 0.4808 \\
\hline 7067 & 422.812 & 420.482 & 40.316 & 0.1106 & 0.5522 \\
\hline
\end{tabular}




\begin{tabular}{|c|c|c|c|c|c|}
\hline 7069 & 423.137 & 420.483 & 40.306 & 0.1104 & 0.6284 \\
\hline 8001 & 441.838 & 440.120 & 0.223 & 0.0913 & 0.3407 \\
\hline 8003 & 442.140 & 440.122 & 0.223 & 0.0913 & 0.3989 \\
\hline 8005 & 442.412 & 440.122 & 0.224 & 0.0913 & 0.4626 \\
\hline 8007 & 442.758 & 440.124 & 0.223 & 0.0914 & 0.5312 \\
\hline 8009 & 443.121 & 440.124 & 0.218 & 0.0914 & 0.6044 \\
\hline 8011 & 441.768 & 440.142 & 5.197 & 0.0941 & 0.3405 \\
\hline 8013 & 442.051 & 440.142 & 5.198 & 0.0941 & 0.3987 \\
\hline 8015 & 442.358 & 440.138 & 5.198 & 0.0940 & 0.4625 \\
\hline 8017 & 442.702 & 440.144 & 5.192 & 0.0941 & 0.5311 \\
\hline 8019 & 443.056 & 440.140 & 5.189 & 0.0939 & 0.6044 \\
\hline 8021 & 441.769 & 440.152 & 10.163 & 0.0967 & 0.3406 \\
\hline 8023 & 442.045 & 440.151 & 10.164 & 0.0965 & 0.3987 \\
\hline 8025 & 442.347 & 440.148 & 10.165 & 0.0966 & 0.4625 \\
\hline 8027 & 442.680 & 440.155 & 10.165 & 0.0966 & 0.5311 \\
\hline 8029 & 443.028 & 440.152 & 10.164 & 0.0965 & 0.6043 \\
\hline 8031 & 441.711 & 440.183 & 20.255 & 0.1012 & 0.3406 \\
\hline 8033 & 441.977 & 440.185 & 20.254 & 0.1011 & 0.3988 \\
\hline 8035 & 442.265 & 440.181 & 20.254 & 0.1011 & 0.4626 \\
\hline 8037 & 442.585 & 440.187 & 20.256 & 0.1010 & 0.5311 \\
\hline 8039 & 442.915 & 440.179 & 20.259 & 0.1010 & 0.6042 \\
\hline 8041 & 441.635 & 440.197 & 30.162 & 0.1052 & 0.3408 \\
\hline 8043 & 441.897 & 440.201 & 30.172 & 0.1051 & 0.3990 \\
\hline 8045 & 442.176 & 440.198 & 30.178 & 0.1053 & 0.4627 \\
\hline 8047 & 442.476 & 440.198 & 30.182 & 0.1052 & 0.5312 \\
\hline 8049 & 442.792 & 440.190 & 30.183 & 0.1051 & 0.6044 \\
\hline 8051 & 441.591 & 440.197 & 40.247 & 0.1090 & 0.3408 \\
\hline 8053 & 441.892 & 440.196 & 40.249 & 0.1093 & 0.3991 \\
\hline 8055 & 442.168 & 440.196 & 40.257 & 0.1089 & 0.4628 \\
\hline 8057 & 442.462 & 440.199 & 40.261 & 0.1090 & 0.5314 \\
\hline 8059 & 442.769 & 440.191 & 40.264 & 0.1090 & 0.6045 \\
\hline 9001 & 461.280 & 459.599 & 0.148 & 0.0893 & 0.3283 \\
\hline 9003 & 461.578 & 459.603 & 0.145 & 0.0893 & 0.3845 \\
\hline 9005 & 461.902 & 459.607 & 0.138 & 0.0891 & 0.4462 \\
\hline 9007 & 462.247 & 459.612 & 0.135 & 0.0891 & 0.5124 \\
\hline 9009 & 462.610 & 459.612 & 0.138 & 0.0891 & 0.5829 \\
\hline 9011 & 461.254 & 459.647 & 5.152 & 0.0923 & 0.3283 \\
\hline 9013 & 461.544 & 459.654 & 5.144 & 0.0920 & 0.3845 \\
\hline 9015 & 461.851 & 459.648 & 5.140 & 0.0921 & 0.4461 \\
\hline 9017 & 462.186 & 459.655 & 5.134 & 0.0921 & 0.5124 \\
\hline 9019 & 462.543 & 459.658 & 5.134 & 0.0920 & 0.5830 \\
\hline 9021 & 461.240 & 459.693 & 10.181 & 0.0949 & 0.3284 \\
\hline 9023 & 461.512 & 459.693 & 10.174 & 0.0948 & 0.3847 \\
\hline 9025 & 461.815 & 459.698 & 10.172 & 0.0947 & 0.4462 \\
\hline 9027 & 462.137 & 459.697 & 10.175 & 0.0948 & 0.5123 \\
\hline 9029 & 462.479 & 459.701 & 10.182 & 0.0948 & 0.5827 \\
\hline 9031 & 461.164 & 459.730 & 20.252 & 0.0995 & 0.3283 \\
\hline 9033 & 461.416 & 459.725 & 20.253 & 0.0995 & 0.3845 \\
\hline 9035 & 461.706 & 459.726 & 20.256 & 0.0994 & 0.4459 \\
\hline 9037 & 462.012 & 459.726 & 20.260 & 0.0994 & 0.5120 \\
\hline 9039 & 462.384 & 459.722 & 20.262 & 0.0994 & 0.5826 \\
\hline 9041 & 461.193 & 459.750 & 30.196 & 0.1038 & 0.3286 \\
\hline 9043 & 461.448 & 459.753 & 30.195 & 0.1037 & 0.3848 \\
\hline 9045 & 461.724 & 459.752 & 30.199 & 0.1037 & 0.4462 \\
\hline 9047 & 462.020 & 459.758 & 30.206 & 0.1036 & 0.5123 \\
\hline 9049 & 462.322 & 459.747 & 30.209 & 0.1035 & 0.5828 \\
\hline
\end{tabular}




\begin{tabular}{|c|c|c|c|c|c|}
\hline 9051 & 461.127 & 459.771 & 40.275 & 0.1076 & 0.3284 \\
\hline 9053 & 461.412 & 459.770 & 40.269 & 0.1076 & 0.3846 \\
\hline 9055 & 461.678 & 459.771 & 40.258 & 0.1077 & 0.4462 \\
\hline 9057 & 461.973 & 459.775 & 40.248 & 0.1076 & 0.5125 \\
\hline 9059 & 462.280 & 459.778 & 40.244 & 0.1075 & 0.5831 \\
\hline 10001 & 482.140 & 480.490 & 0.183 & 0.0871 & 0.3163 \\
\hline 10003 & 482.424 & 480.488 & 0.183 & 0.0871 & 0.3704 \\
\hline 10005 & 482.742 & 480.496 & 0.183 & 0.0872 & 0.4297 \\
\hline 10007 & 483.033 & 480.497 & 0.184 & 0.0869 & 0.4933 \\
\hline 10009 & 483.391 & 480.498 & 0.184 & 0.0871 & 0.5611 \\
\hline 10011 & 482.078 & 480.517 & 5.144 & 0.0903 & 0.3162 \\
\hline 10013 & 482.341 & 480.510 & 5.145 & 0.0903 & 0.3702 \\
\hline 10015 & 482.642 & 480.510 & 5.146 & 0.0902 & 0.4294 \\
\hline 10017 & 482.966 & 480.513 & 5.146 & 0.0902 & 0.4931 \\
\hline 10019 & 483.312 & 480.511 & 5.147 & 0.0901 & 0.5610 \\
\hline 10021 & 482.227 & 480.677 & 5.215 & 0.0903 & 0.3160 \\
\hline 10023 & 482.511 & 480.684 & 5.214 & 0.0903 & 0.3700 \\
\hline 10025 & 482.806 & 480.680 & 5.210 & 0.0903 & 0.4292 \\
\hline 10027 & 483.138 & 480.686 & 5.210 & 0.0902 & 0.4929 \\
\hline 10029 & 483.481 & 480.686 & 5.209 & 0.0902 & 0.5608 \\
\hline 10031 & 482.183 & 480.688 & 10.157 & 0.0931 & 0.3160 \\
\hline 10033 & 482.446 & 480.684 & 10.158 & 0.0931 & 0.3700 \\
\hline 10035 & 482.738 & 480.686 & 10.159 & 0.0931 & 0.4292 \\
\hline 10037 & 483.049 & 480.687 & 10.160 & 0.0930 & 0.4927 \\
\hline 10039 & 483.380 & 480.683 & 10.161 & 0.0930 & 0.5606 \\
\hline 10041 & 481.966 & 480.703 & 20.361 & 0.0975 & 0.3161 \\
\hline 10043 & 482.213 & 480.697 & 20.361 & 0.0977 & 0.3701 \\
\hline 10045 & 482.494 & 480.698 & 20.361 & 0.0977 & 0.4293 \\
\hline 10047 & 482.982 & 480.693 & 20.360 & 0.0975 & 0.4931 \\
\hline 10049 & 483.304 & 480.699 & 20.359 & 0.0975 & 0.5611 \\
\hline 10051 & 482.044 & 480.705 & 30.461 & 0.1022 & 0.3162 \\
\hline 10053 & 482.282 & 480.698 & 30.461 & 0.1021 & 0.3702 \\
\hline 10055 & 482.650 & 480.698 & 30.461 & 0.1020 & 0.4295 \\
\hline 10057 & 482.933 & 480.694 & 30.460 & 0.1020 & 0.4932 \\
\hline 10059 & 483.244 & 480.699 & 30.460 & 0.1019 & 0.5611 \\
\hline 10061 & 482.044 & 480.700 & 40.419 & 0.1060 & 0.3162 \\
\hline 10063 & 482.282 & 480.703 & 40.419 & 0.1061 & 0.3703 \\
\hline 10065 & 482.544 & 480.705 & 40.419 & 0.1061 & 0.4295 \\
\hline 10067 & 482.815 & 480.699 & 40.421 & 0.1060 & 0.4932 \\
\hline 10069 & 483.115 & 480.703 & 40.421 & 0.1061 & 0.5611 \\
\hline 11001 & 502.136 & 500.513 & 0.435 & 0.0850 & 0.3053 \\
\hline 11003 & 502.423 & 500.518 & 0.436 & 0.0849 & 0.3575 \\
\hline 11005 & 502.729 & 500.523 & 0.444 & 0.0849 & 0.4145 \\
\hline 11007 & 503.059 & 500.522 & 0.446 & 0.0848 & 0.4759 \\
\hline 11009 & 503.416 & 500.524 & 0.448 & 0.0848 & 0.5414 \\
\hline 11011 & 502.132 & 500.548 & 5.197 & 0.0880 & 0.3052 \\
\hline 11013 & 502.409 & 500.554 & 5.190 & 0.0880 & 0.3574 \\
\hline 11015 & 502.708 & 500.555 & 5.188 & 0.0881 & 0.4147 \\
\hline 11017 & 503.028 & 500.554 & 5.186 & 0.0881 & 0.4761 \\
\hline 11019 & 503.370 & 500.558 & 5.191 & 0.0880 & 0.5416 \\
\hline 11021 & 502.074 & 500.580 & 10.192 & 0.0911 & 0.3051 \\
\hline 11023 & 502.329 & 500.576 & 10.193 & 0.0911 & 0.3572 \\
\hline 11025 & 502.630 & 500.589 & 10.195 & 0.0911 & 0.4144 \\
\hline 11027 & 502.935 & 500.583 & 10.196 & 0.0910 & 0.4758 \\
\hline 11029 & 503.273 & 500.589 & 10.194 & 0.0910 & 0.5414 \\
\hline 11031 & 501.983 & 500.625 & 20.349 & 0.0965 & 0.3051 \\
\hline
\end{tabular}




$\begin{array}{llllll}11033 & 502.232 & 500.622 & 20.338 & 0.0966 & 0.3574 \\ 11035 & 502.537 & 500.625 & 20.333 & 0.0965 & 0.4146 \\ 11037 & 502.832 & 500.626 & 20.331 & 0.0964 & 0.4761 \\ 11039 & 503.146 & 500.627 & 20.334 & 0.0964 & 0.5417 \\ 11041 & 501.790 & 500.637 & 30.448 & 0.1010 & 0.3051 \\ 11043 & 502.027 & 500.636 & 30.449 & 0.1010 & 0.3572 \\ 11045 & 502.296 & 500.641 & 30.451 & 0.1010 & 0.4144 \\ 11047 & 502.580 & 500.646 & 30.451 & 0.1009 & 0.4758 \\ 11049 & 503.060 & 500.637 & 30.452 & 0.1009 & 0.5415 \\ 11051 & 501.948 & 500.658 & 40.475 & 0.1052 & 0.3053 \\ 11053 & 502.176 & 500.659 & 40.477 & 0.1051 & 0.3574 \\ 11055 & 502.436 & 500.663 & 40.478 & 0.1050 & 0.4146 \\ 11057 & 502.703 & 500.658 & 40.479 & 0.1049 & 0.4761 \\ 11059 & 502.992 & 500.661 & 40.480 & 0.1049 & 0.5417\end{array}$

Table A2. Thermal conductivity for Jet-A-3638 in the liquid phase.

\begin{tabular}{|c|c|c|c|c|c|}
\hline Point ID & $\begin{array}{c}T_{0} \\
(\mathrm{~K})\end{array}$ & $\begin{array}{c}T_{\mathrm{e}} \\
(\mathrm{K})\end{array}$ & $\begin{array}{c}P_{\mathrm{e}} \\
(\mathrm{MPa})\end{array}$ & $\begin{array}{c}\lambda_{\mathrm{e}} \\
\left(\mathrm{W} \cdot \mathrm{m}^{-1} \mathrm{~K}^{-1}\right)\end{array}$ & $\begin{array}{c}q \\
\left(\mathrm{~W} \cdot \mathrm{m}^{-1}\right)\end{array}$ \\
\hline 1001 & 299.529 & 301.523 & 0.139 & 0.1117 & 0.4632 \\
\hline 1003 & 299.531 & 301.866 & 0.140 & 0.1116 & 0.5423 \\
\hline 1005 & 299.527 & 302.236 & 0.140 & 0.1116 & 0.6291 \\
\hline 1007 & 299.530 & 302.637 & 0.140 & 0.1115 & 0.7223 \\
\hline 1009 & 299.530 & 303.069 & 0.127 & 0.1114 & 0.8221 \\
\hline 1011 & 299.541 & 301.455 & 5.175 & 0.1133 & 0.4631 \\
\hline 1013 & 299.541 & 301.793 & 5.170 & 0.1132 & 0.5423 \\
\hline 1015 & 299.542 & 302.160 & 5.164 & 0.1132 & 0.6290 \\
\hline 1017 & 299.537 & 302.552 & 5.162 & 0.1131 & 0.7222 \\
\hline 1019 & 299.538 & 302.976 & 5.158 & 0.1130 & 0.8216 \\
\hline 1021 & 299.545 & 301.430 & 9.801 & 0.1147 & 0.4631 \\
\hline 1023 & 299.549 & 301.767 & 9.739 & 0.1146 & 0.5423 \\
\hline 1025 & 299.545 & 302.175 & 9.678 & 0.1145 & 0.6291 \\
\hline 1027 & 299.545 & 302.567 & 9.619 & 0.1145 & 0.7223 \\
\hline 1029 & 299.541 & 302.982 & 9.563 & 0.1144 & 0.8218 \\
\hline 1031 & 299.557 & 301.435 & 14.851 & 0.1160 & 0.4633 \\
\hline 1033 & 299.554 & 301.773 & 14.119 & 0.1159 & 0.5424 \\
\hline 1035 & 299.550 & 302.138 & 13.551 & 0.1157 & 0.6291 \\
\hline 1037 & 299.548 & 302.529 & 13.074 & 0.1155 & 0.7223 \\
\hline 1039 & 299.548 & 302.949 & 12.663 & 0.1152 & 0.8217 \\
\hline 2001 & 317.067 & 319.004 & 0.189 & 0.1092 & 0.4431 \\
\hline 2003 & 317.087 & 319.364 & 0.211 & 0.1092 & 0.5187 \\
\hline 2005 & 317.102 & 319.748 & 0.227 & 0.1091 & 0.6016 \\
\hline 2007 & 317.120 & 320.165 & 0.242 & 0.1091 & 0.6907 \\
\hline 2009 & 317.132 & 320.601 & 0.256 & 0.1091 & 0.7858 \\
\hline 2011 & 317.272 & 319.133 & 5.134 & 0.1111 & 0.4427 \\
\hline 2013 & 317.289 & 319.483 & 5.148 & 0.1108 & 0.5183 \\
\hline 2015 & 317.303 & 319.862 & 5.163 & 0.1110 & 0.6012 \\
\hline 2017 & 317.316 & 320.265 & 5.178 & 0.1109 & 0.6902 \\
\hline 2019 & 317.328 & 320.695 & 5.184 & 0.1108 & 0.7854 \\
\hline 2021 & 317.532 & 319.448 & 10.150 & 0.1125 & 0.4428 \\
\hline 2023 & 317.541 & 319.782 & 10.176 & 0.1125 & 0.5182 \\
\hline 2025 & 317.555 & 320.153 & 10.194 & 0.1125 & 0.6010 \\
\hline 2027 & 317.563 & 320.549 & 10.207 & 0.1124 & 0.6900 \\
\hline
\end{tabular}




\begin{tabular}{|c|c|c|c|c|c|}
\hline 2029 & 317.578 & 320.976 & 10.218 & 0.1124 & 0.7851 \\
\hline 2031 & 317.685 & 319.483 & 20.061 & 0.1157 & 0.4425 \\
\hline 2033 & 317.698 & 319.819 & 20.045 & 0.1156 & 0.5180 \\
\hline 2035 & 317.707 & 320.181 & 20.024 & 0.1156 & 0.6008 \\
\hline 2037 & 317.719 & 320.568 & 20.007 & 0.1155 & 0.6898 \\
\hline 2039 & 317.730 & 320.979 & 19.988 & 0.1155 & 0.7848 \\
\hline 2041 & 317.831 & 319.597 & 26.754 & 0.1175 & 0.4425 \\
\hline 2043 & 317.836 & 320.009 & 24.973 & 0.1170 & 0.5180 \\
\hline 2045 & 317.835 & 320.372 & 23.951 & 0.1167 & 0.6008 \\
\hline 2047 & 317.844 & 320.761 & 23.234 & 0.1164 & 0.6898 \\
\hline 2049 & 317.853 & 321.174 & 22.684 & 0.1163 & 0.7848 \\
\hline 3001 & 338.468 & 340.321 & 0.207 & 0.1062 & 0.4206 \\
\hline 3003 & 338.473 & 340.647 & 0.212 & 0.1062 & 0.4925 \\
\hline 3005 & 338.478 & 341.008 & 0.209 & 0.1060 & 0.5713 \\
\hline 3007 & 338.488 & 341.403 & 0.204 & 0.1060 & 0.6561 \\
\hline 3009 & 338.492 & 341.818 & 0.203 & 0.1060 & 0.7466 \\
\hline 3011 & 338.636 & 340.492 & 5.414 & 0.1081 & 0.4206 \\
\hline 3013 & 338.640 & 340.813 & 5.403 & 0.1081 & 0.4927 \\
\hline 3015 & 338.644 & 341.163 & 5.407 & 0.1080 & 0.5714 \\
\hline 3017 & 338.652 & 341.546 & 5.416 & 0.1081 & 0.6560 \\
\hline 3019 & 338.661 & 341.951 & 5.425 & 0.1079 & 0.7463 \\
\hline 3021 & 338.700 & 340.494 & 10.105 & 0.1099 & 0.4204 \\
\hline 3023 & 338.709 & 340.821 & 10.092 & 0.1100 & 0.4925 \\
\hline 3025 & 338.710 & 341.164 & 10.079 & 0.1097 & 0.5714 \\
\hline 3027 & 338.717 & 341.539 & 10.083 & 0.1097 & 0.6560 \\
\hline 3029 & 338.716 & 341.932 & 10.091 & 0.1097 & 0.7463 \\
\hline 3031 & 338.769 & 340.523 & 20.136 & 0.1132 & 0.4204 \\
\hline 3033 & 338.773 & 340.831 & 20.134 & 0.1135 & 0.4922 \\
\hline 3035 & 338.773 & 341.165 & 20.120 & 0.1135 & 0.5712 \\
\hline 3037 & 338.773 & 341.527 & 20.110 & 0.1132 & 0.6560 \\
\hline 3039 & 338.782 & 341.918 & 20.106 & 0.1132 & 0.7464 \\
\hline 3041 & 338.824 & 340.487 & 30.069 & 0.1165 & 0.4204 \\
\hline 3043 & 338.825 & 340.787 & 30.046 & 0.1165 & 0.4922 \\
\hline 3045 & 338.829 & 341.114 & 30.015 & 0.1164 & 0.5709 \\
\hline 3047 & 338.832 & 341.468 & 29.965 & 0.1163 & 0.6558 \\
\hline 3049 & 338.837 & 341.848 & 29.932 & 0.1164 & 0.7463 \\
\hline 3051 & 338.851 & 340.561 & 30.996 & 0.1167 & 0.4204 \\
\hline 3053 & 338.853 & 340.861 & 30.654 & 0.1166 & 0.4922 \\
\hline 3055 & 338.857 & 341.192 & 30.363 & 0.1165 & 0.5709 \\
\hline 3057 & 338.857 & 341.547 & 30.107 & 0.1162 & 0.6555 \\
\hline 3059 & 338.861 & 341.924 & 29.862 & 0.1161 & 0.7462 \\
\hline 4001 & 358.082 & 359.910 & 0.281 & 0.1033 & 0.4023 \\
\hline 4003 & 358.089 & 360.234 & 0.287 & 0.1033 & 0.4710 \\
\hline 4005 & 358.091 & 360.587 & 0.293 & 0.1032 & 0.5463 \\
\hline 4007 & 358.097 & 360.960 & 0.300 & 0.1032 & 0.6272 \\
\hline 4009 & 358.101 & 361.361 & 0.305 & 0.1031 & 0.7135 \\
\hline 4011 & 358.150 & 359.922 & 5.079 & 0.1053 & 0.4021 \\
\hline 4013 & 358.153 & 360.235 & 5.084 & 0.1054 & 0.4709 \\
\hline 4015 & 358.156 & 360.575 & 5.090 & 0.1053 & 0.5461 \\
\hline 4017 & 358.164 & 360.948 & 5.094 & 0.1052 & 0.6270 \\
\hline 4019 & 358.164 & 361.338 & 5.097 & 0.1051 & 0.7133 \\
\hline 4021 & 358.222 & 359.987 & 10.072 & 0.1073 & 0.4021 \\
\hline 4023 & 358.225 & 360.296 & 10.075 & 0.1072 & 0.4708 \\
\hline 4025 & 358.229 & 360.633 & 10.059 & 0.1072 & 0.5464 \\
\hline 4027 & 358.228 & 360.991 & 10.055 & 0.1071 & 0.6274 \\
\hline 4029 & 358.235 & 361.379 & 10.056 & 0.1070 & 0.7138 \\
\hline
\end{tabular}




\begin{tabular}{|c|c|c|c|c|c|}
\hline 4031 & 358.276 & 359.984 & 20.197 & 0.1111 & 0.4021 \\
\hline 4033 & 358.279 & 360.281 & 20.200 & 0.1109 & 0.4708 \\
\hline 4035 & 358.279 & 360.602 & 20.203 & 0.1109 & 0.5461 \\
\hline 4037 & 358.282 & 360.955 & 20.187 & 0.1109 & 0.6273 \\
\hline 4039 & 358.284 & 361.328 & 20.184 & 0.1108 & 0.7137 \\
\hline 4041 & 358.321 & 359.970 & 30.400 & 0.1144 & 0.4021 \\
\hline 4043 & 358.322 & 360.259 & 30.403 & 0.1145 & 0.4708 \\
\hline 4045 & 358.322 & 360.569 & 30.396 & 0.1145 & 0.5463 \\
\hline 4047 & 358.325 & 360.911 & 30.398 & 0.1143 & 0.6271 \\
\hline 4049 & 358.322 & 361.269 & 30.387 & 0.1145 & 0.7138 \\
\hline 4051 & 358.350 & 359.945 & 39.278 & 0.1175 & 0.4021 \\
\hline 4053 & 358.350 & 360.225 & 39.136 & 0.1174 & 0.4709 \\
\hline 4055 & 358.347 & 360.531 & 39.002 & 0.1173 & 0.5462 \\
\hline 4057 & 358.354 & 360.868 & 38.876 & 0.1172 & 0.6271 \\
\hline 4059 & 358.352 & 361.221 & 38.753 & 0.1171 & 0.7135 \\
\hline 5001 & 378.914 & 380.728 & 0.241 & 0.1005 & 0.3849 \\
\hline 5003 & 378.916 & 381.040 & 0.238 & 0.1003 & 0.4507 \\
\hline 5005 & 378.914 & 381.370 & 0.241 & 0.1001 & 0.5227 \\
\hline 5007 & 378.916 & 381.732 & 0.247 & 0.1000 & 0.6000 \\
\hline 5009 & 378.918 & 382.123 & 0.251 & 0.1000 & 0.6826 \\
\hline 5011 & 378.953 & 380.690 & 5.093 & 0.1025 & 0.3847 \\
\hline 5013 & 378.955 & 380.990 & 5.098 & 0.1023 & 0.4504 \\
\hline 5015 & 378.952 & 381.315 & 5.100 & 0.1024 & 0.5223 \\
\hline 5017 & 378.954 & 381.672 & 5.103 & 0.1022 & 0.5997 \\
\hline 5019 & 378.951 & 382.047 & 5.104 & 0.1021 & 0.6824 \\
\hline 5021 & 378.969 & 380.661 & 10.042 & 0.1046 & 0.3848 \\
\hline 5023 & 378.966 & 380.954 & 10.049 & 0.1044 & 0.4504 \\
\hline 5025 & 378.970 & 381.279 & 10.052 & 0.1044 & 0.5224 \\
\hline 5027 & 378.970 & 381.628 & 10.054 & 0.1044 & 0.5997 \\
\hline 5029 & 378.969 & 381.995 & 10.055 & 0.1043 & 0.6824 \\
\hline 5031 & 378.996 & 380.608 & 20.271 & 0.1086 & 0.3846 \\
\hline 5033 & 378.995 & 380.892 & 20.266 & 0.1085 & 0.4503 \\
\hline 5035 & 378.993 & 381.204 & 20.257 & 0.1087 & 0.5225 \\
\hline 5037 & 378.993 & 381.538 & 20.249 & 0.1085 & 0.6000 \\
\hline 5039 & 378.996 & 381.953 & 20.241 & 0.1084 & 0.6829 \\
\hline 5041 & 379.013 & 380.596 & 30.354 & 0.1124 & 0.3847 \\
\hline 5043 & 379.011 & 380.867 & 30.353 & 0.1123 & 0.4504 \\
\hline 5045 & 379.010 & 381.172 & 30.355 & 0.1123 & 0.5224 \\
\hline 5047 & 379.005 & 381.495 & 30.345 & 0.1122 & 0.6000 \\
\hline 5049 & 379.012 & 381.851 & 30.337 & 0.1120 & 0.6828 \\
\hline 5051 & 379.023 & 380.533 & 40.332 & 0.1157 & 0.3847 \\
\hline 5053 & 379.028 & 380.805 & 40.332 & 0.1156 & 0.4504 \\
\hline 5055 & 379.022 & 381.097 & 40.332 & 0.1157 & 0.5224 \\
\hline 5057 & 379.025 & 381.414 & 40.324 & 0.1155 & 0.5999 \\
\hline 5059 & 379.021 & 381.751 & 40.308 & 0.1155 & 0.6828 \\
\hline 6001 & 397.146 & 398.949 & 0.309 & 0.0974 & 0.3704 \\
\hline 6003 & 397.154 & 399.261 & 0.317 & 0.0975 & 0.4336 \\
\hline 6005 & 397.164 & 399.606 & 0.325 & 0.0975 & 0.5029 \\
\hline 6007 & 397.171 & 399.973 & 0.332 & 0.0974 & 0.5774 \\
\hline 6009 & 397.182 & 400.367 & 0.338 & 0.0973 & 0.6569 \\
\hline 6011 & 397.207 & 398.971 & 0.132 & 0.0975 & 0.3700 \\
\hline 6013 & 397.223 & 399.296 & 0.129 & 0.0975 & 0.4333 \\
\hline 6015 & 397.227 & 399.638 & 0.131 & 0.0972 & 0.5026 \\
\hline 6017 & 397.231 & 399.996 & 0.136 & 0.0973 & 0.5770 \\
\hline 6019 & 397.238 & 400.388 & 0.145 & 0.0973 & 0.6564 \\
\hline 6021 & 397.311 & 398.985 & 5.093 & 0.1001 & 0.3699 \\
\hline
\end{tabular}




\begin{tabular}{|c|c|c|c|c|c|}
\hline 6023 & 397.324 & 399.294 & 5.092 & 0.0999 & 0.4332 \\
\hline 6025 & 397.327 & 399.625 & 5.093 & 0.0998 & 0.5025 \\
\hline 6027 & 397.335 & 399.977 & 5.098 & 0.0997 & 0.5768 \\
\hline 6029 & 397.336 & 400.353 & 5.106 & 0.0997 & 0.6562 \\
\hline 6031 & 397.394 & 399.055 & 10.156 & 0.1023 & 0.3699 \\
\hline 6033 & 397.398 & 399.351 & 10.160 & 0.1023 & 0.4331 \\
\hline 6035 & 397.406 & 399.675 & 10.160 & 0.1022 & 0.5024 \\
\hline 6037 & 397.410 & 400.023 & 10.162 & 0.1021 & 0.5768 \\
\hline 6039 & 397.415 & 400.391 & 10.170 & 0.1021 & 0.6562 \\
\hline 6041 & 397.466 & 399.068 & 20.278 & 0.1064 & 0.3698 \\
\hline 6043 & 397.473 & 399.354 & 20.272 & 0.1064 & 0.4331 \\
\hline 6045 & 397.470 & 399.659 & 20.271 & 0.1062 & 0.5024 \\
\hline 6047 & 397.477 & 399.996 & 20.274 & 0.1063 & 0.5768 \\
\hline 6049 & 397.481 & 400.355 & 20.279 & 0.1062 & 0.6563 \\
\hline 6051 & 397.558 & 399.115 & 30.305 & 0.1104 & 0.3698 \\
\hline 6053 & 397.561 & 399.390 & 30.307 & 0.1103 & 0.4329 \\
\hline 6055 & 397.557 & 399.682 & 30.309 & 0.1102 & 0.5021 \\
\hline 6057 & 397.564 & 400.006 & 30.310 & 0.1103 & 0.5766 \\
\hline 6059 & 397.569 & 400.352 & 30.312 & 0.1102 & 0.6561 \\
\hline 6061 & 397.633 & 399.142 & 40.400 & 0.1138 & 0.3698 \\
\hline 6063 & 397.631 & 399.405 & 40.402 & 0.1138 & 0.4329 \\
\hline 6065 & 397.637 & 399.699 & 40.401 & 0.1138 & 0.5021 \\
\hline 6067 & 397.642 & 400.009 & 40.400 & 0.1140 & 0.5766 \\
\hline 6069 & 397.636 & 400.335 & 40.400 & 0.1139 & 0.6561 \\
\hline 7001 & 418.050 & 419.815 & 0.253 & 0.0948 & 0.3548 \\
\hline 7003 & 418.054 & 420.122 & 0.261 & 0.0947 & 0.4153 \\
\hline 7005 & 418.061 & 420.455 & 0.265 & 0.0947 & 0.4817 \\
\hline 7007 & 418.072 & 420.720 & 0.270 & 0.0946 & 0.5529 \\
\hline 7009 & 418.077 & 421.104 & 0.278 & 0.0945 & 0.6290 \\
\hline 7011 & 418.139 & 419.756 & 5.182 & 0.0973 & 0.3547 \\
\hline 7013 & 418.147 & 420.046 & 5.186 & 0.0974 & 0.4152 \\
\hline 7015 & 418.150 & 420.372 & 5.190 & 0.0973 & 0.4816 \\
\hline 7017 & 418.155 & 420.721 & 5.194 & 0.0973 & 0.5529 \\
\hline 7019 & 418.166 & 421.098 & 5.200 & 0.0972 & 0.6291 \\
\hline 7021 & 418.275 & 419.897 & 10.180 & 0.0998 & 0.3546 \\
\hline 7023 & 418.277 & 420.191 & 10.178 & 0.0998 & 0.4152 \\
\hline 7025 & 418.285 & 420.511 & 10.177 & 0.0997 & 0.4816 \\
\hline 7027 & 418.286 & 420.847 & 10.173 & 0.0996 & 0.5531 \\
\hline 7029 & 418.289 & 421.205 & 10.178 & 0.0996 & 0.6292 \\
\hline 7031 & 418.343 & 419.902 & 20.267 & 0.1044 & 0.3545 \\
\hline 7033 & 418.336 & 420.166 & 20.271 & 0.1043 & 0.4150 \\
\hline 7035 & 418.342 & 420.475 & 20.266 & 0.1043 & 0.4815 \\
\hline 7037 & 418.346 & 420.801 & 20.259 & 0.1042 & 0.5530 \\
\hline 7039 & 418.350 & 421.148 & 20.260 & 0.1043 & 0.6292 \\
\hline 7041 & 418.396 & 419.896 & 30.283 & 0.1083 & 0.3546 \\
\hline 7043 & 418.403 & 420.166 & 30.280 & 0.1084 & 0.4152 \\
\hline 7045 & 418.401 & 420.451 & 30.280 & 0.1084 & 0.4816 \\
\hline 7047 & 418.404 & 420.764 & 30.283 & 0.1083 & 0.5530 \\
\hline 7049 & 418.406 & 421.093 & 30.286 & 0.1084 & 0.6292 \\
\hline 7051 & 418.442 & 419.873 & 40.318 & 0.1123 & 0.3545 \\
\hline 7053 & 418.439 & 420.123 & 40.313 & 0.1122 & 0.4151 \\
\hline 7055 & 418.442 & 420.406 & 40.307 & 0.1124 & 0.4816 \\
\hline 7057 & 418.446 & 420.714 & 40.306 & 0.1122 & 0.5530 \\
\hline 7059 & 418.446 & 421.030 & 40.301 & 0.1123 & 0.6292 \\
\hline 8001 & 439.401 & 441.055 & 0.283 & 0.0922 & 0.3402 \\
\hline 8003 & 439.414 & 441.365 & 0.287 & 0.0922 & 0.3983 \\
\hline
\end{tabular}




\begin{tabular}{|c|c|c|c|c|c|}
\hline 8005 & 439.412 & 441.678 & 0.290 & 0.0921 & 0.4619 \\
\hline 8007 & 439.412 & 442.024 & 0.293 & 0.0920 & 0.5304 \\
\hline 8009 & 439.416 & 442.391 & 0.294 & 0.0919 & 0.6035 \\
\hline 8011 & 439.451 & 441.068 & 5.095 & 0.0949 & 0.3402 \\
\hline 8013 & 439.455 & 441.357 & 5.099 & 0.0949 & 0.3983 \\
\hline 8015 & 439.455 & 441.669 & 5.100 & 0.0949 & 0.4619 \\
\hline 8017 & 439.454 & 441.997 & 5.101 & 0.0948 & 0.5304 \\
\hline 8019 & 439.455 & 442.360 & 5.103 & 0.0947 & 0.6035 \\
\hline 8021 & 439.485 & 441.057 & 10.102 & 0.0976 & 0.3402 \\
\hline 8023 & 439.490 & 441.338 & 10.103 & 0.0975 & 0.3983 \\
\hline 8025 & 439.492 & 441.642 & 10.106 & 0.0974 & 0.4620 \\
\hline 8027 & 439.493 & 441.972 & 10.106 & 0.0975 & 0.5305 \\
\hline 8029 & 439.497 & 442.323 & 10.109 & 0.0974 & 0.6036 \\
\hline 8031 & 439.534 & 441.016 & 20.423 & 0.1025 & 0.3402 \\
\hline 8033 & 439.542 & 441.285 & 20.425 & 0.1024 & 0.3983 \\
\hline 8035 & 439.539 & 441.572 & 20.427 & 0.1024 & 0.4620 \\
\hline 8037 & 439.538 & 441.883 & 20.428 & 0.1023 & 0.5304 \\
\hline 8039 & 439.540 & 442.217 & 20.427 & 0.1023 & 0.6035 \\
\hline 8041 & 439.570 & 440.969 & 30.537 & 0.1068 & 0.3402 \\
\hline 8043 & 439.571 & 441.221 & 30.538 & 0.1068 & 0.3983 \\
\hline 8045 & 439.571 & 441.501 & 30.538 & 0.1068 & 0.4620 \\
\hline 8047 & 439.572 & 441.803 & 30.532 & 0.1068 & 0.5306 \\
\hline 8049 & 439.575 & 442.125 & 30.529 & 0.1068 & 0.6037 \\
\hline 8051 & 439.599 & 440.964 & 40.385 & 0.1108 & 0.3402 \\
\hline 8053 & 439.597 & 441.209 & 40.387 & 0.1108 & 0.3983 \\
\hline 8055 & 439.594 & 441.479 & 40.387 & 0.1109 & 0.4620 \\
\hline 8057 & 439.600 & 441.770 & 40.382 & 0.1107 & 0.5306 \\
\hline 8059 & 439.597 & 442.079 & 40.377 & 0.1106 & 0.6038 \\
\hline 9001 & 459.926 & 461.620 & 0.176 & 0.0894 & 0.3276 \\
\hline 9003 & 459.929 & 461.857 & 0.180 & 0.0894 & 0.3835 \\
\hline 9005 & 459.936 & 462.183 & 0.185 & 0.0894 & 0.4447 \\
\hline 9007 & 459.937 & 462.512 & 0.188 & 0.0893 & 0.5106 \\
\hline 9009 & 459.938 & 462.877 & 0.189 & 0.0892 & 0.5809 \\
\hline 9011 & 459.977 & 461.576 & 5.141 & 0.0926 & 0.3276 \\
\hline 9013 & 459.972 & 461.848 & 5.147 & 0.0925 & 0.3835 \\
\hline 9015 & 459.981 & 462.160 & 5.151 & 0.0925 & 0.4447 \\
\hline 9017 & 459.983 & 462.487 & 5.154 & 0.0925 & 0.5106 \\
\hline 9019 & 459.982 & 462.840 & 5.157 & 0.0924 & 0.5809 \\
\hline 9021 & 459.999 & 461.512 & 10.160 & 0.0951 & 0.3275 \\
\hline 9023 & 460.004 & 461.789 & 10.158 & 0.0950 & 0.3835 \\
\hline 9025 & 460.003 & 462.083 & 10.159 & 0.0949 & 0.4448 \\
\hline 9027 & 460.006 & 462.405 & 10.165 & 0.0949 & 0.5106 \\
\hline 9029 & 460.009 & 462.753 & 10.168 & 0.0949 & 0.5809 \\
\hline 9031 & 460.042 & 461.486 & 20.580 & 0.1004 & 0.3276 \\
\hline 9033 & 460.047 & 461.750 & 20.587 & 0.1004 & 0.3834 \\
\hline 9035 & 460.048 & 462.033 & 20.587 & 0.1003 & 0.4447 \\
\hline 9037 & 460.043 & 462.334 & 20.589 & 0.1003 & 0.5106 \\
\hline 9039 & 460.042 & 462.656 & 20.592 & 0.1002 & 0.5810 \\
\hline 9041 & 460.086 & 461.498 & 30.374 & 0.1050 & 0.3275 \\
\hline 9043 & 460.087 & 461.749 & 30.376 & 0.1048 & 0.3835 \\
\hline 9045 & 460.082 & 462.014 & 30.377 & 0.1048 & 0.4448 \\
\hline 9047 & 460.078 & 462.302 & 30.378 & 0.1049 & 0.5107 \\
\hline 9049 & 460.079 & 462.613 & 30.378 & 0.1047 & 0.5810 \\
\hline 9051 & 460.094 & 461.416 & 40.317 & 0.1089 & 0.3275 \\
\hline 9053 & 460.089 & 461.652 & 40.318 & 0.1090 & 0.3835 \\
\hline 9055 & 460.082 & 461.903 & 40.317 & 0.1089 & 0.4448 \\
\hline
\end{tabular}




\begin{tabular}{|c|c|c|c|c|c|}
\hline 9057 & 460.087 & 462.193 & 40.316 & 0.1089 & 0.5107 \\
\hline 9059 & 460.084 & 462.490 & 40.318 & 0.1088 & 0.5811 \\
\hline 10001 & 479.411 & 481.097 & 0.336 & 0.0871 & 0.3161 \\
\hline 10003 & 479.412 & 481.381 & 0.340 & 0.0870 & 0.3700 \\
\hline 10005 & 479.415 & 481.696 & 0.343 & 0.0870 & 0.4291 \\
\hline 10007 & 479.415 & 482.031 & 0.345 & 0.0870 & 0.4926 \\
\hline 10009 & 479.420 & 482.389 & 0.347 & 0.0870 & 0.5605 \\
\hline 10011 & 479.438 & 481.018 & 5.174 & 0.0904 & 0.3159 \\
\hline 10013 & 479.441 & 481.295 & 5.176 & 0.0904 & 0.3699 \\
\hline 10015 & 479.438 & 481.591 & 5.178 & 0.0903 & 0.4290 \\
\hline 10017 & 479.441 & 481.917 & 5.180 & 0.0903 & 0.4926 \\
\hline 10019 & 479.437 & 482.255 & 5.182 & 0.0903 & 0.5604 \\
\hline 10021 & 479.457 & 480.979 & 10.139 & 0.0936 & 0.3159 \\
\hline 10023 & 479.460 & 481.249 & 10.141 & 0.0934 & 0.3699 \\
\hline 10025 & 479.458 & 481.540 & 10.143 & 0.0934 & 0.4290 \\
\hline 10027 & 479.458 & 481.849 & 10.144 & 0.0933 & 0.4926 \\
\hline 10029 & 479.465 & 482.187 & 10.145 & 0.0933 & 0.5605 \\
\hline 10031 & 479.480 & 480.776 & 20.316 & 0.0984 & 0.3159 \\
\hline 10033 & 479.479 & 481.025 & 20.317 & 0.0983 & 0.3699 \\
\hline 10035 & 479.479 & 481.307 & 20.320 & 0.0983 & 0.4290 \\
\hline 10037 & 479.480 & 481.604 & 20.323 & 0.0983 & 0.4926 \\
\hline 10039 & 479.477 & 481.922 & 20.325 & 0.0981 & 0.5605 \\
\hline 10041 & 479.520 & 480.915 & 30.444 & 0.1032 & 0.3160 \\
\hline 10043 & 479.521 & 481.159 & 30.446 & 0.1032 & 0.3700 \\
\hline 10045 & 479.521 & 481.428 & 30.443 & 0.1031 & 0.4292 \\
\hline 10047 & 479.517 & 481.709 & 30.430 & 0.1030 & 0.4930 \\
\hline 10049 & 479.523 & 482.019 & 30.426 & 0.1030 & 0.5610 \\
\hline 10051 & 479.537 & 480.848 & 40.385 & 0.1075 & 0.3161 \\
\hline 10053 & 479.543 & 481.093 & 40.375 & 0.1075 & 0.3702 \\
\hline 10055 & 479.537 & 481.339 & 40.372 & 0.1073 & 0.4294 \\
\hline 10057 & 479.537 & 481.617 & 40.369 & 0.1073 & 0.4931 \\
\hline 10059 & 479.533 & 481.903 & 40.373 & 0.1072 & 0.5610 \\
\hline 11001 & 498.852 & 500.487 & 0.272 & 0.0847 & 0.3054 \\
\hline 11003 & 498.859 & 500.779 & 0.272 & 0.0846 & 0.3575 \\
\hline 11005 & 498.860 & 501.086 & 0.272 & 0.0846 & 0.4146 \\
\hline 11007 & 498.868 & 501.425 & 0.273 & 0.0845 & 0.4761 \\
\hline 11009 & 498.865 & 501.775 & 0.273 & 0.0845 & 0.5416 \\
\hline 11011 & 498.891 & 500.429 & 5.205 & 0.0883 & 0.3053 \\
\hline 11013 & 498.890 & 500.696 & 5.207 & 0.0883 & 0.3574 \\
\hline 11015 & 498.891 & 500.993 & 5.209 & 0.0882 & 0.4146 \\
\hline 11017 & 498.894 & 501.317 & 5.210 & 0.0882 & 0.4760 \\
\hline 11019 & 498.892 & 501.649 & 5.210 & 0.0881 & 0.5416 \\
\hline 11021 & 498.917 & 500.411 & 10.153 & 0.0913 & 0.3053 \\
\hline 11023 & 498.922 & 500.676 & 10.156 & 0.0914 & 0.3575 \\
\hline 11025 & 498.917 & 500.955 & 10.159 & 0.0914 & 0.4146 \\
\hline 11027 & 498.920 & 501.269 & 10.159 & 0.0914 & 0.4760 \\
\hline 11029 & 498.918 & 501.594 & 10.157 & 0.0914 & 0.5417 \\
\hline 11031 & 498.959 & 500.316 & 20.481 & 0.0971 & 0.3053 \\
\hline 11033 & 498.959 & 500.567 & 20.481 & 0.0972 & 0.3574 \\
\hline 11035 & 498.952 & 500.827 & 20.483 & 0.0971 & 0.4146 \\
\hline 11037 & 498.952 & 501.120 & 20.485 & 0.0971 & 0.4760 \\
\hline 11039 & 498.956 & 501.437 & 20.487 & 0.0971 & 0.5416 \\
\hline 11041 & 498.980 & 500.173 & 30.448 & 0.1016 & 0.3053 \\
\hline 11043 & 498.983 & 500.414 & 30.450 & 0.1015 & 0.3575 \\
\hline 11045 & 498.980 & 500.669 & 30.452 & 0.1016 & 0.4146 \\
\hline 11047 & 498.976 & 500.951 & 30.451 & 0.1016 & 0.4761 \\
\hline
\end{tabular}




$\begin{array}{llllll}11049 & 498.979 & 501.252 & 30.444 & 0.1013 & 0.5419 \\ 11051 & 498.975 & 500.341 & 30.450 & 0.1011 & 0.3055 \\ 11053 & 498.980 & 500.585 & 30.444 & 0.1014 & 0.3577 \\ 11055 & 498.979 & 500.846 & 30.440 & 0.1016 & 0.4149 \\ 11057 & 498.989 & 501.139 & 30.440 & 0.1014 & 0.4765 \\ 11059 & 498.982 & 501.429 & 30.445 & 0.1014 & 0.5420 \\ 11061 & 498.998 & 500.288 & 40.475 & 0.1061 & 0.3054 \\ 11063 & 498.996 & 500.510 & 40.477 & 0.1059 & 0.3576 \\ 11065 & 498.995 & 500.762 & 40.474 & 0.1061 & 0.4148 \\ 11067 & 498.992 & 501.029 & 40.465 & 0.1060 & 0.4764 \\ 11069 & 499.002 & 501.329 & 40.464 & 0.1059 & 0.5421\end{array}$

Table \$ $\mathrm{u}$. Thermal conductivity Jet-A-4658 in the liquid phase.

\begin{tabular}{|c|c|c|c|c|c|}
\hline Point ID & $\begin{array}{c}T_{0} \\
(\mathrm{~K})\end{array}$ & $\begin{array}{c}T_{\mathrm{e}} \\
(\mathrm{K})\end{array}$ & $\begin{array}{c}P_{\mathrm{e}} \\
(\mathrm{MPa})\end{array}$ & $\begin{array}{c}\lambda_{\mathrm{e}} \\
\left(\mathrm{W} \cdot \mathrm{m}^{-1} \mathrm{~K}^{-1}\right)\end{array}$ & $\begin{array}{c}q \\
\left(\mathrm{~W} \cdot \mathrm{m}^{-1}\right)\end{array}$ \\
\hline 1001 & 300.096 & 301.759 & 0.169 & 0.1119 & 0.3909 \\
\hline 1003 & 300.100 & 302.080 & 0.173 & 0.1120 & 0.4654 \\
\hline 1005 & 300.103 & 302.430 & 0.175 & 0.1120 & 0.5451 \\
\hline 1007 & 300.102 & 302.800 & 0.177 & 0.1119 & 0.6322 \\
\hline 1009 & 300.100 & 303.201 & 0.178 & 0.1118 & 0.7259 \\
\hline 1011 & 300.131 & 301.771 & 5.661 & 0.1135 & 0.3913 \\
\hline 1013 & 300.131 & 302.085 & 5.660 & 0.1137 & 0.4658 \\
\hline 1015 & 300.130 & 302.421 & 5.669 & 0.1136 & 0.5453 \\
\hline 1017 & 300.132 & 302.789 & 5.677 & 0.1135 & 0.6323 \\
\hline 1019 & 300.131 & 303.186 & 5.683 & 0.1135 & 0.7260 \\
\hline 1021 & 300.120 & 301.726 & 10.376 & 0.1151 & 0.3910 \\
\hline 1023 & 300.121 & 302.035 & 10.377 & 0.1149 & 0.4654 \\
\hline 1025 & 300.124 & 302.371 & 10.378 & 0.1150 & 0.5451 \\
\hline 1027 & 300.120 & 302.734 & 10.378 & 0.1149 & 0.6322 \\
\hline 1029 & 300.125 & 303.132 & 10.379 & 0.1148 & 0.7258 \\
\hline 1031 & 300.144 & 301.699 & 20.338 & 0.1178 & 0.3911 \\
\hline 1033 & 300.144 & 302.000 & 20.341 & 0.1177 & 0.4655 \\
\hline 1035 & 300.144 & 302.325 & 20.345 & 0.1177 & 0.5450 \\
\hline 1037 & 300.138 & 302.674 & 20.346 & 0.1177 & 0.6321 \\
\hline 1039 & 300.140 & 303.062 & 20.345 & 0.1176 & 0.7258 \\
\hline 1041 & 300.157 & 301.659 & 29.673 & 0.1202 & 0.3911 \\
\hline 1043 & 300.153 & 301.950 & 29.503 & 0.1202 & 0.4655 \\
\hline 1045 & 300.153 & 302.273 & 29.339 & 0.1200 & 0.5450 \\
\hline 1047 & 300.154 & 302.629 & 29.142 & 0.1199 & 0.6327 \\
\hline 1049 & 300.153 & 303.008 & 28.981 & 0.1200 & 0.7267 \\
\hline 1051 & 300.151 & 301.688 & 30.288 & 0.1204 & 0.3916 \\
\hline 1053 & 300.154 & 301.993 & 30.042 & 0.1202 & 0.4661 \\
\hline 1055 & 300.149 & 302.307 & 29.829 & 0.1202 & 0.5455 \\
\hline 1057 & 300.148 & 302.658 & 29.623 & 0.1201 & 0.6324 \\
\hline 1059 & 300.145 & 303.033 & 29.424 & 0.1200 & 0.7260 \\
\hline 2001 & 318.502 & 320.420 & 0.261 & 0.1097 & 0.4444 \\
\hline 2003 & 318.500 & 320.745 & 0.253 & 0.1095 & 0.5205 \\
\hline 2005 & 318.502 & 321.108 & 0.248 & 0.1095 & 0.6038 \\
\hline 2007 & 318.501 & 321.498 & 0.248 & 0.1094 & 0.6932 \\
\hline 2009 & 318.506 & 321.919 & 0.257 & 0.1094 & 0.7884 \\
\hline 2011 & 318.517 & 320.396 & 5.594 & 0.1114 & 0.4441 \\
\hline 2013 & 318.517 & 320.722 & 5.595 & 0.1112 & 0.5200 \\
\hline
\end{tabular}




\begin{tabular}{|c|c|c|c|c|c|}
\hline 2015 & 318.519 & 321.081 & 5.594 & 0.1113 & 0.6032 \\
\hline 2017 & 318.523 & 321.471 & 5.592 & 0.1112 & 0.6926 \\
\hline 2019 & 318.518 & 321.876 & 5.573 & 0.1112 & 0.7884 \\
\hline 2021 & 318.537 & 320.389 & 10.323 & 0.1129 & 0.4441 \\
\hline 2023 & 318.535 & 320.709 & 10.324 & 0.1128 & 0.5200 \\
\hline 2025 & 318.536 & 321.067 & 10.317 & 0.1128 & 0.6033 \\
\hline 2027 & 318.536 & 321.447 & 10.301 & 0.1127 & 0.6929 \\
\hline 2029 & 318.544 & 321.859 & 10.292 & 0.1127 & 0.7885 \\
\hline 2031 & 318.557 & 320.350 & 20.726 & 0.1161 & 0.4441 \\
\hline 2033 & 318.561 & 320.669 & 20.710 & 0.1161 & 0.5202 \\
\hline 2035 & 318.557 & 321.009 & 20.696 & 0.1159 & 0.6036 \\
\hline 2037 & 318.558 & 321.381 & 20.690 & 0.1159 & 0.6931 \\
\hline 2039 & 318.558 & 321.778 & 20.685 & 0.1159 & 0.7886 \\
\hline 2041 & 318.570 & 320.306 & 30.271 & 0.1187 & 0.4445 \\
\hline 2043 & 318.577 & 320.621 & 30.268 & 0.1188 & 0.5205 \\
\hline 2045 & 318.574 & 320.955 & 30.267 & 0.1187 & 0.6037 \\
\hline 2047 & 318.567 & 321.309 & 30.274 & 0.1187 & 0.6930 \\
\hline 2049 & 318.571 & 321.698 & 30.284 & 0.1186 & 0.7882 \\
\hline 2051 & 318.585 & 320.312 & 39.924 & 0.1214 & 0.4446 \\
\hline 2053 & 318.582 & 320.611 & 39.862 & 0.1213 & 0.5206 \\
\hline 2055 & 318.580 & 320.941 & 39.802 & 0.1211 & 0.6038 \\
\hline 2057 & 318.584 & 321.300 & 39.744 & 0.1211 & 0.6933 \\
\hline 2059 & 318.581 & 321.678 & 39.692 & 0.1212 & 0.7887 \\
\hline 3001 & 337.063 & 339.014 & 0.430 & 0.1070 & 0.4248 \\
\hline 3003 & 337.079 & 339.362 & 0.446 & 0.1070 & 0.4973 \\
\hline 3005 & 337.095 & 339.640 & 0.461 & 0.1070 & 0.5767 \\
\hline 3007 & 337.117 & 340.054 & 0.474 & 0.1070 & 0.6621 \\
\hline 3009 & 337.134 & 340.487 & 0.449 & 0.1069 & 0.7542 \\
\hline 3011 & 337.462 & 339.323 & 0.216 & 0.1070 & 0.4249 \\
\hline 3013 & 337.476 & 339.664 & 0.248 & 0.1070 & 0.4972 \\
\hline 3015 & 337.492 & 340.035 & 0.280 & 0.1069 & 0.5763 \\
\hline 3017 & 337.503 & 340.432 & 0.298 & 0.1068 & 0.6615 \\
\hline 3019 & 337.520 & 340.862 & 0.315 & 0.1069 & 0.7526 \\
\hline 3021 & 337.672 & 339.502 & 5.177 & 0.1089 & 0.4241 \\
\hline 3023 & 337.686 & 339.839 & 5.191 & 0.1088 & 0.4965 \\
\hline 3025 & 337.693 & 340.197 & 5.201 & 0.1088 & 0.5759 \\
\hline 3027 & 337.710 & 340.596 & 5.214 & 0.1086 & 0.6612 \\
\hline 3029 & 337.721 & 341.011 & 5.227 & 0.1086 & 0.7522 \\
\hline 3031 & 337.815 & 339.635 & 10.394 & 0.1106 & 0.4242 \\
\hline 3033 & 337.826 & 339.962 & 10.410 & 0.1106 & 0.4966 \\
\hline 3035 & 337.833 & 340.316 & 10.427 & 0.1105 & 0.5759 \\
\hline 3037 & 337.847 & 340.701 & 10.441 & 0.1104 & 0.6611 \\
\hline 3039 & 337.859 & 341.112 & 10.453 & 0.1104 & 0.7521 \\
\hline 3041 & 337.956 & 339.722 & 20.258 & 0.1139 & 0.4242 \\
\hline 3043 & 337.969 & 340.044 & 20.271 & 0.1139 & 0.4966 \\
\hline 3045 & 337.970 & 340.383 & 20.287 & 0.1138 & 0.5758 \\
\hline 3047 & 337.982 & 340.755 & 20.303 & 0.1136 & 0.6610 \\
\hline 3049 & 337.998 & 341.157 & 20.316 & 0.1137 & 0.7519 \\
\hline 3051 & 338.080 & 339.801 & 30.330 & 0.1170 & 0.4241 \\
\hline 3053 & 338.088 & 340.107 & 30.334 & 0.1170 & 0.4966 \\
\hline 3055 & 338.102 & 340.453 & 30.346 & 0.1170 & 0.5758 \\
\hline 3057 & 338.106 & 340.808 & 30.358 & 0.1168 & 0.6610 \\
\hline 3059 & 338.114 & 341.191 & 30.373 & 0.1168 & 0.7519 \\
\hline 3061 & 338.207 & 339.894 & 40.361 & 0.1200 & 0.4240 \\
\hline 3063 & 338.219 & 340.199 & 40.382 & 0.1198 & 0.4963 \\
\hline 3065 & 338.223 & 340.524 & 40.397 & 0.1199 & 0.5755 \\
\hline
\end{tabular}




\begin{tabular}{|c|c|c|c|c|c|}
\hline 3067 & 338.230 & 340.876 & 40.410 & 0.1197 & 0.6607 \\
\hline 3069 & 338.233 & 341.246 & 40.420 & 0.1197 & 0.7516 \\
\hline 4001 & 358.387 & 360.194 & 0.259 & 0.1041 & 0.4043 \\
\hline 4003 & 358.400 & 360.527 & 0.264 & 0.1040 & 0.4734 \\
\hline 4005 & 358.412 & 360.887 & 0.253 & 0.1039 & 0.5494 \\
\hline 4007 & 358.416 & 361.266 & 0.252 & 0.1038 & 0.6310 \\
\hline 4009 & 358.430 & 361.680 & 0.259 & 0.1039 & 0.7179 \\
\hline 4011 & 358.553 & 360.358 & 5.239 & 0.1061 & 0.4043 \\
\hline 4013 & 358.563 & 360.628 & 5.250 & 0.1060 & 0.4732 \\
\hline 4015 & 358.571 & 360.980 & 5.259 & 0.1060 & 0.5489 \\
\hline 4017 & 358.577 & 361.353 & 5.257 & 0.1058 & 0.6304 \\
\hline 4019 & 358.586 & 361.753 & 5.249 & 0.1058 & 0.7175 \\
\hline 4021 & 358.679 & 360.458 & 10.300 & 0.1079 & 0.4042 \\
\hline 4023 & 358.689 & 360.774 & 10.296 & 0.1079 & 0.4735 \\
\hline 4025 & 358.695 & 361.119 & 10.295 & 0.1079 & 0.5493 \\
\hline 4027 & 358.707 & 361.488 & 10.298 & 0.1078 & 0.6307 \\
\hline 4029 & 358.712 & 361.830 & 10.310 & 0.1078 & 0.7173 \\
\hline 4031 & 358.804 & 360.472 & 20.139 & 0.1115 & 0.4043 \\
\hline 4033 & 358.810 & 360.776 & 20.145 & 0.1114 & 0.4734 \\
\hline 4035 & 358.819 & 361.107 & 20.154 & 0.1115 & 0.5490 \\
\hline 4037 & 358.827 & 361.463 & 20.168 & 0.1114 & 0.6301 \\
\hline 4039 & 358.830 & 361.840 & 20.179 & 0.1114 & 0.7168 \\
\hline 4041 & 358.923 & 360.572 & 30.297 & 0.1149 & 0.4040 \\
\hline 4043 & 358.928 & 360.866 & 30.306 & 0.1150 & 0.4730 \\
\hline 4045 & 358.932 & 361.185 & 30.313 & 0.1148 & 0.5486 \\
\hline 4047 & 358.938 & 361.533 & 30.318 & 0.1147 & 0.6299 \\
\hline 4049 & 358.945 & 361.904 & 30.302 & 0.1147 & 0.7171 \\
\hline 4051 & 359.000 & 360.569 & 40.347 & 0.1181 & 0.4039 \\
\hline 4053 & 359.007 & 360.857 & 40.354 & 0.1180 & 0.4730 \\
\hline 4055 & 359.005 & 361.211 & 40.359 & 0.1180 & 0.5487 \\
\hline 4057 & 359.014 & 361.553 & 40.364 & 0.1179 & 0.6300 \\
\hline 4059 & 359.019 & 361.913 & 40.355 & 0.1179 & 0.7170 \\
\hline 5001 & 377.692 & 379.446 & 0.229 & 0.1013 & 0.3878 \\
\hline 5003 & 377.700 & 379.761 & 0.233 & 0.1013 & 0.4541 \\
\hline 5005 & 377.707 & 380.107 & 0.248 & 0.1012 & 0.5265 \\
\hline 5007 & 377.711 & 380.473 & 0.258 & 0.1011 & 0.6044 \\
\hline 5009 & 377.716 & 380.867 & 0.266 & 0.1010 & 0.6876 \\
\hline 5011 & 377.778 & 379.525 & 5.242 & 0.1034 & 0.3876 \\
\hline 5013 & 377.786 & 379.837 & 5.230 & 0.1034 & 0.4541 \\
\hline 5015 & 377.793 & 380.176 & 5.229 & 0.1033 & 0.5268 \\
\hline 5017 & 377.799 & 380.540 & 5.230 & 0.1033 & 0.6049 \\
\hline 5019 & 377.808 & 380.926 & 5.249 & 0.1033 & 0.6878 \\
\hline 5021 & 377.863 & 379.557 & 10.147 & 0.1055 & 0.3876 \\
\hline 5023 & 377.864 & 379.856 & 10.158 & 0.1054 & 0.4538 \\
\hline 5025 & 377.871 & 380.189 & 10.166 & 0.1054 & 0.5264 \\
\hline 5027 & 377.878 & 380.546 & 10.173 & 0.1053 & 0.6043 \\
\hline 5029 & 377.882 & 380.925 & 10.170 & 0.1052 & 0.6877 \\
\hline 5031 & 377.966 & 379.571 & 20.199 & 0.1094 & 0.3877 \\
\hline 5033 & 377.969 & 379.861 & 20.212 & 0.1094 & 0.4539 \\
\hline 5035 & 377.976 & 380.230 & 20.223 & 0.1093 & 0.5263 \\
\hline 5037 & 377.980 & 380.572 & 20.229 & 0.1093 & 0.6043 \\
\hline 5039 & 377.986 & 380.942 & 20.235 & 0.1092 & 0.6875 \\
\hline 5041 & 378.047 & 379.657 & 30.249 & 0.1130 & 0.3875 \\
\hline 5043 & 378.054 & 379.945 & 30.254 & 0.1129 & 0.4538 \\
\hline 5045 & 378.051 & 380.246 & 30.259 & 0.1129 & 0.5263 \\
\hline 5047 & 378.059 & 380.584 & 30.265 & 0.1128 & 0.6043 \\
\hline
\end{tabular}




\begin{tabular}{|c|c|c|c|c|c|}
\hline 5049 & 378.062 & 380.940 & 30.262 & 0.1128 & 0.6877 \\
\hline 5051 & 378.108 & 379.669 & 40.426 & 0.1164 & 0.3875 \\
\hline 5053 & 378.107 & 379.941 & 40.430 & 0.1163 & 0.4538 \\
\hline 5055 & 378.113 & 380.244 & 40.435 & 0.1163 & 0.5263 \\
\hline 5057 & 378.116 & 380.569 & 40.438 & 0.1162 & 0.6043 \\
\hline 5059 & 378.119 & 380.914 & 40.426 & 0.1162 & 0.6878 \\
\hline 6001 & 397.892 & 399.625 & 0.179 & 0.0984 & 0.3716 \\
\hline 6003 & 397.897 & 399.933 & 0.183 & 0.0984 & 0.4351 \\
\hline 6005 & 397.899 & 400.268 & 0.185 & 0.0984 & 0.5047 \\
\hline 6007 & 397.905 & 400.631 & 0.176 & 0.0983 & 0.5797 \\
\hline 6009 & 397.908 & 401.012 & 0.177 & 0.0982 & 0.6596 \\
\hline 6011 & 397.959 & 399.671 & 5.265 & 0.1009 & 0.3715 \\
\hline 6013 & 397.965 & 399.974 & 5.261 & 0.1008 & 0.4352 \\
\hline 6015 & 397.972 & 400.261 & 5.259 & 0.1007 & 0.5048 \\
\hline 6017 & 397.975 & 400.615 & 5.261 & 0.1007 & 0.5796 \\
\hline 6019 & 397.983 & 400.993 & 5.262 & 0.1006 & 0.6594 \\
\hline 6021 & 398.036 & 399.691 & 10.282 & 0.1030 & 0.3716 \\
\hline 6023 & 398.045 & 399.990 & 10.281 & 0.1030 & 0.4351 \\
\hline 6025 & 398.047 & 400.307 & 10.283 & 0.1030 & 0.5047 \\
\hline 6027 & 398.052 & 400.655 & 10.286 & 0.1030 & 0.5795 \\
\hline 6029 & 398.062 & 401.032 & 10.291 & 0.1029 & 0.6593 \\
\hline 6031 & 398.229 & 399.826 & 20.219 & 0.1072 & 0.3715 \\
\hline 6033 & 398.229 & 400.107 & 20.221 & 0.1073 & 0.4350 \\
\hline 6035 & 398.237 & 400.419 & 20.221 & 0.1070 & 0.5046 \\
\hline 6037 & 398.236 & 400.750 & 20.224 & 0.1071 & 0.5794 \\
\hline 6039 & 398.243 & 401.106 & 20.229 & 0.1070 & 0.6592 \\
\hline 6041 & 398.290 & 399.833 & 30.311 & 0.1110 & 0.3715 \\
\hline 6043 & 398.290 & 400.103 & 30.310 & 0.1110 & 0.4350 \\
\hline 6045 & 398.297 & 400.408 & 30.312 & 0.1109 & 0.5046 \\
\hline 6047 & 398.299 & 400.727 & 30.315 & 0.1109 & 0.5794 \\
\hline 6049 & 398.296 & 401.065 & 30.314 & 0.1108 & 0.6592 \\
\hline 6051 & 398.348 & 399.834 & 40.459 & 0.1146 & 0.3715 \\
\hline 6053 & 398.352 & 400.102 & 40.459 & 0.1146 & 0.4350 \\
\hline 6055 & 398.349 & 400.385 & 40.459 & 0.1145 & 0.5046 \\
\hline 6057 & 398.353 & 400.701 & 40.459 & 0.1146 & 0.5794 \\
\hline 6059 & 398.354 & 401.032 & 40.465 & 0.1145 & 0.6591 \\
\hline 7001 & 418.962 & 420.670 & 0.329 & 0.0960 & 0.3563 \\
\hline 7003 & 418.961 & 420.965 & 0.334 & 0.0959 & 0.4171 \\
\hline 7005 & 418.962 & 421.286 & 0.335 & 0.0959 & 0.4838 \\
\hline 7007 & 418.961 & 421.633 & 0.337 & 0.0958 & 0.5555 \\
\hline 7009 & 418.963 & 422.007 & 0.338 & 0.0957 & 0.6320 \\
\hline 7011 & 418.980 & 420.586 & 5.253 & 0.1001 & 0.3562 \\
\hline 7013 & 418.986 & 420.935 & 5.257 & 0.0984 & 0.4171 \\
\hline 7015 & 418.984 & 421.248 & 5.258 & 0.0984 & 0.4838 \\
\hline 7017 & 418.981 & 421.586 & 5.252 & 0.0984 & 0.5556 \\
\hline 7019 & 418.983 & 421.953 & 5.242 & 0.0982 & 0.6323 \\
\hline 7021 & 419.002 & 420.619 & 10.394 & 0.1010 & 0.3563 \\
\hline 7023 & 419.004 & 420.905 & 10.383 & 0.1009 & 0.4173 \\
\hline 7025 & 419.008 & 421.218 & 10.382 & 0.1008 & 0.4841 \\
\hline 7027 & 419.007 & 421.543 & 10.380 & 0.1008 & 0.5559 \\
\hline 7029 & 419.008 & 421.901 & 10.378 & 0.1007 & 0.6325 \\
\hline 7031 & 419.043 & 420.573 & 20.240 & 0.1053 & 0.3562 \\
\hline 7033 & 419.043 & 420.844 & 20.243 & 0.1052 & 0.4171 \\
\hline 7035 & 419.039 & 421.137 & 20.245 & 0.1051 & 0.4838 \\
\hline 7037 & 419.041 & 421.459 & 20.246 & 0.1050 & 0.5555 \\
\hline 7039 & 419.043 & 421.802 & 20.241 & 0.1049 & 0.6322 \\
\hline
\end{tabular}




\begin{tabular}{|c|c|c|c|c|c|}
\hline 7041 & 419.062 & 420.509 & 30.369 & 0.1092 & 0.3562 \\
\hline 7043 & 419.059 & 420.770 & 30.371 & 0.1092 & 0.4171 \\
\hline 7045 & 419.061 & 421.057 & 30.370 & 0.1092 & 0.4838 \\
\hline 7047 & 419.063 & 421.370 & 30.356 & 0.1091 & 0.5557 \\
\hline 7049 & 419.059 & 421.696 & 30.352 & 0.1091 & 0.6324 \\
\hline 7051 & 419.086 & 420.506 & 40.407 & 0.1128 & 0.3564 \\
\hline 7053 & 419.085 & 420.758 & 40.406 & 0.1129 & 0.4174 \\
\hline 7055 & 419.081 & 421.031 & 40.410 & 0.1129 & 0.4840 \\
\hline 7057 & 419.085 & 421.334 & 40.416 & 0.1129 & 0.5556 \\
\hline 7059 & 419.081 & 421.649 & 40.419 & 0.1128 & 0.6322 \\
\hline 8001 & 439.283 & 440.964 & 0.387 & 0.0934 & 0.3425 \\
\hline 8003 & 439.293 & 441.265 & 0.398 & 0.0933 & 0.4009 \\
\hline 8005 & 439.293 & 441.586 & 0.406 & 0.0933 & 0.4650 \\
\hline 8007 & 439.301 & 441.938 & 0.410 & 0.0933 & 0.5338 \\
\hline 8009 & 439.313 & 442.319 & 0.403 & 0.0931 & 0.6076 \\
\hline 8011 & 439.364 & 440.972 & 5.234 & 0.0962 & 0.3423 \\
\hline 8013 & 439.370 & 441.265 & 5.232 & 0.0960 & 0.4009 \\
\hline 8015 & 439.372 & 441.579 & 5.224 & 0.0961 & 0.4651 \\
\hline 8017 & 439.386 & 441.924 & 5.225 & 0.0960 & 0.5341 \\
\hline 8019 & 439.386 & 442.279 & 5.227 & 0.0959 & 0.6076 \\
\hline 8021 & 439.437 & 441.020 & 10.276 & 0.0988 & 0.3425 \\
\hline 8023 & 439.439 & 441.299 & 10.277 & 0.0987 & 0.4010 \\
\hline 8025 & 439.446 & 441.604 & 10.282 & 0.0986 & 0.4650 \\
\hline 8027 & 439.446 & 441.930 & 10.290 & 0.0986 & 0.5338 \\
\hline 8029 & 439.452 & 442.284 & 10.294 & 0.0985 & 0.6073 \\
\hline 8031 & 439.515 & 441.025 & 20.367 & 0.1035 & 0.3423 \\
\hline 8033 & 439.522 & 441.299 & 20.371 & 0.1035 & 0.4008 \\
\hline 8035 & 439.522 & 441.588 & 20.374 & 0.1034 & 0.4649 \\
\hline 8037 & 439.522 & 441.903 & 20.375 & 0.1034 & 0.5338 \\
\hline 8039 & 439.523 & 442.240 & 20.367 & 0.1033 & 0.6075 \\
\hline 8041 & 439.576 & 441.017 & 30.385 & 0.1075 & 0.3425 \\
\hline 8043 & 439.579 & 441.278 & 30.380 & 0.1077 & 0.4011 \\
\hline 8045 & 439.578 & 441.555 & 30.380 & 0.1077 & 0.4652 \\
\hline 8047 & 439.584 & 441.859 & 30.386 & 0.1075 & 0.5340 \\
\hline 8049 & 439.579 & 442.175 & 30.396 & 0.1076 & 0.6074 \\
\hline 8051 & 439.620 & 440.989 & 40.408 & 0.1117 & 0.3423 \\
\hline 8053 & 439.616 & 441.229 & 40.412 & 0.1116 & 0.4008 \\
\hline 8055 & 439.616 & 441.502 & 40.416 & 0.1116 & 0.4649 \\
\hline 8057 & 439.616 & 441.790 & 40.418 & 0.1115 & 0.5338 \\
\hline 8059 & 439.617 & 442.102 & 40.419 & 0.1115 & 0.6073 \\
\hline 9001 & 459.247 & 460.894 & 0.411 & 0.0903 & 0.3299 \\
\hline 9003 & 459.244 & 461.181 & 0.413 & 0.0904 & 0.3863 \\
\hline 9005 & 459.249 & 461.498 & 0.415 & 0.0903 & 0.4480 \\
\hline 9007 & 459.257 & 461.847 & 0.422 & 0.0902 & 0.5142 \\
\hline 9009 & 459.256 & 462.208 & 0.428 & 0.0901 & 0.5850 \\
\hline 9011 & 459.309 & 460.902 & 5.251 & 0.0933 & 0.3297 \\
\hline 9013 & 459.314 & 461.190 & 5.254 & 0.0933 & 0.3860 \\
\hline 9015 & 459.323 & 461.506 & 5.254 & 0.0932 & 0.4478 \\
\hline 9017 & 459.326 & 461.838 & 5.246 & 0.0932 & 0.5144 \\
\hline 9019 & 459.328 & 462.191 & 5.244 & 0.0931 & 0.5853 \\
\hline 9021 & 459.365 & 460.887 & 10.221 & 0.0965 & 0.3297 \\
\hline 9023 & 459.372 & 461.163 & 10.224 & 0.0964 & 0.3860 \\
\hline 9025 & 459.374 & 461.463 & 10.227 & 0.0964 & 0.4477 \\
\hline 9027 & 459.376 & 461.784 & 10.221 & 0.0963 & 0.5142 \\
\hline 9029 & 459.383 & 462.133 & 10.218 & 0.0963 & 0.5852 \\
\hline 9031 & 459.510 & 460.871 & 20.444 & 0.1015 & 0.3296 \\
\hline
\end{tabular}




\begin{tabular}{|c|c|c|c|c|c|}
\hline 9033 & 459.515 & 461.138 & 20.446 & 0.1014 & 0.3859 \\
\hline 9035 & 459.516 & 461.423 & 20.449 & 0.1014 & 0.4477 \\
\hline 9037 & 459.520 & 461.734 & 20.449 & 0.1014 & 0.5141 \\
\hline 9039 & 459.518 & 462.056 & 20.449 & 0.1013 & 0.5849 \\
\hline 9041 & 459.550 & 460.915 & 30.365 & 0.1057 & 0.3298 \\
\hline 9043 & 459.548 & 461.183 & 30.370 & 0.1058 & 0.3861 \\
\hline 9045 & 459.550 & 461.455 & 30.373 & 0.1057 & 0.4478 \\
\hline 9047 & 459.552 & 461.753 & 30.375 & 0.1057 & 0.5142 \\
\hline 9049 & 459.553 & 462.064 & 30.377 & 0.1057 & 0.5850 \\
\hline 9051 & 459.582 & 460.934 & 40.496 & 0.1100 & 0.3300 \\
\hline 9053 & 459.579 & 461.169 & 40.502 & 0.1100 & 0.3863 \\
\hline 9055 & 459.576 & 461.429 & 40.506 & 0.1099 & 0.4480 \\
\hline 9057 & 459.580 & 461.714 & 40.511 & 0.1098 & 0.5143 \\
\hline 9059 & 459.581 & 462.015 & 40.513 & 0.1098 & 0.5852 \\
\hline 10001 & 479.309 & 480.930 & 0.226 & 0.0881 & 0.3182 \\
\hline 10003 & 479.313 & 481.219 & 0.227 & 0.0880 & 0.3726 \\
\hline 10005 & 479.319 & 481.535 & 0.234 & 0.0880 & 0.4320 \\
\hline 10007 & 479.327 & 481.875 & 0.242 & 0.0880 & 0.4959 \\
\hline 10009 & 479.331 & 482.237 & 0.248 & 0.0879 & 0.5641 \\
\hline 10011 & 479.386 & 480.981 & 5.186 & 0.0914 & 0.3180 \\
\hline 10015 & 479.395 & 481.566 & 5.193 & 0.0913 & 0.4320 \\
\hline 10017 & 479.400 & 481.898 & 5.188 & 0.0912 & 0.4962 \\
\hline 10019 & 479.404 & 482.251 & 5.184 & 0.0911 & 0.5647 \\
\hline 10021 & 479.433 & 480.924 & 10.302 & 0.0944 & 0.3182 \\
\hline 10023 & 479.435 & 481.193 & 10.308 & 0.0944 & 0.3725 \\
\hline 10025 & 479.433 & 481.478 & 10.311 & 0.0943 & 0.4321 \\
\hline 10027 & 479.441 & 481.801 & 10.314 & 0.0943 & 0.4961 \\
\hline 10029 & 479.444 & 482.138 & 10.318 & 0.0943 & 0.5644 \\
\hline 10031 & 479.489 & 480.767 & 20.363 & 0.0997 & 0.3181 \\
\hline 10033 & 479.494 & 481.024 & 20.365 & 0.0997 & 0.3726 \\
\hline 10035 & 479.486 & 481.291 & 20.369 & 0.0997 & 0.4321 \\
\hline 10037 & 479.493 & 481.596 & 20.371 & 0.0997 & 0.4962 \\
\hline 10039 & 479.497 & 481.918 & 20.373 & 0.0996 & 0.5645 \\
\hline 10041 & 479.297 & 480.657 & 30.321 & 0.1043 & 0.3184 \\
\hline 10043 & 479.281 & 480.862 & 30.301 & 0.1043 & 0.3729 \\
\hline 10045 & 479.249 & 481.079 & 30.286 & 0.1043 & 0.4326 \\
\hline 10047 & 479.243 & 481.352 & 30.274 & 0.1042 & 0.4967 \\
\hline 10049 & 479.228 & 481.632 & 30.264 & 0.1042 & 0.5652 \\
\hline 10051 & 479.242 & 480.566 & 40.454 & 0.1085 & 0.3184 \\
\hline 10053 & 479.245 & 480.802 & 40.455 & 0.1085 & 0.3729 \\
\hline 10055 & 479.248 & 481.059 & 40.456 & 0.1085 & 0.4325 \\
\hline 10057 & 479.252 & 481.337 & 40.463 & 0.1084 & 0.4966 \\
\hline 10059 & 479.256 & 481.636 & 40.468 & 0.1084 & 0.5650 \\
\hline 11001 & 499.690 & 501.277 & 0.450 & 0.0858 & 0.3068 \\
\hline 11003 & 499.693 & 501.560 & 0.450 & 0.0857 & 0.3593 \\
\hline 11005 & 499.687 & 501.861 & 0.453 & 0.0856 & 0.4167 \\
\hline 11007 & 499.696 & 502.203 & 0.456 & 0.0856 & 0.4783 \\
\hline 11009 & 499.692 & 502.547 & 0.460 & 0.0856 & 0.5441 \\
\hline 11011 & 499.737 & 501.289 & 5.240 & 0.0892 & 0.3068 \\
\hline 11013 & 499.745 & 501.573 & 5.244 & 0.0891 & 0.3591 \\
\hline 11015 & 499.749 & 501.873 & 5.250 & 0.0890 & 0.4165 \\
\hline 11017 & 499.748 & 502.183 & 5.253 & 0.0890 & 0.4782 \\
\hline 11019 & 499.756 & 502.535 & 5.257 & 0.0889 & 0.5440 \\
\hline 11021 & 499.795 & 501.311 & 10.272 & 0.0922 & 0.3068 \\
\hline 11023 & 499.793 & 501.566 & 10.280 & 0.0922 & 0.3591 \\
\hline 11025 & 499.799 & 501.860 & 10.284 & 0.0922 & 0.4164 \\
\hline
\end{tabular}




$\begin{array}{llllll}11027 & 499.803 & 502.171 & 10.287 & 0.0922 & 0.4781 \\ 11029 & 499.808 & 502.459 & 10.290 & 0.0921 & 0.5440 \\ 11031 & 499.857 & 501.081 & 20.483 & 0.0978 & 0.3066 \\ 11033 & 499.853 & 501.517 & 20.486 & 0.0977 & 0.3591 \\ 11035 & 499.860 & 501.798 & 20.486 & 0.0977 & 0.4166 \\ 11037 & 499.860 & 502.092 & 20.477 & 0.0977 & 0.4785 \\ 11039 & 499.866 & 502.408 & 20.474 & 0.0976 & 0.5445 \\ 11043 & 499.919 & 501.459 & 30.417 & 0.1028 & 0.3593 \\ 11045 & 499.918 & 501.717 & 30.421 & 0.1026 & 0.4166 \\ 11047 & 499.911 & 501.988 & 30.425 & 0.1026 & 0.4784 \\ 11049 & 499.919 & 502.296 & 30.428 & 0.1026 & 0.5443 \\ 11051 & 499.945 & 501.211 & 40.398 & 0.1069 & 0.3069 \\ 11053 & 499.947 & 501.442 & 40.397 & 0.1070 & 0.3593 \\ 11055 & 499.946 & 501.692 & 40.391 & 0.1070 & 0.4167 \\ 11057 & 499.945 & 501.961 & 40.381 & 0.1069 & 0.4785 \\ 11059 & 499.945 & 502.249 & 40.369 & 0.1069 & 0.5444\end{array}$

Table A4. Thermal conductivity for JP-8-3773 in the liquid phase.

$\begin{array}{cccccc}\text { Point ID } & T_{0} & T_{\mathrm{e}} & P_{\mathrm{e}} & \begin{array}{c}\lambda_{\mathrm{e}} \\ (\mathrm{K})\end{array} & \begin{array}{c}q \\ (\mathrm{~K})\end{array} \\ \begin{array}{ccccc}(\mathrm{MPa}) \\ (001\end{array} & 300.750 & 302.502 & 0.781 & 0.1157 & 0.3448 \\ 1002 & 300.748 & 302.502 & 0.781 & 0.1157 & 0.3448 \\ 1003 & 300.750 & 302.731 & 0.782 & 0.1158 & 0.3893 \\ 1004 & 300.748 & 302.727 & 0.782 & 0.1158 & 0.3893 \\ 1005 & 300.748 & 302.969 & 0.782 & 0.1157 & 0.4364 \\ 1006 & 300.749 & 302.971 & 0.783 & 0.1157 & 0.4364 \\ 1007 & 300.748 & 303.226 & 0.783 & 0.1155 & 0.4863 \\ 1008 & 300.749 & 303.225 & 0.783 & 0.1155 & 0.4862 \\ 1009 & 300.747 & 303.495 & 0.783 & 0.1154 & 0.5387 \\ 1010 & 300.751 & 303.497 & 0.783 & 0.1151 & 0.5387 \\ 1011 & 300.758 & 302.486 & 5.400 & 0.1173 & 0.3448 \\ 1012 & 300.747 & 302.475 & 5.400 & 0.1173 & 0.3448 \\ 1013 & 300.753 & 302.709 & 5.402 & 0.1173 & 0.3893 \\ 1014 & 300.754 & 302.708 & 5.403 & 0.1173 & 0.3893 \\ 1015 & 300.755 & 302.948 & 5.404 & 0.1173 & 0.4365 \\ 1016 & 300.752 & 302.945 & 5.405 & 0.1172 & 0.4364 \\ 1017 & 300.752 & 303.195 & 5.406 & 0.1172 & 0.4863 \\ 1018 & 300.751 & 303.196 & 5.406 & 0.1172 & 0.4863 \\ 1019 & 300.756 & 303.467 & 11.733 & 0.1171 & 0.5388 \\ 1020 & 300.755 & 303.465 & 11.736 & 0.1168 & 0.5388 \\ 1021 & 300.759 & 302.449 & 11.738 & 0.1187 & 0.3448 \\ 1022 & 300.750 & 302.444 & 11.740 & 0.1187 & 0.3448 \\ 1023 & 300.755 & 302.671 & 11.742 & 0.1187 & 0.3893 \\ 1024 & 300.755 & 302.670 & 11.743 & 0.1187 & 0.3893 \\ 1026 & 300.753 & 302.907 & 11.743 & 0.1181 & 0.4365 \\ 1027 & 300.756 & 303.159 & 11.742 & 0.1180 & 0.4862 \\ 1029 & 300.755 & 303.422 & 11.741 & 0.1187 & 0.5388\end{array}$




\begin{tabular}{|c|c|c|c|c|c|}
\hline 1030 & 300.752 & 303.416 & 11.740 & 0.1187 & 0.5388 \\
\hline 1031 & 300.771 & 302.410 & 20.455 & 0.1218 & 0.3448 \\
\hline 032 & 300.771 & 302.409 & 20.455 & 0.1218 & 0.3448 \\
\hline 033 & 300.766 & 302.623 & 20.454 & 0.1218 & 0.3893 \\
\hline 034 & 300.769 & 302.623 & 20.454 & 0.1218 & 0.3893 \\
\hline 1035 & 300.766 & 302.853 & 20.454 & 0.1219 & 0.4364 \\
\hline 1036 & 300.770 & 302.855 & 20.455 & 0.1220 & 0.4364 \\
\hline 1037 & 300.765 & 303.094 & 20.455 & 0.1219 & 0.4862 \\
\hline 1038 & 300.771 & 303.099 & 20.456 & 0.1219 & 0.4863 \\
\hline 1039 & 300.767 & 303.354 & 20.457 & 0.1218 & 0.5387 \\
\hline 1041 & 300.785 & 302.393 & 30.829 & 0.1245 & 0.3448 \\
\hline 1042 & 300.782 & 302.389 & 30.829 & 0.1245 & 0.3448 \\
\hline 1043 & 300.784 & 302.606 & 30.829 & 0.1244 & 0.3893 \\
\hline 1044 & 300.785 & 302.606 & 30.828 & 0.1244 & 0.3893 \\
\hline 1045 & 300.781 & 302.830 & 30.830 & 0.1242 & 0.4364 \\
\hline 1046 & 300.783 & 302.831 & 30.831 & 0.1237 & 0.4364 \\
\hline 1047 & 300.785 & 303.076 & 30.834 & 0.1243 & 0.4862 \\
\hline 1048 & 300.783 & 303.074 & 40.906 & 0.1243 & 0.4862 \\
\hline 1049 & 300.784 & 303.326 & 40.909 & 0.1238 & 0.5387 \\
\hline 1050 & 300.781 & 303.322 & 40.912 & 0.1239 & 0.5387 \\
\hline 1051 & 300.789 & 302.364 & 40.912 & 0.1271 & 0.3448 \\
\hline 1052 & 300.787 & 302.363 & 40.916 & 0.1271 & 0.3448 \\
\hline 1053 & 300.791 & 302.577 & 40.918 & 0.1270 & 0.3893 \\
\hline 1054 & 300.792 & 302.576 & 40.919 & 0.1270 & 0.3892 \\
\hline 1055 & 300.783 & 302.793 & 40.921 & 0.1272 & 0.4364 \\
\hline 1056 & 300.787 & 302.796 & 40.923 & 0.1272 & 0.4364 \\
\hline 1057 & 300.788 & 303.031 & 40.923 & 0.1271 & 0.4862 \\
\hline 1058 & 300.788 & 303.029 & 50.744 & 0.1271 & 0.4862 \\
\hline 1059 & 300.785 & 303.274 & 50.744 & 0.1270 & 0.5387 \\
\hline 1060 & 300.787 & 303.276 & 50.748 & 0.1264 & 0.5387 \\
\hline 1061 & 300.796 & 302.359 & 50.750 & 0.1296 & 0.3447 \\
\hline 1062 & 300.792 & 302.354 & 50.749 & 0.1296 & 0.3447 \\
\hline 1063 & 300.794 & 302.572 & 50.750 & 0.1297 & 0.3891 \\
\hline 1064 & 300.796 & 302.572 & 50.751 & 0.1297 & 0.3892 \\
\hline 1065 & 300.793 & 302.787 & 60.438 & 0.1298 & 0.4363 \\
\hline 1066 & 300.792 & 302.787 & 60.426 & 0.1299 & 0.4363 \\
\hline 1067 & 300.795 & 303.020 & 60.413 & 0.1296 & 0.4861 \\
\hline 1068 & 300.791 & 303.014 & 60.400 & 0.1295 & 0.4861 \\
\hline 1069 & 300.794 & 303.262 & 60.389 & 0.1294 & 0.5386 \\
\hline 1070 & 300.788 & 303.255 & 60.376 & 0.1293 & 0.5386 \\
\hline 1071 & 300.798 & 302.319 & 60.366 & 0.1319 & 0.3447 \\
\hline 1072 & 300.795 & 302.317 & 60.356 & 0.1319 & 0.3447 \\
\hline 1073 & 300.797 & 302.522 & 60.346 & 0.1317 & 0.3892 \\
\hline 1074 & 300.798 & 302.524 & 60.334 & 0.1317 & 0.3892 \\
\hline 1075 & 300.795 & 302.734 & 0.781 & 0.1318 & 0.4363 \\
\hline 1076 & 300.795 & 302.734 & 0.781 & 0.1317 & 0.4363 \\
\hline 1077 & 300.798 & 302.963 & 0.782 & 0.1317 & 0.4861 \\
\hline 1078 & 300.795 & 302.960 & 0.782 & 0.1317 & 0.4861 \\
\hline
\end{tabular}




\begin{tabular}{llllll}
1079 & 300.796 & 303.199 & 0.782 & 0.1316 & 0.5386 \\
1080 & 300.790 & 303.196 & 0.783 & 0.1314 & 0.5386 \\
2003 & 355.094 & 357.010 & 0.783 & 0.1050 & 0.3506 \\
2004 & 355.098 & 357.013 & 0.783 & 0.1049 & 0.3506 \\
2005 & 355.100 & 357.256 & 0.783 & 0.1053 & 0.3930 \\
2006 & 355.099 & 357.253 & 0.783 & 0.1053 & 0.3930 \\
2007 & 355.102 & 357.508 & 5.400 & 0.1054 & 0.4379 \\
2008 & 355.105 & 357.513 & 5.400 & 0.1054 & 0.4379 \\
2009 & 355.107 & 357.778 & 5.402 & 0.1054 & 0.4851 \\
2010 & 355.110 & 357.781 & 5.403 & 0.1053 & 0.4851 \\
2011 & 355.146 & 356.812 & 5.404 & 0.1076 & 0.3105 \\
2012 & 355.144 & 356.813 & 5.405 & 0.1076 & 0.3105 \\
2015 & 355.150 & 357.276 & 5.406 & 0.1072 & 0.3930 \\
2016 & 355.150 & 357.274 & 5.406 & 0.1072 & 0.3930 \\
2017 & 355.147 & 357.520 & 11.733 & 0.1073 & 0.4379 \\
2018 & 355.157 & 357.527 & 11.736 & 0.1073 & 0.4379 \\
2019 & 355.149 & 357.780 & 11.738 & 0.1072 & 0.4851 \\
2020 & 355.154 & 357.783 & 11.740 & 0.1071 & 0.4851 \\
2021 & 355.183 & 356.825 & 11.742 & 0.1093 & 0.3105 \\
2022 & 355.182 & 356.828 & 11.743 & 0.1087 & 0.3105 \\
2023 & 355.186 & 357.051 & 11.743 & 0.1085 & 0.3505 \\
2024 & 355.183 & 357.048 & 11.742 & 0.1086 & 0.3506 \\
2025 & 355.188 & 357.283 & 11.741 & 0.1093 & 0.3930 \\
2026 & 355.186 & 357.283 & 11.740 & 0.1092 & 0.3930 \\
2027 & 355.191 & 357.529 & 20.455 & 0.1093 & 0.4378 \\
2028 & 355.193 & 357.529 & 20.455 & 0.1092 & 0.4379 \\
2029 & 355.188 & 357.784 & 20.454 & 0.1088 & 0.4851 \\
2030 & 355.194 & 357.787 & 20.454 & 0.1087 & 0.4851 \\
2031 & 355.242 & 356.830 & 20.454 & 0.1135 & 0.3105 \\
2032 & 355.237 & 356.826 & 20.455 & 0.1135 & 0.3105 \\
2033 & 355.241 & 357.040 & 20.455 & 0.1133 & 0.3505 \\
2034 & 355.242 & 357.040 & 20.456 & 0.1132 & 0.3506 \\
2035 & 355.244 & 357.265 & 20.457 & 0.1127 & 0.3930 \\
2036 & 355.236 & 357.257 & 30.829 & 0.1128 & 0.3930 \\
2037 & 355.245 & 357.501 & 30.829 & 0.1126 & 0.4378 \\
2038 & 355.240 & 357.495 & 30.829 & 0.1125 & 0.4379 \\
2039 & 355.244 & 357.749 & 30.828 & 0.1128 & 0.4851 \\
2040 & 355.249 & 357.754 & 30.830 & 0.1129 & 0.4851 \\
2043 & 355.278 & 357.015 & 30.831 & 0.1166 & 0.3505 \\
2044 & 355.286 & 357.023 & 30.834 & 0.1166 & 0.3506 \\
2046 & 355.278 & 357.228 & 40.906 & 0.1168 & 0.3930 \\
& 355.282 & 357.233 & 40.909 & 0.1167 & 0.3930 \\
\hline & 355.285 & 357.466 & 40.912 & 0.1155 & 0.4378 \\
\hline & 355.284 & 357.463 & 40.912 & 0.1158 & 0.4379 \\
\hline & 357.706 & 40.916 & 0.1156 & 0.4851 \\
\hline & 357.710 & 40.918 & 0.1156 & 0.4851 \\
\hline & 356.808 & 40.921 & 0.1199 & 0.3105
\end{tabular}




\begin{tabular}{llllll}
2053 & 355.304 & 357.001 & 40.923 & 0.1193 & 0.3505 \\
2054 & 355.311 & 357.008 & 40.923 & 0.1193 & 0.3505 \\
2055 & 355.307 & 357.216 & 50.744 & 0.1187 & 0.3930 \\
2056 & 355.307 & 357.216 & 50.744 & 0.1192 & 0.3930 \\
2057 & 355.311 & 357.443 & 50.748 & 0.1197 & 0.4378 \\
2058 & 355.304 & 357.435 & 50.750 & 0.1198 & 0.4378 \\
2059 & 355.308 & 357.675 & 50.749 & 0.1193 & 0.4851 \\
2060 & 355.301 & 357.668 & 50.750 & 0.1192 & 0.4851 \\
2063 & 355.318 & 356.963 & 50.751 & 0.1229 & 0.3505 \\
2064 & 355.323 & 356.969 & 60.438 & 0.1229 & 0.3505 \\
2065 & 355.322 & 357.174 & 60.426 & 0.1222 & 0.3930 \\
2066 & 355.317 & 357.179 & 60.413 & 0.1222 & 0.3930 \\
2067 & 355.321 & 357.401 & 60.400 & 0.1229 & 0.4378 \\
2068 & 355.315 & 357.395 & 60.389 & 0.1226 & 0.4378 \\
2069 & 355.319 & 357.628 & 60.376 & 0.1225 & 0.4851 \\
2070 & 355.319 & 357.626 & 60.366 & 0.1225 & 0.4851 \\
2072 & 355.331 & 356.765 & 60.356 & 0.1248 & 0.3104 \\
2073 & 355.331 & 356.955 & 60.346 & 0.1247 & 0.3505 \\
2074 & 355.334 & 356.954 & 60.334 & 0.1247 & 0.3505 \\
2075 & 355.336 & 357.161 & 0.781 & 0.1249 & 0.3929 \\
2076 & 355.327 & 357.152 & 0.781 & 0.1247 & 0.3929 \\
2077 & 355.335 & 357.375 & 0.782 & 0.1254 & 0.4378 \\
2078 & 355.328 & 357.364 & 0.782 & 0.1254 & 0.4378 \\
2079 & 355.331 & 357.594 & 0.782 & 0.1261 & 0.4850 \\
2080 & 355.330 & 357.590 & 0.783 & 0.1261 & 0.4851 \\
3001 & 404.755 & 406.536 & 0.783 & 0.0967 & 0.3003 \\
3003 & 404.757 & 406.775 & 0.783 & 0.0965 & 0.3391 \\
3004 & 404.754 & 406.776 & 0.783 & 0.0964 & 0.3391 \\
3005 & 404.759 & 407.027 & 0.783 & 0.0961 & 0.3801 \\
3006 & 404.762 & 407.033 & 5.400 & 0.0957 & 0.3801 \\
3007 & 404.760 & 407.294 & 5.400 & 0.0952 & 0.4235 \\
3009 & 404.769 & 407.586 & 5.402 & 0.0961 & 0.4691 \\
3010 & 404.764 & 407.581 & 5.403 & 0.0962 & 0.4692 \\
3011 & 404.792 & 406.526 & 5.404 & 0.0993 & 0.3003 \\
3012 & 404.795 & 406.528 & 5.405 & 0.0994 & 0.3003 \\
3013 & 404.797 & 406.760 & 5.406 & 0.0986 & 0.3391 \\
3014 & 404.791 & 406.754 & 5.406 & 0.0986 & 0.3391 \\
3015 & 404.797 & 407.002 & 11.733 & 0.0992 & 0.3801 \\
3016 & 404.792 & 406.995 & 11.736 & 0.0991 & 0.3801 \\
3017 & 404.799 & 407.260 & 11.738 & 0.0990 & 0.4235 \\
3019 & 404.792 & 407.525 & 11.740 & 0.0991 & 0.4692 \\
3021 & 404.816 & 406.498 & 11.742 & 0.1011 & 0.3003 \\
3022 & 404.810 & 406.493 & 11.743 & 0.1011 & 0.3003 \\
3032 & 404.808 & 407.210 & 11.743 & 0.1007 & 0.4235 \\
& 404.811 & 407.213 & 11.742 & 0.1000 & 0.4235 \\
\hline 028 & 404.809 & 407.474 & 11.741 & 0.1000 & 0.4692 \\
\hline
\end{tabular}




\begin{tabular}{|c|c|c|c|c|c|}
\hline 3035 & 404.815 & 406.980 & 20.455 & 0.1006 & 0.3801 \\
\hline 3036 & 404.810 & 406.958 & 20.454 & 0.1001 & 0.3801 \\
\hline 037 & 404.814 & 407.234 & 20.454 & 0.1005 & 0.4235 \\
\hline 038 & 404.813 & 407.233 & 20.454 & 0.1001 & 0.4235 \\
\hline 3039 & 404.815 & 407.500 & 20.455 & 0.1002 & 0.4692 \\
\hline 3040 & 404.816 & 407.499 & 20.455 & 0.0999 & 0.4692 \\
\hline 3041 & 404.840 & 406.453 & 20.456 & 0.1061 & 0.3004 \\
\hline 3042 & 404.842 & 406.458 & 20.457 & 0.1061 & 0.3003 \\
\hline 3043 & 404.837 & 406.671 & 30.829 & 0.1062 & 0.3391 \\
\hline 3044 & 404.837 & 406.665 & 30.829 & 0.1060 & 0.3391 \\
\hline 3047 & 404.835 & 407.136 & 30.829 & 0.1056 & 0.4235 \\
\hline 3048 & 404.836 & 407.137 & 30.828 & 0.1055 & 0.4236 \\
\hline 3049 & 404.835 & 407.390 & 30.830 & 0.1058 & 0.4692 \\
\hline 3050 & 404.833 & 407.387 & 30.831 & 0.1058 & 0.4692 \\
\hline 3053 & 404.853 & 406.616 & 30.834 & 0.1099 & 0.3391 \\
\hline 3054 & 404.851 & 406.616 & 40.906 & 0.1100 & 0.3392 \\
\hline 3055 & 404.851 & 406.834 & 40.909 & 0.1101 & 0.3802 \\
\hline 3056 & 404.852 & 406.835 & 40.912 & 0.1100 & 0.3802 \\
\hline 3057 & 404.851 & 407.067 & 40.912 & 0.1100 & 0.4235 \\
\hline 3058 & 404.850 & 407.061 & 40.916 & 0.1100 & 0.4235 \\
\hline 3059 & 404.852 & 407.309 & 40.918 & 0.1099 & 0.4693 \\
\hline 3060 & 404.849 & 407.306 & 40.919 & 0.1100 & 0.4693 \\
\hline 3061 & 404.861 & 406.367 & 40.921 & 0.1139 & 0.3004 \\
\hline 3062 & 404.854 & 406.356 & 40.923 & 0.1139 & 0.3004 \\
\hline 3063 & 404.866 & 406.571 & 40.923 & 0.1139 & 0.3391 \\
\hline 3064 & 404.857 & 406.562 & 50.744 & 0.1139 & 0.3391 \\
\hline 3065 & 404.861 & 406.777 & 50.744 & 0.1138 & 0.3802 \\
\hline 3066 & 404.859 & 406.772 & 50.748 & 0.1137 & 0.3802 \\
\hline 3067 & 404.854 & 406.993 & 50.750 & 0.1137 & 0.4235 \\
\hline 3068 & 404.862 & 407.001 & 50.749 & 0.1138 & 0.4236 \\
\hline 3069 & 404.857 & 407.231 & 50.750 & 0.1137 & 0.4692 \\
\hline 3070 & 404.859 & 407.232 & 50.751 & 0.1137 & 0.4692 \\
\hline 3071 & 404.870 & 406.332 & 60.438 & 0.1174 & 0.3003 \\
\hline 3072 & 404.865 & 406.359 & 60.426 & 0.1174 & 0.3003 \\
\hline 3073 & 404.868 & 406.558 & 60.413 & 0.1174 & 0.3390 \\
\hline 3074 & 404.862 & 406.550 & 60.400 & 0.1173 & 0.3390 \\
\hline 3075 & 404.864 & 406.757 & 60.389 & 0.1173 & 0.3801 \\
\hline 3076 & 404.865 & 406.759 & 60.376 & 0.1173 & 0.3801 \\
\hline 3077 & 404.861 & 406.971 & 60.366 & 0.1172 & 0.4235 \\
\hline 3078 & 404.863 & 406.973 & 60.356 & 0.1172 & 0.4234 \\
\hline 3079 & 404.865 & 407.204 & 60.346 & 0.1172 & 0.4692 \\
\hline 3080 & 404.860 & 407.199 & 60.334 & 0.1172 & 0.4692 \\
\hline 3081 & 404.874 & 406.290 & 0.781 & 0.1206 & 0.3003 \\
\hline 3082 & 404.866 & 406.284 & 0.781 & 0.1205 & 0.3003 \\
\hline 3083 & 404.870 & 406.476 & 0.782 & 0.1205 & 0.3391 \\
\hline 3084 & 404.873 & 406.524 & 0.782 & 0.1204 & 0.3390 \\
\hline 3085 & 404.868 & 406.723 & 0.782 & 0.1203 & 0.3801 \\
\hline 3086 & 404.863 & 406.718 & 0.783 & 0.1203 & 0.3800 \\
\hline
\end{tabular}




\begin{tabular}{|c|c|c|c|c|c|}
\hline 3087 & 404.864 & 406.928 & 0.783 & 0.1203 & 0.4234 \\
\hline 3088 & 404.869 & 406.932 & 0.783 & 0.1203 & 0.4235 \\
\hline 089 & 404.867 & 407.156 & 0.783 & 0.1202 & 0.4691 \\
\hline 3090 & 404.864 & 407.152 & 0.783 & 0.1202 & 0.4691 \\
\hline 091 & 404.736 & 406.460 & 5.400 & 0.1024 & 0.3002 \\
\hline 092 & 404.740 & 406.425 & 5.400 & 0.1029 & 0.3002 \\
\hline 3093 & 404.740 & 406.645 & 5.402 & 0.1030 & 0.3389 \\
\hline 094 & 404.745 & 406.654 & 5.403 & 0.1030 & 0.3389 \\
\hline 3095 & 404.748 & 406.888 & 5.404 & 0.1027 & 0.3799 \\
\hline 3096 & 404.742 & 406.881 & 5.405 & 0.1024 & 0.3799 \\
\hline 3097 & 404.744 & 407.134 & 5.406 & 0.1028 & 0.4233 \\
\hline 3098 & 404.750 & 407.140 & 5.406 & 0.1027 & 0.4233 \\
\hline 3099 & 404.745 & 407.394 & 11.733 & 0.1028 & 0.4690 \\
\hline 3100 & 404.758 & 407.411 & 11.736 & 0.1029 & 0.4690 \\
\hline 4001 & 451.962 & 453.817 & 11.738 & 0.0877 & 0.2878 \\
\hline 4002 & 451.965 & 453.825 & 11.740 & 0.0873 & 0.2878 \\
\hline 4003 & 451.964 & 454.068 & 11.742 & 0.0879 & 0.3249 \\
\hline 4004 & 451.968 & 454.072 & 11.743 & 0.0871 & 0.3249 \\
\hline 4005 & 451.970 & 454.336 & 11.743 & 0.0883 & 0.3642 \\
\hline 4006 & 451.972 & 454.340 & 11.742 & 0.0880 & 0.3642 \\
\hline 4007 & 451.972 & 454.613 & 11.741 & 0.0882 & 0.4058 \\
\hline 4008 & 451.973 & 454.614 & 11.740 & 0.0884 & 0.4058 \\
\hline 4009 & 451.980 & 454.908 & 20.455 & 0.0879 & 0.4496 \\
\hline 4010 & 451.980 & 454.904 & 20.455 & 0.0881 & 0.4496 \\
\hline 4011 & 451.988 & 453.763 & 20.454 & 0.0908 & 0.2878 \\
\hline 4012 & 451.995 & 453.770 & 20.454 & 0.0914 & 0.2878 \\
\hline 4013 & 451.991 & 454.001 & 20.454 & 0.0913 & 0.3249 \\
\hline 4014 & 451.993 & 454.002 & 20.455 & 0.0913 & 0.3249 \\
\hline 4015 & 451.994 & 454.250 & 20.455 & 0.0919 & 0.3642 \\
\hline 4016 & 451.993 & 454.249 & 20.456 & 0.0919 & 0.3642 \\
\hline 4017 & 451.991 & 454.507 & 20.457 & 0.0913 & 0.4058 \\
\hline 4018 & 451.990 & 454.507 & 30.829 & 0.0915 & 0.4058 \\
\hline 4021 & 452.021 & 453.726 & 30.829 & 0.0957 & 0.2878 \\
\hline 4022 & 452.016 & 453.719 & 30.829 & 0.0956 & 0.2878 \\
\hline 4023 & 452.021 & 453.949 & 30.828 & 0.0958 & 0.3249 \\
\hline 4024 & 452.021 & 453.950 & 30.830 & 0.0958 & 0.3249 \\
\hline 4025 & 452.026 & 454.196 & 30.831 & 0.0957 & 0.3642 \\
\hline 4027 & 452.022 & 454.451 & 30.834 & 0.0949 & 0.4058 \\
\hline 4028 & 452.027 & 454.459 & 40.906 & 0.0948 & 0.4058 \\
\hline 4029 & 452.021 & 454.720 & 40.909 & 0.0948 & 0.4496 \\
\hline 4030 & 452.024 & 454.715 & 40.912 & 0.0945 & 0.4496 \\
\hline 4031 & 452.055 & 453.727 & 40.912 & 0.0990 & 0.2877 \\
\hline 4033 & 452.051 & 453.934 & 40.916 & 0.0998 & 0.3249 \\
\hline 4034 & 452.047 & 453.927 & 40.918 & 0.0998 & 0.3248 \\
\hline 4035 & 452.046 & 454.157 & 40.919 & 0.0989 & 0.3642 \\
\hline 4036 & 452.052 & 454.164 & 40.921 & 0.0997 & 0.3642 \\
\hline 4037 & 452.056 & 454.410 & 40.923 & 0.0998 & 0.4057 \\
\hline 4038 & 452.054 & 454.408 & 40.923 & 0.0998 & 0.4058 \\
\hline
\end{tabular}




\begin{tabular}{|c|c|c|c|c|c|}
\hline 4039 & 452.049 & 454.662 & 50.744 & 0.0997 & 0.4495 \\
\hline 4040 & 452.053 & 454.670 & 50.744 & 0.0988 & 0.4495 \\
\hline 4041 & 452.078 & 453.644 & 50.748 & 0.1042 & 0.2878 \\
\hline 4042 & 452.077 & 453.640 & 50.750 & 0.1042 & 0.2878 \\
\hline 4043 & 452.074 & 453.853 & 50.749 & 0.1034 & 0.3249 \\
\hline 4044 & 452.073 & 453.848 & 50.750 & 0.1034 & 0.3249 \\
\hline 4045 & 452.078 & 454.075 & 50.751 & 0.1036 & 0.3642 \\
\hline 4046 & 452.071 & 454.070 & 60.438 & 0.1036 & 0.3642 \\
\hline 4047 & 452.073 & 454.305 & 60.426 & 0.1041 & 0.4058 \\
\hline 4048 & 452.075 & 454.307 & 60.413 & 0.1042 & 0.4058 \\
\hline 4051 & 452.096 & 453.603 & 60.400 & 0.1075 & 0.2877 \\
\hline 4052 & 452.088 & 453.595 & 60.389 & 0.1076 & 0.2878 \\
\hline 4053 & 452.097 & 453.806 & 60.376 & 0.1069 & 0.3249 \\
\hline 4054 & 452.092 & 453.798 & 60.366 & 0.1069 & 0.3249 \\
\hline 4055 & 452.096 & 454.020 & 60.356 & 0.1070 & 0.3642 \\
\hline 4056 & 452.093 & 454.016 & 60.346 & 0.1071 & 0.3642 \\
\hline 4057 & 452.093 & 454.243 & 60.334 & 0.1069 & 0.4058 \\
\hline 4058 & 452.093 & 454.242 & 0.781 & 0.1069 & 0.4057 \\
\hline 4059 & 452.087 & 454.470 & 0.781 & 0.1068 & 0.4496 \\
\hline 4061 & 452.108 & 453.542 & 0.782 & 0.1122 & 0.2877 \\
\hline 4062 & 452.110 & 453.547 & 0.782 & 0.1121 & 0.2877 \\
\hline 4063 & 452.110 & 453.738 & 0.782 & 0.1120 & 0.3249 \\
\hline 4064 & 452.110 & 453.740 & 0.783 & 0.1119 & 0.3249 \\
\hline 4070 & 452.104 & 454.386 & 0.783 & 0.1114 & 0.4496 \\
\hline 4071 & 452.103 & 453.592 & 0.783 & 0.1121 & 0.2877 \\
\hline 4072 & 452.099 & 453.587 & 0.783 & 0.1121 & 0.2877 \\
\hline 4073 & 452.092 & 453.773 & 0.783 & 0.1122 & 0.3248 \\
\hline 4074 & 452.104 & 453.784 & 5.400 & 0.1122 & 0.3248 \\
\hline 4075 & 452.103 & 453.986 & 5.400 & 0.1121 & 0.3641 \\
\hline 4076 & 452.100 & 453.988 & 5.402 & 0.1120 & 0.3641 \\
\hline 4077 & 452.100 & 454.206 & 5.403 & 0.1111 & 0.4057 \\
\hline 4078 & 452.100 & 454.203 & 5.404 & 0.1113 & 0.4057 \\
\hline 4079 & 452.100 & 454.433 & 5.405 & 0.1119 & 0.4495 \\
\hline 4080 & 452.098 & 454.436 & 5.406 & 0.1117 & 0.4495 \\
\hline 4081 & 452.113 & 453.518 & 5.406 & 0.1153 & 0.2877 \\
\hline 4082 & 452.108 & 453.512 & 11.733 & 0.1156 & 0.2877 \\
\hline 4083 & 452.113 & 453.707 & 11.736 & 0.1154 & 0.3248 \\
\hline 4084 & 452.109 & 453.702 & 11.738 & 0.1151 & 0.3248 \\
\hline 4085 & 452.107 & 453.899 & 11.740 & 0.1154 & 0.3642 \\
\hline 4086 & 452.108 & 453.899 & 11.742 & 0.1156 & 0.3642 \\
\hline 4087 & 452.109 & 454.119 & 11.743 & 0.1146 & 0.4057 \\
\hline 4088 & 452.110 & 454.118 & 11.743 & 0.1148 & 0.4057 \\
\hline 4089 & 452.106 & 454.333 & 11.742 & 0.1155 & 0.4495 \\
\hline 4090 & 452.107 & 454.336 & 11.741 & 0.1155 & 0.4495 \\
\hline 4091 & 452.073 & 453.601 & 11.740 & 0.1117 & 0.2876 \\
\hline 4092 & 452.070 & 453.598 & 20.455 & 0.1116 & 0.2876 \\
\hline 4093 & 452.076 & 453.803 & 20.455 & 0.1114 & 0.3248 \\
\hline 4094 & 452.073 & 453.803 & 20.454 & 0.1117 & 0.3247 \\
\hline
\end{tabular}




\begin{tabular}{|c|c|c|c|c|c|}
\hline 4095 & 452.073 & 453.975 & 20.454 & 0.1120 & 0.3641 \\
\hline 4096 & 452.076 & 453.978 & 20.454 & 0.1121 & 0.3641 \\
\hline 4097 & 452.071 & 454.191 & 20.455 & 0.1120 & 0.4057 \\
\hline 4098 & 452.076 & 454.196 & 20.455 & 0.1119 & 0.4056 \\
\hline 4099 & 452.075 & 454.425 & 20.456 & 0.1119 & 0.4494 \\
\hline 4100 & 452.071 & 454.422 & 20.457 & 0.1117 & 0.4495 \\
\hline 4101 & 452.048 & 453.618 & 30.829 & 0.1071 & 0.2877 \\
\hline 4102 & 452.050 & 453.620 & 30.829 & 0.1069 & 0.2876 \\
\hline 4103 & 452.052 & 453.801 & 30.829 & 0.1075 & 0.3248 \\
\hline 4104 & 452.053 & 453.801 & 30.828 & 0.1072 & 0.3248 \\
\hline 4105 & 452.050 & 454.012 & 30.830 & 0.1079 & 0.3641 \\
\hline 4106 & 452.053 & 454.016 & 30.831 & 0.1078 & 0.3641 \\
\hline 4107 & 452.050 & 454.240 & 30.834 & 0.1073 & 0.4056 \\
\hline 4108 & 452.056 & 454.248 & 40.906 & 0.1069 & 0.4056 \\
\hline 4109 & 452.051 & 454.481 & 40.909 & 0.1074 & 0.4494 \\
\hline 4110 & 452.051 & 454.480 & 40.912 & 0.1072 & 0.4494 \\
\hline 5003 & 495.464 & 497.561 & 40.912 & 0.0826 & 0.3002 \\
\hline 5004 & 495.466 & 497.567 & 40.916 & 0.0818 & 0.3002 \\
\hline 5006 & 495.473 & 497.832 & 40.918 & 0.0817 & 0.3366 \\
\hline 5007 & 495.475 & 498.107 & 40.919 & 0.0818 & 0.3749 \\
\hline 5008 & 495.472 & 498.106 & 40.921 & 0.0819 & 0.3750 \\
\hline 5009 & 495.478 & 498.397 & 40.923 & 0.0820 & 0.4154 \\
\hline 5010 & 495.484 & 498.402 & 40.923 & 0.0820 & 0.4154 \\
\hline 5011 & 495.490 & 497.336 & 50.744 & 0.0818 & 0.2659 \\
\hline 5015 & 495.494 & 497.847 & 50.744 & 0.0817 & 0.3366 \\
\hline 5016 & 495.494 & 497.848 & 50.748 & 0.0816 & 0.3366 \\
\hline 5019 & 495.497 & 498.403 & 50.750 & 0.0824 & 0.4154 \\
\hline 5020 & 495.502 & 498.408 & 50.749 & 0.0821 & 0.4154 \\
\hline 5021 & 495.527 & 497.280 & 50.750 & 0.0863 & 0.2659 \\
\hline 5022 & 495.529 & 497.280 & 50.751 & 0.0863 & 0.2659 \\
\hline 5023 & 495.529 & 497.510 & 60.438 & 0.0862 & 0.3002 \\
\hline 5024 & 495.525 & 497.504 & 60.426 & 0.0862 & 0.3002 \\
\hline 5026 & 495.530 & 497.768 & 60.413 & 0.0857 & 0.3366 \\
\hline 5027 & 495.527 & 498.035 & 60.400 & 0.0852 & 0.3750 \\
\hline 5028 & 495.525 & 498.015 & 60.389 & 0.0859 & 0.3750 \\
\hline 5033 & 495.543 & 497.452 & 60.376 & 0.0904 & 0.3002 \\
\hline 5034 & 495.546 & 497.454 & 60.366 & 0.0903 & 0.3002 \\
\hline 5035 & 495.545 & 497.686 & 60.356 & 0.0899 & 0.3366 \\
\hline 5036 & 495.546 & 497.684 & 60.346 & 0.0896 & 0.3366 \\
\hline 5037 & 495.541 & 497.929 & 60.334 & 0.0894 & 0.3750 \\
\hline 5038 & 495.542 & 497.927 & 0.781 & 0.0893 & 0.3750 \\
\hline 5039 & 495.548 & 498.194 & 0.781 & 0.0900 & 0.4154 \\
\hline 5041 & 495.556 & 497.131 & 0.782 & 0.0946 & 0.2659 \\
\hline 5042 & 495.557 & 497.131 & 0.782 & 0.0944 & 0.2659 \\
\hline 5043 & 495.561 & 497.373 & 0.782 & 0.0946 & 0.3002 \\
\hline 5044 & 495.558 & 497.368 & 0.783 & 0.0946 & 0.3002 \\
\hline 5045 & 495.556 & 497.593 & 0.783 & 0.0948 & 0.3366 \\
\hline 5046 & 495.552 & 497.586 & 0.783 & 0.0939 & 0.3366 \\
\hline
\end{tabular}




\begin{tabular}{|c|c|c|c|c|c|}
\hline 5047 & 495.554 & 497.822 & 0.783 & 0.0941 & 0.3750 \\
\hline 5048 & 495.552 & 497.824 & 0.783 & 0.0941 & 0.3749 \\
\hline 5049 & 495.554 & 498.074 & 5.400 & 0.0938 & 0.4155 \\
\hline 5050 & 495.548 & 498.071 & 5.400 & 0.0937 & 0.4154 \\
\hline 5051 & 495.558 & 497.083 & 5.402 & 0.0983 & 0.2659 \\
\hline 5052 & 495.561 & 497.084 & 5.403 & 0.0982 & 0.2659 \\
\hline 5053 & 495.559 & 497.284 & 5.404 & 0.0986 & 0.3002 \\
\hline 5054 & 495.559 & 497.282 & 5.405 & 0.0985 & 0.3002 \\
\hline 5056 & 495.554 & 497.491 & 5.406 & 0.0981 & 0.3366 \\
\hline 5057 & 495.554 & 497.720 & 5.406 & 0.0993 & 0.3750 \\
\hline 5058 & 495.552 & 497.719 & 11.733 & 0.0992 & 0.3750 \\
\hline 5059 & 495.554 & 497.955 & 11.736 & 0.0993 & 0.4154 \\
\hline 5060 & 495.558 & 497.961 & 11.738 & 0.0990 & 0.4154 \\
\hline 5061 & 495.575 & 497.010 & 11.740 & 0.1028 & 0.2659 \\
\hline 5062 & 495.573 & 497.008 & 11.742 & 0.1019 & 0.2659 \\
\hline 5064 & 495.572 & 497.200 & 11.743 & 0.1026 & 0.3002 \\
\hline 5065 & 495.572 & 497.410 & 11.743 & 0.1021 & 0.3366 \\
\hline 5066 & 495.567 & 497.407 & 11.742 & 0.1031 & 0.3366 \\
\hline 5067 & 495.565 & 497.620 & 11.741 & 0.1016 & 0.3750 \\
\hline 5068 & 495.571 & 497.627 & 11.740 & 0.1023 & 0.3750 \\
\hline 5069 & 495.568 & 497.857 & 20.455 & 0.1025 & 0.4155 \\
\hline 5070 & 495.571 & 497.861 & 20.455 & 0.1017 & 0.4155 \\
\hline 5071 & 495.582 & 496.997 & 20.454 & 0.1077 & 0.2659 \\
\hline 5072 & 495.584 & 497.000 & 20.454 & 0.1077 & 0.2659 \\
\hline 5073 & 495.579 & 497.182 & 20.454 & 0.1079 & 0.3002 \\
\hline 5074 & 495.583 & 497.182 & 20.455 & 0.1078 & 0.3002 \\
\hline 5075 & 495.576 & 497.374 & 20.455 & 0.1083 & 0.3365 \\
\hline 5076 & 495.574 & 497.375 & 20.456 & 0.1074 & 0.3365 \\
\hline 5078 & 495.577 & 497.590 & 20.457 & 0.1064 & 0.3749 \\
\hline 5079 & 495.579 & 497.814 & 30.829 & 0.1065 & 0.4154 \\
\hline 5080 & 495.579 & 497.806 & 30.829 & 0.1066 & 0.415 \\
\hline 5091 & 495.621 & 497.036 & 30.829 & 0.1110 & 0.2657 \\
\hline 5092 & 495.619 & 497.032 & 30.828 & 0.1111 & 0.2658 \\
\hline 5093 & 495.626 & 497.222 & 30.830 & 0.1109 & 0.3001 \\
\hline 5094 & 495.622 & 497.217 & 30.831 & 0.1106 & 0.3001 \\
\hline 5095 & 495.621 & 497.406 & 30.834 & 0.1101 & 0.336 \\
\hline 5096 & 495.619 & 497.407 & 40.906 & 0.1104 & 0.336 \\
\hline 5097 & 495.617 & 497.607 & 40.909 & 0.1109 & 0.374 \\
\hline 5098 & 495.621 & 497.611 & 40.912 & 0.1109 & 0.3748 \\
\hline 5099 & 495.621 & 497.831 & 40.912 & 0.1097 & 0.4152 \\
\hline 5100 & 495.622 & 497.832 & 40.916 & 0.1101 & 0.4152 \\
\hline 6001 & 547.296 & 549.127 & 40.918 & 0.0764 & 0.2427 \\
\hline 6002 & 547.305 & 549.139 & 40.919 & 0.0763 & 0.242 \\
\hline 6003 & 547.301 & 549.371 & 40.921 & 0.0763 & 0.274 \\
\hline 6004 & 547.304 & 549.376 & 40.923 & 0.0762 & 0.274 \\
\hline 6005 & 547.318 & 549.641 & 40.923 & 0.0759 & 0.307 \\
\hline 6006 & 547.313 & 549.639 & 50.744 & 0.0762 & 0.307 \\
\hline 6007 & 547.317 & 549.908 & 50.744 & 0.0755 & 0.342 \\
\hline
\end{tabular}




\begin{tabular}{|c|c|c|c|c|c|}
\hline 6008 & 547.320 & 549.917 & 50.748 & 0.0753 & 0.3422 \\
\hline 6009 & 547.322 & 550.197 & 50.750 & 0.0756 & 0.3792 \\
\hline 010 & 547.329 & 550.207 & 50.749 & 0.0757 & 0.3792 \\
\hline 013 & 547.357 & 549.306 & 50.750 & 0.0796 & 0.2740 \\
\hline 014 & 547.356 & 549.301 & 50.751 & 0.0806 & 0.2740 \\
\hline 6015 & 547.352 & 549.539 & 60.438 & 0.0805 & 0.3072 \\
\hline 6016 & 547.356 & 549.549 & 60.426 & 0.0799 & 0.3072 \\
\hline 6017 & 547.357 & 549.802 & 60.413 & 0.0802 & 0.3422 \\
\hline 6018 & 547.358 & 549.802 & 60.400 & 0.0799 & 0.3422 \\
\hline 6019 & 547.365 & 550.078 & 60.389 & 0.0802 & 0.3791 \\
\hline 6020 & 547.359 & 550.076 & 60.376 & 0.0800 & 0.3792 \\
\hline 6021 & 547.374 & 548.996 & 60.366 & 0.0838 & 0.2427 \\
\hline 6022 & 547.372 & 548.992 & 60.356 & 0.0838 & 0.2427 \\
\hline 6023 & 547.367 & 549.210 & 60.346 & 0.0833 & 0.2740 \\
\hline 6024 & 547.371 & 549.214 & 60.334 & 0.0837 & 0.2740 \\
\hline 6025 & 547.372 & 549.437 & 0.781 & 0.0833 & 0.3072 \\
\hline 6026 & 547.374 & 549.437 & 0.781 & 0.0829 & 0.3072 \\
\hline 6027 & 547.372 & 549.682 & 0.782 & 0.0837 & 0.3422 \\
\hline 6028 & 547.371 & 549.681 & 0.782 & 0.0835 & 0.3422 \\
\hline 6029 & 547.377 & 549.942 & 0.782 & 0.0840 & 0.3792 \\
\hline 6030 & 547.378 & 549.943 & 0.783 & 0.0839 & 0.3792 \\
\hline 6031 & 547.403 & 548.960 & 0.783 & 0.0887 & 0.2427 \\
\hline 6032 & 547.388 & 548.952 & 0.783 & 0.0883 & 0.2428 \\
\hline 6033 & 547.399 & 549.163 & 0.783 & 0.0885 & 0.2741 \\
\hline 6034 & 547.400 & 549.164 & 0.783 & 0.0889 & 0.2740 \\
\hline 6035 & 547.397 & 549.373 & 5.400 & 0.0895 & 0.3072 \\
\hline 6036 & 547.395 & 549.379 & 5.400 & 0.0896 & 0.3072 \\
\hline 6037 & 547.393 & 549.607 & 5.402 & 0.0882 & 0.3423 \\
\hline 6039 & 547.394 & 549.861 & 5.403 & 0.0883 & 0.3793 \\
\hline 6040 & 547.393 & 549.845 & 5.404 & 0.0882 & 0.3792 \\
\hline 6042 & 547.405 & 548.875 & 5.405 & 0.0947 & 0.2428 \\
\hline 6045 & 547.401 & 549.274 & 5.406 & 0.0943 & 0.3073 \\
\hline 6046 & 547.402 & 549.268 & 5.406 & 0.0945 & 0.3073 \\
\hline 6047 & 547.400 & 549.483 & 11.733 & 0.0948 & 0.3424 \\
\hline 6048 & 547.406 & 549.490 & 11.736 & 0.0946 & 0.3424 \\
\hline 6049 & 547.404 & 549.717 & 11.738 & 0.0948 & 0.3793 \\
\hline 6050 & 547.398 & 549.712 & 11.740 & 0.0943 & 0.3793 \\
\hline 6051 & 547.418 & 548.769 & 11.742 & 0.0985 & 0.2428 \\
\hline 6052 & 547.427 & 548.776 & 11.743 & 0.0997 & 0.2428 \\
\hline 6053 & 547.421 & 548.955 & 11.743 & 0.0990 & 0.2741 \\
\hline 6054 & 547.425 & 548.956 & 11.742 & 0.0989 & 0.2742 \\
\hline 6055 & 547.427 & 549.206 & 11.741 & 0.0994 & 0.3073 \\
\hline 6056 & 547.425 & 549.200 & 11.740 & 0.0995 & 0.3073 \\
\hline 6057 & 547.424 & 549.408 & 20.455 & 0.1000 & 0.3423 \\
\hline 6058 & 547.426 & 549.411 & 20.455 & 0.0990 & 0.3424 \\
\hline 6059 & 547.431 & 549.634 & 20.454 & 0.0997 & 0.3793 \\
\hline 6060 & 547.426 & 549.634 & 20.454 & 0.0982 & 0.3793 \\
\hline 6061 & 547.459 & 548.770 & 20.454 & 0.1044 & 0.2428 \\
\hline
\end{tabular}




$\begin{array}{llllll}6062 & 547.453 & 548.761 & 20.455 & 0.1043 & 0.2428 \\ 6063 & 547.452 & 548.939 & 20.455 & 0.1042 & 0.2741 \\ 6064 & 547.456 & 548.941 & 20.456 & 0.1035 & 0.2741 \\ 6065 & 547.460 & 549.132 & 20.457 & 0.1043 & 0.3073 \\ 6066 & 547.456 & 549.132 & 30.829 & 0.1037 & 0.3073 \\ 6067 & 547.458 & 549.333 & 30.829 & 0.1028 & 0.3424 \\ 6071 & 547.481 & 548.778 & 30.829 & 0.1080 & 0.2428 \\ 6072 & 547.485 & 548.783 & 30.828 & 0.1079 & 0.2428 \\ 6073 & 547.483 & 548.947 & 30.830 & 0.1079 & 0.2741 \\ 6074 & 547.489 & 548.957 & 30.831 & 0.1080 & 0.2741 \\ 6075 & 547.488 & 549.132 & 30.834 & 0.1080 & 0.3073 \\ 6076 & 547.489 & 549.138 & 40.906 & 0.1076 & 0.3073 \\ 6077 & 547.489 & 549.324 & 40.909 & 0.1076 & 0.3424 \\ 6078 & 547.487 & 549.323 & 40.912 & 0.1079 & 0.3424 \\ 6079 & 547.484 & 549.520 & 40.912 & 0.1078 & 0.3794 \\ 6080 & 547.489 & 549.529 & 40.916 & 0.1078 & 0.3793\end{array}$

Table A5. Thermal conductivity of liquid S-8.

\begin{tabular}{ccccccc}
\hline Point ID & $\begin{array}{c}T_{0} \\
(\mathrm{~K})\end{array}$ & $\begin{array}{c}T_{\mathrm{e}} \\
(\mathrm{K})\end{array}$ & $\begin{array}{c}P_{\mathrm{e}} \\
(\mathrm{MPa})\end{array}$ & $\begin{array}{c}\rho_{\mathrm{e}} \\
\left(\mathrm{mol} \cdot \mathrm{L}^{-1}\right)\end{array}$ & $\begin{array}{c}\lambda_{\mathrm{e}} \\
\left(\mathrm{W} \cdot \mathrm{m}^{-1} \mathrm{~K}^{-1}\right)\end{array}$ & $\begin{array}{c}q \\
\left(\mathrm{~W} \cdot \mathrm{m}^{-1}\right)\end{array}$ \\
\hline 1013 & 301.957 & 303.640 & 0.095 & 4.245 & 0.1169 & 0.3730 \\
1015 & 301.929 & 303.922 & 0.095 & 4.244 & 0.1176 & 0.4439 \\
1017 & 301.909 & 304.236 & 0.095 & 4.243 & 0.1179 & 0.5199 \\
1019 & 301.885 & 304.575 & 0.095 & 4.241 & 0.1176 & 0.6032 \\
1021 & 301.671 & 303.087 & 0.510 & 4.250 & 0.1168 & 0.3085 \\
1023 & 301.662 & 303.369 & 0.502 & 4.248 & 0.1170 & 0.3734 \\
1025 & 301.655 & 303.686 & 0.498 & 4.247 & 0.1169 & 0.4445 \\
1027 & 301.648 & 304.022 & 0.497 & 4.245 & 0.1175 & 0.5205 \\
1029 & 301.643 & 304.388 & 0.501 & 4.244 & 0.1171 & 0.6035 \\
1031 & 301.441 & 302.846 & 0.342 & 4.250 & 0.1166 & 0.3086 \\
1033 & 301.437 & 303.137 & 0.333 & 4.249 & 0.1170 & 0.3736 \\
1035 & 301.434 & 303.459 & 0.325 & 4.247 & 0.1173 & 0.4447 \\
1037 & 301.434 & 303.803 & 0.319 & 4.246 & 0.1167 & 0.5207 \\
1039 & 301.430 & 304.180 & 0.312 & 4.244 & 0.1176 & 0.6040 \\
1041 & 301.547 & 302.957 & 5.249 & 4.271 & 0.1201 & 0.3086 \\
1043 & 301.562 & 303.222 & 5.266 & 4.270 & 0.1189 & 0.3734 \\
1045 & 301.584 & 303.574 & 5.278 & 4.269 & 0.1190 & 0.4445 \\
1047 & 301.605 & 303.947 & 5.292 & 4.267 & 0.1188 & 0.5205 \\
1049 & 301.620 & 304.346 & 5.305 & 4.266 & 0.1184 & 0.6037 \\
1051 & 301.743 & 303.175 & 10.283 & 4.291 & 0.1199 & 0.3085 \\
1053 & 301.750 & 303.478 & 10.286 & 4.290 & 0.1204 & 0.3734 \\
1055 & 301.754 & 303.807 & 10.286 & 4.289 & 0.1210 & 0.4444 \\
1057 & 301.764 & 304.156 & 10.287 & 4.287 & 0.1211 & 0.5204 \\
1059 & 301.764 & 304.530 & 10.289 & 4.286 & 0.1203 & 0.6037
\end{tabular}




\begin{tabular}{|c|c|c|c|c|c|c|}
\hline 1061 & 301.816 & 303.449 & 20.266 & 4.330 & 0.1244 & 0.373 \\
\hline 1063 & 301.819 & 303.767 & 20.259 & 4.328 & 0.1234 & 0.444 \\
\hline 1065 & 301.826 & 304.107 & 20.258 & 4.327 & 0.1242 & 0.520 \\
\hline 1067 & 301.832 & 304.474 & 20.258 & 4.326 & 0.1241 & 0.603 \\
\hline 1069 & 301.833 & 304.867 & 20.260 & 4.324 & 0.1236 & 0.692 \\
\hline 1071 & 301.975 & 303.572 & 30.348 & 4.366 & 0.1281 & 0.373 \\
\hline 1073 & 301.998 & 303.909 & 30.369 & 4.365 & 0.1274 & 0.444 \\
\hline 1075 & 302.019 & 304.260 & 30.390 & 4.363 & 0.1274 & 0.519 \\
\hline 1077 & 302.043 & 304.647 & 30.412 & 4.362 & 0.1269 & 0.603 \\
\hline 1079 & 302.067 & 305.070 & 30.434 & 4.360 & 0.1267 & 0.692 \\
\hline 1081 & 302.364 & 303.977 & 40.266 & 4.398 & 0.1294 & 0.372 \\
\hline 1083 & 302.369 & 304.280 & 40.265 & 4.397 & 0.1290 & 0.443 \\
\hline 1085 & 302.370 & 304.606 & 40.265 & 4.395 & 0.1295 & 0.519 \\
\hline 1087 & 302.365 & 304.952 & 40.269 & 4.394 & 0.1300 & 0.602 \\
\hline 1089 & 302.361 & 305.320 & 40.275 & 4.393 & 0.1301 & 0.692 \\
\hline 1091 & 302.342 & 303.768 & 50.044 & 4.429 & 0.1329 & 0.372 \\
\hline 1093 & 302.330 & 304.045 & 50.033 & 4.428 & 0.1314 & 0.443 \\
\hline 1095 & 302.322 & 304.348 & 50.023 & 4.427 & 0.1332 & 0.519 \\
\hline 1097 & 302.311 & 304.821 & 50.010 & 4.426 & 0.1327 & 0.602 \\
\hline 1099 & 302.297 & 305.173 & 49.995 & 4.424 & 0.1330 & 0.691 \\
\hline 1101 & 302.144 & 303.689 & 58.820 & 4.456 & 0.1354 & 0.373 \\
\hline 1103 & 302.130 & 303.956 & 58.602 & 4.454 & 0.1346 & 0.44 \\
\hline 1105 & 302.109 & 304.240 & 58.405 & 4.453 & 0.1350 & 0.520 \\
\hline 1107 & 302.095 & 304.560 & 58.216 & 4.451 & 0.1353 & 0.603 \\
\hline 1109 & 302.082 & 304.905 & 58.039 & 4.449 & 0.1341 & 0.692 \\
\hline 1111 & 302.126 & 303.623 & 65.938 & 4.476 & 0.1376 & 0.373 \\
\hline 1113 & 302.141 & 303.944 & 64.626 & 4.471 & 0.1368 & 0.443 \\
\hline 1115 & 302.151 & 304.278 & 63.559 & 4.467 & 0.1353 & 0.519 \\
\hline 1117 & 302.168 & 304.650 & 62.667 & 4.464 & 0.1353 & 0.602 \\
\hline 1119 & 302.178 & 305.028 & 61.911 & 4.460 & 0.1365 & 0.692 \\
\hline 2001 & 321.327 & 322.975 & 0.135 & 4.162 & 0.1145 & 0.355 \\
\hline 2003 & 321.330 & 323.297 & 0.136 & 4.161 & 0.1145 & 0.423 \\
\hline 2005 & 321.324 & 323.627 & 0.133 & 4.160 & 0.1138 & 0.495 \\
\hline 2007 & 321.319 & 323.941 & 0.129 & 4.158 & 0.1150 & 0.574 \\
\hline 2009 & 321.312 & 324.328 & 0.123 & 4.157 & 0.1140 & 0.660 \\
\hline 2011 & 320.975 & 322.406 & 5.148 & 4.190 & 0.1162 & 0.355 \\
\hline 2013 & 320.960 & 322.692 & 5.124 & 4.189 & 0.1160 & 0.423 \\
\hline 2015 & 320.951 & 323.222 & 5.105 & 4.186 & 0.1162 & 0.496 \\
\hline 2017 & 320.945 & 323.572 & 5.094 & 4.185 & 0.1161 & 0.575 \\
\hline 2019 & 320.947 & 323.960 & 5.091 & 4.183 & 0.1157 & 0.661 \\
\hline 2021 & 321.084 & 322.709 & 10.277 & 4.213 & 0.1175 & 0.356 \\
\hline 2023 & 321.103 & 323.045 & 10.289 & 4.211 & 0.1180 & 0.423 \\
\hline 2025 & 321.123 & 323.400 & 10.300 & 4.210 & 0.1178 & 0.496 \\
\hline 2027 & 321.144 & 323.783 & 10.316 & 4.209 & 0.1171 & 0.575 \\
\hline 2029 & 321.162 & 324.191 & 10.334 & 4.207 & 0.1187 & 0.660 \\
\hline 2031 & 320.956 & 322.481 & 19.958 & 4.256 & 0.1208 & 0.356 \\
\hline
\end{tabular}




\begin{tabular}{|c|c|c|c|c|c|c|}
\hline 2033 & 320.952 & 322.769 & 19.953 & 4.255 & 0.1216 & 0.4240 \\
\hline 2035 & 320.954 & 323.090 & 19.953 & 4.253 & 0.1212 & 0.4964 \\
\hline 2037 & 320.968 & 323.454 & 19.959 & 4.252 & 0.1214 & 0.5758 \\
\hline 2039 & 320.973 & 323.831 & 19.971 & 4.251 & 0.1210 & 0.6610 \\
\hline 2041 & 321.196 & 322.736 & 30.236 & 4.296 & 0.1253 & 0.3560 \\
\hline 2043 & 321.219 & 323.061 & 30.248 & 4.294 & 0.1245 & 0.4238 \\
\hline 2045 & 321.235 & 323.400 & 30.258 & 4.293 & 0.1247 & 0.4963 \\
\hline 2047 & 321.251 & 323.764 & 30.269 & 4.292 & 0.1247 & 0.5757 \\
\hline 2049 & 321.268 & 324.159 & 30.280 & 4.291 & 0.1251 & 0.6610 \\
\hline 2051 & 321.207 & 322.736 & 40.378 & 4.333 & 0.1285 & 0.3561 \\
\hline 2053 & 321.185 & 322.993 & 40.359 & 4.332 & 0.1283 & 0.4239 \\
\hline 2055 & 321.167 & 323.271 & 40.341 & 4.331 & 0.1281 & 0.4964 \\
\hline 2057 & 321.151 & 323.585 & 40.332 & 4.329 & 0.1274 & 0.5756 \\
\hline 2059 & 321.131 & 323.912 & 40.323 & 4.328 & 0.1283 & 0.6608 \\
\hline 2061 & 321.286 & 322.764 & 50.582 & 4.367 & 0.1315 & 0.3560 \\
\hline 2063 & 321.309 & 323.076 & 50.601 & 4.366 & 0.1311 & 0.4237 \\
\hline 2065 & 321.328 & 323.407 & 50.620 & 4.365 & 0.1313 & 0.4961 \\
\hline 2067 & 321.345 & 323.764 & 50.636 & 4.364 & 0.1303 & 0.5754 \\
\hline 2069 & 321.359 & 324.139 & 50.652 & 4.363 & 0.1314 & 0.6607 \\
\hline 2071 & 321.419 & 322.936 & 60.482 & 4.398 & 0.1338 & 0.3559 \\
\hline 2073 & 321.406 & 323.197 & 60.463 & 4.397 & 0.1337 & 0.4236 \\
\hline 2075 & 321.392 & 323.474 & 60.441 & 4.396 & 0.1343 & 0.4960 \\
\hline 2077 & 321.371 & 323.768 & 60.420 & 4.395 & 0.1340 & 0.5754 \\
\hline 2079 & 321.357 & 324.091 & 60.395 & 4.394 & 0.1346 & 0.6606 \\
\hline 2081 & 321.163 & 322.519 & 69.044 & 4.425 & 0.1360 & 0.3562 \\
\hline 2083 & 321.159 & 322.785 & 69.016 & 4.424 & 0.1375 & 0.4239 \\
\hline 2085 & 321.160 & 323.069 & 68.990 & 4.423 & 0.1364 & 0.4964 \\
\hline 2087 & 321.167 & 323.392 & 68.969 & 4.422 & 0.1360 & 0.5758 \\
\hline 2089 & 321.179 & 323.753 & 68.947 & 4.421 & 0.1358 & 0.661 \\
\hline 3001 & 337.824 & 339.476 & 0.188 & 4.092 & 0.1106 & 0.3422 \\
\hline 3003 & 337.828 & 339.786 & 0.193 & 4.091 & 0.1116 & 0.407 \\
\hline 3005 & 337.834 & 340.125 & 0.197 & 4.089 & 0.1117 & 0.477 \\
\hline 3007 & 337.838 & 340.487 & 0.202 & 4.088 & 0.1117 & 0.553 \\
\hline 3009 & 337.843 & 340.874 & 0.205 & 4.086 & 0.1118 & 0.6353 \\
\hline 3011 & 337.913 & 339.475 & 5.412 & 4.121 & 0.1139 & 0.3422 \\
\hline 3013 & 337.917 & 339.778 & 5.415 & 4.120 & 0.1138 & 0.4073 \\
\hline 3015 & 337.917 & 340.102 & 5.418 & 4.118 & 0.1139 & 0.4769 \\
\hline 3017 & 337.922 & 340.460 & 5.421 & 4.117 & 0.1141 & 0.5532 \\
\hline 3019 & 337.925 & 340.842 & 5.424 & 4.115 & 0.1136 & 0.635 \\
\hline 3021 & 337.965 & 339.518 & 10.140 & 4.145 & 0.1156 & 0.342 \\
\hline 3023 & 337.969 & 339.817 & 10.141 & 4.144 & 0.1157 & 0.407 \\
\hline 3025 & 337.970 & 340.136 & 10.128 & 4.142 & 0.1161 & 0.477 \\
\hline 3027 & 337.977 & 340.490 & 10.124 & 4.141 & 0.1159 & 0.553 \\
\hline 3029 & 337.979 & 340.866 & 10.122 & 4.139 & 0.1162 & 0.635 \\
\hline 3031 & 338.036 & 339.548 & 20.415 & 4.193 & 0.1197 & 0.342 \\
\hline 3033 & 338.037 & 339.836 & 20.412 & 4.192 & 0.1199 & 0.407 \\
\hline
\end{tabular}




\begin{tabular}{|c|c|c|c|c|c|c|}
\hline 3035 & 338.039 & 340.147 & 20.410 & 4.191 & 0.1201 & 0.4772 \\
\hline 3037 & 338.040 & 340.490 & 20.409 & 4.190 & 0.1199 & 0.5535 \\
\hline 3039 & 338.043 & 340.854 & 20.408 & 4.189 & 0.1194 & 0.635 \\
\hline 3041 & 338.095 & 339.574 & 30.197 & 4.235 & 0.1233 & 0.342 \\
\hline 3043 & 338.098 & 339.859 & 30.204 & 4.234 & 0.1236 & 0.407 \\
\hline 3045 & 338.102 & 340.163 & 30.213 & 4.233 & 0.1237 & 0.477 \\
\hline 3047 & 338.098 & 340.487 & 30.222 & 4.232 & 0.1231 & 0.553 \\
\hline 3049 & 338.100 & 340.844 & 30.228 & 4.231 & 0.1237 & 0.635 \\
\hline 3051 & 338.131 & 339.566 & 40.187 & 4.274 & 0.1267 & 0.342 \\
\hline 3053 & 338.138 & 339.848 & 40.184 & 4.273 & 0.1274 & 0.407 \\
\hline 3055 & 338.138 & 340.141 & 40.182 & 4.272 & 0.1269 & 0.477 \\
\hline 3057 & 338.142 & 340.468 & 40.180 & 4.271 & 0.1268 & 0.553 \\
\hline 3059 & 338.137 & 340.812 & 40.181 & 4.270 & 0.1268 & 0.635 \\
\hline 3061 & 338.173 & 339.564 & 50.546 & 4.312 & 0.1299 & 0.342 \\
\hline 3063 & 338.173 & 339.834 & 50.541 & 4.311 & 0.1298 & 0.407 \\
\hline 3065 & 338.176 & 340.125 & 50.536 & 4.310 & 0.1299 & 0.477 \\
\hline 3067 & 338.180 & 340.447 & 50.534 & 4.309 & 0.1295 & 0.553 \\
\hline 3069 & 338.177 & 340.783 & 50.531 & 4.308 & 0.1290 & 0.635 \\
\hline 3072 & 338.203 & 339.554 & 60.331 & 4.345 & 0.1335 & 0.342 \\
\hline 3074 & 338.208 & 339.823 & 60.331 & 4.344 & 0.1333 & 0.407 \\
\hline 3076 & 338.202 & 340.100 & 60.328 & 4.343 & 0.1328 & 0.476 \\
\hline 3078 & 338.203 & 340.412 & 60.309 & 4.342 & 0.1329 & 0.553 \\
\hline 3080 & 338.207 & 340.751 & 60.296 & 4.341 & 0.1329 & 0.635 \\
\hline 3082 & 338.226 & 339.537 & 69.455 & 4.374 & 0.1352 & 0.342 \\
\hline 3084 & 338.231 & 339.848 & 69.449 & 4.373 & 0.1355 & 0.407 \\
\hline 3086 & 338.229 & 340.130 & 69.449 & 4.372 & 0.1360 & 0.477 \\
\hline 3088 & 338.232 & 340.432 & 69.448 & 4.371 & 0.1350 & 0.553 \\
\hline 3090 & 338.229 & 340.756 & 69.447 & 4.370 & 0.1353 & 0.635 \\
\hline 4001 & 357.955 & 359.827 & 0.147 & 4.004 & 0.1084 & 0.389 \\
\hline 4003 & 357.975 & 360.169 & 0.159 & 4.003 & 0.1080 & 0.456 \\
\hline 4005 & 357.987 & 360.540 & 0.168 & 4.001 & 0.1079 & 0.525 \\
\hline 4007 & 357.999 & 360.932 & 0.178 & 4.000 & 0.1084 & 0.607 \\
\hline 4009 & 358.015 & 361.359 & 0.191 & 3.998 & 0.1075 & 0.691 \\
\hline 4011 & 358.334 & 360.181 & 0.397 & 4.004 & 0.1083 & 0.389 \\
\hline 4013 & 358.346 & 360.515 & 0.406 & 4.003 & 0.1089 & 0.455 \\
\hline 4015 & 358.358 & 360.885 & 0.412 & 4.001 & 0.1083 & 0.528 \\
\hline 4017 & 358.373 & 361.279 & 0.417 & 4.000 & 0.1082 & 0.606 \\
\hline 4019 & 358.388 & 361.697 & 0.429 & 3.998 & 0.1078 & 0.690 \\
\hline 4021 & 358.506 & 360.379 & 5.123 & 4.033 & 0.1103 & 0.389 \\
\hline 4023 & 358.516 & 360.707 & 5.130 & 4.032 & 0.1102 & 0.455 \\
\hline 4025 & 358.528 & 360.968 & 5.137 & 4.031 & 0.1105 & 0.528 \\
\hline 4027 & 358.538 & 361.351 & 5.144 & 4.029 & 0.1104 & 0.606 \\
\hline 4029 & 358.549 & 361.756 & 5.156 & 4.028 & 0.1104 & 0.690 \\
\hline 4031 & 358.653 & 360.455 & 10.216 & 4.062 & 0.1128 & 0.388 \\
\hline 4033 & 358.664 & 360.782 & 10.222 & 4.061 & 0.1128 & 0.455 \\
\hline 4035 & 358.669 & 361.128 & 10.228 & 4.060 & 0.1122 & 0.528 \\
\hline
\end{tabular}




\begin{tabular}{|c|c|c|c|c|c|c|}
\hline 4037 & 358.681 & 361.505 & 10.216 & 4.058 & 0.1126 & 0.6069 \\
\hline 4039 & 358.690 & 361.902 & 10.217 & 4.057 & 0.1124 & 0.6906 \\
\hline 4041 & 358.788 & 360.533 & 19.951 & 4.113 & 0.1167 & 0.3892 \\
\hline 4043 & 358.797 & 360.846 & 19.952 & 4.112 & 0.1166 & 0.4557 \\
\hline 4045 & 358.812 & 361.190 & 19.963 & 4.111 & 0.1168 & 0.5285 \\
\hline 4047 & 358.812 & 361.543 & 19.973 & 4.110 & 0.1171 & 0.6067 \\
\hline 4049 & 358.828 & 361.934 & 19.987 & 4.108 & 0.1163 & 0.6902 \\
\hline 4051 & 358.909 & 360.580 & 30.512 & 4.163 & 0.1210 & 0.3889 \\
\hline 4053 & 358.913 & 360.877 & 30.520 & 4.162 & 0.1208 & 0.455 \\
\hline 4055 & 358.923 & 361.206 & 30.519 & 4.161 & 0.1208 & 0.5282 \\
\hline 4057 & 358.925 & 361.552 & 30.509 & 4.159 & 0.1214 & 0.606 \\
\hline 4059 & 358.928 & 361.924 & 30.512 & 4.158 & 0.1208 & 0.690 \\
\hline 4061 & 359.024 & 360.680 & 40.478 & 4.205 & 0.1249 & 0.389 \\
\hline 4063 & 359.028 & 360.971 & 40.480 & 4.204 & 0.1239 & 0.455 \\
\hline 4065 & 359.034 & 361.285 & 40.484 & 4.203 & 0.1247 & 0.5286 \\
\hline 4067 & 359.038 & 361.630 & 40.497 & 4.202 & 0.1244 & 0.6067 \\
\hline 4069 & 359.038 & 361.987 & 40.511 & 4.201 & 0.1244 & 0.6901 \\
\hline 4071 & 359.104 & 360.680 & 50.282 & 4.243 & 0.1276 & 0.389 \\
\hline 4073 & 359.105 & 361.014 & 50.282 & 4.242 & 0.1277 & 0.4557 \\
\hline 4075 & 359.107 & 361.322 & 50.283 & 4.241 & 0.1278 & 0.5286 \\
\hline 4077 & 359.110 & 361.650 & 50.292 & 4.240 & 0.1272 & 0.606 \\
\hline 4079 & 359.116 & 362.007 & 50.303 & 4.239 & 0.1272 & 0.690 \\
\hline 4081 & 359.187 & 360.744 & 60.423 & 4.280 & 0.1312 & 0.389 \\
\hline 4083 & 359.190 & 361.021 & 60.432 & 4.279 & 0.1312 & 0.455 \\
\hline 4085 & 359.192 & 361.324 & 60.444 & 4.278 & 0.1311 & 0.528 \\
\hline 4087 & 359.190 & 361.643 & 60.450 & 4.278 & 0.1300 & 0.6064 \\
\hline 4089 & 359.195 & 361.988 & 60.457 & 4.276 & 0.1316 & 0.6899 \\
\hline 4091 & 359.234 & 360.768 & 68.584 & 4.308 & 0.1338 & 0.389 \\
\hline 4093 & 359.237 & 361.040 & 68.585 & 4.307 & 0.1337 & 0.455 \\
\hline 4095 & 359.240 & 361.339 & 68.587 & 4.306 & 0.1331 & 0.5283 \\
\hline 4097 & 359.253 & 361.666 & 68.592 & 4.305 & 0.1336 & 0.6064 \\
\hline 4099 & 359.253 & 362.000 & 68.591 & 4.304 & 0.1339 & 0.6899 \\
\hline 5001 & 377.752 & 379.509 & 8.533 & 3.976 & 0.1089 & 0.3737 \\
\hline 5003 & 377.766 & 379.832 & 8.545 & 3.975 & 0.1096 & 0.4376 \\
\hline 5005 & 377.775 & 380.174 & 8.554 & 3.974 & 0.1091 & 0.5075 \\
\hline 5007 & 377.788 & 380.549 & 8.539 & 3.972 & 0.1088 & 0.5832 \\
\hline 5009 & 377.801 & 380.946 & 8.535 & 3.970 & 0.1084 & 0.6637 \\
\hline 5011 & 377.851 & 379.684 & 0.270 & 3.919 & 0.1048 & 0.373 \\
\hline 5013 & 377.860 & 380.004 & 0.253 & 3.917 & 0.1045 & 0.437 \\
\hline 5015 & 377.872 & 380.368 & 0.256 & 3.916 & 0.1048 & 0.508 \\
\hline 5017 & 377.886 & 380.704 & 0.259 & 3.914 & 0.1046 & 0.583 \\
\hline 5019 & 377.893 & 381.104 & 0.265 & 3.913 & 0.1044 & 0.663 \\
\hline 5021 & 377.992 & 379.748 & 5.185 & 3.953 & 0.1072 & 0.373 \\
\hline 5023 & 378.004 & 380.074 & 5.191 & 3.952 & 0.1077 & 0.437 \\
\hline 5025 & 378.011 & 380.418 & 5.178 & 3.950 & 0.1075 & 0.507 \\
\hline 5027 & 378.023 & 380.795 & 5.179 & 3.949 & 0.1068 & 0.5830 \\
\hline
\end{tabular}




\begin{tabular}{|c|c|c|c|c|c|c|}
\hline 5029 & 378.035 & 381.195 & 5.181 & 3.947 & 0.1064 & 0.6633 \\
\hline 5031 & 378.135 & 379.869 & 10.373 & 3.986 & 0.1097 & 0.3734 \\
\hline 5033 & 378.143 & 380.177 & 10.379 & 3.985 & 0.1096 & 0.4373 \\
\hline 5035 & 378.152 & 380.519 & 10.384 & 3.984 & 0.1101 & 0.507 \\
\hline 5037 & 378.163 & 380.890 & 10.379 & 3.982 & 0.1096 & 0.582 \\
\hline 5039 & 378.179 & 381.282 & 10.373 & 3.981 & 0.1102 & 0.663 \\
\hline 5041 & 378.268 & 379.931 & 20.142 & 4.043 & 0.1146 & 0.373 \\
\hline 5043 & 378.275 & 380.230 & 20.150 & 4.042 & 0.1144 & 0.437 \\
\hline 5045 & 378.285 & 380.561 & 20.156 & 4.041 & 0.1139 & 0.507 \\
\hline 5047 & 378.296 & 380.916 & 20.156 & 4.039 & 0.1139 & 0.582 \\
\hline 5049 & 378.298 & 381.286 & 20.141 & 4.038 & 0.1140 & 0.662 \\
\hline 5051 & 378.383 & 379.974 & 30.345 & 4.095 & 0.1183 & 0.373 \\
\hline 5053 & 378.389 & 380.261 & 30.353 & 4.094 & 0.1179 & 0.437 \\
\hline 5055 & 378.398 & 380.582 & 30.360 & 4.093 & 0.1188 & 0.507 \\
\hline 5057 & 378.401 & 380.920 & 30.367 & 4.092 & 0.1185 & 0.582 \\
\hline 5059 & 378.408 & 381.278 & 30.373 & 4.091 & 0.1184 & 0.662 \\
\hline 5061 & 378.503 & 380.072 & 40.331 & 4.141 & 0.1226 & 0.373 \\
\hline 5063 & 378.499 & 380.343 & 40.338 & 4.140 & 0.1225 & 0.437 \\
\hline 5065 & 378.513 & 380.659 & 40.343 & 4.139 & 0.1215 & 0.507 \\
\hline 5067 & 378.514 & 380.983 & 40.339 & 4.138 & 0.1222 & 0.582 \\
\hline 5069 & 378.525 & 381.344 & 40.323 & 4.137 & 0.1225 & 0.662 \\
\hline 5071 & 378.590 & 380.128 & 50.227 & 4.182 & 0.1260 & 0.373 \\
\hline 5073 & 378.587 & 380.392 & 50.231 & 4.182 & 0.1260 & 0.437 \\
\hline 5075 & 378.594 & 380.699 & 50.237 & 4.181 & 0.1261 & 0.507 \\
\hline 5077 & 378.596 & 381.020 & 50.242 & 4.180 & 0.1261 & 0.582 \\
\hline 5079 & 378.601 & 381.358 & 50.246 & 4.179 & 0.1263 & 0.662 \\
\hline 5081 & 378.658 & 380.162 & 60.412 & 4.222 & 0.1295 & 0.373 \\
\hline 5083 & 378.657 & 380.425 & 60.420 & 4.221 & 0.1289 & 0.437 \\
\hline 5085 & 378.664 & 380.720 & 60.425 & 4.220 & 0.1295 & 0.507 \\
\hline 5087 & 378.668 & 381.032 & 60.429 & 4.219 & 0.1298 & 0.582 \\
\hline 5089 & 378.672 & 381.362 & 60.432 & 4.218 & 0.1291 & 0.662 \\
\hline 5091 & 378.716 & 380.191 & 67.328 & 4.247 & 0.1307 & 0.373 \\
\hline 5093 & 378.714 & 380.450 & 67.139 & 4.246 & 0.1307 & 0.437 \\
\hline 5095 & 378.717 & 380.745 & 66.955 & 4.244 & 0.1309 & 0.507 \\
\hline 5097 & 378.719 & 381.050 & 66.766 & 4.242 & 0.1309 & 0.582 \\
\hline 5099 & 378.722 & 381.379 & 66.576 & 4.241 & 0.1310 & 0.662 \\
\hline 6001 & 399.395 & 401.184 & 0.108 & 3.823 & 0.1016 & 0.357 \\
\hline 6003 & 399.392 & 401.486 & 0.108 & 3.821 & 0.1006 & 0.418 \\
\hline 6005 & 399.389 & 401.817 & 0.114 & 3.820 & 0.1009 & 0.484 \\
\hline 6007 & 399.391 & 402.177 & 0.119 & 3.818 & 0.1015 & 0.556 \\
\hline 6009 & 399.391 & 402.561 & 0.120 & 3.817 & 0.1010 & 0.633 \\
\hline 6011 & 399.665 & 401.413 & 0.268 & 3.823 & 0.1013 & 0.356 \\
\hline 6013 & 399.668 & 401.726 & 0.268 & 3.822 & 0.1008 & 0.417 \\
\hline 6015 & 399.669 & 402.067 & 0.253 & 3.820 & 0.1010 & 0.484 \\
\hline 6017 & 399.667 & 402.424 & 0.248 & 3.818 & 0.1007 & 0.556 \\
\hline 6019 & 399.675 & 402.822 & 0.245 & 3.817 & 0.1008 & 0.633 \\
\hline
\end{tabular}




\begin{tabular}{|c|c|c|c|c|c|c|}
\hline 6021 & 399.683 & 401.387 & 5.081 & 3.862 & 0.1044 & 0.3566 \\
\hline 6023 & 399.687 & 401.693 & 5.068 & 3.861 & 0.1040 & 0.4178 \\
\hline 6025 & 399.682 & 402.013 & 5.063 & 3.860 & 0.1040 & 0.4847 \\
\hline 6027 & 399.683 & 402.418 & 5.062 & 3.858 & 0.1037 & 0.5566 \\
\hline 6029 & 399.683 & 402.799 & 5.070 & 3.856 & 0.1039 & 0.6331 \\
\hline 6031 & 399.702 & 401.407 & 10.182 & 3.900 & 0.1064 & 0.3568 \\
\hline 6033 & 399.701 & 401.699 & 10.181 & 3.899 & 0.1068 & 0.4178 \\
\hline 6035 & 399.699 & 402.019 & 10.184 & 3.897 & 0.1065 & 0.4846 \\
\hline 6037 & 399.698 & 402.366 & 10.190 & 3.896 & 0.1065 & 0.5563 \\
\hline 6039 & 399.694 & 402.731 & 10.194 & 3.895 & 0.1067 & 0.6329 \\
\hline 6041 & 399.732 & 401.353 & 20.145 & 3.965 & 0.1113 & 0.3567 \\
\hline 6043 & 399.730 & 401.633 & 20.150 & 3.964 & 0.1112 & 0.417 \\
\hline 6045 & 399.725 & 401.936 & 20.155 & 3.963 & 0.1112 & 0.484 \\
\hline 6047 & 399.726 & 402.273 & 20.158 & 3.961 & 0.1117 & 0.556 \\
\hline 6049 & 399.729 & 402.631 & 20.160 & 3.960 & 0.1111 & 0.632 \\
\hline 6051 & 399.751 & 401.284 & 30.065 & 4.021 & 0.1159 & 0.356 \\
\hline 6053 & 399.749 & 401.557 & 30.075 & 4.020 & 0.1154 & 0.417 \\
\hline 6055 & 399.746 & 401.858 & 30.080 & 4.019 & 0.1160 & 0.484 \\
\hline 6057 & 399.750 & 402.187 & 30.082 & 4.018 & 0.1153 & 0.5562 \\
\hline 6059 & 399.745 & 402.524 & 30.086 & 4.017 & 0.1159 & 0.632 \\
\hline 6063 & 399.767 & 401.581 & 40.311 & 4.071 & 0.1211 & 0.417 \\
\hline 6065 & 399.763 & 401.870 & 40.315 & 4.071 & 0.1199 & 0.484 \\
\hline 6067 & 399.762 & 402.184 & 40.317 & 4.070 & 0.1205 & 0.556 \\
\hline 6069 & 399.760 & 402.516 & 40.319 & 4.068 & 0.1201 & 0.6330 \\
\hline 6071 & 399.777 & 401.254 & 49.938 & 4.116 & 0.1243 & 0.3570 \\
\hline 6073 & 399.779 & 401.518 & 49.869 & 4.115 & 0.1241 & 0.4180 \\
\hline 6075 & 399.776 & 401.795 & 49.805 & 4.114 & 0.1240 & 0.4848 \\
\hline 6077 & 399.775 & 402.106 & 49.748 & 4.113 & 0.1239 & 0.5565 \\
\hline 6079 & 399.773 & 402.432 & 49.693 & 4.112 & 0.1239 & 0.633 \\
\hline 6081 & 399.793 & 401.354 & 55.002 & 4.138 & 0.1248 & 0.3569 \\
\hline 6083 & 399.783 & 401.653 & 53.060 & 4.129 & 0.1238 & 0.418 \\
\hline 6085 & 399.777 & 401.905 & 51.965 & 4.123 & 0.1238 & 0.4848 \\
\hline 6087 & 399.775 & 402.218 & 51.227 & 4.119 & 0.1239 & 0.5567 \\
\hline 6089 & 399.769 & 402.551 & 50.637 & 4.115 & 0.1235 & 0.6336 \\
\hline 7001 & 418.662 & 420.400 & 0.102 & 3.736 & 0.0980 & 0.3437 \\
\hline 7003 & 418.670 & 420.719 & 0.101 & 3.734 & 0.0983 & 0.4025 \\
\hline 7005 & 418.675 & 421.059 & 0.102 & 3.733 & 0.0980 & 0.4669 \\
\hline 7007 & 418.673 & 421.414 & 0.104 & 3.731 & 0.0978 & 0.5360 \\
\hline 7009 & 418.679 & 421.803 & 0.106 & 3.729 & 0.0976 & 0.6097 \\
\hline 7011 & 418.723 & 420.439 & 5.140 & 3.782 & 0.1018 & 0.3437 \\
\hline 7013 & 418.725 & 420.740 & 5.143 & 3.781 & 0.1010 & 0.402 \\
\hline 7015 & 418.731 & 421.074 & 5.146 & 3.780 & 0.1013 & 0.466 \\
\hline 7017 & 418.729 & 421.421 & 5.151 & 3.778 & 0.1008 & 0.535 \\
\hline 7019 & 418.738 & 421.801 & 5.158 & 3.777 & 0.1007 & 0.609 \\
\hline 7021 & 418.811 & 420.469 & 10.555 & 3.827 & 0.1039 & 0.343 \\
\hline 7023 & 418.822 & 420.771 & 10.554 & 3.825 & 0.1037 & 0.4024 \\
\hline
\end{tabular}




\begin{tabular}{|c|c|c|c|c|c|c|}
\hline 7025 & 418.831 & 421.100 & 10.554 & 3.824 & 0.1037 & 0.4668 \\
\hline 7027 & 418.831 & 421.439 & 10.555 & 3.823 & 0.1036 & 0.5360 \\
\hline 7029 & 418.839 & 421.814 & 10.559 & 3.821 & 0.1036 & 0.6098 \\
\hline 7031 & 418.918 & 420.525 & 20.239 & 3.895 & 0.1094 & 0.3436 \\
\hline 7033 & 418.922 & 420.806 & 20.235 & 3.894 & 0.1093 & 0.402 \\
\hline 7035 & 418.926 & 421.116 & 20.234 & 3.893 & 0.1090 & 0.4669 \\
\hline 7037 & 418.933 & 421.456 & 20.237 & 3.892 & 0.1088 & 0.5360 \\
\hline 7039 & 418.936 & 421.808 & 20.243 & 3.891 & 0.1087 & 0.6098 \\
\hline 7041 & 418.999 & 420.554 & 30.475 & 3.958 & 0.1139 & 0.3437 \\
\hline 7043 & 419.010 & 420.833 & 30.474 & 3.957 & 0.1134 & 0.4025 \\
\hline 7045 & 419.009 & 421.128 & 30.477 & 3.956 & 0.1136 & 0.466 \\
\hline 7047 & 419.012 & 421.444 & 30.482 & 3.955 & 0.1135 & 0.535 \\
\hline 7049 & 419.014 & 421.786 & 30.489 & 3.954 & 0.1129 & 0.609 \\
\hline 7051 & 419.079 & 420.583 & 40.435 & 4.012 & 0.1179 & 0.343 \\
\hline 7053 & 419.081 & 420.849 & 40.442 & 4.011 & 0.1178 & 0.402 \\
\hline 7055 & 419.084 & 421.137 & 40.448 & 4.010 & 0.1170 & 0.466 \\
\hline 7057 & 419.086 & 421.451 & 40.452 & 4.009 & 0.1174 & 0.535 \\
\hline 7059 & 419.092 & 421.790 & 40.456 & 4.008 & 0.1171 & 0.609 \\
\hline 7061 & 419.136 & 420.591 & 49.169 & 4.054 & 0.1220 & 0.343 \\
\hline 7063 & 419.142 & 420.856 & 48.957 & 4.053 & 0.1215 & 0.402 \\
\hline 7065 & 419.138 & 421.136 & 48.747 & 4.051 & 0.1209 & 0.466 \\
\hline 7067 & 419.143 & 421.446 & 48.536 & 4.049 & 0.1200 & 0.535 \\
\hline 7069 & 419.145 & 421.767 & 48.316 & 4.047 & 0.1205 & 0.609 \\
\hline 8001 & 439.886 & 441.678 & 0.247 & 3.638 & 0.0949 & 0.330 \\
\hline 8003 & 439.890 & 441.940 & 0.248 & 3.637 & 0.0948 & 0.386 \\
\hline 8005 & 439.893 & 442.271 & 0.249 & 3.635 & 0.0950 & 0.448 \\
\hline 8007 & 439.895 & 442.630 & 0.253 & 3.634 & 0.0945 & 0.515 \\
\hline 8009 & 439.905 & 442.968 & 0.257 & 3.632 & 0.0943 & 0.5862 \\
\hline 8011 & 439.983 & 441.663 & 5.101 & 3.690 & 0.0978 & 0.330 \\
\hline 8013 & 439.988 & 441.957 & 5.106 & 3.689 & 0.0976 & 0.386 \\
\hline 8015 & 439.988 & 442.275 & 5.111 & 3.688 & 0.0981 & 0.448 \\
\hline 8017 & 439.993 & 442.627 & 5.114 & 3.686 & 0.0978 & 0.514 \\
\hline 8019 & 439.998 & 442.998 & 5.117 & 3.685 & 0.0980 & 0.585 \\
\hline 8021 & 440.042 & 441.693 & 10.160 & 3.738 & 0.1007 & 0.330 \\
\hline 8023 & 440.042 & 441.979 & 10.164 & 3.737 & 0.1014 & 0.3867 \\
\hline 8025 & 440.047 & 442.295 & 10.168 & 3.735 & 0.1011 & 0.4485 \\
\hline 8027 & 440.050 & 442.631 & 10.174 & 3.734 & 0.1010 & 0.514 \\
\hline 8029 & 440.056 & 442.997 & 10.178 & 3.733 & 0.1010 & 0.585 \\
\hline 8031 & 440.105 & 441.633 & 20.377 & 3.820 & 0.1073 & 0.330 \\
\hline 8033 & 440.100 & 441.901 & 20.375 & 3.819 & 0.1065 & 0.386 \\
\hline 8035 & 440.104 & 442.198 & 20.371 & 3.818 & 0.1066 & 0.448 \\
\hline 8037 & 440.107 & 442.522 & 20.371 & 3.816 & 0.1063 & 0.5152 \\
\hline 8039 & 440.111 & 442.868 & 20.376 & 3.815 & 0.1066 & 0.586 \\
\hline 8041 & 440.153 & 441.664 & 30.286 & 3.886 & 0.1116 & 0.330 \\
\hline 8043 & 440.148 & 441.920 & 30.286 & 3.885 & 0.1116 & 0.386 \\
\hline 8045 & 440.154 & 442.210 & 30.290 & 3.884 & 0.1118 & 0.448 \\
\hline
\end{tabular}




\begin{tabular}{|c|c|c|c|c|c|c|}
\hline 8047 & 440.149 & 442.511 & 30.295 & 3.883 & 0.1119 & 0.5151 \\
\hline 8049 & 440.149 & 442.835 & 30.301 & 3.882 & 0.1119 & 0.5860 \\
\hline 8051 & 440.185 & 441.620 & 40.345 & 3.945 & 0.1156 & 0.3304 \\
\hline 8053 & 440.187 & 441.875 & 40.332 & 3.944 & 0.1162 & 0.3869 \\
\hline 8055 & 440.190 & 442.152 & 40.321 & 3.944 & 0.1159 & 0.4487 \\
\hline 8057 & 440.186 & 442.446 & 40.315 & 3.943 & 0.1157 & 0.5151 \\
\hline 8059 & 440.182 & 442.757 & 40.307 & 3.942 & 0.1160 & 0.5860 \\
\hline 8061 & 440.195 & 441.649 & 41.920 & 3.954 & 0.1166 & 0.3303 \\
\hline 8063 & 440.185 & 441.897 & 41.449 & 3.951 & 0.1161 & 0.3868 \\
\hline 8065 & 440.179 & 442.172 & 41.049 & 3.947 & 0.1168 & 0.4486 \\
\hline 8067 & 440.177 & 442.471 & 40.704 & 3.945 & 0.1159 & 0.5150 \\
\hline 8069 & 440.175 & 442.789 & 40.401 & 3.942 & 0.1159 & 0.5859 \\
\hline 9001 & 460.245 & 461.930 & 0.191 & 3.539 & 0.0917 & 0.3185 \\
\hline 9003 & 460.235 & 462.212 & 0.192 & 3.538 & 0.0915 & 0.3728 \\
\hline 9005 & 460.228 & 462.532 & 0.193 & 3.536 & 0.0917 & 0.4323 \\
\hline 9007 & 460.218 & 462.861 & 0.194 & 3.535 & 0.0914 & 0.4963 \\
\hline 9009 & 460.216 & 463.227 & 0.194 & 3.533 & 0.0914 & 0.5646 \\
\hline 9011 & 460.218 & 461.822 & 5.456 & 3.605 & 0.0952 & 0.3182 \\
\hline 9013 & 460.220 & 462.105 & 5.458 & 3.604 & 0.0956 & 0.372 \\
\hline 9015 & 460.220 & 462.416 & 5.462 & 3.603 & 0.0959 & 0.432 \\
\hline 9017 & 460.217 & 462.748 & 5.463 & 3.601 & 0.0955 & 0.496 \\
\hline 9019 & 460.219 & 463.107 & 5.460 & 3.600 & 0.0953 & 0.5647 \\
\hline 9021 & 460.289 & 461.908 & 10.329 & 3.657 & 0.0991 & 0.3183 \\
\hline 9023 & 460.295 & 462.193 & 10.334 & 3.656 & 0.0988 & 0.372 \\
\hline 9025 & 460.297 & 462.496 & 10.338 & 3.655 & 0.0987 & 0.432 \\
\hline 9027 & 460.298 & 462.827 & 10.341 & 3.653 & 0.0989 & \\
\hline 9029 & 460.302 & 463.179 & 10.344 & 3.652 & 0.0984 & 0.564 \\
\hline 9031 & 460.365 & 461.853 & 20.311 & 3.746 & 0.1053 & 0.318 \\
\hline 9033 & 460.368 & 462.123 & 20.315 & 3.745 & 0.1043 & 0.372 \\
\hline 9035 & 460.372 & 462.421 & 20.317 & 3.744 & 0.1038 & 0.432 \\
\hline 9037 & 460.370 & 462.728 & 20.312 & 3.743 & 0.1047 & 0.496 \\
\hline 9039 & 460.384 & 463.074 & 20.305 & 3.741 & 0.1044 & 0.564 \\
\hline 9041 & 460.426 & 461.837 & 30.198 & 3.819 & 0.1095 & 0.318 \\
\hline 9043 & 460.422 & 462.092 & 30.202 & 3.818 & 0.1094 & 0.372 \\
\hline 9045 & 460.425 & 462.374 & 30.204 & 3.817 & 0.1099 & 0.432 \\
\hline 9047 & 460.424 & 462.669 & 30.201 & 3.816 & 0.1097 & 0.496 \\
\hline 9049 & 460.427 & 462.996 & 30.193 & 3.815 & 0.1098 & 0.564 \\
\hline 9055 & 460.479 & 462.392 & 39.784 & 3.878 & 0.1141 & 0.432 \\
\hline 9057 & 460.484 & 462.687 & 39.721 & 3.876 & 0.1139 & 0.496 \\
\hline 9059 & 460.485 & 462.993 & 39.661 & 3.875 & 0.1141 & 0.565 \\
\hline 9061 & 460.535 & 461.966 & 42.387 & 3.894 & 0.1158 & 0.318 \\
\hline 9063 & 460.531 & 462.217 & 41.417 & 3.888 & 0.1146 & 0.372 \\
\hline 9065 & 460.530 & 462.503 & 40.644 & 3.882 & 0.1144 & 0.432 \\
\hline 9067 & 460.525 & 462.792 & 40.011 & 3.878 & 0.1141 & 0.496 \\
\hline 9069 & 460.522 & 463.106 & 39.488 & 3.874 & 0.1145 & 0.565 \\
\hline 10001 & 480.862 & 482.558 & 0.238 & 3.435 & 0.0890 & 0.306 \\
\hline
\end{tabular}




\begin{tabular}{|c|c|c|c|c|c|c|}
\hline 10003 & 480.867 & 482.860 & 0.237 & 3.433 & 0.0889 & 0.3593 \\
\hline 10005 & 480.871 & 483.185 & 0.238 & 3.432 & 0.0885 & 0.4167 \\
\hline 10007 & 480.877 & 483.536 & 0.237 & 3.430 & 0.0887 & 0.4785 \\
\hline 10009 & 480.884 & 483.913 & 0.238 & 3.428 & 0.0886 & 0.5444 \\
\hline 10011 & 480.929 & 482.553 & 5.166 & 3.508 & 0.0925 & 0.3069 \\
\hline 10013 & 480.929 & 482.830 & 5.169 & 3.507 & 0.0929 & 0.3593 \\
\hline 10015 & 480.932 & 483.146 & 5.175 & 3.505 & 0.0926 & 0.4167 \\
\hline 10017 & 480.932 & 483.468 & 5.178 & 3.504 & 0.0928 & 0.4784 \\
\hline 10019 & 480.935 & 483.830 & 5.181 & 3.502 & 0.0925 & 0.5443 \\
\hline 10021 & 480.979 & 482.557 & 10.227 & 3.570 & 0.0962 & 0.3070 \\
\hline 10023 & 480.976 & 482.826 & 10.228 & 3.569 & 0.0957 & 0.3594 \\
\hline 10025 & 480.978 & 483.127 & 10.229 & 3.568 & 0.0964 & 0.4169 \\
\hline 10027 & 480.978 & 483.446 & 10.233 & 3.566 & 0.0960 & 0.4786 \\
\hline 10029 & 480.980 & 483.787 & 10.239 & 3.565 & 0.0964 & 0.5445 \\
\hline 10042 & 481.072 & 482.521 & 20.214 & 3.670 & 0.1023 & 0.3197 \\
\hline 10044 & 481.072 & 482.776 & 20.215 & 3.669 & 0.1021 & 0.3744 \\
\hline 10046 & 481.073 & 483.049 & 20.216 & 3.668 & 0.1022 & 0.4343 \\
\hline 10048 & 481.070 & 483.337 & 20.219 & 3.667 & 0.1022 & 0.4986 \\
\hline 10050 & 481.076 & 483.661 & 20.222 & 3.666 & 0.1020 & 0.5672 \\
\hline 10052 & 481.134 & 482.424 & 30.227 & 3.751 & 0.1078 & 0.3197 \\
\hline 10054 & 481.129 & 482.655 & 30.227 & 3.750 & 0.1077 & 0.3744 \\
\hline 10056 & 481.130 & 482.916 & 30.222 & 3.749 & 0.1079 & 0.4344 \\
\hline 10058 & 481.131 & 483.194 & 30.220 & 3.748 & 0.1077 & 0.4987 \\
\hline 10060 & 481.125 & 483.534 & 30.218 & 3.747 & 0.1075 & 0.5676 \\
\hline 10062 & 481.147 & 482.429 & 38.228 & 3.806 & 0.1116 & 0.3199 \\
\hline 10064 & 481.146 & 482.659 & 37.952 & 3.803 & 0.1114 & 0.3745 \\
\hline 10066 & 481.136 & 482.901 & 37.705 & 3.801 & 0.1113 & 0.4344 \\
\hline 10068 & 481.130 & 483.169 & 37.478 & 3.799 & 0.1111 & 0.4988 \\
\hline 10070 & 481.125 & 483.452 & 37.265 & 3.796 & 0.1110 & 0.5676 \\
\hline 11001 & 501.375 & 503.024 & 0.450 & 3.328 & 0.0858 & 0.3080 \\
\hline 11003 & 501.377 & 503.253 & 0.451 & 3.327 & 0.0857 & 0.3607 \\
\hline 11005 & 501.380 & 503.568 & 0.453 & 3.325 & 0.0857 & 0.4183 \\
\hline 11007 & 501.387 & 503.900 & 0.451 & 3.323 & 0.0857 & 0.4804 \\
\hline 11009 & 501.387 & 504.255 & 0.450 & 3.321 & 0.0855 & 0.5466 \\
\hline 11011 & 501.401 & 502.944 & 5.134 & 3.412 & 0.0899 & 0.3079 \\
\hline 11013 & 501.399 & 503.212 & 5.135 & 3.410 & 0.0898 & 0.3607 \\
\hline 11015 & 501.400 & 503.506 & 5.135 & 3.409 & 0.0898 & 0.4183 \\
\hline 11017 & 501.399 & 503.819 & 5.136 & 3.408 & 0.0897 & 0.4803 \\
\hline 11019 & 501.401 & 504.162 & 5.137 & 3.406 & 0.0897 & 0.5465 \\
\hline 11021 & 501.412 & 502.906 & 10.181 & 3.483 & 0.0936 & 0.3079 \\
\hline 11023 & 501.412 & 503.165 & 10.182 & 3.482 & 0.0936 & 0.3607 \\
\hline 11025 & 501.408 & 503.446 & 10.183 & 3.481 & 0.0935 & 0.4183 \\
\hline 11027 & 501.406 & 503.750 & 10.183 & 3.480 & 0.0934 & 0.4803 \\
\hline 11029 & 501.407 & 504.076 & 10.183 & 3.478 & 0.0934 & 0.5465 \\
\hline 11031 & 501.406 & 502.853 & 15.115 & 3.542 & 0.0970 & 0.3080 \\
\hline 11033 & 501.401 & 503.103 & 15.115 & 3.541 & 0.0969 & 0.3607 \\
\hline
\end{tabular}




$\begin{array}{lllllll}11035 & 501.409 & 503.383 & 15.116 & 3.540 & 0.0969 & 0.4183 \\ 11037 & 501.400 & 503.671 & 15.117 & 3.539 & 0.0968 & 0.4803 \\ 11039 & 501.405 & 503.988 & 15.118 & 3.538 & 0.0968 & 0.5465 \\ 11041 & 501.410 & 502.814 & 20.195 & 3.595 & 0.1001 & 0.3081 \\ 11043 & 501.410 & 503.060 & 20.197 & 3.594 & 0.1000 & 0.3607 \\ 11045 & 501.405 & 503.317 & 20.199 & 3.593 & 0.1000 & 0.4183 \\ 11047 & 501.401 & 503.600 & 20.199 & 3.592 & 0.1000 & 0.4803 \\ 11049 & 501.399 & 503.898 & 20.199 & 3.591 & 0.0999 & 0.5465 \\ 11051 & 501.398 & 502.754 & 25.203 & 3.642 & 0.1030 & 0.3080 \\ 11053 & 501.401 & 502.993 & 25.200 & 3.641 & 0.1029 & 0.3608 \\ 11055 & 501.402 & 503.252 & 25.199 & 3.640 & 0.1028 & 0.4185 \\ 11057 & 501.395 & 503.526 & 25.198 & 3.639 & 0.1027 & 0.4805 \\ 11059 & 501.391 & 503.824 & 25.199 & 3.638 & 0.1028 & 0.5466 \\ 11061 & 501.381 & 502.704 & 30.260 & 3.684 & 0.1057 & 0.3080 \\ 11063 & 501.380 & 502.934 & 30.256 & 3.683 & 0.1057 & 0.3608 \\ 11065 & 501.375 & 503.183 & 30.255 & 3.682 & 0.1057 & 0.4185 \\ 11067 & 501.375 & 503.456 & 30.253 & 3.681 & 0.1055 & 0.4805 \\ 11069 & 501.375 & 503.745 & 30.254 & 3.681 & 0.1056 & 0.5466 \\ 11071 & 501.376 & 502.588 & 35.386 & 3.724 & 0.1083 & 0.3079 \\ 11073 & 501.375 & 502.812 & 35.385 & 3.723 & 0.1082 & 0.3606 \\ 11075 & 501.370 & 503.056 & 35.384 & 3.722 & 0.1083 & 0.4183 \\ 11077 & 501.370 & 503.327 & 35.376 & 3.721 & 0.1081 & 0.4804 \\ 11079 & 501.367 & 503.609 & 35.372 & 3.720 & 0.1084 & 0.5466 \\ 11081 & 501.373 & 502.620 & 39.367 & 3.752 & 0.1103 & 0.3079 \\ 11083 & 501.372 & 502.848 & 39.213 & 3.750 & 0.1100 & 0.3607 \\ 11085 & 501.376 & 503.100 & 39.068 & 3.748 & 0.1101 & 0.4184 \\ 11087 & 501.375 & 503.356 & 38.930 & 3.746 & 0.1101 & 0.4804 \\ 11089 & 501.371 & 503.639 & 38.799 & 3.745 & 0.1101 & 0.5465\end{array}$






